\title{
Generation and analysis of $T$ cell receptor transgenic rats to model CNS autoimmunity
}

\author{
Dissertation \\ for the award of the degree \\ “Doctor rerum naturalium” (Dr. rer. nat.) \\ of the Georg-August-Universität Göttingen
}

within the doctoral program Molecular Physiology of the Brain

of the Georg-August University School of Science (GAUSS)

submitted by

Alexandra Kitz

from Dortmund

Göttingen 2013 
$1^{\text {st }}$ Member of the Thesis Committee (Reviewer): Prof. Dr. Wolfgang Brück, Department of Neuropathology, University Medical School, Göttingen

$2^{\text {nd }}$ Member of the Thesis Committee (Reviewer): Prof. Dr. Dr. Detlev Schild, Department of Neurophysiology and Cellular Biophysics, University Medical School, Göttingen

$3^{\text {rd }}$ Member of the Thesis Committee: Prof. Dr. Dr. Hannelore Ehrenreich, Clinical Neuroscience, Max Planck Institute of Experimental Medicine, Göttingen

$4^{\text {th }}$ Member of the Thesis Committee: Prof. Dr. Alexander Flügel, Department of Neuroimmunology, Institute for Multiple Sclerosis Research, Göttingen 


\section{DECLARATION}

I hereby declare that I have written this PhD thesis entitled "Generation and analysis of T cell receptor transgenic rats to model CNS autoimmunity" independently and with no other sources and aids than quoted. This thesis has not been submitted elsewhere for any academic degree.

Alexandra Kitz Göttingen, September 2013 


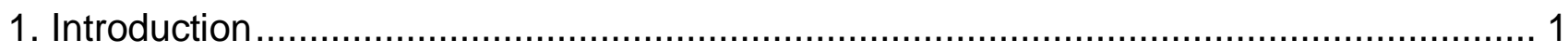

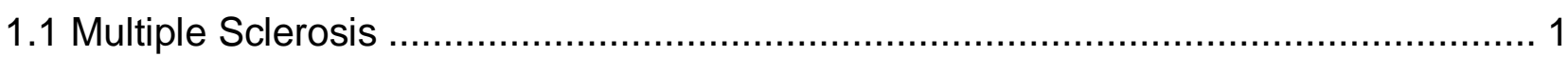

1.2 Central Nervous System - an immune privileged organ........................................ 4

1.3 Experimental Autoimmune Encephalomyelitis.................................................. 5

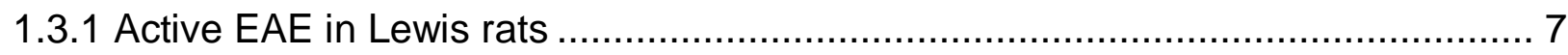

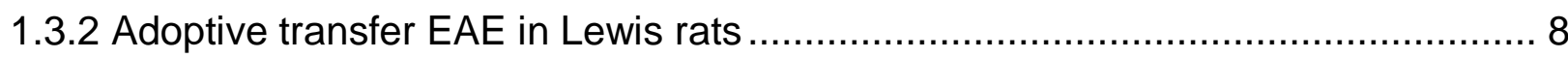

1.3.3 TCR transgenic mouse models for studying CNS autoimmunity ........................ 9

1.4 Structure and diversity of T cell receptors ........................................................ 12

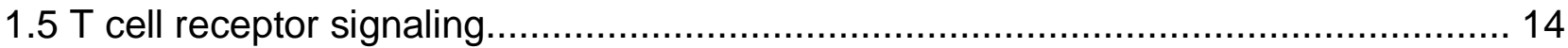

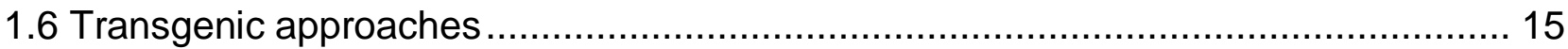

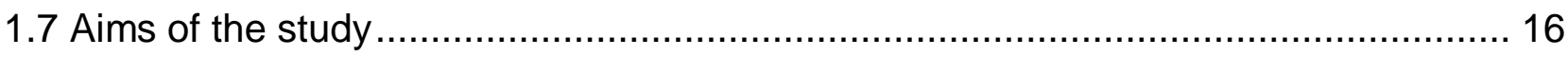

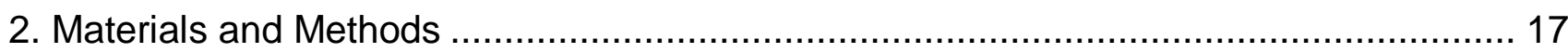

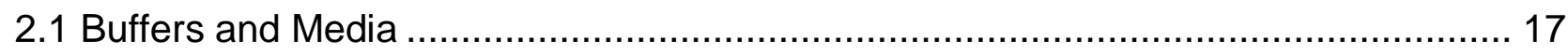

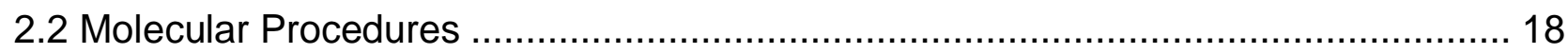

2.2.1 RNA extraction and complementary DNA synthesis ....................................... 18

2.2.2 Polymerase Chain Reaction (PCR) ........................................................ 18

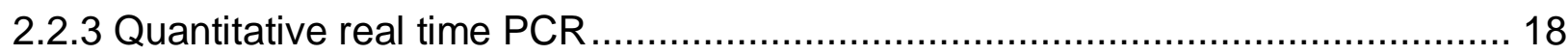

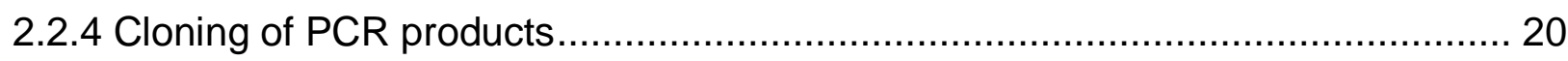

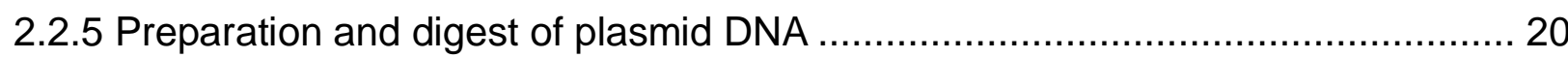

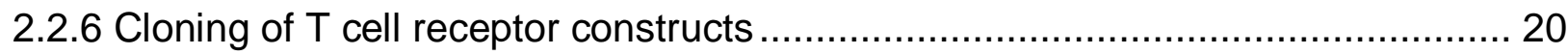

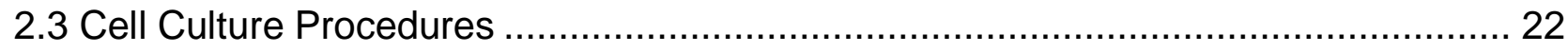

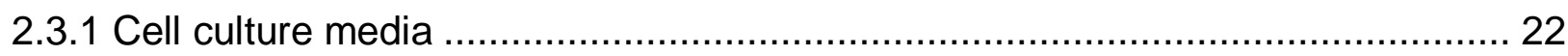

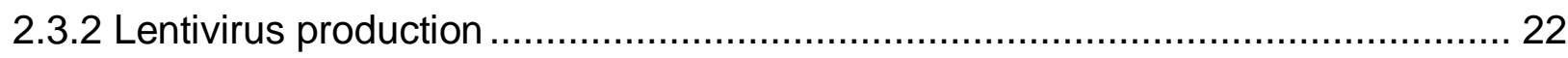

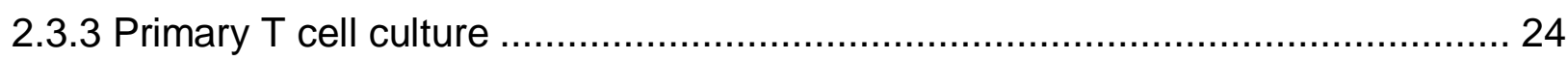

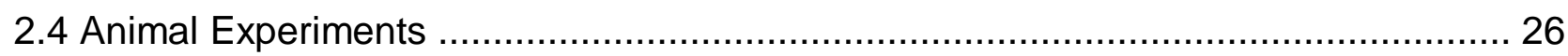

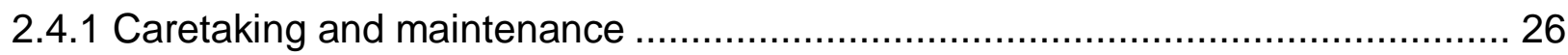

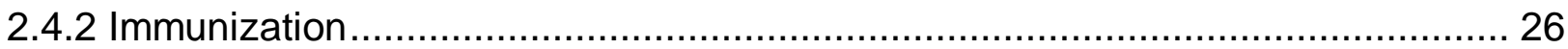

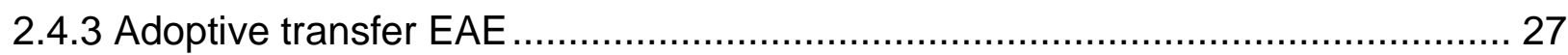

2.4.4 Subcutaneous transfer of T cells.......................................................... 27

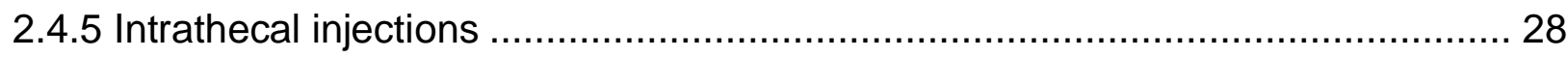

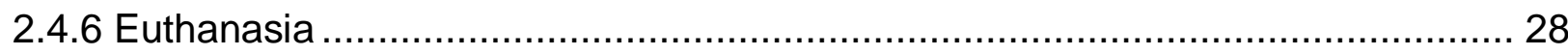

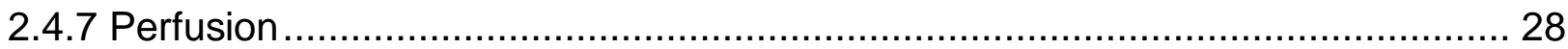




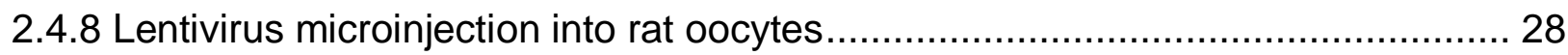

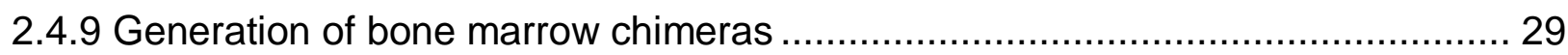

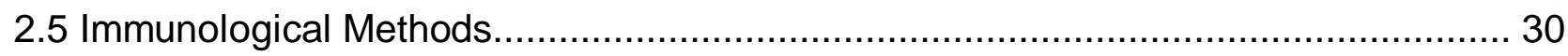

2.5.1 Preparation of cell suspensions from organs ………................................. 30

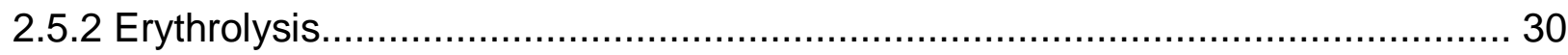

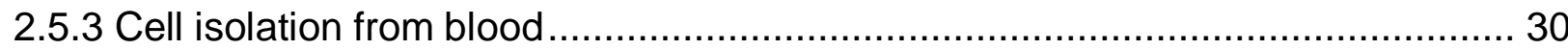

2.5.4 Cell isolation from spinal cord using a Percoll gradient ................................... 30

2.5.5 Separation of T cells via magnetic sorting ........................................................ 31

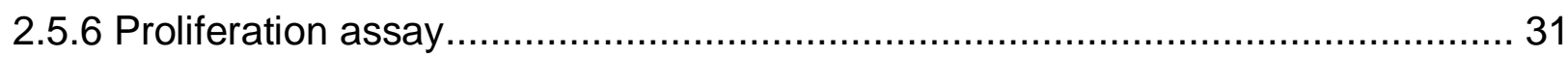

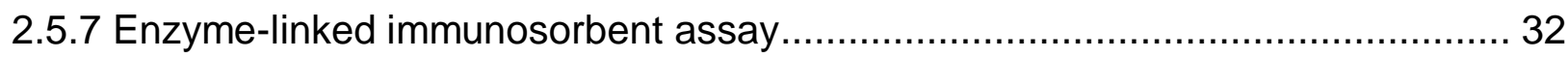

2.5.8 FACS analysis of cell surface marker using fluorescently labeled antibodies .... 32

2.5.9 Intracellular staining of cytokines .............................................................. 33

2.5.10 FACS analysis and sorting of fluorescently labeled cells .............................. 33

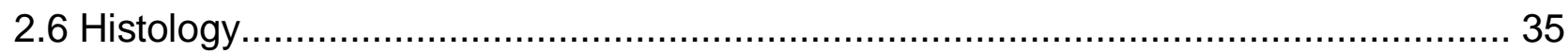

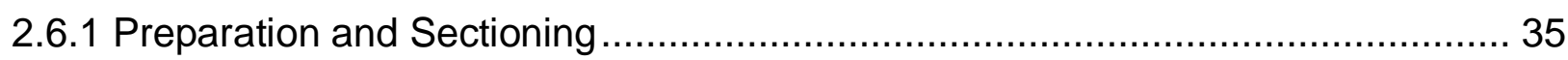

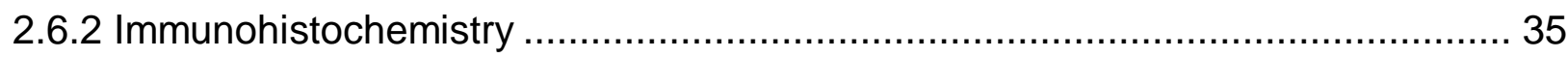

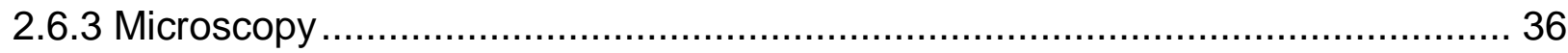

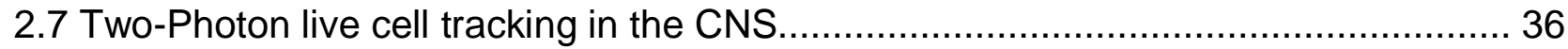

2.7.1 Two-Photon live cell tracking in the CNS: Procedure ...................................... 36

2.7.2 Two-Photon live cell tracking in the CNS: Analysis ...................................... 37

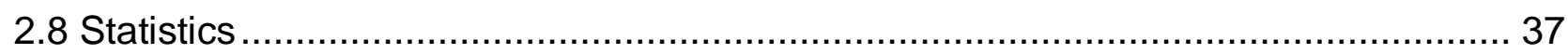

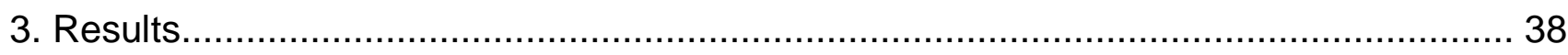

3.1 Generation and characterization of TCR transgenic rats ..................................... 38

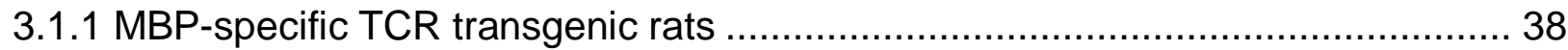

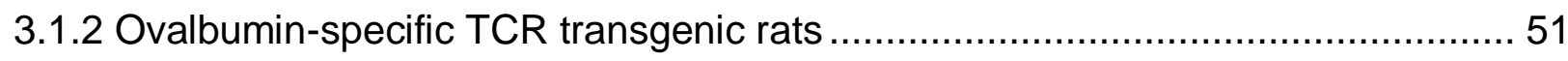

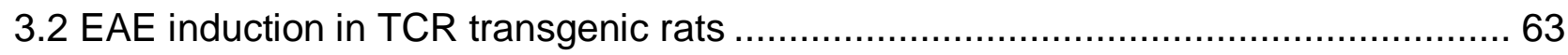

3.2.1 rMT-II rats developed active EAE with an accelerated disease onset................ 63

3.2.2 rMT-II rats developed EAE upon suboptimal immunization............................... 65

3.2.3 Susceptibility of $\mathrm{rMT}-\mathrm{II}$ rats to a repeated immunization and FK506 treatment ... 66

3.2.4 Classical immunization is required for induction of EAE in rMT-II rats ...............68

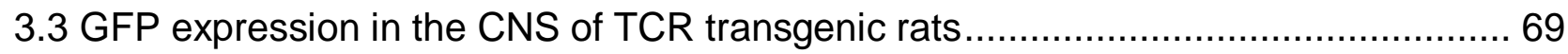

3.4 Migratory pattern of primary $T$ cells in comparison to effector $T$ cell lines ................ 73

3.4.1 Effector T cell lines established from $\mathrm{rMT}^{-\mathrm{II}^{+/+}}$and $\mathrm{rOT}-\mathrm{II}^{+/+}$rats ....................... 73 
3.4.2 Encephalitogenic potential of $\mathrm{rMT}-\mathrm{II}^{+/+}$effector $\mathrm{T}$ cells

3.4.3 Transfer of splenic $\mathrm{rMT}^{-\mathrm{II}^{+/+}}$cells before immunization accelerates the onset of active EAE.

3.4.4 Migratory pattern of splenic $\mathrm{rMT}^{-\mathrm{II}^{+/+}}$cells and effector $\mathrm{rMT}^{-\mathrm{II}^{+/+}} \mathrm{T}$ cells after local activation in lymph nodes

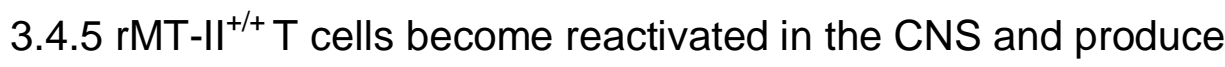
proinflammatory cytokines

3.4.6 Intravascular crawling at the blood-brain barrier distinguishes effector from splenic $\mathrm{rMT}^{-\mathrm{II}^{+/+}} \mathrm{T}$ cells

3.4.7 Splenic $\mathrm{rMT}^{-\mathrm{II}^{+/+}} \mathrm{T}$ cells can develop into central-memory T cells

3.4.8 Migratory pattern of splenic $\mathrm{rOT}-\mathrm{II}^{+/+}$cells and effector $\mathrm{rOT}-\mathrm{II}^{+/+} \mathrm{T}$ cells after local activation

3.4.9 Gene expression profile of splenic rOT- $\mathrm{II}^{+/+}$cells and effector $\mathrm{rOT}-\mathrm{II}^{+/+} \mathrm{T}$ cells after local activation 90

4 Discussion 91

4.1 Generation and initial analysis of TCR transgenic rats 91

4.1.1 MBP-specific TCR transgenic rats 91

4.1.2 OVA-specific TCR transgenic rats. 94

4.2 EAE development in TCR transgenic Lewis rat strains 97

4.2.1 Active EAE induction in TCR transgenic animals 97

4.3 Migratory routes and activation pattern of naïve and effector T cells 99

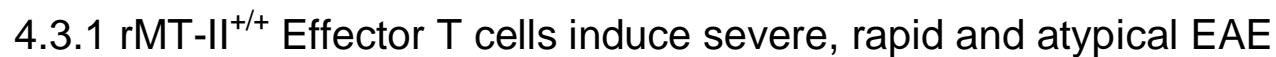
99

4.3.2 Splenic and effector $\mathrm{rMT}-\mathrm{II}^{+/+}$cells accelerate EAE onset after local activation 100

4.3.3 Splenic and effector $\mathrm{rMT}^{-\mathrm{II}^{+/+}} \mathrm{T}$ cells infiltrate the CNS utilizing different sets of chemokine receptors 101

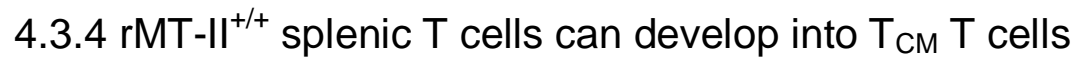
102

4.3.5 Migratory pattern is a T cell intrinsic feature 103

5 Summary 104

6 References 106

7 Abbreviations 116

8 Acknowledments 117

9 Curriculum vitae 118 


\section{INTRODUCTION}

The immune system represents a collection of cellular elements and defensive mechanisms to protect the host organism from a variety of microbial pathogens. It can be divided into the innate and the adaptive immune system. Innate immunity is a fast response system comprising phagocytic cells like macrophages, dendritic cells, neutrophils as well as mast cells, eosinophils, basophils and natural killer cells. Cells of the innate immune system recognize a broad range of pathogen-associated molecular patterns (PAMPs) and initiate immune reactions. The adaptive immune system consists of lymphocytes ( $T$ and $B$ cells) and is characterized by a slower but highly specific response and formation of an immunological memory. $T$ and $B$ cells recognize pathogens by specific receptors and upon activation cause their elimination. The primary tasks of the immune system are the maintenance of tissue homeostasis and providing a defense against pathogens throughout the organism. However, under certain circumstances the responses of adaptive immunity are directed against self-tissue, causing autoimmune diseases such as rheumatoid arthritis, type I diabetes or multiple sclerosis.

\subsection{MULTIPLE SCLEROSIS}

Multiple Sclerosis (MS) is an inflammatory demyelinating disease of the central nervous system (Compston and Coles, 2002). Multiple sclerosis manifests as a highly heterogenic disease with regard to clinical symptoms, disease course, histopathology and response to therapies. With a prevalence of around $0.15 \%$ in the Caucasian population, MS is the most common chronic progressive disorder of the CNS. Disease onset is between the age of 20 and 50 years and the disease occurs twice as frequently in women as in men. The symptoms fall into a broad range: motor and sensory dysfunctions often including impairment of vision are the most commonly observed, but symptoms also can comprise cognitive disturbance, fatigue or pain. Four main forms of disease progression have been defined (Lublin and Reingold, 1996): relapse-remitting (RR-MS, 80 \%), mostly followed by a secondary-progressive disease course (SP-MS, $65 \%$ of RR-MS patients), primaryprogressive (PP-MS, 10-20 \%) and progressive-relapsing (PR-MS, $10 \%$ ). 
The etiology of MS is poorly understood. Several factors have been proposed to contribute to MS pathogenesis including environmental risk factors (hygiene hypothesis), genetic predispositions and previous pathogen infections, e.g. with the Epstein-Barr virus (Ascherio and Munger, 2007; Compston and Coles, 2002).

Genetic studies revealed a number of polymorphisms in genes encoding MHC molecules (HLA) essential for antigen presentation and molecules involved in $T$ cell biology such as IL-2R $\alpha$, IL-7R or CD6 (Gourraud et al., 2012) which are associated with a higher risk of MS. This strongly argues for the (auto)immune nature of MS. On the tissue level, the disease is characterized by the formation of lesions, also termed plaques, in the brain and spinal cord - predominately in the white matter - with the loss of myelin (demyelination) that is in many cases associated with axonal degeneration and gliosis. Commonly, the infiltration of immune cells including $T$ lymphocytes and macrophages are found within such lesions. Although B cells are infrequently found within the MS-affected CNS, the presence of so called "oligoclonal bands" (considered as autoantibodies) in the cerebrospinal fluid of MS patients also suggests the involvement of humoral immunity. Therefore, in the absence of evidences for any involvement of pathogenic microorganisms, this picture can be interpreted as destructive reaction of the immune system directed against self-CNS tissue resulting in functional impairment (e.g. motor or sensory dysfunction, Nylander and Hafler, 2012).

Histopathologically, MS lesions can be classified into four demyelination patterns (Lucchinetti et al., 2000). Pattern I and II are characterized by the infiltration of T cells and macrophages clustered around small veins and venules and a sharp border between myelinated and demyelinated regions. The hallmark of pattern II is the evidence for local immunoglobulin deposition and activation of the complement system. Pattern III comprises distal oligodendropathy with fuzzy demarcation from normal white matter, preferential loss of myelin-associated glycoprotein (MAG) and signs of vasculitis all of which resembles a virus-associated or ischemic human CNS pathology. The rarely observed pattern IV is characterized by prominent degeneration of oligodendrocytes in the periplaque zone (Lucchinetti et al., 2000). In all four types of lesions the infiltration of immune cells is evident, however for the patterns III and IV the primary event triggering myelin damage may not be the autoimmune attack but rather exogenous (viral infection) or endogenous (metabolic defect in oligodendroglia) factors (Lassmann et al., 2001). 
It has not been possible to identify a single molecule as a universal target for the autoimmune response in MS. Autoreactive $\mathrm{T}$ cells responding to myelin-derived selfantigens such as myelin basic protein (MBP), proteolipid protein (PLP) and myelin oligodendrocyte glycoprotein (MOG) as well as oligodendrocyte-specific proteins like transaldolase and $\alpha \beta$-crystalline (Nylander and Hafler, 2012) are present in the immune repertoires of both healthy individuals and MS patients (Schmidt, 1999). For many of those specificities, such as the one toward MBP, increased numbers of activated $\mathrm{T}$ cells were reported in MS patients. Some candidate antigens (expressed on the cell membrane) causing $B$ cell responses and production of autoantibodies have been identified. For instance, in neuromyelitis optica (NMO), an inflammatory and demyelinating disease affecting mainly the optic nerve but also the spinal cord, an antibody response is directed against aquaporin-4 (AQP4). Markedly, in NMO lesions a profound loss of AQP4 astrocytes could be observed (Brück et al., 2012). In MS, autoantibody response to the potassium channel KIR4.1 was found in $47 \%$ of patients (Srivastava et al., 2012). Whether a T cell response to AQP4 and KIR4.1 also occurs in the context of MS still remains to be determined.

Finally, one of the most convincing arguments in favor of an (auto)immune pathogenesis of MS is the fact that current therapies demonstrating efficacy in MS patients target primarily, if not exclusively, the immune system (Table 1.1).

Table 1.1: Therapeutic compounds applied for MS treatment targeting the immune system.

\begin{tabular}{l|l} 
Mechanism & Treatment \\
\hline Inhibition of proliferation & Mitoxantron, Azathioprine, Teriflunomide, Daclizumab (mAb to CD25) \\
\hline Hormonal immunosuppression & Dexamethasone (Glucocorticoids) \\
\hline T cell depletion & Alemtuzumab (mAb to CD52) \\
\hline Block of T cell migration & Natalizumab (mAb to VLA4), Fingolimod (antagonist of S1P receptors) \\
\hline Immunomodulation & Interferon-beta, Laquinimod, Copaxone (Glatiramer acetate) \\
\hline B-cell depletion & Rituximab (mAb to CD20)
\end{tabular}

Collectively, many of the above described features suggest that a $T$ cell mediated autoimmune reaction is a mainstay of human MS pathogenesis and that a better understanding of how immune cells operate during neuroinflammation would contribute to more efficient and safe treatment opportunities. 
The CNS has a particular relationship to the immune system termed as immune privilege. Immune privilege is characterized by the lower magnitude and higher activation threshold for the adaptive immune response. Experimentally, the immune privilege of the CNS was first demonstrated in a study of allograft rejection using transplantation of mouse skin grafts into the brain or periphery (MEDAWAR, 1948). This special state of the CNS evolved to provide a balance between the need on the one hand for immune-mediated protection against viral, bacterial and fungal infections and neoplastic transformation taking place within the CNS and on the other hand the danger of irreversible and fatal immune-mediate damage to the CNS. The latter is highly relevant for the brain as it is constrained by bones, populated by terminally differentiated neurons unable to self-renew mitotically and extremely vulnerable to stress (e.g. hypoxia, free radicals, toxins etc.) and contains structures controlling vital physiologic functions such as blood circulation and respiration. Under these circumstances excessive inflammatory reactions are inevitably associated with collateral tissue damage and represent a great threat for the survival of an organism.

The immune privileged status of the CNS is maintained by several mechanisms. First, in contrast to many other organs such as skin, lung or gut, the CNS lacks an afferent lymphatic system. If passive traffic of soluble CNS antigens or their active carriage by migrating antigen-presenting cells (APCs) toward lymphoid organs occurs at all, this is likely to happen at the sites where the cerebrospinal fluid (CSF) can get in contact with tissues drained by lymphatic vessels. For instance, the CSF circulating around olfactorial nerves can reach the mucosa of the nasal cavity and from there enter the draining cervical lymph nodes. Second, CNS tissue is separated from blood circulation by the blood-brain barrier (BBB). Highly specialized endothelial cells are joined by tight junctions effectively preventing free entry of molecules and cells into the CNS. The brain endothelium lacks fenestration and expresses very low levels of adhesion molecules, such as ICAM-1, used by leukocytes to extravasate. Together with a few pericytes, the BBB endothelium is covered by a basement membrane, limiting perivascular space from the side of blood circulation. From the side of the CNS parenchyma, processes of astrocytes called endfeet form a continuous layer of glia limitans covered by another thin membrane. Residing within the perivascular space, perivascular phagocytes can be found (also called perivascular macrophages), fibroblast-like cells producing the extracellular matrix, collagen fibers and 
the cerebrospinal fluid. Also, the processes of microglia cells extended from the parenchyma end up in the perivascular space (Engelhardt and Sorokin, 2009; Engelhardt and Ransohoff, 2005). Third, CNS tissue per se represents an immunohostile environment. This property refers to the negligible expression of immune factors such as MHC molecules and proinflammatory cytokines and chemokines in the healthy CNS.

The former view that the CNS is sequestered from the peripheral immune system (Barker and Billingham, 1977) has changed. In histological analysis of healthy humans or rodents, T cells could be detected at very low frequencies in perivascular, subarachnoid or meningeal spaces indicating the CNS being a target for constant immune surveillance (Deli et al., 2005). As these cells are not activated, they do not further penetrate the CNS tissue and do not accumulate locally. This rapidly changes however when innate immune cells become activated, e.g. in case of viral/bacterial infection or stroke, resulting in a massive influx of myeloid cells and T lymphocytes from circulation.

A variety of questions dealing with immune privilege and immune surveillance of the CNS arise in the context of MS: How is central and peripheral tolerance of myelin-reactive T cells towards self-CNS tissue maintained? How do CNS derived antigens become presented to T cells outside and within the CNS and what is the role of subtypes of antigen presenting cells (APCs)? Which properties of T cells allow transmigration of the BBB and the entry into the CNS parenchyma and which of them can be therapeutically targeted in MS patients? What subsets of $T$ cells are crucial for the initiation, progression and resolution of neuroinflammation? What is the interplay between inflammation and degeneration of CNS tissue (e.g. demyelination and axonal damage) and subsequent repair? Many of these questions cannot be answered efficiently without the aid of animal models.

\subsection{EXPERIMENTAL AUTOIMMUNE ENCEPHALOMYELITIS}

The heterogeneity of MS, the limited amount of patient-derived material available for analysis and ethical constrains substantially complicate research of MS. Therefore, understanding molecular mechanisms of neuroinflammation and development of new therapeutic options require experimental modeling of human pathology in animals. No spontaneous MS-like disease has been reported in commonly used laboratory species. A demyelinating CNS pathology can be induced in rodents by infection with certain viruses (e.g. Theiler's murine encephalomyelitis virus, Miller et al., 1997) or by toxic damage of 
oligodendroglia (cuprizone in mice, lysolecitin in rats, Blakemore, 1973; Mitchell and Caren, 1982). However, the classical animal model to mimic MS-like symptoms in order to study autoimmune processes in the CNS is experimental autoimmune encephalomyelitis, $E A E$ ('t Hart et al., 2011). Active EAE can be induced by the immunization of animals (that is injection of antigen in combination with adjuvant) with components of the myelin sheath (Fig. 1.1) in a variety of species, e.g. in primates (Rivers et al., 1933), dogs (THOMAS et al., 1950), rats (LIPTON and FREUND, 1952) or mice (OLITSKY and YAGER, 1949). Passive EAE can be induced by the adoptive transfer of myelin-specific T cells in mice and rats (BELL and PATERSON, 1960).

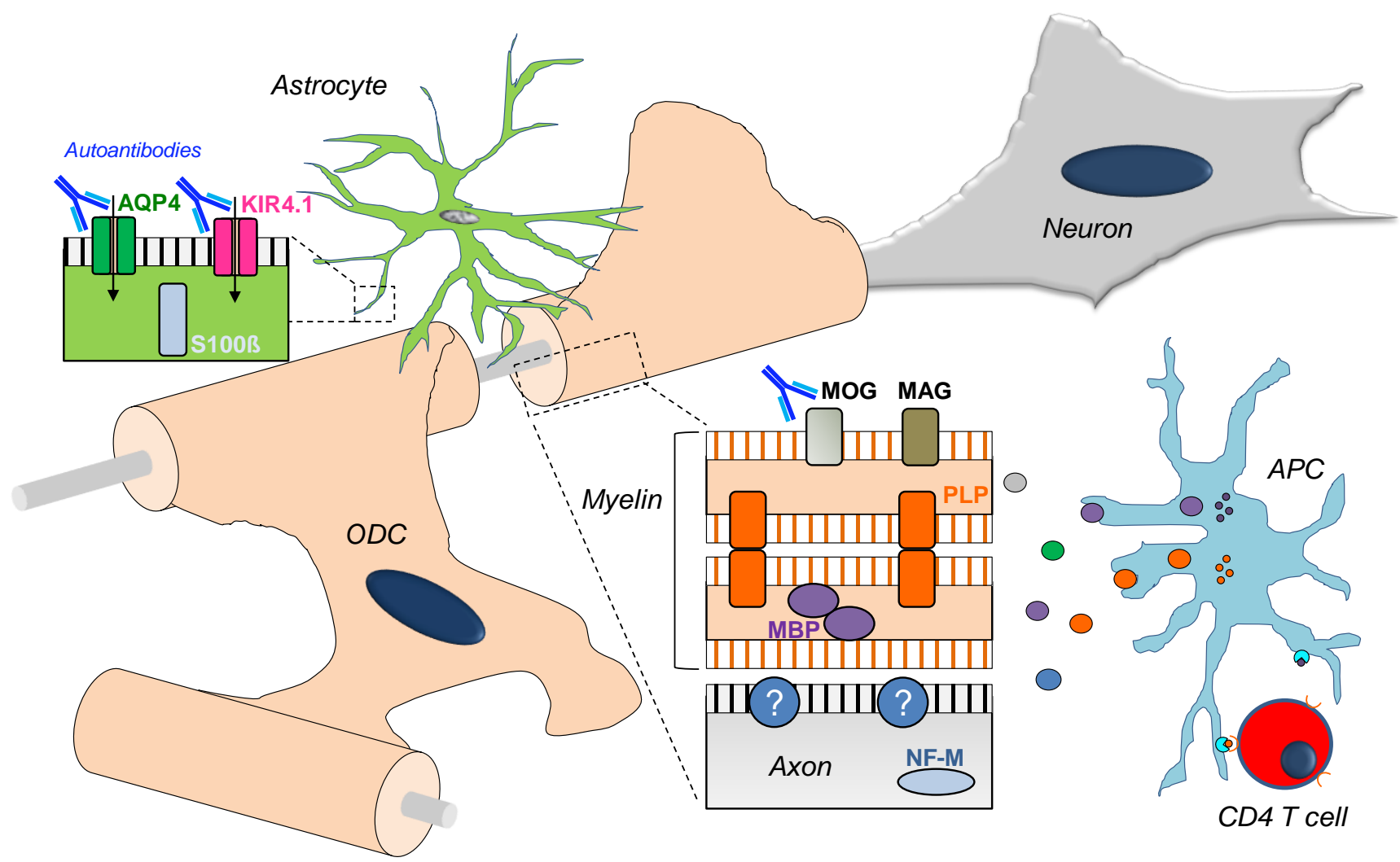

Figure 1.1: CNS autoantigens implicated in MS or experimental autoimmunity. ODC, oligodendrocyte. MOG, myelin oligodendrocyte glycoprotein. MAG, myelin-associated glycoprotein. MBP, myelin basic protein. PLP, proteolipid protein. NF-M, medium-sized neurofilament. $\mathrm{S} 100 \beta$, S100 calcium binding protein B. AQP4, aquaporin 4. KIR4.1, potassium channel. APC, antigen-presenting cell.

The genetic background of rodent strains and the nature of antigens used for immunization determine the pathology and the disease course (Examples see Tab. 1.2 and Fig. 1.2).

Widely used active mouse EAE models are the $\mathrm{MOG}_{35-55}$-induced chronic paralytic disease in the C57BL/6 strain and the $\mathrm{PLP}_{139-151}$-induced relapsing-remitting EAE in the SJL/J strain. The use of adjuvants for the induction of EAE and the fact that inflammatory 
infiltrates in the EAE-affected CNS tissue dominate over signs of demyelination distinguish the model from human MS disease. Also, an inbred (homogeneous) genetic background of mice and their housing under conditions devoid of a natural microbial environment make a profound distinction to human autoimmunity. However, the ability to manipulate individual cell types and processes by genetic and/or pharmacologic means places rodent EAE as valuable and highly demanded tool in the field of neuroimmunological research.

Table 1.2: Myelin antigens used for induction of EAE in different species.

\begin{tabular}{l|l|l} 
Species/strain & Autoantigen & Disease course \\
\hline Mouse - C57N/BL6 & MOG & Chronic (Mendel et al., 1995) \\
\hline Mouse - SJL/J & PLP & Relapsing-Remitting (Tuohy et al., 1988) \\
\hline Mouse - C3HeB/Fej & MOG & Atypical EAE course (Stromnes et al., 2008) \\
\hline Rat - Lewis rat & MBP & Monophasic (LIPTON and FREUND, 1952; LIPTON and FREUND, 1953) \\
\hline Rat - Lewis rat & Spinal cord homogenate & Monophasic (Wekerle and Sun, 2010) \\
\hline Rat - Brown Norway & MOG & Neuromyelitis optica (Weissert et al., 1998) \\
\hline Rat - Brown Norway & Spinal cord homogenate & Monophasic (Wekerle and Sun, 2010) \\
\hline Rat - Dark Agouti & MBP & Monophasic (Momcilovic et al., 2008; Stosic-Grujicic et al., 2004) \\
\hline Rat - Dark Agouti & Spinal cord homogenate & Chronic-relapsing EAE (Wekerle and Sun, 2010) \\
\hline Marmosets & MOG & Relapsing-Remitting (Kap et al., 2008; Jagessar et al., 2010)
\end{tabular}

\subsubsection{ACTIVE EAE IN LEWIS RATS}

In Lewis rats, EAE manifests as an acute monophasic paralytic disease (Fig. 1.2). It can be actively induced via immunization of naïve rats with myelin basic protein emulsified in complete Freund's adjuvant (CFA). Ten days after active immunization, Lewis rats develop EAE accompanied by loss of body weight and starting with a paresis of the tail and ascending to a complete paralysis of the hind limbs. Remarkably, the disease course is monophasic and animals recover completely. The development of clinical symptoms is accompanied by perivascular infiltration of T cells and macrophages (Huitinga et al., 1995) detected primarily in the spinal cord. Lewis rats challenged with a second MBP immunization did not develop a second disease bout (Sun et al., 1999). The reason for this resistance could be an induction of regulatory $\mathrm{T}$ cells (Tregs). Interestingly, low-dose treatment of Lewis rats with cyclosporine $A$, that presumably affects predominately Treg cells which are strongly dependent on IL-2, did not prevent EAE but converted the disease course to a chronic/relapsing form (Polman et al., 1988). Furthermore, Lewis rat EAE is a 
useful model to investigate new therapeutic drugs, e.g. anti-VLA-4 mAb (Yednock et al., 1992), laquinimod (Yang et al., 2004; Noseworthy et al., 2000) or fingolimod (Fujino et al., 2003).

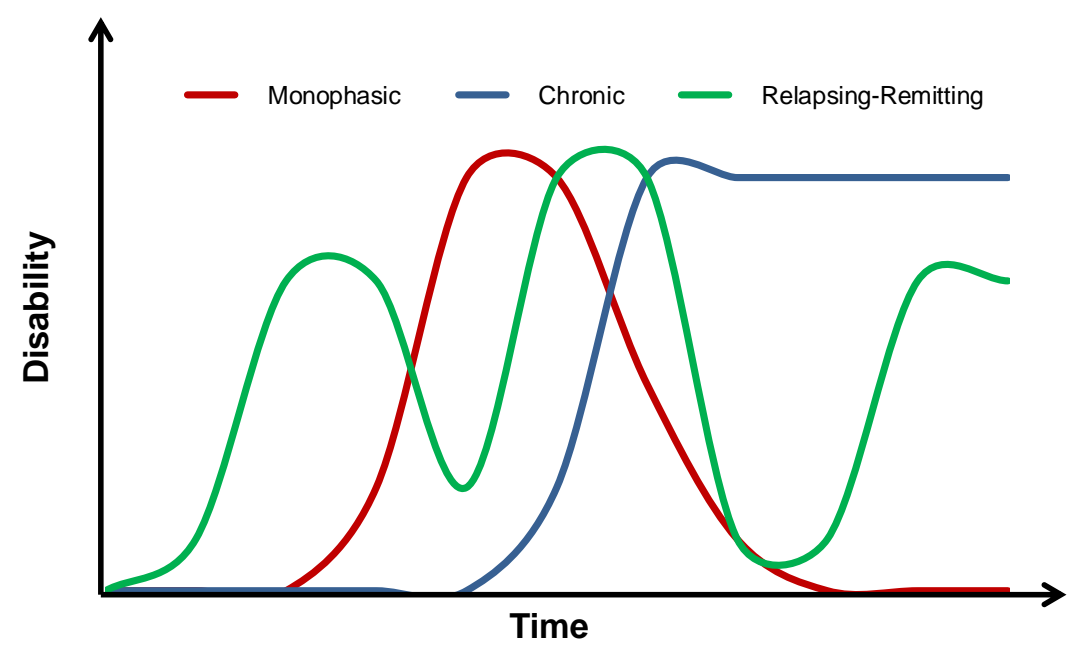

Figure 1.2: Types of disease course in EAE models

\subsubsection{ADOPTIVE TRANSFER EAE IN LEWIS RATS}

EAE in Lewis rats can be induced via the adoptive transfer of MBP-specific CD4 ${ }^{+}$effector T cells activated ex vivo (Ben-Nun et al., 1981). The disease course is again monophasic starting with a paresis of the tail and ascending to a complete hind limb paralysis. Afterwards, the animals recover completely.

Transfer EAE convincingly proved the crucial role for myelin-specific $T$ cells in EAE development. Transfer EAE is a potent model to study the behaviour and function of pathogenic $\mathrm{T}$ cells in vivo. One advantage of using the adoptive transfer of myelin specific T cells to evoke EAE is the possibility to genetically engineer these $T$ cells to express fluorescent markers or other genes using ex vivo T cell culture (Flügel et al., 1999). Using GFP-tagged $\mathrm{T}_{\mathrm{MBP}}$ lines the migratory route of the transferred pathogenic $\mathrm{T}$ cells can be followed in vivo and the migratory behavior outside and within the CNS can be visualized using two-photon live microscopy (Bartholomäus et al., 2009).

Remarkably, recipient rats do not develop EAE directly after T cell transfer but only after a prodromal phase of about 3 days (Wekerle et al., 1994). Within this period, the transferred $T$ cells are largely absent in the circulation and home preferentially into the spleen and the lung (Odoardi et al., 2012). The observation that adoptively transferred $\mathrm{T}$ cell blasts do not 
attack the CNS directly after transfer was explained until recently by a T cell hostile milieu of the CNS and the integrity of the blood-brain barrier (Greter et al., 2005). To evoke inflammation and the development of paralysis, T cells were thought to infiltrate the CNS in two distinct waves: First, a few pioneer $\mathrm{T}$ cells were believed to transmigrate the bloodbrain barrier and become reactivated within the CNS thereby causing an inflammatory milieu and BBB damage. Then, a second wave of myelin specific $T$ cells was thought to enter the CNS causing the clinical symptoms (Odoardi et al., 2007; Wekerle et al., 1986).

Recently, Odoardi et al. could demonstrate that transferred T cells home into peripheral milieus like lung and spleen during the prodromal phase. There, the $T$ cells acquire a migratory phenotype by down-regulating inflammatory factors (IFN $\gamma, T N F \alpha$ ) and upregulating adhesion molecules (LFA-1, VLA-4, Ninjurin1) and chemokine receptors (CXCR3, CXCR4, S1 $\mathrm{P}_{1}$ ). As T cells isolated from spleens of rats in the preclinical phase of atEAE induce disease much faster than freshly activated blast do upon retransfer in naïve animals, the phenotype acquired in peripheral organs seems to enable the $T$ cells to efficiently cross an apparently intact blood-brain barrier and get reactivated by local antigen presenting cells within the CNS causing EAE (Odoardi et al., 2012).

\subsubsection{TCR TRANSGENIC MOUSE MODELS FOR STUDYING CNS AUTOIMMUNITY}

Studying autoimmunity in the mouse is greatly facilitated by using transgenic mouse strains with a myelin-specific $T$ cell receptor (as well as $B$ cell receptor). In these mice, nearly all $T$ cells of the immune repertoire express the transgenic T cell receptor (TCRtg) with a defined specificity for a given autoantigen. Therefore TCRtg mice can be used to analyse autoantigen specific $\mathrm{T}$ cells in immune reactions both in vitro and in vivo. Additionally, some of the TCRtg mouse lines do also develop EAE spontaneously and can be used to investigate the initial $T$ cell activation causing the disease.

Until now, there is a broad range of TCR transgenic mouse strains available with different EAE initiation and progression patterns (Tab. 1.3).

The first myelin specific TCR transgenic mouse lines were described by Goverman et al. (1993) expressing a MHCIl-restricted TCR specific for MBP. In these mice, EAE could be induced via active immunization with an earlier disease onset and stronger disease phenotype. The disease could even be evoked by administration of non-specific immune stimuli like CFA or lipopolysaccharide (LPS). Interestingly, when kept under specific 
pathogen-free conditions instead of germ-free housing, some individuals of this mouse line developed EAE spontaneously.

Additionally, the MHCll-restricted MBP-specific TCR transgenic mouse line developed by Lafaille et al. (1994) displayed a spontaneous EAE incidence of around $14 \%$. This could be increased to $100 \%$ by crossing these mice to the RAG1-knockout background. These mice then lack all $B$ cells and non-transgenic $T$ cells.

In 2003, Bettelli et al. reported the first MHCll-restricted MOG-specific TCR transgenic mice (2D2 mice). Here, the TCR recognized the MOG peptide 35-55 and the mice developed spontaneous paralytic EAE to a very low degree. However, around $30 \%$ of the mice spontaneously developed optic neuritis.

The 2D2 mice were then crossed with $\mathrm{IgH}^{\mathrm{MOG}}$ mice (Litzenburger et al., 1998), which express the heavy chain of the MOG specific demyelinating antibody 8.18c5 instead of the endogenous $\mathrm{JH}$ sequence. In these double-transgenic mice expressing both MOG-specific T cells and antibodies, the disease incidence was increased to $50-60 \%$ with an earlier disease onset and a stronger disease phenotype compared to 2D2 mice (Bettelli et al., 2006; Krishnamoorthy et al., 2006).

Mice expressing a MOG-specific TCR for the peptide 92-106 on the SJL/J background developed spontaneous EAE with a relapse-remitting phenotype with an even stronger manifestation of demyelination when additionally crossed with the $\operatorname{lgH}^{\mathrm{MOG}}$ mice (Pollinger et al., 2009).

In multiple sclerosis patients, it was demonstrated that not only $\mathrm{CD}^{+}{ }^{+} \mathrm{T}$ cells play a role in neuroinflammatory processes but also that myelin-specific $\mathrm{CD}^{+} \mathrm{T}$ cells can be found in CNS lesions and the cerebrospinal fluid (Babbe et al., 2000). Also, myelin-specific CD8 ${ }^{+}$ T cells can induce axonal loss via "collateral bystander damage" (Sobottka et al., 2009). To further characterize the role of myelin-specific $\mathrm{CD}^{+} \mathrm{T}$ cells in immune responses, the Goverman lab introduced a MHC-I restricted MBP-specific TCR transgenic mouse strain (Huseby et al., 2001a).

Along this line, transgenic mice were created expressing ovalbumin under the control of the MBP promoter driving expression in oligodendrocytes (ODC-OVA). In these mice, unless actively immunized, $\mathrm{CD}^{+} \mathrm{T}$ cells and $\mathrm{B}$ cells remain ignorant of the antigen (Cao et al., 2006). This observation could also be confirmed in animals expressing a MHC class II restricted OVA-specific TCR (Barnden et al., 1998) as CD4 ${ }^{+}$T cells did not recognize ovalbumin expressed by oligodendrocytes ( $\mathrm{Na}$ et al., 2008). However, when ODC-OVA mice were crossed to the OT-I transgenic line (MHC class I restricted OVA-specific TCR, 
Hogquist et al., 1994)) mice spontaneously developed lethal demyelinating EAE with lesions in cerebellum, optic nerve and spinal cord ( $\mathrm{Na}$ et al., 2008). Of interest, in single transgenic ODC-OVA mice OVA-reactive $\mathrm{CD}^{+} \mathrm{T}$ cells were shown to be actively removed from the immune repertoire by a mechanism which could not be entirely elucidated ( $\mathrm{Na}$ et al., 2012).

Table 1.3: Overview of TCR-transgenic mouse strains used in neuroimmunology

\begin{tabular}{|c|c|c|c|c|c|c|}
\hline Strain & Background & Autoantigen & Restriction & TCR & Onset & Reference \\
\hline 172.10 & B10.PL & $\mathrm{MBP}_{\mathrm{Ac} 1-11}$ & MHCII & $\begin{array}{l}V \alpha 2.3 \\
V \beta 8.2\end{array}$ & $\begin{array}{l}\text { Spontaneous } \\
14-44 \%\end{array}$ & (Goverman et al., 1993) \\
\hline \multirow[t]{2}{*}{19} & C57N/BL6 & $\mathrm{MBP}_{\mathrm{Ac} 1-9}$ & $\mathrm{MHCII}$ & $\begin{array}{l}\vee \alpha 4 \\
V \beta 8.2\end{array}$ & $100 \%$ (RAG1 KO) & (Lafaille et al., 1994) \\
\hline & B10.PL & $\mathrm{MBP}_{121-150}$ & $\mathrm{MHCl}$ & $\begin{array}{l}V \alpha 2 \\
V \beta 4\end{array}$ & $0 \%$ & (Huseby et al., 2001b) \\
\hline Ob.1A12 & C57N/BL6 & $\mathrm{MBP}_{84-120}$ & HLADR2 & $\begin{array}{l}\vee \alpha 3 \\
V \beta 2.1\end{array}$ & $100 \%$ (RAG1 KO) & (Madsen et al., 1999) \\
\hline 2D2 & C57N/BL6 & $\mathrm{MOG}_{35-55}$ & $\mathrm{MHCII}$ & $\begin{array}{l}V \alpha 3.2 \\
V \beta 11\end{array}$ & $\begin{array}{l}4 \% \text { EAE } \\
30 \% \text { Optic Neuritis }\end{array}$ & $\begin{array}{l}\text { (Bettelli et al., 2003; Bettelli et al., } \\
\text { 2006) }\end{array}$ \\
\hline $\begin{array}{l}2 \mathrm{D} 2 \mathrm{x} \\
\lg \mathrm{H}^{\mathrm{MOG}}\end{array}$ & C57N/BL6 & $\mathrm{MOG}_{35-55}$ & MHCII & $\begin{array}{l}\mathrm{V} \alpha 3.2 \\
\mathrm{~V} \beta 11\end{array}$ & $50 \% \mathrm{EAE}$ & $\begin{array}{l}\text { (Bettelli et al., 2006; Krishnamoorthy } \\
\text { et al., 2006) }\end{array}$ \\
\hline \multirow[t]{2}{*}{ RR mice } & SJL/J & $\mathrm{MOG}_{92-106}$ & MHCII & $\begin{array}{l}\text { V } \alpha 8.3 \\
V \beta 4\end{array}$ & $\begin{array}{l}\text { Spontaneous RR } \\
\text { EAE }\end{array}$ & (Pollinger et al., 2009) \\
\hline & SJL/J & $\mathrm{PLP}_{139-151}$ & MHCII & $\begin{array}{l}\vee \alpha 11 \\
V \beta 16\end{array}$ & $\begin{array}{l}\text { Spontaneous } \\
8-83 \%\end{array}$ & (Waldner et al., 2000) \\
\hline $\begin{array}{l}\text { OT-Ix } \\
\text { ODC-OVA }\end{array}$ & C57N/BL6 & $\mathrm{OVA}_{257-262}$ & $\mathrm{MHCl}$ & $\begin{array}{l}V \alpha 2 \\
V \beta 5\end{array}$ & none & (Hogquist et al., 1994) \\
\hline $\begin{array}{l}\text { OT-II } x \\
\text { ODC-OVA }\end{array}$ & C57N/BL6 & $\mathrm{OVA}_{323-339}$ & $\mathrm{MHCll}$ & $\begin{array}{l}\text { V } \alpha 2 \\
V \beta 5\end{array}$ & none & (Barnden et al., 1998) \\
\hline $1 \mathrm{C} 6$ & NOD & $\mathrm{MOG}_{35-55}$ & $\mathrm{MHCll}$ and I & $\begin{array}{l}\vee \alpha 5 \\
V \beta 7\end{array}$ & $\begin{array}{l}\text { Rarely } \\
\text { spontaneous, } \\
\text { RR EAE }\end{array}$ & (Anderson et al., 2012) \\
\hline $\begin{array}{l}1 \mathrm{C} 6 \mathrm{x} \\
\operatorname{lgH}^{\mathrm{MOG}}\end{array}$ & NOD & $\mathrm{MOG}_{35-55}$ & MHCII and I & $\begin{array}{l}\vee \alpha 5 \\
V \beta 7\end{array}$ & $\begin{array}{l}\text { Spontaneous } \\
45-79 \%\end{array}$ & (Anderson et al., 2012) \\
\hline
\end{tabular}


T cells recognize antigenic determinants via the surface-expressed T cell receptor, TCR. Structurally, a T cell receptor consists of a $\alpha$-chain and $\beta$-chain linked to each other via disulfide bridges and can recognize antigenic peptides bound to a MHC complex. The $\alpha-$ and $\beta$ - chains can be further divided into a constant region, identical for all T cells, and a variable region, determining specificity. The TCR is expressed on the cell surface as a complex with CD3 subunits $(\gamma-, \delta$-, two $\varepsilon$ chains and two $\zeta$ polypeptide chains) which are also important for signal transduction (Wucherpfennig et al., 2010).

As the encoding of all antigenic receptors necessary to confer sufficient protection of the host by individual genes would require too much of genomic capacity, a mechanism called somatic recombination or $\mathrm{V}(\mathrm{D}) \mathrm{J}$ recombination has evolved. $\mathrm{V}(\mathrm{D}) \mathrm{J}$ recombination generates a highly diverse repertoire of BCRs and TCRs (Schatz and Swanson, 2011). TCR genes are organized as an array of $\mathrm{V}$ (ariable), $\mathrm{D}$ (iversity) and $\mathrm{J}$ (unction) segments, one constant region for the $\alpha$ chain and two constant regions for the $\beta$ chain genes each preceded by a D-J cluster (Krangel, 2009). During T cell development in the thymus, these segments are rearranged with each other via site specific recombination resulting in deletion of intervening sequences (Fig. 1.3). At the same time few non-templated nucleotides can be added or removed at the junction sites. 


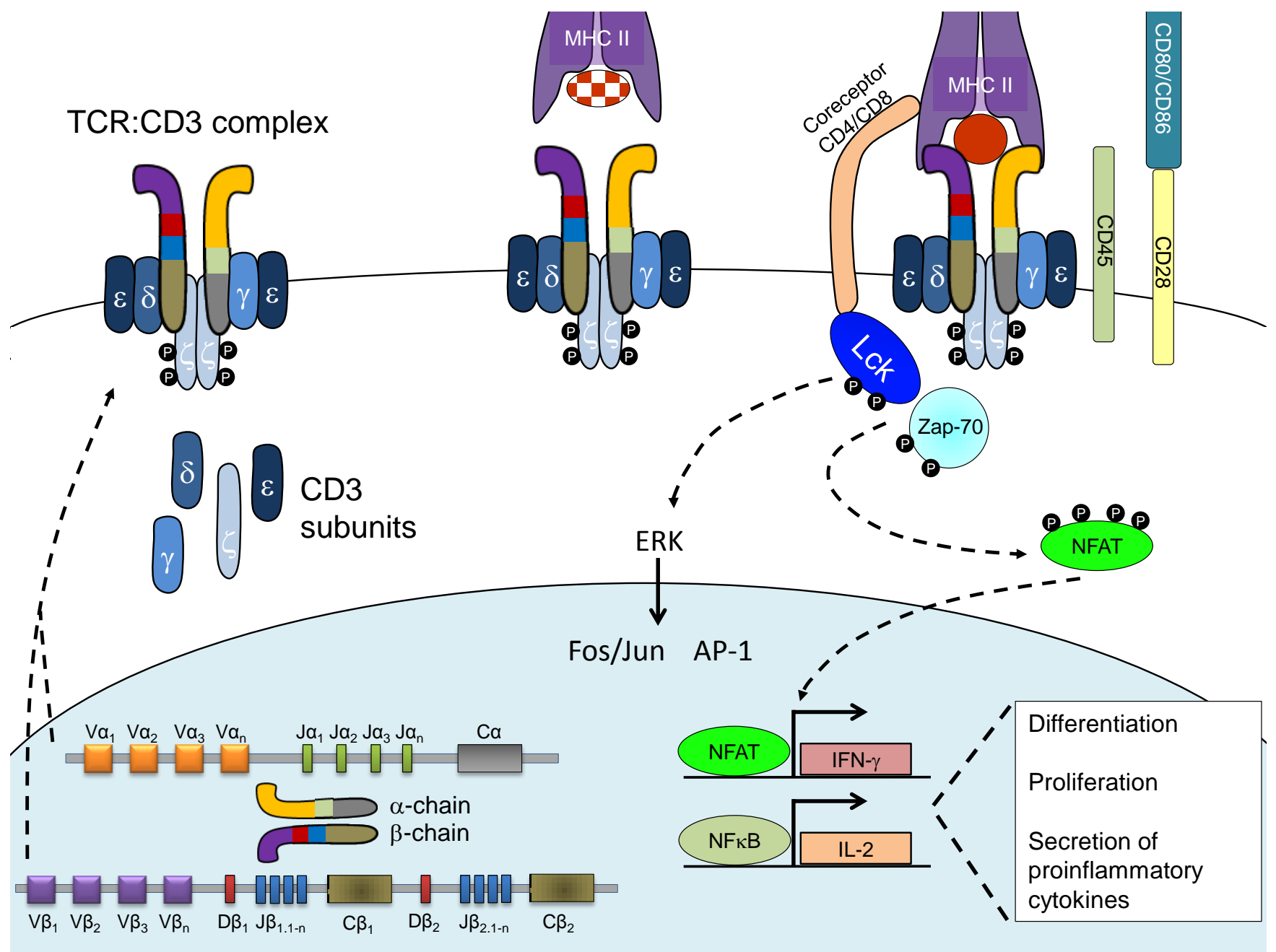

Figure 1.3: Structure of the TCR complex and the down-stream signaling. TCR $\alpha$ - and $\beta$-chains are assembled by recombination of $\mathrm{V}$ (ariable), $\mathrm{D}$ (iversity), $\mathrm{J}$ (unction) and splicing to $\mathrm{C}$ (onstant) chain regions. The rearranged TCR forms a complex with CD3 subunits and is transported to the cell surface enabling its interaction with antigen presented in the context of MHC presentation. TCR binding to peptide-MHC triggers down-stream signaling pathways resulting in activation of transcription factors (e.g. Nuclear Factor 'kappa-light-chain-enhancer' of activated B-cells or Nuclear Factor of Activated $T$ cells) driving $T$ cell differentiation, proliferation and cytokine production.

During thymic development of $\alpha \beta T$ cells (at the CD4 ${ }^{-}{ }^{-} 8^{-}$stage), the genomic $\mathrm{D}$ segment of the $\beta$-chain is first fused to one of the $J \beta$ segments and then to one of the upstream VB segments (Krangel, 2009). The leader sequence and exons of the constant region are combined with the VDJ exon during splicing of a primary RNA transcript. Later, at the $\mathrm{CD}^{+} \mathrm{CD}^{+}$double-positive stage, $\mathrm{V}_{\alpha}$ and $\mathrm{J}_{\alpha}$ undergo rearrangement. Due to these rearrangements of numerous gene segments (e.g. $>20 \vee \beta$ and $>70 \vee \alpha$ ), the combinatorial diversity of a $\mathrm{T}$ cell receptor repertoire can be around $10^{16}$ (Tonegawa, 1983; Davis and Bjorkman, 1988). The diversity of peripheral $\alpha \beta$ T cells with completed thymic development was estimated to be around $10^{7}$ (Arstila et al., 1999). This reduction is due to selection 
processes taking place within the thymus. Functionality of the TCR is tested during the development first in a process called $\beta$ selection, and subsequently by positive and negative selection.

For $\beta$-selection, the $\beta$-chain is expressed together with a pre-T $\alpha$ invariant chain to test structural properties that permit the expression of the pre-T $\alpha$-TCR $\beta$ pair in complex with CD3 on the cell surface. Those thymocytes that passed the $\beta$-selection checkpoint, temporally shut down $\mathrm{V}(\mathrm{D}) \mathrm{J}$-recombination, proliferate and transit to the $\mathrm{CD} 4^{+} \mathrm{CD} 8^{+}$stage. There, the $\alpha$ chain is rearranged, translated and expressed as $\alpha \beta T C R: C D 3$ complex. During positive selection, the interaction of the $\alpha \beta T C R$ with a MHC molecule is tested leading to the deletion of $\mathrm{T}$ cells expressing a TCR unable to bind to MHC molecules. Lastly, during negative selection, the TCR interaction to self-peptides is tested and TCRs recognizing self-peptides expressed in the thymus are deleted from the repertoire (BURNET, 1959; Kappler et al., 1987). After passing positive and negative selection, T cells down-regulate the expression of one of the coreceptors resulting in either CD4 or CD8 single-positive $\mathrm{T}$ cells depending on whether the TCR interacted with a MHC class I or MHC class II molecule (Teh et al., 1988).

\subsection{T CELL RECEPTOR SIGNALING}

After thymocyte development, functional $\mathrm{T}$ cells leave the thymus and recirculate in the periphery. Naïve T cells become activated when antigen loaded APCs meet them in lymph nodes or spleen (Fig. 1.3). Upon antigen recognition via $\alpha \beta T C R: C D 3 / p M H C$ interaction, an immunological synapse is formed bringing the TCR:CD3 complexes in close proximity to CD45 and the coreceptor molecule. Intracellular domains of the CD3 subunits contain ITAMs (immunoreceptor tyrosine-based activation motif) and both the TCR:CD3 complex as well as the coreceptor are associated with the tyrosine kinases Fyn and Lck. Close proximity of the tyrosine phosphatase CD45 enables the dephosphorylation of Fyn and Lck leading to the subsequent phosphorylation of $\mathrm{CD} 3 \zeta$ chains. This enables the association and activation of ZAP-70 ( $\zeta$-associated protein 70 ) resulting in the activation of many downstream targets. One of them, phospholipase C- $\gamma(\mathrm{PLC} \gamma)$ cleaves phosphatidylinositolbiphosphate into diacylglycerine (DAG) and inositoltriphosphate $\left(\mathrm{IP}_{3}\right)$. DAG activates a transduction pathway leading to the activation of protein kinase $C$ and the transcription 
factor $\mathrm{NF}_{\kappa \mathrm{B}}$ whereas $\mathrm{IP}_{3}$ leads to depletion of intracellular calcium stores driving influx of extracellular calcium that in turn mediates nuclear translocation of the transcription factor NFAT (nuclear factor of activated T cells). Both transcription factors enable the gene transcription of factors driving $T$ cell proliferation and the production of cytokines (IFN $\gamma$, TNF $\alpha$, IL-2, IL-4, IL-17 and others, Brownlie and Zamoyska, 2013).

\subsection{TRANSGENIC APPROACHES}

In mice, TCR transgenic animals have been obtained via pronuclear injection of DNA expression constructs shuttling rearranged TCR sequences into oocytes. Although these constructs are randomly integrated into the host genome, they can be engineered to contain regulatory elements, such as promoters and enhancers driving expression in T cells (e.g. Kouskoff et al., 1995) in a developmentally controlled manner. Classically, the generation of transgenic rats was also achieved by pronuclear DNA injection (Mullins and Mullins, 1996) but this is a technically challenging and costly process. The use of selfinactivating lentiviruses became an alternative to generate transgenic mice and rats (Lois et al., 2002). In Lewis rats, this method was successfully used to create a number of transgenic strains, with such properties as ubiquitously expressed GFP and conditional knock-down of an insulin receptor (van den Brandt et al., 2004; Herold et al., 2008). A limitation of using the lentiviral approach is the restricted capacity of the viral genome, precluding integration of all necessary regulatory elements in addition to the sequence of two TCR chains. Von Holst et al. reported the generation of TCR transgenic chimeric mice by retroviral transduction of bone-marrow and transfer to irradiated hosts (Holst et al., 2006). In this retrogenic approach, surface expression of a transgenic TCR encoded by integrated provirus occurs only in cells committed to CD3 expression. Retrogenic mice do not transmit TCR expression to the next generation and have to be produced anew for multiple experiments. However, these studies imply that germline competent lentiviral vectors equipped with multicistronic cassettes can be used in rats to confer stable expression of TCRs with predetermined specificity to mature T cells in vivo.

Recently, conditions were defined for establishing and propagating germ-line competent rat ES cells ( $\mathrm{Li}$ et al., 2008). This breakthrough enabled the generation of mutant rats by gene targeting using homologous recombination in ES culture, e.g. generating a p53 knock-out 
strain (Tong et al., 2011) and establishing knock-in strains expressing GFP (Blair et al., 2012) or tdTomato (Kobayashi et al., 2012). Additionally, new methods for generation of "loss-of-function" mutants were introduced into the rat genetic toolset e.g. utilizing TALEN-, Cas9-, or zinc finger nuclease-mediated targeting (Carroll, 2011; Shen et al., 2013; Zhang et al., 2011; Geurts et al., 2009). The latter method was successfully applied for the generation of Rag1 knock-out rats (Zschemisch et al., 2012). As the amount of knock-out rat strains will increase within the next years, the generation of TCR transgenic Lewis rats will provide a useful tool for immunological studies.

\subsection{AIMS OF THE STUDY}

Rodent EAE represents a central model for studying autoimmunity in the CNS and delineating putative therapeutic targets for MS treatment. Lewis rat adoptive transfer EAE has proven to be extremely useful in learning about the migration of effector CD4 T cells through the body and specifically at the BBB during an autoimmune attack. It is particularly well suited for intravital microscopy studies (Bartholomaus et al., 2009; Odoardi et al., 2012; Lodygin et al., 2013).

However, several limitations also exist, namely that pathogenic naïve $T$ cells are not accessible, the onset of EAE is not spontaneous, and that no chronic or relapsing disease can be studied. Also, this model is biased toward a CD4 ${ }^{+}$Th1-driven response due to the used adjuvant. Lessons from TCR transgenic mice suggest that some of these limitations can be overcome by generating a transgenic rat strain in which the majority of $\mathrm{T}$ cells express a TCR specific for CNS autoantigens.

During this project we therefore pursue two aims:

1. Generation and characterization of TCR transgenic Lewis rats carrying $T$ cell receptors specific for the myelin basic protein (i) and the non-self model antigen ovalbumin (ii).

2. Analysis of migratory routes, T cell phenotypes and pathogenesis of EAE induced by in vivo primed T cells. 


\section{MATERIALS AND METHODS}

\subsection{BUFFERS AND MEDIA}

Table 2.1: Basic buffer and media compositions

\begin{tabular}{|c|c|c|}
\hline Buffer & Composition* & Used for \\
\hline 10x PBS & $\begin{array}{l}80 \mathrm{mM} \mathrm{Na}_{2} \mathrm{HPO}_{4} \\
1.5 \mathrm{M} \mathrm{NaCl} \\
20 \mathrm{mM} \mathrm{KH}_{2} \mathrm{PO}_{4} \\
30 \mathrm{mM} \mathrm{KCl} \\
\mathrm{pH} 7.4\end{array}$ & Isopercoll \\
\hline $1 \times$ PBS & $10 \times$ PBS diluted in A. dest & Basic buffer \\
\hline 10x TBE & $\begin{array}{l}\mathrm{M} \text { Tris } \\
0.9 \mathrm{M} \text { boric acid } \\
0.01 \mathrm{M} \text { EDTA }\end{array}$ & \\
\hline $1 \times \mathrm{TBE}$ & $10 \times$ TBE diluted in $\mathrm{A}$. dest & Gel electrophoresis \\
\hline AcK Buffer & $\begin{array}{l}0.15 \mathrm{M} \mathrm{NH}_{4} \mathrm{Cl} \\
10 \mathrm{mM} \mathrm{KHCO}_{3} \\
0.1 \mathrm{mM} \mathrm{EDTA}\end{array}$ & Lysis of Erythrocytes \\
\hline FACS Buffer & $\begin{array}{l}0.5 \% \text { BSA (Code \# BSA-10) } \\
0.05 \% \text { Natrium acide } \\
\text { in PBS }\end{array}$ & FACS stainings \\
\hline LB Medium & $25 \mathrm{~g} / \mathrm{l}$ Luria/Miller LB medium & Culturing of bacteria \\
\hline LB Agar & $\begin{array}{l}1 \% \text { tryptone } \\
0.5 \% \text { yeast extract } \\
10 \mathrm{mM} \mathrm{NaCl} \\
1.5 \% \text { agar }\end{array}$ & Culturing of bacteria \\
\hline SOC Medium & $\begin{array}{l}2 \% \text { tryptone } \\
0.5 \% \text { yeast extract } \\
10 \mathrm{mM} \mathrm{NaCl} \\
2.5 \mathrm{mM} \mathrm{KCl} \mathrm{mM} \mathrm{MgCl}_{2} \\
10 \mathrm{mM} \mathrm{MgSO}_{4}\end{array}$ & Transformation of bacteria \\
\hline
\end{tabular}

* If not indicated otherwise components of buffers and media were purchased from CARL ROTH GmbH, Karlsruhe, Germany. 


\subsubsection{RNA EXTRACTION AND COMPLEMENTARY DNA SYNTHESIS}

RNA was isolated from cell suspensions or organs using the RNeasy Kit (Qiagen, Hilden, Germany) and transcribed into cDNA using random hexamer primers (FirstStrand cDNA Synthesis Kit, Thermo Fischer Scientific Inc., Waltham, US) as recommended by the manufacturer.

cDNA samples were either stored at $-20^{\circ} \mathrm{C}$ or directly used as templates for PCR reactions.

\subsubsection{POLYMERASE CHAIN REACTION (PCR)}

For generation of lentiviral or retroviral expression constructs, genes of interest, e.g. TCR receptor alpha and beta chains, were amplified by PCR from rat cDNA isolated from clonal cell lines. Briefly, $10 \mu$ of 2 x DreamTaq Polymerase Mix (Thermo Fischer Scientific Inc., Waltham, US) and $1 \mu \mathrm{l}$ of forward and $1 \mu \mathrm{l}$ of reverse primer at a concentration of $10 \mu \mathrm{M}$ (See Tab 2.4, Biomers, UIm, Germany) were mixed with $7 \mu$ cDNA and incubated using the following PCR programme (Tab. 2.2, Eppendorf Mastercycler EP, Hamburg, Germany):

Table 2.2: Standard PCR programme for amplification of rat TCR CDNA

\begin{tabular}{l|l|l|l} 
& Step & Temperature & Time \\
\hline & Initial denaturation & $95^{\circ} \mathrm{C}$ & $2 \mathrm{~min}$ \\
\hline \multirow{3}{*}{30 cycles } & Denaturation & $95^{\circ} \mathrm{C}$ & $40 \mathrm{sec}$ \\
& Annealing & $57^{\circ} \mathrm{C}$ & $45 \mathrm{sec}$ \\
& Elongation & $72^{\circ} \mathrm{C}$ & $80 \mathrm{sec}$ \\
\hline & Final elongation & $72^{\circ} \mathrm{C}$ & $5 \mathrm{~min}$
\end{tabular}

PCR products were loaded to $0.8 \%$ agarose gels and electrophoresed at $100 \mathrm{~V}$ for 30 $45 \mathrm{~min}$. For molecular cloning, DNA fragments were excised from the gel using a one-way scalpel (BBraun Melsungen AG, Sempach, Switzerland).

\subsubsection{QUANTITATIVE REAL TIME PCR}

Analysis of gene expression was achieved by semi-quantitative real time PCR (qPCR) using the StepOnePlus Real Time PCR System (Applied Biosystems, Darmstadt, Germany) and the corresponding StepOne Software v2.0. 
Beta-actin was used as a housekeeping gene. Custom designed qPCR primers and probes (Tab. 2.3) were ordered from Sigma Aldrich (Munich, Germany) with FAM-TAMRA as fluorophore-quencher pairs.

Single strand CDNA was diluted 1:50 and $7.5 \mu \mathrm{l}$ were mixed with $12.5 \mu \mathrm{l}$ ready-to-use RTPCR mix (including dNTPS/dUTPs, HotGoldStar DNA polymerase, $5 \mathrm{mM}$ final $\mathrm{MgCl}_{2}$ concentration; Eurogentec, Seraing, Belgium) and $5 \mu \mathrm{l}$ of Primer-Probe mixtures and transferred into one well of a 96-well qPCR plate (Sarstedt AG \& Co, Nümbrecht, Germany).

Table 2.3: Primer and probe sequences for quantitative real time PCR

\begin{tabular}{|c|c|}
\hline Gene & Oligonucleotide sequences \\
\hline$\beta$ actin & $\begin{array}{l}\text { Fw: 5'-GTA CAA CCT CCT TGC AGC TCC T -3' } \\
\text { Rev: 5'-TTG TCG ACG ACG AGC GC -3' } \\
\text { Probe: 5'-Fam-CGC CAC CAG TTC GCC ATG GAT -Tamra-3' }\end{array}$ \\
\hline $\mathrm{IFN} \gamma$ & $\begin{array}{l}\text { Fw: 5'-AAC AGT AAA GCA AAA AAG GAT GCA TT -3' } \\
\text { Rev: 5'-TTC ATT GAC AGC TTT GTG CTG G -3' } \\
\text { Probe: 5'-Fam-CGC CAA GTT CGA GGT GAA CAA CCC -Tamra-3' }\end{array}$ \\
\hline IL-2 & $\begin{array}{l}\text { Fw: 5'-CTC CCC ATG ATG CTC ACG TT-3' } \\
\text { Rev: 5'-TCA TTT TCC AGG CAC TGA AGA TG-3' } \\
\text { Probe: 5'-Fam-CAA TTC TGT GGC CTG CTT GG -Tamra-3' }\end{array}$ \\
\hline IL-4 & $\begin{array}{l}\text { Fw: 5'- CGG TGA ACT GAG GAA ACT CTG TAG A-3' } \\
\text { Rev: 5'-TCA GTG TTG TGA GCG TGG ACTC-3' } \\
\text { Probe: 5'-Fam-CGG TCT GAA CTC ACT GAG AAG CTG CAAC -Tamra-3' }\end{array}$ \\
\hline IL-10 & $\begin{array}{l}\text { Fw: 5'-GAA GAC CCT CTG GAT ACA GCT GC-3' } \\
\text { Rev: 5'-TGC TCC ACT GCC TTG CTT TT-3' } \\
\text { Probe: 5'-Fam-CGC TGT CAT CGA TTT CTC CCC TGT GA -Tamra-3' }\end{array}$ \\
\hline IL-17 & $\begin{array}{l}\text { Fw: 5'-GAG TCC CCG GAG AAT TCC AT -3' } \\
\text { Rev: 5'-GAG TAC CGC TGC CTT CAC TGT -3' } \\
\text { Probe: 5'-Fam-ATG TGC CTG ATG CTG TT -Tamra-3' }\end{array}$ \\
\hline $\mathrm{TNF} \alpha$ & $\begin{array}{l}\text { Fw: 5'-TCG AGT GAC AAG CCC GTA GC-3' } \\
\text { Rev: 5'-CTC AGC CAC TCC AGC TCC TC -3' } \\
\text { Probe: 5'-Fam-CGT CGT AGC AAA CCA CCA AGC AGA -Tamra-3' }\end{array}$ \\
\hline CCR2 & $\begin{array}{l}\text { Fw: 5'-CAC TTA GAG CAG GCC ATG CA-3' } \\
\text { Rev: 5'-GGA GAG ATA CCT TCG GAA CTTC -3' } \\
\text { Probe: 5'-Fam-TGA CAG AGA CTC TTG GAA TGA CAC ACT GCTG -Tamra-3' }\end{array}$ \\
\hline CCR5 & $\begin{array}{l}\text { Fw: 5'-GTT CTC CTG TGG ACC GGG TAT AG -3' } \\
\text { Rev: 5'- ATT GTC AAA CGC TTC TGC AAA C -3' } \\
\text { Probe: 5'-Fam-AGC TTA CAC GAT CAG GAT TGA CTT GC - Tamra-3' }\end{array}$ \\
\hline CCR7 & $\begin{array}{l}\text { Fw: 5'- GTG TAG TCC ACG GTG GTG TTC TC-3' } \\
\text { Rev: 5'- CTG GTC ATT TCC AGG TGT GCT -3' } \\
\text { Probe: 5'-Fam-CCG ATG TAG TCG TCT GTG A -Tamra-3' }\end{array}$ \\
\hline CXCR3 & $\begin{array}{l}\text { Fw: 5'- AGC AGC CAA GCC ATG TAC CTT -3' } \\
\text { Rev: 5'- TAG GGA GAT GTG CTG TTT TCC A -3' } \\
\text { Probe: 5'-Fam-AGG TCA GTG AAC GTC AAG TGC TAG ATG -Tamra-3' }\end{array}$ \\
\hline
\end{tabular}




\subsubsection{CLONING OF PCR PRODUCTS}

DNA fragments were extracted from agarose gels using the GeneJet Gel Extraction Kit (Thermo Fischer Scientific Inc., Waltham, US) according to the manufacturer's instructions. Eluted PCR fragments were either introduced into pJet1.2 shuttle vector by blunt-end ligation (CloneJet PCR Cloning Kit, Thermo Fischer Scientific Inc., Waltham, US) or into pCR4 shuttle vector (TOPO-Ta-Cloning kit, Invitrogen, Carlsbad, CA, US) following the manufacturer's instructions.

The ligation or pJet1.2/TOPO-reaction mixes were transformed into chemically competent $\mathrm{DH} 5 \alpha$ E. coli followed by ampicillin selection.

\subsubsection{PREPARATION AND DIGEST OF PLASMID DNA}

Bacterial colonies were picked from agarose plates and inoculated into ampicillin-containing LB-medium at $37^{\circ} \mathrm{C}$ and cultured overnight with shaking.

According to the manufacturer's instructions plasmid DNA was isolated using GeneJet Plasmid Miniprep Kit (Thermo Fischer Scientific Inc., Waltham, US)

Identity of cloned fragments was confirmed by restriction analyses and DNA sequencing (performed at SeqLab, Göttingen, Germany). For digestion, plasmid DNA was incubated with FastDigest enzymes in FastDigest Buffer (Thermo Fischer Scientific Inc., Waltham, US) and analyzed via agarose gel electrophoresis.

\subsubsection{CLONING OF T CELL RECEPTOR CONSTRUCTS}

T cell receptor sequences specific for myelin basic protein or chicken ovalbumin were obtained from monoclonal $\mathrm{T}$ cell clones. Cloning strategies are described in detail in chapter 3.1.1 with the primer sequences shown in table 2.4. 
Table 2.4: Primer sequences for TCR cloning

\begin{tabular}{|c|c|c|}
\hline Primer & Sequence & Source \\
\hline & Primers for gene families of rat $\mathrm{V} \alpha$ segments & \\
\hline $\mathrm{RV} \alpha 1$ & AAGAAGGCAGATTCACATCA & \multirow{16}{*}{ (Buenafe et al., 1997) } \\
\hline $\mathrm{RV} \alpha 2$ & GGAAGGCCCTGTACTCCTGA & \\
\hline $\mathrm{RV} \alpha 3$ & GCTCCTCAAGTACTATTCAGG & \\
\hline $\mathrm{RV} \alpha 4$ & GAAGGGAAGCAGCAGAGGKT & \\
\hline $\mathrm{RV} \alpha 5$ & TGTCCTACTGAACAAGAAAGAC & \\
\hline $\mathrm{RV} \alpha 6$ & CATCTAACAGTATGGCCTTCC & \\
\hline $\mathrm{RV} \alpha 7$ & TCTCAGAACCAGAGGAGTGG & \\
\hline $\mathrm{RV} \alpha 8$ & CAGACTCTGCCCTGTACTAC & \\
\hline $\mathrm{R} \vee \alpha 10$ & GAAGAGTGGAAGACTGACATC & \\
\hline $\mathrm{RV} \alpha 11$ & GAACGGGAGGTTAAAGTCAAC & \\
\hline $\mathrm{RV} \alpha 12$ & AGACTATGTGGCAAATGAAGTG & \\
\hline $\mathrm{RV} \alpha 13$ & TCCACTTTGTGATAGACATTCG & \\
\hline $\mathrm{RV} \alpha 15$ & CCTGCTAATGTTAATACGTTCC & \\
\hline $\mathrm{RV} \alpha 16$ & ATGGTTTTCCTTATTCGTCAGG & \\
\hline $\mathrm{RV} \alpha 23$ & TCATATCTGTACGTTCGAATAAG & \\
\hline \multirow[t]{2}{*}{$\mathrm{RV} \alpha 24$} & AGCCAACAGAAGGAGGACTG & \\
\hline & TCR C $\alpha$-region primers & \\
\hline RTAC1 & ATGGGCCCGCAATGGCCCCGTTGCTCTTGG & \multirow{3}{*}{ (Shirwan et al., 1993) } \\
\hline RTAC2 & ATCCCGGGCAGAGGGTGATGTTATCAGACTGG & \\
\hline RTAC3 & GCTGGTACACAGCAGGCTCTGGG & \\
\hline & $\underline{\text { TCR } C \beta \text {-region primers }}$ & \\
\hline RTCB.1 & AAGGGCCCACCAGCTCAGCTCCACATGGTCAGG & \multirow{3}{*}{ (Shirwan et al., 1993) } \\
\hline RTCB.2 & TACCCGGGCTCAAACAAGGAGACCTTGGGTGG & \\
\hline RTCB.3 & CATAGAATTCCACTTGGCAGCGGAAGTGGT & \\
\hline
\end{tabular}

\begin{tabular}{l|l|} 
& 2A-like linker primers \\
\hline P2Afw & GGATCCGCAACAAACTTCTCCTTGTTGAAGCAGGCAGGCGACGTCGA \\
\hline P2Arev & ACTTCGCTGGCTCTGGGGGCCCGGGGTTCTCCTCGACGTCGCCTGCCTGCTT \\
\hline
\end{tabular}

\begin{tabular}{l|l|} 
& TCR $\alpha$ and $\beta$ primers for amplification of full-length cDNA \\
\hline Rn_Va2 XbFw & TCTAGAATGGACAAGATCCTGACAGCATC \\
\hline RnCaBH1.rev & CCGGATCCACTGGACCACAGCCTTAGCGTCA \\
\hline Vbeta8.2 ApaFw & GGGCCCATGTCAAACACTGCCCTCTCTAACTC \\
\hline RnVa13OVA\#15.fw & TCTAGAATGAAGGCATCCATTCACACTGTATTC \\
\hline Vb16-Ap1.fw & GGGCCCATGGACAGCTGGCTGATTTTTAGTTGGA \\
\hline Vbrev (C $\beta 1)$ RnCB1X1 rev & CTCGAGTCAGGACTCTTTCTTTTGACCATAGTCATCACA
\end{tabular}




\subsection{CELL CULTURE PROCEDURES}

\subsubsection{CELL CULTURE MEDIA}

Table 2.5: Cell culture media compositions

\begin{tabular}{|c|c|c|}
\hline Medium & Composition & Used for \\
\hline DMEM & $\begin{array}{l}\text { Gibco DMEM Powder (Invitrogen, Carlsbad, USA) } \\
1.2 \mathrm{~g} / \mathrm{NaHCO}{ }_{3} \text { (Carl Roth, Karlsruhe, Germany) }\end{array}$ & Basic cell culture medium \\
\hline $\mathrm{EH}$ & $\begin{array}{l}\text { DMEM } \\
25 \text { mM Gibco Hepes (Invitrogen, Carlsbad, USA) }\end{array}$ & Cell suspensions from organs \\
\hline $\mathrm{TCM}=\mathrm{T}$ cell medium & $\begin{array}{l}\text { DMEM } \\
1 \% \text { Gibco non-essential amino acids (Invitrogen, Carlsbad, USA) } \\
1 \% \text { Gibco sodium pyruvate (Invitrogen, Carlsbad, USA) } \\
1 \% \text { Gibco Penicillin/Streptomycin (Invitrogen, Carlsbad, USA) } \\
1: 100 \text { L-glutamine (Pan Biotech GmbH, Aidenbach, Germany) } \\
1: 100 \text { :-asparagine Monohydrate (Sigma Aldrich, Munich, Germany) } \\
4 \mu \mathrm{l} / / \beta \text {-mercaptoethanol (stock } 13,6 \mathrm{M} \text {, Invitrogen, Carlsbad, USA) }\end{array}$ & $\begin{array}{l}\text { Basic medium for } T \text { cell and } \\
\text { fibroblast culture }\end{array}$ \\
\hline $\mathrm{TCM}+10 \% \mathrm{FCS}$ & TCM, $10 \%$ Fetal Calf Serum (Biochom Ag, Berlin, Germany) & Fibroblast culture \\
\hline RM (Restimulation Medium) & TCM, $1 \%$ rat serum & $\mathrm{T}$ cell restimulation \\
\hline TCGF ( $T$ cell growth factor) & $\begin{array}{l}\text { TCM } \\
10 \% \text { horse serum (Biochom Ag, Berlin, Germany) } \\
5 \% \text { Conditioned medium from mouse splenocytes treated with the } \\
\text { mitogen Concanavalin A (Sigma Aldrich, Munich, Germany) - } \\
\text { (Rosenberg et al., 1978) }\end{array}$ & $\begin{array}{l}\mathrm{T} \text { cell maintenance and growth } \\
\text { promotion }\end{array}$ \\
\hline Freezing Medium & $\begin{array}{l}\text { TCM } \\
80 \% \text { horse serum (Biochom Ag, Berlin, Germany) } \\
10 \% \text { DMSO (Carl Roth GmbH, Karlsruhe, Germany) }\end{array}$ & Freezing of cells \\
\hline
\end{tabular}

\subsubsection{LENTIVIRUS PRODUCTION}

\subsubsection{TRANSFECTION OF HEK 293T CELLS}

For preparation of lentiviruses, human embryonic kidney (HEK) 293T cells were transfected by the calcium phosphate method using a $3^{\text {rd }}$ generation packaging system (Dull et al., 1998) including two packaging plasmids (pRRE containing Gag and Pol and pRSV-Rev), one envelope plasmid (pMD2.g encoding for VSVG, Fig. 2.1) and the transfer plasmid based on the pFUGW self-inactivating lentiviral expression vector (Lois et al., 2002). 


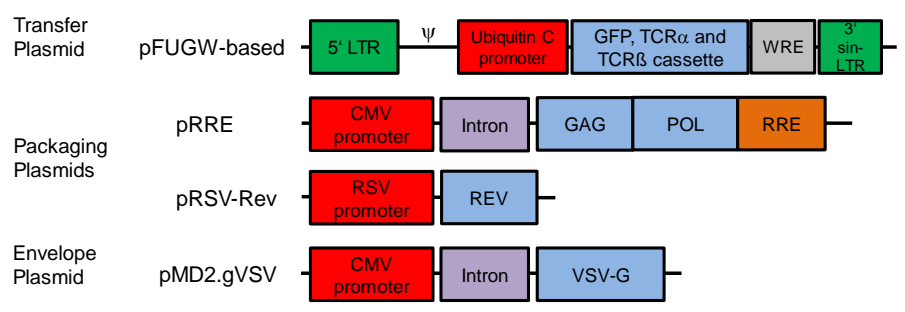

Figure 2.1: Schema of $3^{\text {rd }}$ generation packaging system vectors.

HEK 293T cells were seeded at a density of $4 \times 10^{6}$ cells in a $10 \mathrm{~cm}$ dish (Sarstedt AG \& Co, Nümbrecht, Germany) and cultured in TCM with $10 \%$ FCS overnight $\left(37^{\circ} \mathrm{C}, 5 \% \mathrm{CO}_{2}\right)$. Prior to the transfection, $25 \mu \mathrm{M}$ choloroquine (Sigma Aldrich, Munich, Germany) was added to the medium for $30 \mathrm{~min}$. Then, the transfer plasmids $(20 \mu \mathrm{g})$, pRRE $(10 \mu \mathrm{g})$, pRSV-Rev $(5 \mu \mathrm{g})$ and pMD2.g $(6 \mu \mathrm{g})$ were mixed in LoTE (10 mM Tris-HCl, $1 \mathrm{mM}$ EDTA) to a volume of $440 \mu \mathrm{L}$. $60 \mu \mathrm{l}$ of $2.5 \mathrm{M} \mathrm{CaCl}_{2}$ and $500 \mu \mathrm{l}$ 2x HBS (50 mM HEPES, $280 \mathrm{mM} \mathrm{NaCl}, 1.5 \mathrm{mM}$ $\mathrm{Na}_{2} \mathrm{HPO}_{4}, \mathrm{pH}$ 7.05) were added and incubated for $10 \mathrm{~min}$. Transfection mixture was carefully applied to the cells. On the next day the medium was replaced with fresh TCM with $10 \%$ FCS.

\subsubsection{LENTIVIRUS HARVESTING AND CONCENTRATION VIA} ULTRACENTRIFUGATION

Concentration of lentivirus was achieved by using ultracentrifugation. Therefore, the supernatant of the transfected 293T HEK cells was collected $48 \mathrm{~h}$ and $72 \mathrm{~h}$ post transfection and filtered through a $0.45 \mu \mathrm{m}$ pore size filter (Cole Parmer, Vernon Hills, IL, US) to remove cell debris. Then, the supernatant was transferred to $30 \mathrm{ml}$ ultracentrifugation tubes (Beckmann Coulter, Fullerton, CA, US) and centrifuged (Sorvall Discovery $90 \mathrm{SE}, 70 \mathrm{Ti}$ rotor) at $26000 \mathrm{rpm}$ for $2 \mathrm{~h}$ at $4^{\circ} \mathrm{C}$. Afterwards, the supernatant was removed and the remaining pellet containing the lentivirus was resuspended in LoTE, aliquoted and stored at $-80^{\circ} \mathrm{C}$.

\subsubsection{DETERMINATION OF INFECTIOUS TITER IN HELA CELLS}

HeLa cells were seeded at a density of 10,000 cells per well in a 24 -well plate (Nunc, Thermo Fischer Scientific Inc., Waltham, US) and transduced with different dilutions of the lentiviral preparation for $48 \mathrm{~h}$ at $37^{\circ} \mathrm{C}$. Afterwards, the infectious titer was determined by flow cytometry analysis of HeLa cells for GFP expression. 


\subsubsection{GENERATION OF RETROVIRAL PACKAGING CELL LINES}

Stable ecotropic retroviral packaging lines were generated using GP86+E mouse fibroblasts (Markowitz et al., 1988) as described (Flügel et al., 1999). Expression constructs are listed in Tab. 2.7. In brief, supernatant from transiently transfected Phoenix E cells was used to infect tunicamycin-pretreated GP86+E fibroblasts. Cells were then selected in puromycin$(2 \mu \mathrm{g} / \mathrm{ml})$ or neomycin- $(1.5 \mathrm{mg} / \mathrm{ml})$ containing medium, sorted by flow cytometry and subcloned by limiting dilution.

Table 2.6: Fibroblast transducer cell line constructs for retroviral transduction of T cells

\begin{tabular}{l|l|l|l} 
Construct & Function & Resistance & Reference \\
\hline eGFP & Enhancement of fluorescent signal for microscopy & Neomycin & (Flügel et al., 1999)
\end{tabular}

\subsubsection{PRIMARY T CELL CULTURE}

Naïve Lewis rats were immunized with myelin basic protein in Complete Freund's Adjuvant (see chapter 2.4.2).

For retroviral transduction of $\mathrm{T}$ cells, packaging cells (GP86+E mouse fibroblasts) were seeded into round-bottom 96-well plates (Nunc, Thermo Fischer Scientific Inc., Waltham, US) at a concentration of 15,000 cells/well in restimulation medium at the day of lymph node harvest.

On day 10 post immunization, draining lymph nodes were harvested in cold $\mathrm{EH}$ buffer. A single-cell suspension of the tissue was prepared under the laminar flow hood and added to the GPE-containing 96-well plates at a concentration of 200,000 cells/well and with the addition of antigen at a concentration of $10 \mu \mathrm{g} / \mathrm{ml}$. On day 2, TCGF medium containing growth factors was added to the cells and if necessary supplemented with antibiotics for cell selection.

On day 7 , T cells were restimulated by the addition of $1.4 \times 10^{6} 30$ Gy-irradiated syngeneic thymocytes per well in restimulation medium with $10 \mu \mathrm{g} / \mathrm{ml}$ antigen. 2 days later, TCGF was added to the cells thereby supplementing antibiotics for cell selection. 24 hours later the best wells were chosen based on the cell's fluorescence and growth appearance and pooled into $60 \mathrm{~mm}$ dishes. 
For further restimulations, $3.5 \times 10^{6} \mathrm{~T}$ cells were mixed with $70 \times 10^{6}$ irradiated syngeneic thymocytes and $10 \mu \mathrm{g} / \mathrm{ml}$ antigen per $60 \mathrm{~mm}$ dish and supplied with TCGF medium on day 2 after restimulation.

\subsubsection{CELL COUNTING}

The number of living cells within a cell suspension was determined using a hemocytometer. The cell suspension was diluted with $0.04 \%$ trypan blue (Sigma Aldrich, Munich, Germany). $10 \mu$ of the dilution were applied to a hemocytometer and living cells counted within the four quadrants of the grid. The cell number was calculated using the following equation:

$$
\frac{\text { Counted Cells }}{\text { Number of Quadrants }} * \text { dilution factor } * 10^{4}=\text { Cells } / \mathrm{ml}
$$

\subsubsection{CRYOCONSERVATION OF CELLS}

Cells were pelleted and resuspended in ice cold freezing medium. $1.5 \mathrm{ml}$ of cell suspension were transferred into cryo tubes (Nunc, Thermo Fischer Scientific Inc., Waltham, US) and immediately stored at $-80^{\circ} \mathrm{C}$ in a freezing chamber (Nunc, Thermo Fischer Scientific Inc., Waltham, US). For longer storage, cells were placed at $-192^{\circ} \mathrm{C}$ in liquid nitrogen.

Cells were thawed by placing the cryo tube in a $37^{\circ} \mathrm{C}$ water bath and transferred into a $50 \mathrm{ml}$ Falcon (Greiner Bio-One International AG, Kremsmünster, Austría) containing $10 \mathrm{ml}$ EH medium supplemented with $10 \%$ FCS. Cells were centrifuged and resuspended in appropriate medium. 


\subsubsection{CARETAKING AND MAINTENANCE}

Lewis rats aged 6-8 weeks were obtained from the animal facility of the University Medical Center Göttingen (UMG). Animal experiments were performed in accordance with local regulations for animal wellfare of Lower Saxony.

Table 2.7: Lewis rat strains used in this study

\begin{tabular}{l|l} 
Rat strains & Genetic Background \\
\hline Lewis rat & Wild type \\
\hline rMT-II & $\begin{array}{l}\text { Transgenic MBP-specific T cell receptor expression coupled to GFP expression } \\
\text { Lewis rat background }\end{array}$ \\
\hline rOT-II & $\begin{array}{l}\text { Transgenic OVA-specific T cell receptor expression coupled to GFP expression } \\
\text { Lewis rat background }\end{array}$ \\
\hline AsRed & Transgenic Lewis rat strain expressing RFP under the control of a ubiquitin C promoter (Lodygin et al., 2013)
\end{tabular}

\subsubsection{IMMUNIZATION}

For analysis of active EAE and for establishing T cell cultures, naïve wild type Lewis rats, rMT-II or rOT-II TCR transgenic Lewis rats were immunized with antigen (guinea pig myelin basic protein or chicken ovalbumin) in Complete Freund's Adjuvant (CFA, Tab 2.8). Antigen emulsion was prepared by mixing equal volumes of the respective antigen $(1 \mathrm{mg} / \mathrm{ml} \mathrm{stock}$ solution in PBS) and CFA (4 mg/ml stock solution in mineral oil) using two tuberculin glass syringes (POULTEN \& GRAF GmbH, Wertheim, Germany) joint via a custom made connector. $150 \mu \mathrm{l}$ of this emulsion were injected subcutaneously close to the tail base (50 $\mu$ l on each side) and the inner side of the hind limbs (25 $\mu$ l on each side) of rats anesthetized by dimethyl ether.

Table 2.8: Reagents for immunization

\begin{tabular}{l|l} 
Antigen & Source \\
\hline Guinea-pig myelin basic protein & Prepared from guinea pig brains as described (Eylar, 1978) \\
\hline Chicken ovalbumin & Sigma Aldrich, Munich, Germany \\
\hline Adjuvant & $\begin{array}{l}\text { Incomplete Freunds Adjuvant (Difco, Becton Dickinson, Franklin Lakes, NJ, USA) } \\
\text { Mycobacterium tuberculosis H37Ra (Difco, Becton Dickinson, Franklin Lakes, NJ, } \\
\text { USA) }\end{array}$
\end{tabular}




\subsubsection{ADOPTIVE TRANSFER EAE}

For triggering transfer EAE, fully activated T cell blasts $\left(3-5 \times 10^{6}\right.$ per rat) were injected into the tail vein of naïve Lewis rats anaesthetized with dimethyl ether. The rats were weighted and scored daily (or twice a day around the onset phase) for clinical symptoms (Tab 2.9). The same scoring system was used for active EAE experiments. Animals reaching a score of 3.5 were eliminated.

Table 2.9: Scoring system for rat experimental autoimmune encephalomyelitis

\begin{tabular}{l|l} 
Score & Clinical Symptom \\
\hline $\mathbf{0}$ & No symptoms \\
\hline $\mathbf{0 . 5}$ & Partial loss of tail tonus \\
\hline $\mathbf{1}$ & Flaccid tail (complete loss of tail tonus) \\
\hline $\mathbf{1 . 5}$ & Flaccid tail and subtle gait disturbance \\
\hline $\mathbf{2}$ & Pronounced weakness of hind limbs, progressed gait disturbance \\
\hline $\mathbf{2 . 5}$ & Pronounced weakness of hind limbs, impaired adduction of hind limbs, paralysis of a single hind limb \\
\hline $\mathbf{3}$ & Paraplegia (complete hind limb paresis); animals are able to actively move forward using their fore limbs \\
\hline $\mathbf{3 . 5}$ & Weakness of fore limbs leading to impaired forward movement \\
\hline $\mathbf{4}$ & Tetraplegia \\
\hline $\mathbf{5}$ & Moribund or dead
\end{tabular}

\subsubsection{SUBCUTANEOUS TRANSFER OF T CELLS}

Naïve T cells were obtained from spleens of naïve transgenic rMT-II or rOT-II rats. Spleens were harvested and plated in $10 \mathrm{~cm}$ polystyrene Petri dishes containing $15 \mathrm{ml} \mathrm{EH}$ medium supplemented with $2 \mathrm{mM}$ EDTA for $30 \mathrm{~min}$ at $37^{\circ} \mathrm{C}$. During the incubation, macrophages and dendritic cells adhere to the plate. Afterwards the floating non-adherent cells (mainly $T$ cells and B cells) were collected, washed once and resuspended in $\mathrm{EH}$ medium with $5 \times 10^{6}$ cells $/ 20 \mu$ l. For subcutaneous transfer, rats were anaesthetized with dimethyl ether and $20 \mu \mathrm{l}$ of the cell solution were injected into the inner side of the right hind limb. Approximately $16 \mathrm{~h}$ post transfer, the recipients were immunized with antigen in CFA $(20 \mu / / r a t)$ at the same location.

Resting effector $T$ cells (meaning $T$ cell lines 6 days after the last antigen stimulation) were taken up in EH medium at a concentration of $5 \times 10^{6} \mathrm{~T}$ cells/20 $\mu \mathrm{l}$ and transferred into animals as described above. 


\subsubsection{INTRATHECAL INJECTIONS}

Rats were anesthetized by a subcutaneous injection of xylazine $(10 \mathrm{mg} / \mathrm{kg})$ and ketamine $(50 \mathrm{mg} / \mathrm{kg})$. With a stereotactic device the head of the rat was fixed by ear bars, tilted downward to almost $90^{\circ}$ and secured by the tooth holder. The site of injection between the cervical vertebrae $\mathrm{C} 1$ and $\mathrm{C} 2$ was disinfected with $70 \%$ ethanol. For injection a $0.5 \mathrm{ml}$ tuberculin syringe (Becton Dickinson, Franklin River, NJ, USA) fixed to the manipulator arm was used. The needle was slowly inserted until it reached the cerebrospinal fluid which was ascertained by aspiration of liquor. Then a total volume of $30 \mu \mathrm{l}$ was injected over a time period of $10 \mathrm{~min}$.

\subsubsection{EUTHANASIA}

For euthanasia, rats were placed in a chamber slowly flooded with $\mathrm{CO}_{2}$.

\subsubsection{PERFUSION}

Rats were perfused with paraformaldehyde (PFA, CARL ROTH GmbH, Karlsruhe, Germany) to preserve the tissue for histological analysis. After euthanizing the rat with $\mathrm{CO}_{2}$, the thorax was opened up and the heart was exposed. The pericard was removed and an incision made into the left ventricle. Then, a cannula connected to a pump via flexible tubes (ISM596B, Ismatec, Wertheim, Germany) was inserted into the left ventricle and fixed with a clamp. Additionally, an incision was made into the right atrium and the pump was started with a flow-rate of $10.71 \mathrm{~m} / \mathrm{s}$ of $1 \times$ PBS to flush out the blood. After 20 min the solution was switched to $4 \%$ PFA for another 20 min. After the perfusion, organs were harvested and stored in $4 \%$ PFA for further processing.

\subsubsection{LENTIVIRUS MICROINJECTION INTO RAT OOCYTES}

Generation of transgenic Lewis rats was performed as reported (Mullins and Mullins, 1996) by Dr. Jens van den Brandt and Dr. Henrike Fischer, Institute of Cellular and Molecular Immunology, working group of Experimental Immunology (Prof. Dr. Holger Reichardt), University Medical Center, Göttingen. 
Briefly, a solution containing concentrated lentivirus was injected into the perivetelline space of single cell embryos isolated from superovulated Lewis females mated on the previous night with Lewis males. Injected zygotes were cultured overnight and as two-cell stage embryos transferred into the oviduct of pseudopregnant recipient Wistar females.

\subsubsection{GENERATION OF BONE MARROW CHIMERAS}

For the generation of bone marrow chimeras, naïve female Lewis rats (age 8-10 weeks) were irradiated with 10 Gy using a X-ray counter kindly provided by the Department of Radiotherapy, UMG Göttingen. Therefore, naïve recipients were anaesthesized with ketamine/xylazin $(50 \mathrm{mg} / \mathrm{kg} / 10 \mathrm{mg} / \mathrm{kg}$ ), placed in the irradiation chamber in groups of 5 rats and irradiated with 1 Gy per minute.

The next day, rOT-II or AsRed donor rats were killed in $\mathrm{CO}_{2}$ and the femur and tibia were collected in cold $\mathrm{EH}$ medium. The bone marrow was flushed out with $\mathrm{EH}$ medium using a $5 \mathrm{ml}$ syringe (BBraun Melsungen AG, Sempach, Switzerland) with a $30 \mathrm{G}$ needle (BD Microlance 3, Becton Dickinson, Franklin Lakes, NJ, USA). Cells were collected and incubated in AcK buffer to destroy erythrocytes. Afterwards, bone marrow cells were resuspended in $\mathrm{EH}$, counted and adjusted to a concentration of $20 \times 10^{6}$ cells per ml. For bone marrow reconstitution, irradiated recipient rats were anaesthetized and the bone marrow cell suspension injected intravenously using a $1 \mathrm{ml}$ syringe with a $22 \mathrm{G}$ needle (BBraun Melsungen AG, Sempach, Switzerland). Reconstituted recipients were observed and weighed daily for a period of two weeks and blood samples were then analyzed for GFP or RFP expression, respectively. 


\subsubsection{PREPARATION OF CELL SUSPENSIONS FROM ORGANS}

Organs were collected in $\mathrm{EH}$ for further processing. Lymph nodes and spleen were brought to suspension by smashing the organs through a metal mesh (provided by UMG Göttingen, in-house machine shop) using a pistil (BBraun Melsungen AG, Sempach, Switzerland). The homogenized organs were taken up, washed once and resuspended in EH medium.

\subsubsection{ERYTHROLYSIS}

Erythrocytes residing e.g. in spleen disturb FACS analysis of cell suspensions. To deplete erythrocytes, cell pellets were resuspended in $5 \mathrm{ml} \mathrm{ACK}$ buffer and incubated for $5 \mathrm{~min}$ on ice. Afterwards, cells were washed in PBS and resuspended in EH medium.

\subsubsection{CELL ISOLATION FROM BLOOD}

Isolation of lymphocytes from blood was achieved using a density gradient based on Ficoll and sodium diatrizoate (Lymphocyte Separation Medium, Lonza, Walkersville, US). The blood was placed on top of the LSM solution and centrifuged for $30 \mathrm{~min}$ at $1600 \mathrm{rpm}$ with slow deceleration. Lymphocytes, that made up a ring within the transparent fraction of the gradient, were collected and stored in EH medium.

\subsubsection{CELL ISOLATION FROM SPINAL CORD USING A PERCOLL GRADIENT}

Isolation of mononuclear cells from spinal cord tissue or meninges was achieved using a Percoll gradient. To this extend, the tissue was smashed through a metal mesh and taken up in EH. A cell suspension of $35 \mathrm{ml} \mathrm{EH}$ was prepared and mixed with $15 \mathrm{ml}$ of isotonic Percoll $(1,124 \mathrm{mg} / \mathrm{ml})$ prior to centrifugation $\left(20^{\circ} \mathrm{C}, 30 \mathrm{~min}, 3780 \mathrm{rpm}\right.$ without acceleration and deceleration). The pellet was taken up in fresh $\mathrm{EH}$ medium. 
$\mathrm{T}$ cells were isolated from pooled spleen and lymph node preparations via negative selection.

To this extend, cells were incubated with biotinylated antibodies or antibodies labeled with tetrameric avidin complexes (StemCell Technologies, Newark, NJ, USA) directed against cell surface markers for macrophages, B cells and NK cells (OX-42, OX-33 and antiCD161) in $1 \mathrm{ml}$ PBS with $2 \%$ FCS and 2 mM EDTA per $5 \times 10^{7}$ cells for 5 min at RT. Then, a TAC-conjugated anti-biotin antibody was applied for additional $5 \mathrm{~min}$ at RT. As a last incubation step, anti-TAC magnetic beads were added for $5 \mathrm{~min}$ at RT. The volume was increased to $8 \mathrm{ml}$ with buffer and the tube placed in an EasySep medium magnet for separation of labeled and non-labeled cells. After $7.5 \mathrm{~min}$, the magnet together with the tube was inverted and the buffer containing the $T$ cell fraction was collected in a fresh tube. Further division of naïve and memory $T$ cells was achieved with the same method using a TAC-conjugated antibody directed against CD62L.

\subsubsection{PROLIFERATION ASSAY}

$\mathrm{T}$ cells $\left(5 \times 10^{4}\right.$ cells/well) were co-cultured with 30 Gy-irradiated syngeneic thymocytes $\left(1.2 \times 10^{6} \mathrm{cells} / \mathrm{ml}\right)$ in $100 \mu \mathrm{l}$ RM per well and stimulated either with $\alpha \mathrm{CD} 3$ and $\alpha \mathrm{CD} 28$ antibodies or with the indicated concentrations of different antigens. MHCll-restriction was tested via blocking of the CD4-MHCII interaction using the $\alpha$-rat OX-6 antibody.

Lymph node suspensions were incubated with antigen in RM using $0.3 \times 10^{6}$ cells/well. 24 hours after stimulation, radioactive thymidine $\left[{ }^{3} \mathrm{H}\right] \mathrm{dT}$ (GE Healthcare Life Sciences, Uppsala, Sweden, $2 \mathrm{Ci} / \mathrm{mmol}$ ) was added to the culture and radioactive counts were measured 16 hours later using a $\beta$ counter (MicroBeta Trilux 1450LSC, PerkinElmer, Waltham, MA, US).

Table 2.10: Antibodies used for cell culture assays

\begin{tabular}{l|l|l|l|l} 
& Host & Clone & Concentration & Company \\
\hline$\alpha$ rat RT1B & mouse & OX-6 & $1 \mu \mathrm{g} / \mathrm{ml}$ & BD Biosciences, San Jose, CA, USA \\
\hline$\alpha$ rat CD3 & mouse & G4.18 & $1 \mu \mathrm{g} / \mathrm{ml}$ & BD Biosciences, San Jose, CA, USA \\
\hline a rat CD28 & mouse & JJ316 & $1 \mu \mathrm{g} / \mathrm{ml}$ & BD Biosciences, San Jose, CA, USA
\end{tabular}


Measurement of cytokine production of $T$ cells in the supernatant was performed using commercially available double-sandwich ELISA kits according to the manufacturer's instruction ( $\alpha$ rat-IFN $\gamma$ and $\alpha$ rat-TNF $\alpha$, BD Biosciences, San Jose, CA, USA).

Briefly, 96-well plates with a polystyrene based surface (Nunc, Thermo Fischer Scientific Inc., Waltham, US) were coated with a cytokine specific Capture Antibody in a $0.2 \mathrm{M}$ sodium azide buffer at $4^{\circ} \mathrm{C}$ overnight. The next day, the plate was washed with ELISA washing buffer (1x PBS + $0.05 \%$ Tween-20 (CARL ROTH GmbH, Karlsruhe, Germany)) and blocked with PBS with $10 \%$ FCS for 1 hour at room temperature prior to the next washing procedure. For qualitative measurement of the sample's cytokine content, a standard curve was added by preparing a serial 1:2 dilution of a maximum standard with recombinant cytokine. After adding the standard dilutions and the samples, the plate was incubated for $2 \mathrm{~h}$ at RT and washed afterwards. A second cytokine specific biotinylated Detection Antibody was added to the plate and incubated for $1 \mathrm{~h}$ at RT prior to a next round of washing. Next, the plate was incubated for $30 \mathrm{~min}$ with the enzyme horseradish peroxidase (HRP) coupled to streptavidin for $30 \mathrm{~min}$ and then washed extensively. Afterwards, the substrate tetramethylbenzidine (TMB) together with $\mathrm{H}_{2} \mathrm{O}_{2}$ was added and incubated for $30 \mathrm{~min}$ in the dark. HRP catalyzes the oxidation of TMB to benzidine blue. The reaction was stopped via addition of acid sulfur and the plate measured with an ELISA reader at $450 \mathrm{~nm}$ wave length. For analysis, the optical density of the sample wells was correlated with the optical density measured for the standard dilutions and the concentration of the cytokines calculated.

\subsubsection{FACS ANALYSIS OF CELL SURFACE MARKER} USING FLUORESCENTLY LABELED ANTIBODIES

For cell surface staining with fluorescently labeled antibodies, $1 \times 10^{6}$ cells were resuspended in $100 \mu$ FACS buffer containing the respective antibodies (see Tab. 2.11) and incubated on ice for $20 \mathrm{~min}$. Cells were centrifuged for $2 \mathrm{~min}$ at $1200 \mathrm{rpm}$ and either incubated with a secondary antibody in $100 \mu \mathrm{l}$ FACS buffer for another 20 min or directly resuspended in $200 \mu \mathrm{l} \mathrm{FACS}$ buffer and transferred into $5 \mathrm{ml}$ FACS tubes (BD Biosciences, San Jose, CA, US) for analysis. 


\subsubsection{INTRACELLULAR STAINING OF CYTOKINES}

Intracellular cytokines were trapped in the Golgi apparatus of restimulated cells by treatment with Brefeldin A $(1 \mu \mathrm{g} / \mathrm{ml}$, Sigma Aldrich, Munich, Germany) $48 \mathrm{~h}$ after restimulation. After $3 \mathrm{~h}$ at $37^{\circ} \mathrm{C}$ with $5 \% \mathrm{CO}_{2}$, cells were centrifuged and fixed in $2 \%$ PFA for 20 min on ice prior to a pretreatment with $1 \times$ BD Perm/Wash buffer (30 min on ice, BD Biosciences, San Jose, CA, US). Afterwards, cells were resuspended in 1 x BD Perm/Wash Buffer containing $\alpha$ IFN $\gamma$-AlexaFluor647 and $\alpha$ IL-17-PE antibodies, incubated for $1 \mathrm{~h}$ on ice and then resuspended in $200 \mu \mathrm{l}$ FACS buffer and transferred to $5 \mathrm{ml}$ FACS tubes.

\subsubsection{FACS ANALYSIS AND SORTING OF FLUORESCENTLY LABELED CELLS}

FACS analysis of cell surface molecules was performed using the flow cytometer FACS Calibur instrument (BD Biosciences, San Jose, CA, USA). Briefly, this system consists of two lasers, an air-cooled argon laser (488 nm excitation) and a red diode laser (640 nm excitation) enabling the possibility of measuring four fluorescent parameters.

For cell sorting, the flow cytometer BD FACS Arialll (BD Biosciences, San Jose, CA, USA) was used equipped with a four-laser system (488 nm, $561 \mathrm{~nm}, 633 \mathrm{~nm}$ and UV). Cells were taken up in EH medium containing $2 \mathrm{mM}$ EDTA and sorted for expression of GFP or surface molecules (e.g. CD62L) at minimum flow-rate of $1000-2000$ events/second at $4^{\circ} \mathrm{C}$ reaching a purity of $90-95 \%$. The collection tube contained $\mathrm{EH}$ medium supplemented with $10 \%$ FCS. Collected cells were centrifuged and taken up in RLT buffer (Qiagen, Hilden, Germany) for RNA extraction or RM for cell culture assays. 
Table 2.11: FACS antibodies

\begin{tabular}{|c|c|c|c|c|c|}
\hline Primary Target & Host & Clone & Label & Dilution & Company* \\
\hline$\alpha$ rat $\alpha \beta T C R$ & mouse & $\mathrm{R} 73$ & AlexaFluor 647 & $1: 400$ & Biolegend \\
\hline$\alpha$ rat $\gamma \delta$ TCR & mouse & V65 & $\mathrm{PE}$ & $1: 400$ & Biolegend \\
\hline$\alpha$ rat $\mathrm{CD} 25$ & mouse & OX-39 & $\mathrm{PE}$ & $1: 400$ & Biolegend \\
\hline$\alpha$ rat CD45RA & mouse & OX-33 & $\mathrm{PE}$ & $1: 250$ & Biolegend \\
\hline a rat CD45RC & mouse & OX-22 & $\mathrm{PE}$ & $1: 300$ & Biolegend \\
\hline$\alpha$ rat $\mathrm{CD} 44 \mathrm{H}$ & mouse & OX-49 & AlexaFluor 647 & $1: 200$ & Biolegend \\
\hline$\alpha$ rat $\operatorname{CD} 8 \alpha$ & mouse & OX-8 & $\mathrm{PE}$ & $1: 400$ & Biolegend \\
\hline$\alpha$ rat $\operatorname{CD} 8 \alpha$ & mouse & OX-8 & biotinylated & $1: 200$ & BD Pharmingen \\
\hline$\alpha$ rat $C D 8 \beta$ & mouse & 341 & AlexaFluor 647 & $1: 400$ & Biolegend \\
\hline$\alpha$ rat CD4 & mouse & OX-35 & PECy5 & $1: 400$ & BD Pharmingen \\
\hline$\alpha$ rat $V \beta 16$ & mouse & HIS42 & & $1: 100$ & AbD Serotec \\
\hline$\alpha$ rat $V \beta 8.2$ & mouse & R78 & & $1: 100$ & SantaCruz Biotechnologies \\
\hline$\alpha$ rat $V \beta 8.5$ & mouse & G101 & & $1: 100$ & AbD Serotec \\
\hline$\alpha$ rat $\alpha \beta T C R$ & mouse & $\mathrm{R} 73$ & biotinylated & $1: 200$ & \\
\hline$\alpha$ rat $C D 3$ & mouse & $1 \mathrm{~F} 4$ & AlexaFluor 647 & $1: 400$ & Biolegend \\
\hline$\alpha$ rat $C D 134$ & mouse & OX-40 & biotinylated & $1: 100$ & \\
\hline$\alpha$ rat RT1B & mouse & OX-6 & FITC & $1: 100$ & AbD Serotec \\
\hline$\alpha$ rat $C D 62 L$ & mouse & OX-85 & $\mathrm{PE}$ & $1: 250$ & Biolegend \\
\hline$a$ rat $C D 11 b / c$ & mouse & OX-42 & AlexaFluor 647 & $1: 200$ & AbD Serotec \\
\hline$\alpha$ rat IFN $\gamma$ & mouse & DB-1 & AlexaFluor 647 & $1: 100$ & Biolegend \\
\hline$\alpha$ rat IL-17A & mouse & TC11-18H10 & $\mathrm{PE}$ & $1: 100$ & BD Pharmingen \\
\hline$\alpha$ rat CD161 & mouse & $10 / 78$ & AlexaFluor 647 & $1: 200$ & Biolegend \\
\hline
\end{tabular}

Isotype Controls

\begin{tabular}{l|l|l|l|l|l}
\hline $\operatorname{lgG} 1$ & mouse & MOPC-21 & AlexaFluor 647 & $1: 100$ & Biolegend \\
\hline $\operatorname{lgG1k}$ & mouse & R3-34 & PE & $1: 100$ & BD Pharmingen \\
\hline
\end{tabular}

$\underline{\text { Secondary antibodies }}$

\begin{tabular}{l|l|l|l|l|l}
\hline anti-mouse & $\begin{array}{l}\text { Rabbit } \\
\text { Goat }\end{array}$ & & APC & $1: 200$ & Jackson ImmunoResearch \\
\hline Streptavidin-APC & & & APC & $1: 500$ & Biolegend \\
\hline Streptavidin-PE & & PE & $1: 500$ & Biolegend \\
\hline Streptavidin-FITC & & & FITC & $1: 500$ & Biolegend \\
\hline Streptavidin-PECy5 & & PE-Cy5 & $1: 500$ & Biolegend
\end{tabular}

*Biolegend (London, UK), BD Pharmingen (San Diego, CA, US), AbD Serotec (Kidlington, UK), SantaCruz Biotechnologies (Dallas, TX, US), Jackson ImmunoResearch (West Grove, PA, US) 


\subsubsection{PREPARATION AND SECTIONING}

Tissues fixed in PFA were embedded in Tissue-Tek (Sakura Finetek, Alphen, The Netherlands) and sectioned using a cryostat (Leica CM-3050-S,Wetzlar, Germany). Slices of the tissue with a thickness of $12 \mu \mathrm{m}$ were mounted on microscope slides (Thermo Fischer Scientific Inc., Waltham, US) and stored at $-20^{\circ} \mathrm{C}$.

\subsubsection{IMMUNOHISTOCHEMISTRY}

Tissue slides were stained for different markers using fluorescent antibodies.

To this extend, slides were thawed and once again fixed in 4 \% PFA for 5 min. Spinal cord sections afterwards were incubated in ice cold methanol with $\mathrm{H}_{2} \mathrm{O}_{2}$ for 5 min and then washed $3 \times 5$ min in 1 x PBS. To avoid unspecific binding of the antibody, the slides were blocked with $10 \%$ FCS and $0.05 \%$ Trition-X-100 (Carl Roth GmbH, Karlsruhe, Germany) in $1 \times$ PBS for $30 \mathrm{~min}$ at room temperature. The primary antibody was diluted in $1 \%$ FCS with $0.05 \%$ Triton-X-100 and applied to the slides overnight at $4^{\circ} \mathrm{C}$. The next day, the slides were washed ( $3 \times 5 \mathrm{~min}$ in $1 \times$ PBS) and if necessary incubated with the secondary antibody for $30 \mathrm{~min}$ at room temperature. The slides were washed as before and subjected to a DAPI staining for $5 \mathrm{~min}$. After a last round of washing, the slides were covered with Fluoromount (Southern Biotech, Birmingham, AL, US) to preserve the fluorescent signal and a cover slip (Thermo Fischer Scientific Inc., Waltham, US).

Table 2.12: Antibodies used for immunohistochemistry

\begin{tabular}{l|l|l|l|l} 
Primary & Host & Clone & Dilution & Company \\
\hline$\alpha$ rat $\alpha \beta$ TCR & mouse & R73 & $1: 500$ & Biolegend, London, UK \\
\hline$\alpha$ rat CD68 & mouse & ED-1 & $1: 250$ & AbD Serotec, Kidlington, UK \\
\hline$\alpha$ rat Iba1 & rabbit & polyclonal & $1: 250$ & Wako Chemicals GmbH, Neuss, Germany \\
\hline$\alpha$ rat GFAP & rabbit & polyclonal & $1: 250$ & Dako, Hamburg, Germany \\
\hline$\alpha$ rat CNPase & mouse & SMI 91 & $1: 200$ & Sternberger Monoclonals Inc., Baltimore, MD, US \\
\hline$\alpha$ mouse-Cy3 & goat & & $1: 1000$ & Jackson ImmunoResearch, West Grove, PA, US \\
\hline$\alpha$ rabbit-AF633 & goat & & $1: 1000$ & Invitrogen, Carlsbad, CA, US \\
\hline DAPI & & & $1: 1000$ & Sigma Aldrich, Munich, Germany
\end{tabular}




\subsubsection{MICROSCOPY}

Epifluorescent microscopy was performed using a Zeiss Axio Observer Fluorescence Microscope in combination with an HXP120C illuminator routed through a Zeiss Plan Apochromat 310 Air Objective. Fluorescent signals were detected using a Zeiss AxioCam HSM video camera.

Confocal microscopy was performed using a LSM 710 equipped with a Plan-Apochromat oil 40x/1.3 (UV) VIS-IR objective and operated by ZEN2009 software (Carl Zeiss, Jena, Germany).

\subsection{TWO-PHOTON LIVE CELL TRACKING IN THE CNS}

\subsubsection{TWO-PHOTON LIVE CELL TRACKING IN THE CNS: PROCEDURE}

Two-photon live imaging experiments were performed by Dr. Christian Schläger as described before (Bartholomaus et al., 2009).

Briefly, animals were anaesthetized with ketamine $(50 \mathrm{mg} / \mathrm{kg})$ and xylazine $(10 \mathrm{mg} / \mathrm{kg})$, intubated and further ventilated with $1.5-2 \%$ isoflurane (Baxter $\mathrm{GmbH}$, Höchstadt a.d. Aisch, Germany). Vital parameters were recorded using Animal Monitor software 7.3x (Volker Staiger, Max-Planck Institute of Neurobiology, Martinsried, Germany) and body temperature was controlled $\left(37-37.5^{\circ} \mathrm{C}\right)$ using a heated pad (Telemeter Electronic $\mathrm{GmbH}$, Donauwörth, Germany).

Live imaging of $T$ cells in the leptomeninges was achieved by preparing a spinal cord window at the level of Th12/L1 by laminectomy. During imaging, spinal cord tissue was prevented from dehydration by covering the tissue with a sodium chloride solution (B.Braun Melsungen AG, Melsungen, Germany).

Technically, two-photon live imaging of $T$ cells was performed using a LSM710/Axio Examiner. Z1 confocal microscope (Carl-Zeiss Microimaging, Jena, Germany) combined with a >2.5Watts Ti:Sapphire Chameleon Vision II Laser device (Coherent GmbH, Dieburg, Germany). Exitation wave lengths were tuned to $880 \mathrm{~nm}$ or $1010 \mathrm{~nm}$. One recording usually covered a $424.27 \times 424.27 \mu \mathrm{m}(512 \times 512$ px $)$ or $2121.35 \times 424.27 \mu \mathrm{m}(2560 \times 512 \mathrm{px})$ area with a tissue depth of 50-100 $\mu \mathrm{m}$. The interval time of the recordings were set to $32 \mathrm{sec}$ or $120 \mathrm{sec}$, respectively. Recordings were acquired and initially processed using the Zen 2009 Software (Carl-Zeiss Microimaging, Jena, Germany) and afterwards edited using ImageJ 1.46i software (National Institute of Health, Bethesda, USA). 
Parameters of $\mathrm{T}$ cell motility (velocity, crawling duration and meandering index) were obtained by analyzing the recordings with the Imaris 7.1.1 software (Bitplane, Zurich, Switzerland) with an automated Imaris Track module.

\subsection{STATISTICS}

Statistical analysis was performed using the Prism software (GraphPad Software Inc., San Diego, CA, US). Data is always depicted as mean \pm standard error of the mean (SEM). For all analyses student's unpaired t-test was used ( $p$-value $>0.05$ : ns, $p$-value $\leq 0.05$ : ${ }^{*}, p$ value $\leq 0.01:^{* \star}, p$-value $\leq 0.001:{ }^{* \star *}, p$-value $\left.\leq 0.0001:{ }^{* \star \star *}\right)$. 


\subsection{GENERATION AND CHARACTERIZATION OF TCR TRANSGENIC RATS}

\subsubsection{MBP-SPECIFIC TCR TRANSGENIC RATS}

\subsubsection{CLONING OF A MBP-SPECIFIC TCR}

To obtain the DNA sequence for the reconstruction of the myelin basic protein specific T cell receptor we used mRNA isolated from the "self-cloned" Lewis rat T cell line Z85. In this line the variable segment of the $B$ chain is known to be VB8.2 for which a monoclonal antibody is available.

Initially, we performed rapid amplification of cDNA 5'-ends (5'-RACE) PCR using gene specific primers binding the constant region of the TCR B-chain. Sequencing of the amplified PCR product revealed the previously described composition of the $B$ chainV $\beta 8.2-J \beta 1.3-C \beta 1$ (Chluba et al., 1989) with the leader exon distinct from the one described earlier, but matching the rat VB8.2 5'-end sequence published elsewhere (Smith et al., 1991). For identification of the $\alpha$-chain, a PCR was performed using a set of primers recognizing families of $V_{\alpha}$-chains (Buenafe et al., 1997) and a reverse primer binding within the constant region of the $\alpha$-chain (Fig. 3.1 A). The resulting PCR products $\left(V_{\alpha} 1\right.$ and $\left.V_{\alpha} 2\right)$ were sequenced and only the sequence of the $\mathrm{V} \alpha 2-\mathrm{PCR}$ fragment $(\mathrm{V} \alpha 2.5-\mathrm{J} \alpha 26-\mathrm{C} \alpha)$ seemed to contain an intact open reading frame (Fig. 3.1 B). The sequence was blasted against the rat genome $\mathrm{NCBI}$ database and the next upstream coding leader exon was identified by comparison to known sequences of the mouse $V_{\alpha 2}$ family of genes (Arden et al., 1995).

The PCR products for both full length $\alpha$-chain and the $\beta$-chain were cloned into shuttle vectors and then fused together via a modified version of the 2A-like linker (P2A, Szymczak and Vignali, 2005) to generate a bicistronic expression cassette. The fused V $\alpha 2.5-P 2 A-$ V $\beta 8.2$ chain was cloned into pEGFP-T2A-C1er, a modified version of the pEGFP-C1 vector (Clontech) with a built-in T2A linker and an additional EcoRI restriction site (pEGFP-T2A$\mathrm{V} \alpha 2.5-\mathrm{cP} 2 \mathrm{~A}-\mathrm{V} \beta$ 8.2). Then, the tricistronic expression cassette was transferred into the lentiviral expression vector pFUGW previously used for generation of transgenic mice (Lois et al., 2002; Fig. 3.1 C).

To assess the surface expression and the functionality of the cloned TCR, $\mathrm{TCR}^{-1-}$ thymoma BW58C cells expressing a chimeric rat-mouse CD28 were cocultured with lentiviral 
concentrate for $48 \mathrm{~h}$ and analyzed for $\mathrm{V} \beta 8.2$ surface expression (34\% of $\mathrm{GFP}^{+} \mathrm{V} \beta 8.2^{+}$ hybridoma cells, Fig. 3.1 D). The transduced BW58C-TCR cells were then mixed with rat thymic antigen presenting cells and challenged with different concentrations of MBP resulting in a dose-dependent production of interleukin-2 (IL-2) in response to the specific antigen MBP but not to OVA (Fig 3.1 E). Taken together, these results proved the correct structure of the cloned TCR as it could be expressed on the cell surface and its specificity and functionality as transduced cells responded to the cognate antigen.

\subsubsection{ANALYSIS OF rMT-II FOUNDER ANIMALS}

Generation of TCR transgenic Lewis rats was achieved by injecting a concentrated lentiviral preparation into the perivitelline space of fertilized oocytes. Zygotes further developing into the two-cell embryo stage during overnight culturing were transferred into pseudopregnant Wistar rat foster females. The rat pups were genotyped and phenotyped three weeks after birth.

For genotyping, genomic tail DNA was used as PCR template with primers binding within the P2A sequence and the variable segment of the $V \beta 8.2$ chain. In the peripheral blood of these animals a low amount of GFP-positive T cells was detected by FACS analysis but no increased V $\beta 8.2$ expression (Fig. $3.1 \mathrm{G}$ ).

Founder animals positive for integration (Fig. 3.1 F) were mated among each other and the F1 generation was again phenotyped by analyzing blood lymphocytes three weeks after birth. In the F1 generation, almost all $\mathrm{CD} 4^{+} \mathrm{T}$ cells expressed GFP and showed increased numbers of $\mathrm{V} \beta 8.2^{+}$cells. We have named the new strain $\underline{\mathrm{rMT}}-\mathrm{II}$, standing for rat $\underline{\mathrm{MBP}}$ specific I cell receptor MHC class $\underline{\text { II }}$-restricted. 


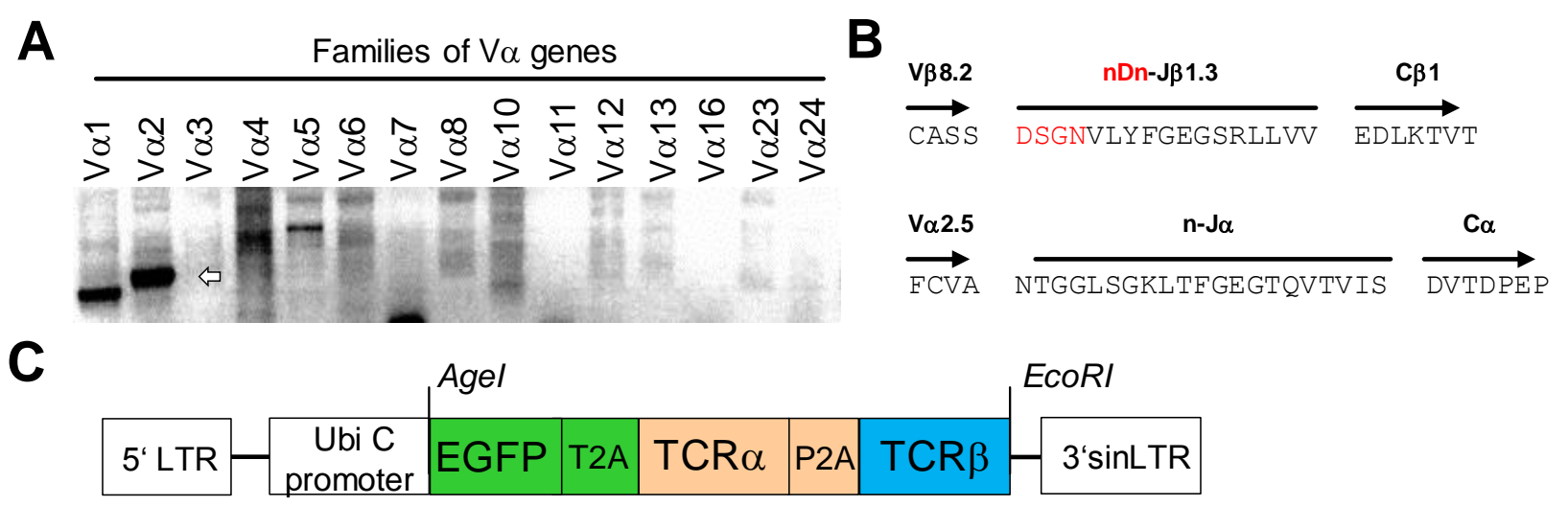

D

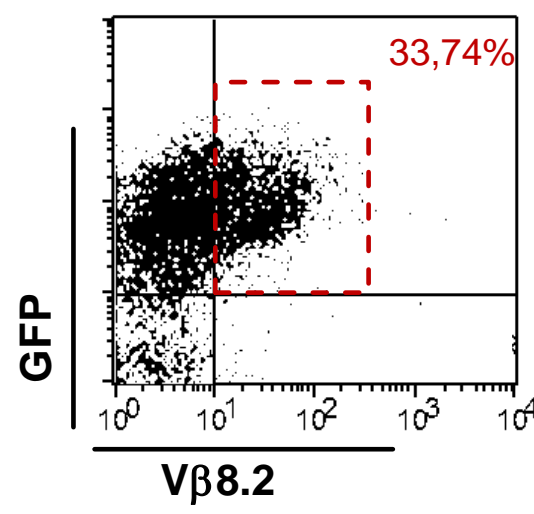

E

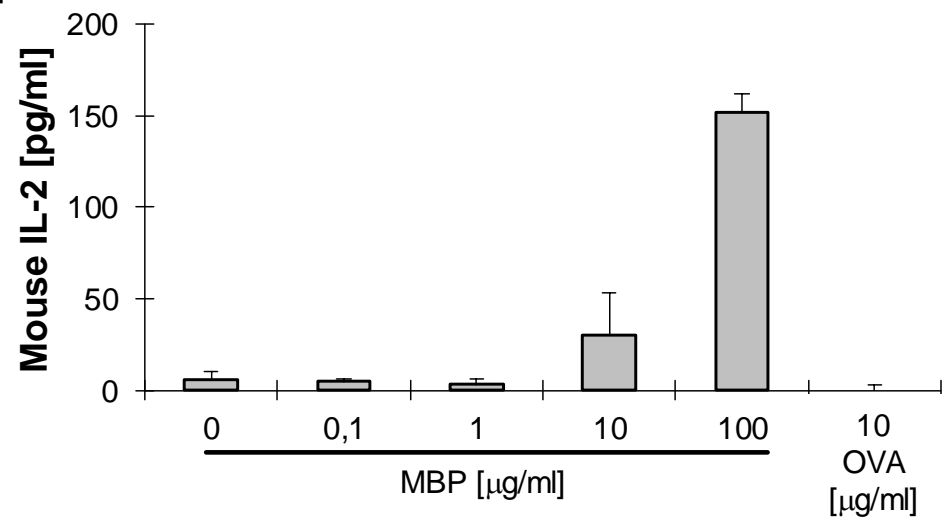

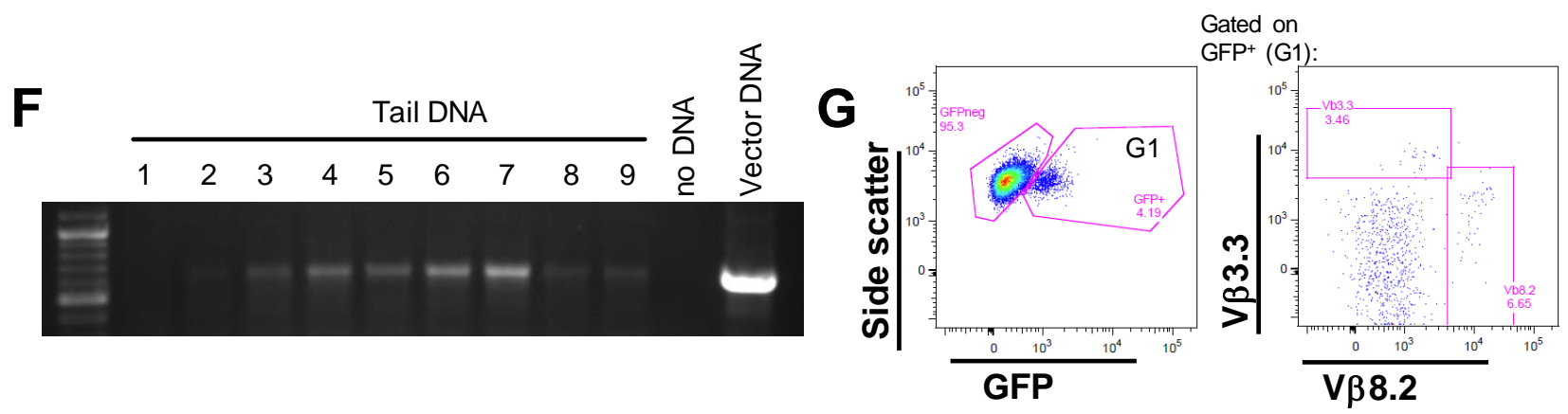

Figure 3.1: Reconstruction of the Lewis rat MBP-specific T cell receptor. (A) $V_{\alpha}$-chain PCR on cDNA template derived from the MBP-specific $T$ cell line $Z 85$ showed a positive signal for $V_{\alpha} 1$ and $V_{\alpha} 2$ gene families. (B) Cloned amino acid sequence for the CDR3 region of $\alpha$ and $B$ TCR chains. C, constant region; J, junction segment; $D$, diversity segment; $V$, variable segment; $n$, nontemplated nucleotides. (C) Schematic of the lentiviral expression construct. Open reading frames for GFP, TCR $\alpha$ and TCR $\beta$ were fused via T2A and P2A sequences and are expressed under the control of the ubiquitin $C$ promoter. Restriction sites used for replacing EGFP by a tricistronic cassette are indicated. (D) Coexpression of GFP and V $\beta 8.2$ TCR in the lentivirally transduced TCR-negative BW58C T cell hybridoma cell line. (E) Induction of mouse IL-2 in response to stimulation with MBP. Concentration of mouse IL-2 was measured by ELISA in supernatants from lentivirus-transduced hybridoma cocultured with Lewis rat APC in the presence of the indicated amount of MBP or OVA. Graphs are depicted as Mean \pm SEM. (F) Founder animals which integrated the transgenic construct were identified by genomic PCR using primers specific for the expression cassette. (G) FACS analysis of blood cells from founder animal no. 4 (F), stained with mAb specific for TCR-VB3.3 and TCRVB8.2 (transgenic chain). Data shown in (G) was generated by Dr. Henrike Fischer, Department of Immunology, laboratory of Prof. Holger Reichardt. 


\subsubsection{3 rMT-II RATS EXPRESS GFP AND THE TRANSGENIC T CELL RECEPTOR}

Crossing of $\mathrm{F} 1 \mathrm{rMT}-\mathrm{Il}$ animals yielded progenies with no, moderate or high GFP expression in frequencies fitting to Mendelian inheritance (Fig 3.2 A, data not shown). Breeding of rats with high GFP expression resulted in animals which were uniformly "high-GFP" suggesting that those rats are homozygous for the rMT-II allele $\left(\mathrm{rMT}^{-\mathrm{II}^{+/+}}\right)$. In rMT- $-\mathrm{II}^{+/+}$rats, the GFP expression levels varied between cell types: it was highest in myeloid cells and NK cells, intermediate in T cells, and lowest in B cells (Fig. 3.2 B).

Both $\mathrm{rMT}^{-\mathrm{II}^{+/}}$and $\mathrm{rMT}_{-} \mathrm{II}^{+/+}$rats showed a significant increase in $\mathrm{T}$ cell numbers expressing the transgenic $\mathrm{V} \beta 8.2$ chain (Fig. $3.2 \mathrm{C}$ ). In these animals, the $\mathrm{V} \beta 8.2^{+} \mathrm{T}$ cells could be further divided into a $T C R^{\text {medium }}-\mathrm{V} \beta 8.2^{\text {high }}$ (red square) and a $T C R^{\text {high }}-\mathrm{V} \beta 8.2^{\text {medium }}$ (purple square)

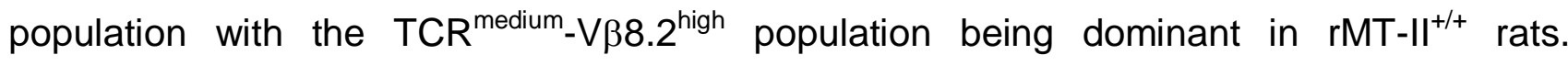

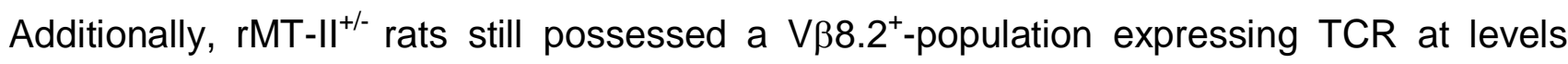
similar to WT littermates. These presumably contain a productively rearranged endogenous

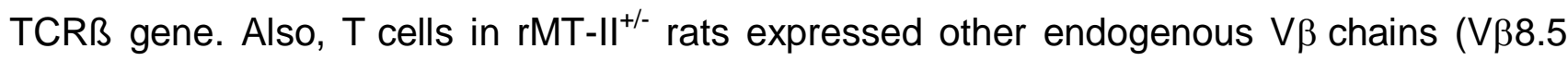
and $\mathrm{V} \beta 16$ ) which were virtually absent in $\mathrm{rMT}-\mathrm{II}^{+/+}$rats. 
A

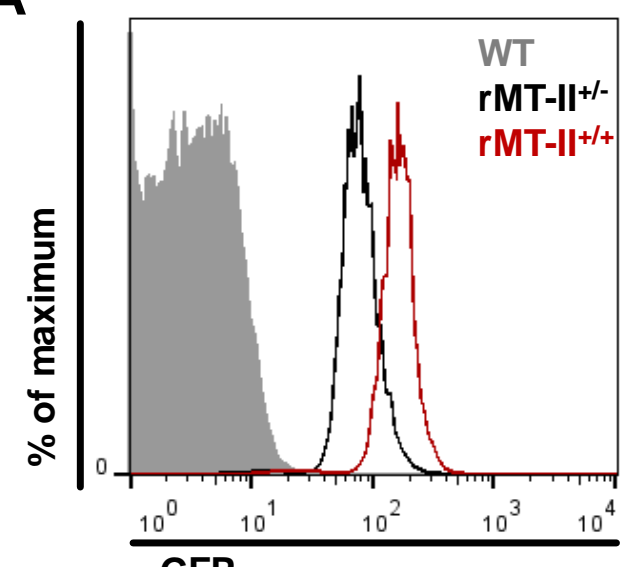

B

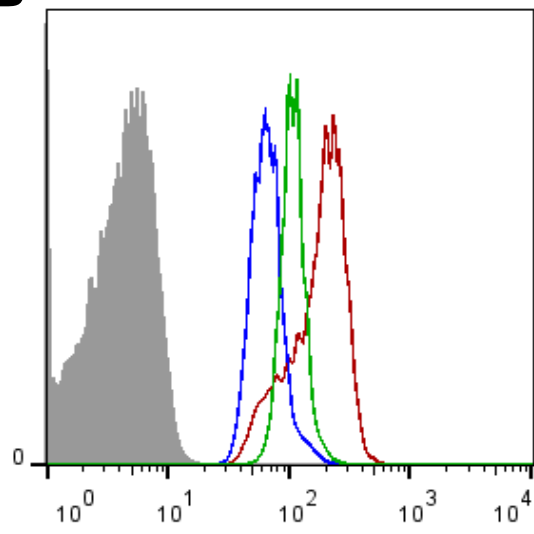

WT Lymphocytes

$B$ cells $\left(0 X-3^{+}\right)$

T cells $\left(\mathrm{abTCR}^{+}\right)$

Myeloid cells (OX-42+)

C

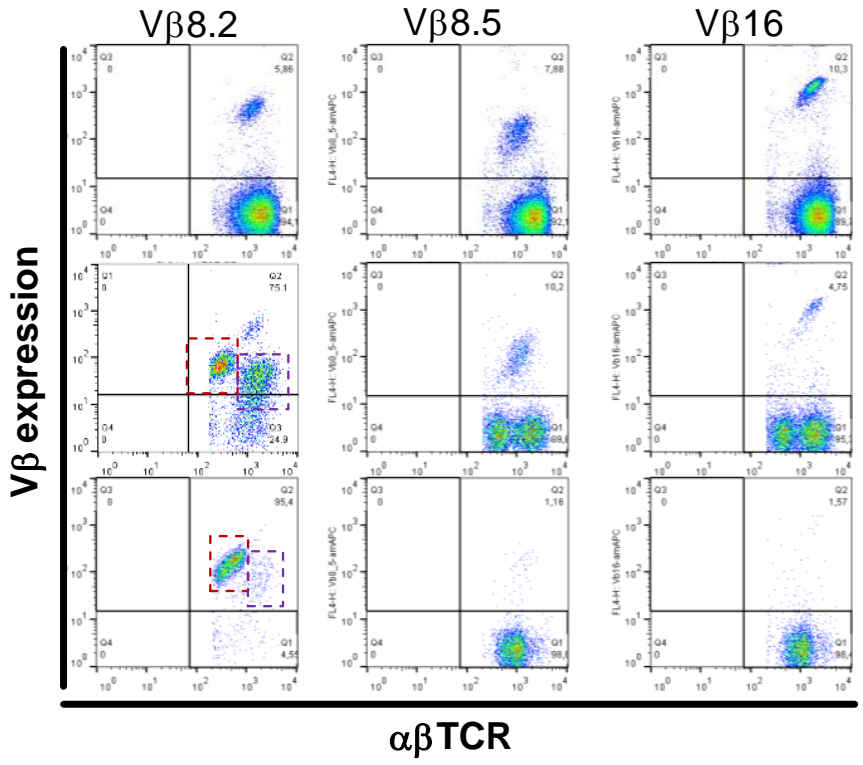

D
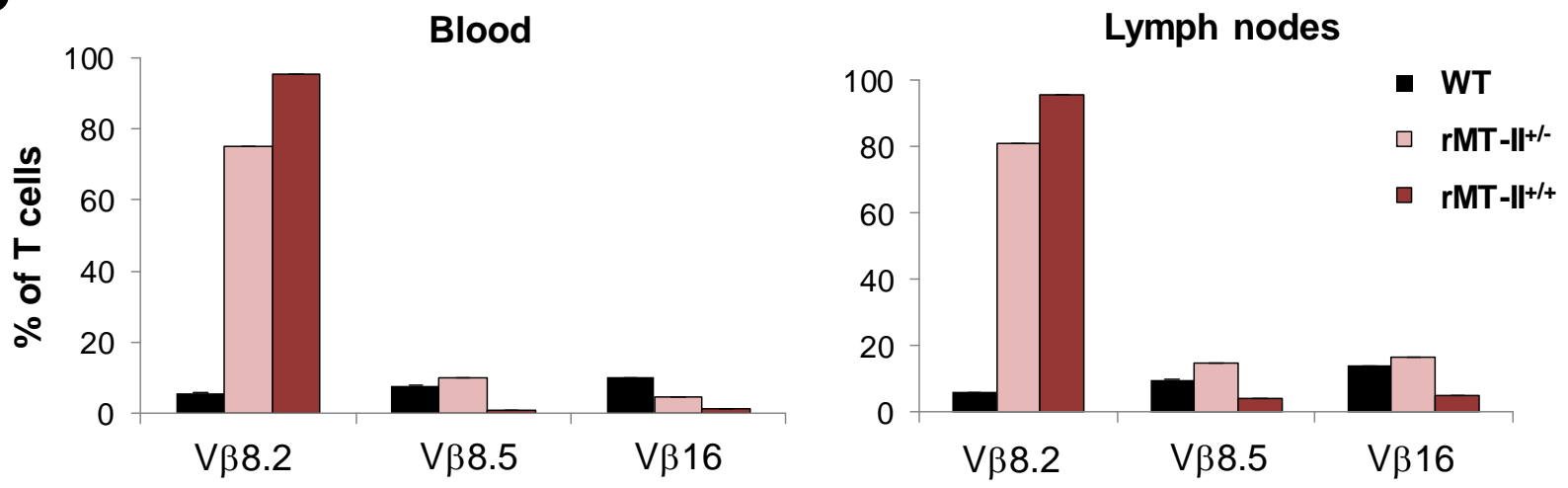

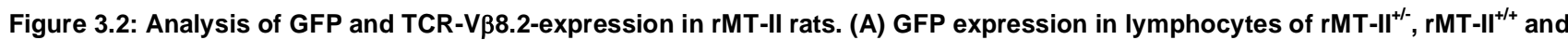

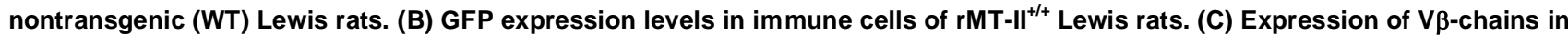
peripheral blood T cells of WT, rMT- $-I^{+/-}$and $\mathrm{rMT}-\mathrm{II}^{+/+}$rats. In rMT-Il rats two populations of TCR transgenic $\mathrm{T}$ cells could be identified: $T_{C R}{ }^{\text {medium }}-\mathrm{V} \beta 8.2^{\text {high }}$ (red square) and $\mathrm{TCR}^{\text {high }}-\mathrm{V} \beta 8.2^{\text {medium }}$ (purple square). (D) Quantification of $\mathrm{V} \beta 8.2^{+} \mathrm{T}$ cells in blood and lymph nodes of WT, rMT-II+- and $\mathrm{rMT}^{+\mathrm{I}^{+/+}}$rats. (C) and (D) gated on $\mathrm{GFP}^{+}$lymphocytes. Data obtained by immunostaining and flow cytometry analysis. (A-D). Graphs depicted as Mean \pm SEM. 
Further, we analyzed the cellularity of lymphoid organs. Whereas the cell numbers were similar between the genotypes in thymus, spleen and blood, a significant reduction of the total cell number was observed in lymph nodes (pooled inguinal, popliteal, axillary, cervical, paraaortic and mesenterial lymph nodes) of $\mathrm{rMT}^{-\mathrm{II}^{++}}$rats. In WT Lewis rats, around $360 \times 10^{6}$ cells were counted per gram organ but were diminished to $250 \times 10^{6}$ cells per

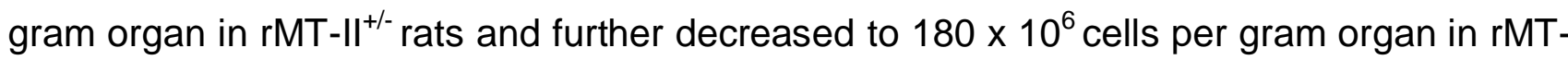
$\mathrm{II}^{+/+}$rats (Fig 3.3 A).

To address whether the reduced cell number is due to a reduction of $T$ cell numbers, lymph node and blood cells were stained for the expression of $\alpha \beta T$ cell receptor and CD45RA, a marker for $\mathrm{B}$ cells. As shown in Figure $3.3 \mathrm{~B}$ and $\mathrm{C}, \mathrm{rMT}^{-\mathrm{II}^{+/}}$rats showed a decreased percentage of $T$ cells and decreased ratio of $T$ cell number/B cell number (T/B). In $\mathrm{rMT}^{-\mathrm{II}^{+/+}}$ animals, the relative number of $T$ cells and the T/B ratio in lymph nodes returned to WT levels, whereas in blood the T/B ratio was lower than in blood of WT littermates.

It was reported before, that distortion of thymic development occurs in TCR transgenic mice (e.g. Barnden et al., 1998; Lacorazza et al., 2001). Therefore, we analyzed thymi and peripheral lymphoid organs from WT and transgenic rats for the expression of CD4 and CD8 surface markers. In WT Lewis rats, around $85 \%$ of thymocytes are double-positive (DP) for $\mathrm{CD} 4^{+}$and $\mathrm{CD} 8^{+}$whereas around $6 \%$ are $\mathrm{CD} 4^{+}$and $5 \%$ are $\mathrm{CD} 8^{+}$single-positive (SP) thymocytes (van den Brandt et al., 2005). Unexpectedly, in the thymus of $\mathrm{rMT}^{-\mathrm{II}^{+/ /}}$rats we observed a strong reduction in the $\mathrm{CD} 4^{+} \mathrm{SP}$ population to $0.7 \%$, while proportions of $\mathrm{CD}^{+} \mathrm{SP}$ and DP cells were slightly increased (Fig. 3.3 D, $7 \%$ and $88 \%$, respectively). There was no accumulation of cells within the double-negative (DN) population. Nevertheless, in the periphery of $\mathrm{rMT}-\mathrm{II}^{+-}$rats, the majority of $\mathrm{T}$ cells were $\mathrm{CD} 4^{+}(60 \%$,

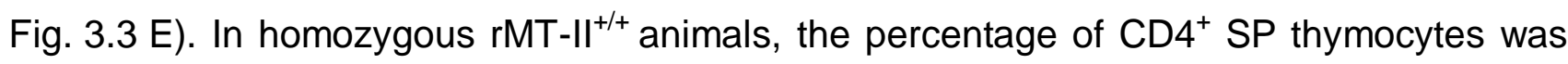
restored to $3.9 \%$, whereas the relative size of the $\mathrm{CD} 8^{+} \mathrm{SP}$ population was significantly increased (9.4\%, Fig. 3.3 D). Interestingly, in $\mathrm{rMT}^{-\mathrm{II}^{+/+}}$lymph nodes (and blood) the singlepositive $\mathrm{CD} 8^{+}$population was reduced to only $5-6 \%$ (versus $25 \%$ in WT) and the vast majority of remaining T cells were $\mathrm{CD}^{+}(75-80 \%$, Fig. $3.3 \mathrm{E})$ 
A

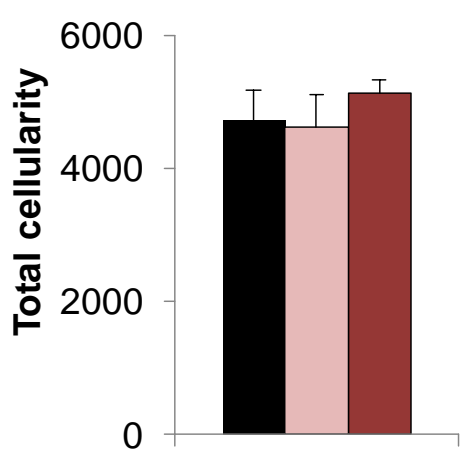

Thymus

B

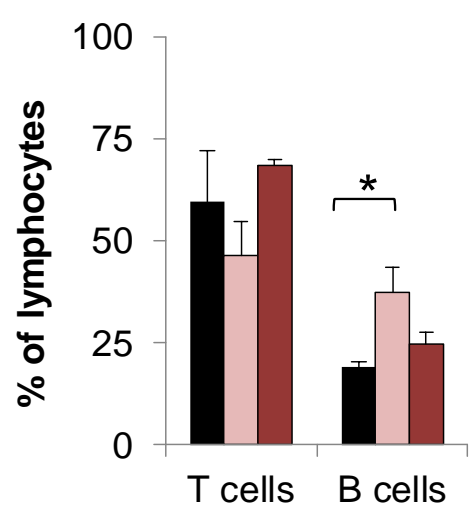

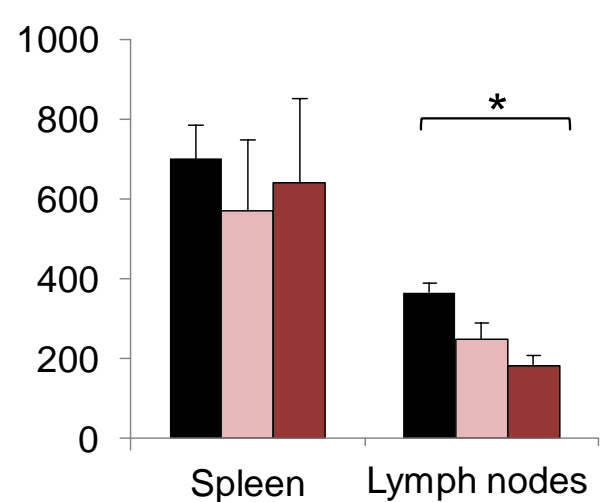

C
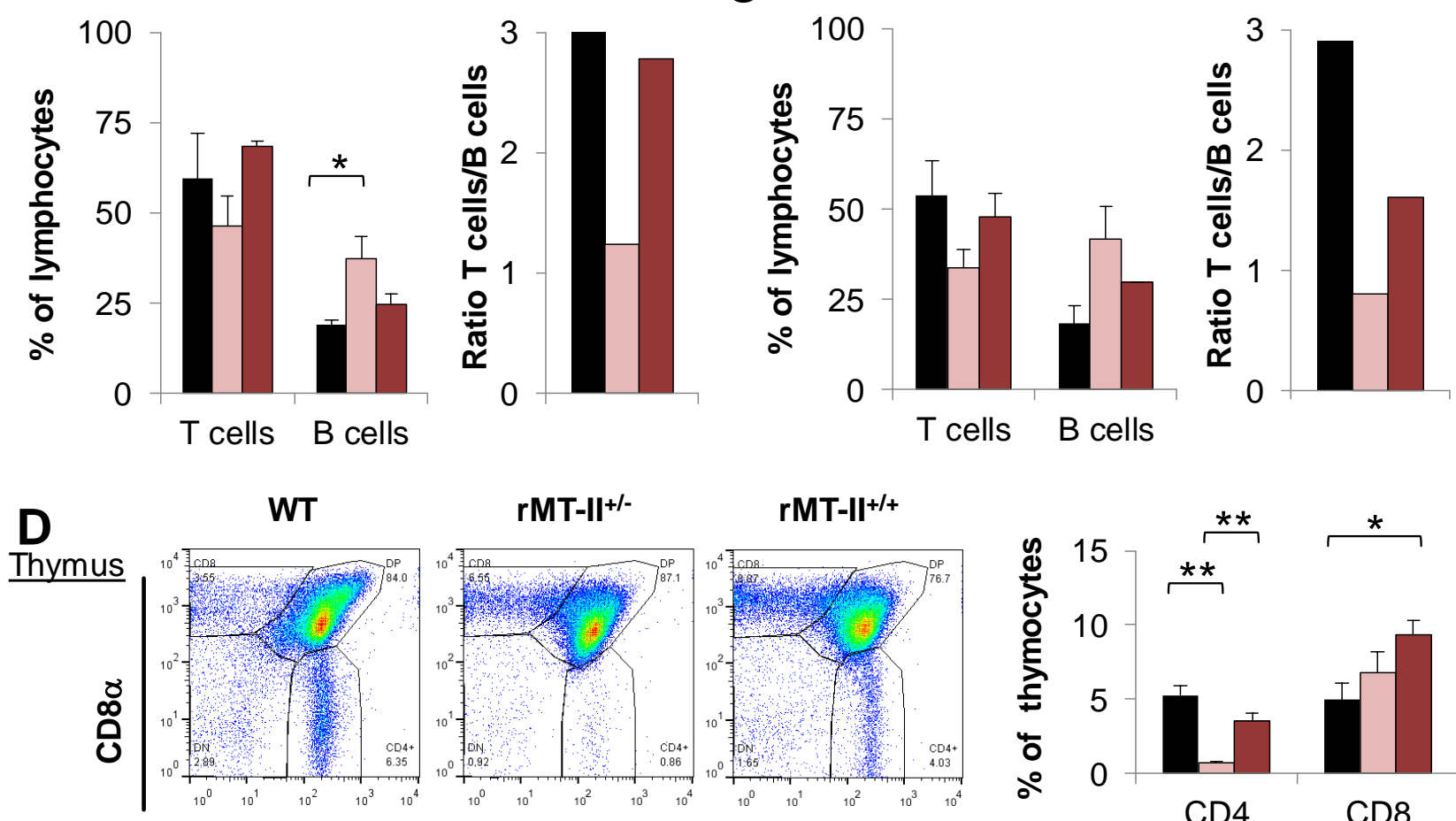

E

\section{CD4}

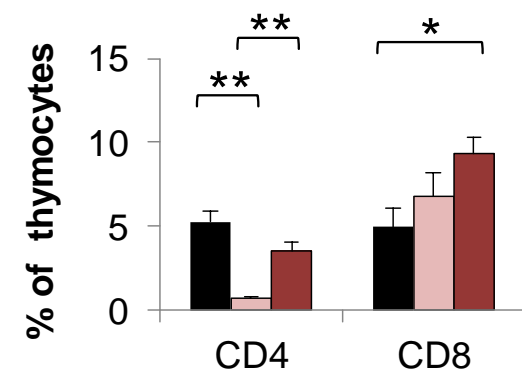

Lymph nodes
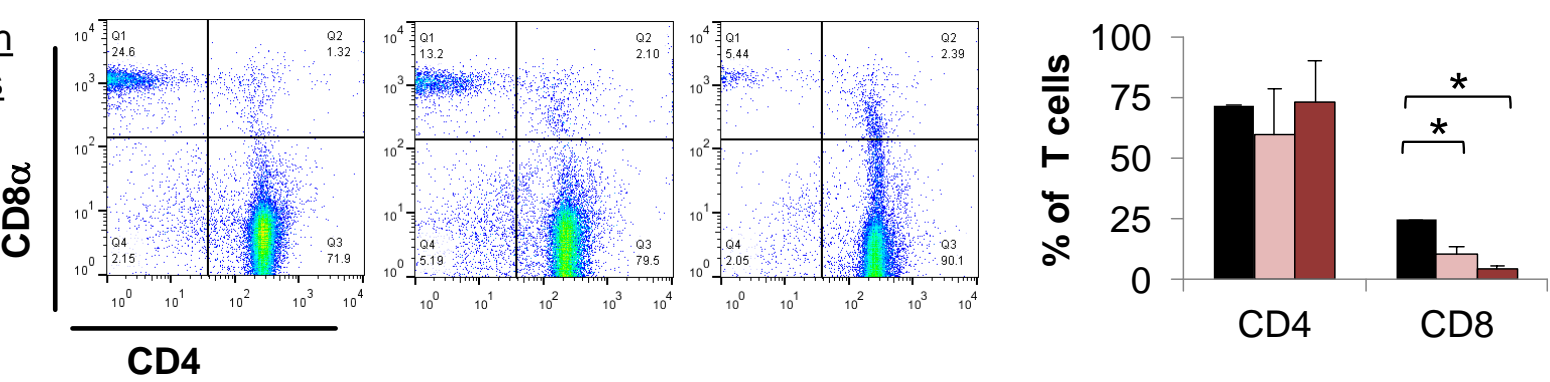

Figure 3.3: (A) Total cellularity of different lymphoid organs was determined by cell counting. Shown are numbers per $\mathrm{g}$ of organ or $\mathrm{ml}$ of blood in millions of cells. Percentages of GFP' $\mathrm{T}$ cells and B cells in lymph nodes (B) and blood (C) determined by flow cytometry. (D,E) Representative FACS plots of CD4/CD8 stained cells isolated from thymus (D) and lymph nodes (E). Quantification of CD4/CD8 expressing GFP ${ }^{+}$lymphocytes depicted on the right. $\mathrm{n}=3$ per genotype. Graphs depicted as Mean \pm SEM. Color code for genotypes (A) applies also to (B-E). 
NK cells belong to the innate immune system whereas NK T cells are a subpopulation of $T$ cells recognizing lipid antigens in the context of the coreceptor CD1d. We analyzed the expression of CD161 (also known as NK1.1) and $\alpha \beta T C R$ in lymph nodes, spleen and in the blood of transgenic rats and found that both NK and NK T cell numbers were slightly increased in $\mathrm{rMT}^{-\mathrm{II}^{+/+}}$animals (Fig. 3.4 A, data shown for lymph nodes only).

Besides developing into $\alpha \beta T$ cells, progenitor cells entering the thymus can develop into $\gamma \delta$ T cells, a distinct T cell lineage expressing a TCR consisting of a $\gamma$ and a $\delta$ chain.

As shown in Figure $3.4 \mathrm{~B}$, in WT $1.4 \%$ of all $\mathrm{CD}^{+}$cells in the lymph nodes (blood $1.2 \%$ ) were $\gamma \delta \mathrm{T}$ cells. The amount of lymph node $\gamma \delta \mathrm{T}$ cells was significantly reduced to $0.76 \%$ in rMT- $\mathrm{II}^{+/-}$rats (blood $0.88 \%$ ) and further decreased to $0.18 \%$ in $\mathrm{rMT}^{-\mathrm{II}^{+/+}}$rats (blood $0.06 \%$ ).
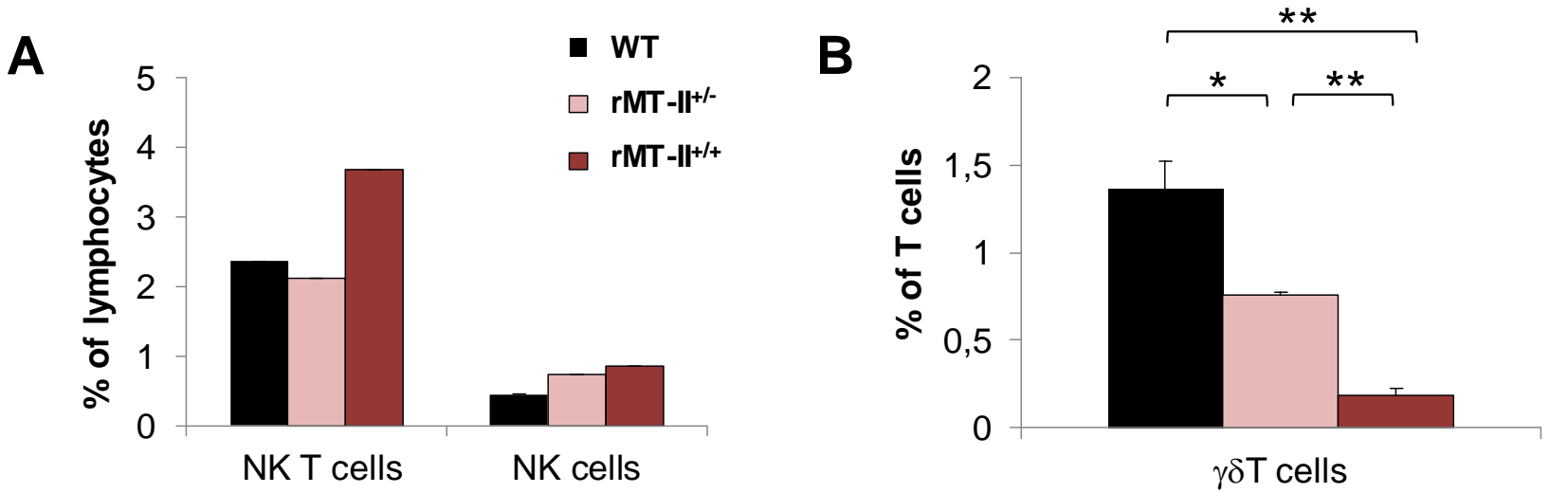

Figure 3.4: (A) Percentages of NK and NK T cells in lymph nodes gated on GFP cells. (B) Percentages of $\gamma \delta$ T cells in the lymph nodes gated on $\mathrm{CD}^{+} \mathrm{GFP}^{+}$cells. $\mathrm{n}=3$ per genotype. Graphs depicted as Mean $\pm \mathrm{SEM}$.

\subsubsection{EX VIVO ANTIGEN RESPONSE OF rMT-II T CELLS}

To address antigen specificity of rMT-II T cells, total lymph node cell preparations were stimulated in vitro with different concentrations of MBP protein isolated from guinea pig brains or synthetic $\mathrm{MBP}_{68-88}$ peptide (immunodominant epitope of MBP in Lewis rats; this peptide is also recognized by the Z 85 cell line). As a positive control, cells were stimulated with plate-bound monoclonal antibodies to rat CD3 and rat CD28 robustly inducing proliferation and production of cytokines. $48 \mathrm{~h}$ after stimulation, cultures were pulsed with $\left[{ }^{3} \mathrm{H}\right]$-thymidine and the incorporation was measured $16 \mathrm{~h}$ later.

Regardless of genotype, $T$ cells rigorously proliferated in response to CD3/CD28 stimulation (Fig. 3.6 A). T cells derived from $\mathrm{rMT}^{-\mathrm{II}^{+/+}}$rats but not from WT rats proliferated in response to $\mathrm{MBP}$ and $\mathrm{MBP}_{68-88}$ in a dose-dependent manner but did not proliferate upon stimulation with ovalbumin. Minimal proliferative response (2.5-fold increase over WT) was present in $\mathrm{rMT}^{-\mathrm{II}^{+-}}$cells at the maximum concentration of antigen. Of note, the $\mathrm{T}$ cell 
proliferation was abrogated in cultures pretreated with OX-6 antibody blocking the RT1.B (rat MHC class II) complex (Fig. 3.6 A).

Upon stimulation, T cells produce proinflammatory cytokines such as IFN $\gamma$ and TNF $\alpha$. LN cells were stimulated as described above and supernatants were assayed by ELISA. Here again, lymphocytes derived from $\mathrm{rMT}^{-\mathrm{II}^{+/+}}$rats produced IFN $\gamma$ in a dose-dependent manner

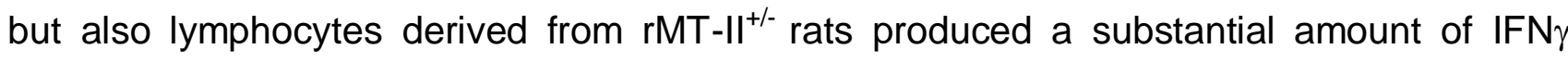
when challenged with 10 and $100 \mu \mathrm{g} / \mathrm{ml} \mathrm{MBP}$ (Fig. 3.6 B). TNF $\alpha$ could only be detected in very low concentrations in the supernatant of stimulated lymphocytes. Production of IFN $\gamma$ was also detected by intracellular staining of stimulated lymphocytes. Upon stimulation with $100 \mu \mathrm{g} / \mathrm{ml} \mathrm{MBP}$, around $20 \%$ of $\mathrm{rMT}^{-\mathrm{II}^{+/+}}$lymphocytes produced IFN $\gamma$ (Fig. $3.6 \mathrm{C}$ ) but not IL-17 (data not shown). Again, the induction of IFN $\gamma$ could be completely abrogated by application of OX-6 antibody.

We analyzed mRNA isolated from $\mathrm{rMT}^{-\mathrm{II}^{+/+}}$lymphocytes at different time points after stimulation by RT-qPCR. IFN $\gamma$ mRNA peaked at $42 \mathrm{~h}$ after stimulation with $10 \mu \mathrm{g}$ of MBP and a mild increase of TNF $\alpha$ mRNA was induced ( $1 / 10$ of IFN $\gamma$ message). Very low amounts of mRNAs of other proinflammatory cytokines, IL-2 and IL-17, were detected at 30-42 $\mathrm{h}$ post stimulation (Fig. 3.5 A). In vitro stimulation of lymphocytes resulted in a rapid upregulation of CXCR3 and CCR7 mRNA within 6 hours after stimulation (Fig. 3.5 B).

A

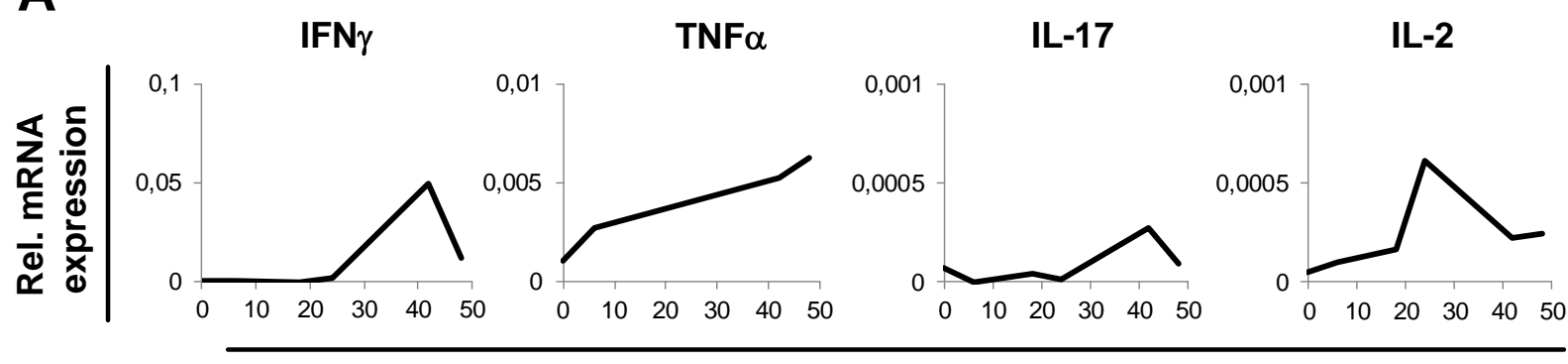

Time after stimulation [h]

B

CXCR3

CCR7

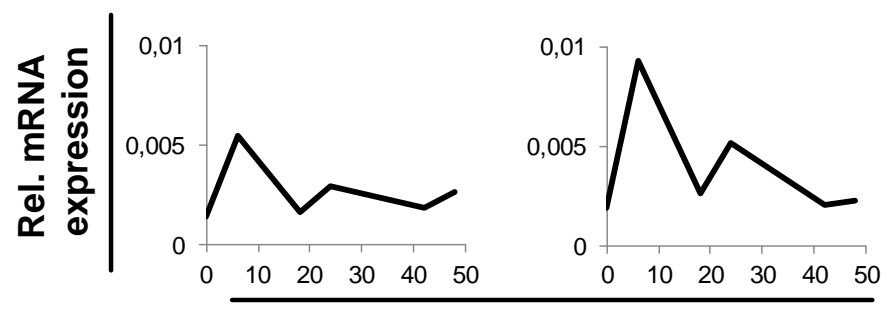

Time after stimulation [h]

Figure 3.5: Kinetic of gene expression in $\mathrm{rMT}^{-\mathrm{II}^{+/+}}$lymph node cells stimulated ex vivo. (A) Expression levels of mRNA of the cytokines IFN $\gamma$, TNF $\alpha$, IL-17 and IL-2 and (B) chemokine receptors CXCR3 and CCR7 after stimulation with $10 \mu \mathrm{g} / \mathrm{ml}$ of MBP. Shown are relative values of mRNA expression normalized to the expression level of the $B$-actin gene. 
A

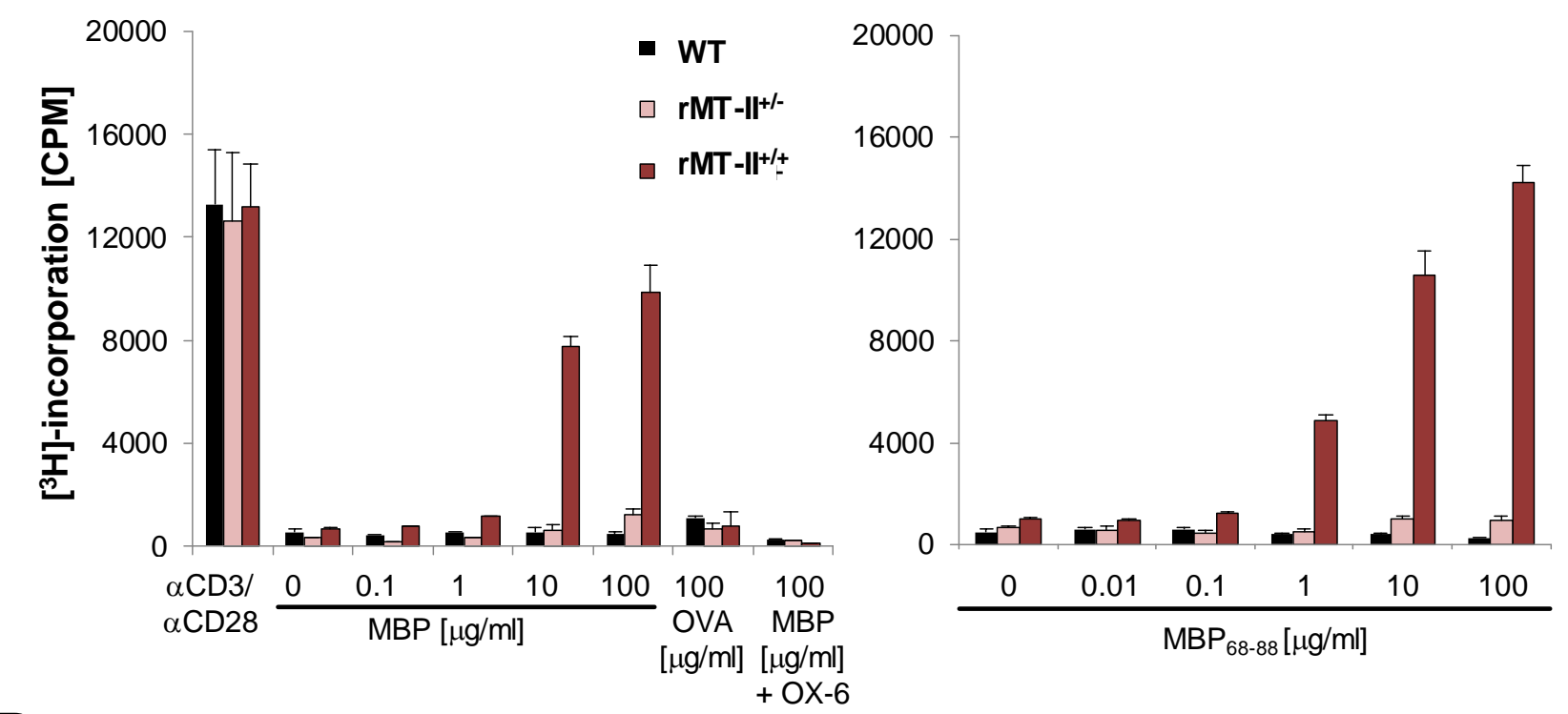

B
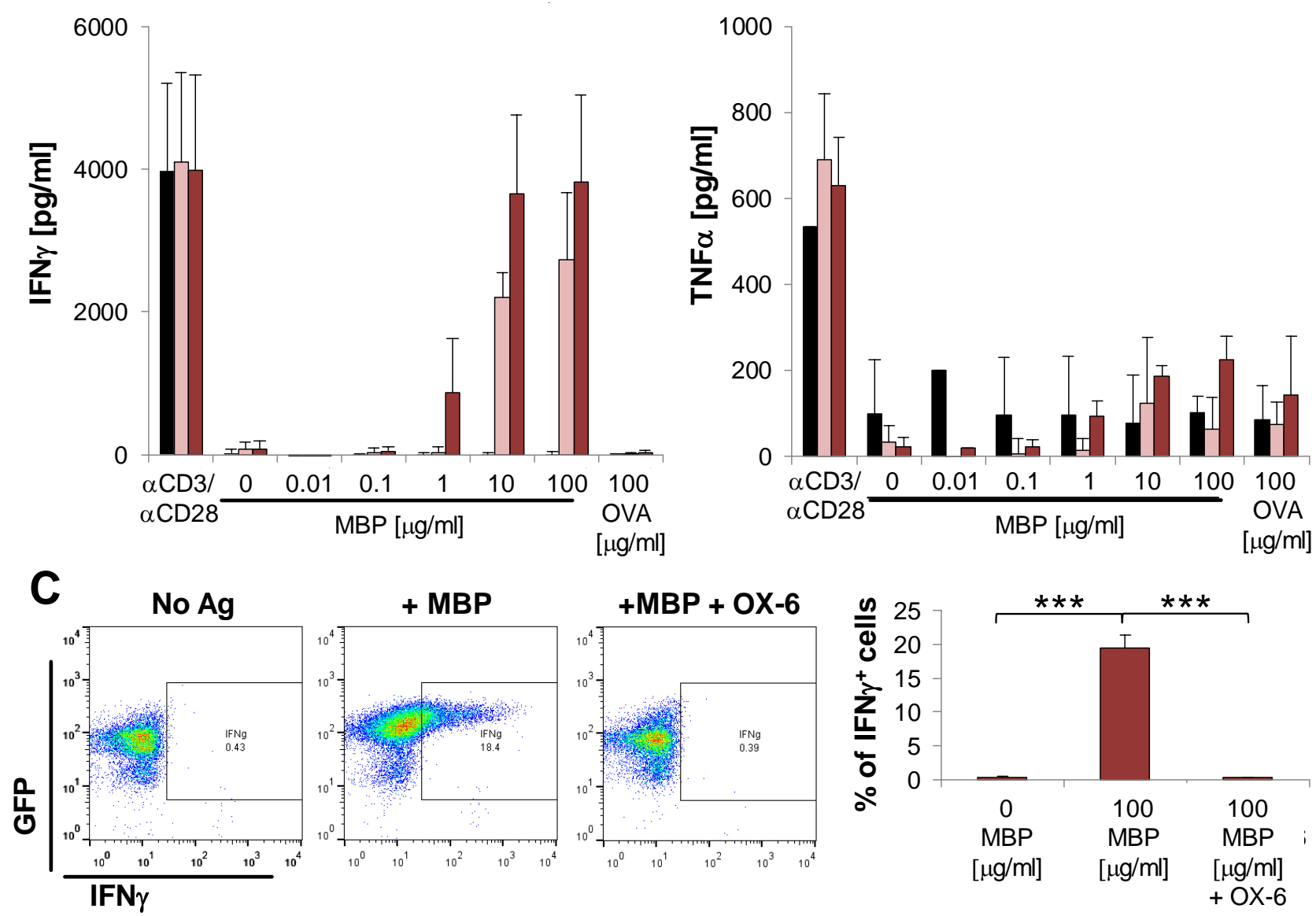

Figure 3.6: Antigen responsiveness of rMT-II lymphocytes in vitro. (A) Results of $\left[{ }^{3} \mathrm{H}\right]$-thymidine incorporation assay performed in rMT-II and WT lymph node cells stimulated with MBP or MBP $_{68-88}$ peptide. (B) IFN $\gamma$ and TNF $\alpha$ production by lymph node cells determined by ELISA $48 \mathrm{~h}$ after stimulation. (C) Representative intracellular IFN $\gamma$ FACS stainings $48 \mathrm{~h}$ after lymphocyte stimulation with indicated conditions. Color code used for (A) applies also for (B) and (C). Diagrams depict Mean \pm SEM. 
Mature $T$ cells can be further subdivided into naïve $T$ cells, which did not encounter their cognate antigen yet, and memory $T$ cells, which encountered their cognate antigen before and are thus able to mount a rapid response to a second antigen encounter. In mice, naïve T cells are defined as a CD62L high CD44 $^{\text {low }}$ population (Sallusto et al., 1999). In rats, CD44 is highly expressed on both naïve and effector/memory $T$ cells and cannot be used to discriminate them, but CD62L (L-selectin) and CD45RC (OX-22) are expressed in naïve rat $\mathrm{T}$ cells and become down-regulated upon differentiation into effector or memory $\mathrm{T}$ cells (Bunce and Bell, 1997).

To further dissect the $\mathrm{T}$ cell subtype responsible for proliferation and cytokine production, lymphocytes isolated from lymph nodes, spleen and blood were analyzed for their surface expression of CD62L (Fig 3.7 A). In lymph nodes and spleen of WT animals around half of the $\mathrm{CD}^{+} \mathrm{T}$ cells were $\mathrm{CD}^{+} \mathrm{L}^{+}$whereas around $80 \%$ of the $\mathrm{CD}^{+} \mathrm{T}$ cells in the blood expressed CD62L. This distribution was almost equal in homozygous $\mathrm{rMT}^{-\mathrm{II}^{+/+}}$rats. Further, $\mathrm{CD} 2 \mathrm{~L}^{+}$and CD62 $\mathrm{L}^{-} \mathrm{T}$ cells were sorted via FACS from lymph nodes of untreated $\mathrm{rMT}^{-\mathrm{II}^{+/+}}$ rats and their gene expression profile analyzed.

$\mathrm{CD}^{+} \mathrm{CD}^{+} \mathrm{L}^{+} \mathrm{T}$ cells expressed lower levels of CCR2, CCR5 and CXCR3 mRNA compared to $\mathrm{CD}^{+} \mathrm{CD}^{-} \mathrm{L}^{-} \mathrm{T}$ cells (Fig. 3.7 B). However, CCR7 mRNA levels were equal in both $\mathrm{CD}_{2} \mathrm{~L}^{+}$and $\mathrm{CD} 62 \mathrm{~L}^{-} \mathrm{T}$ cells. mRNA expression levels of Tbet and FoxP3 were higher in $\mathrm{CD}^{+} \mathrm{CD}^{+} \mathrm{L}^{-} \mathrm{T}$ cells.

T cells were separated for $\mathrm{CD} 2 \mathrm{~L}^{+}$and $\mathrm{CD} 2 \mathrm{~L}^{-} \mathrm{T}$ cell populations via MACS sorting and challenged with different concentrations of MBP in vitro to determine the impact of each population on $\mathrm{T}$ cell proliferation and cytokine production.

Although $\mathrm{CD} 2 \mathrm{~L}^{-}$memory $\mathrm{T}$ cells are supposed to provide a rapid immune response upon rechallenge with their respective antigen (Ahmed and Gray, 1996; Zinkernagel et al., 1996), our data demonstrates that $\mathrm{CD}_{2} \mathrm{~L}^{+}$naïve $\mathrm{T}$ cells responded stronger to challenge with MBP in vitro with regards to proliferation and proinflammatory cytokine production (Fig. 3.7 C and D). 


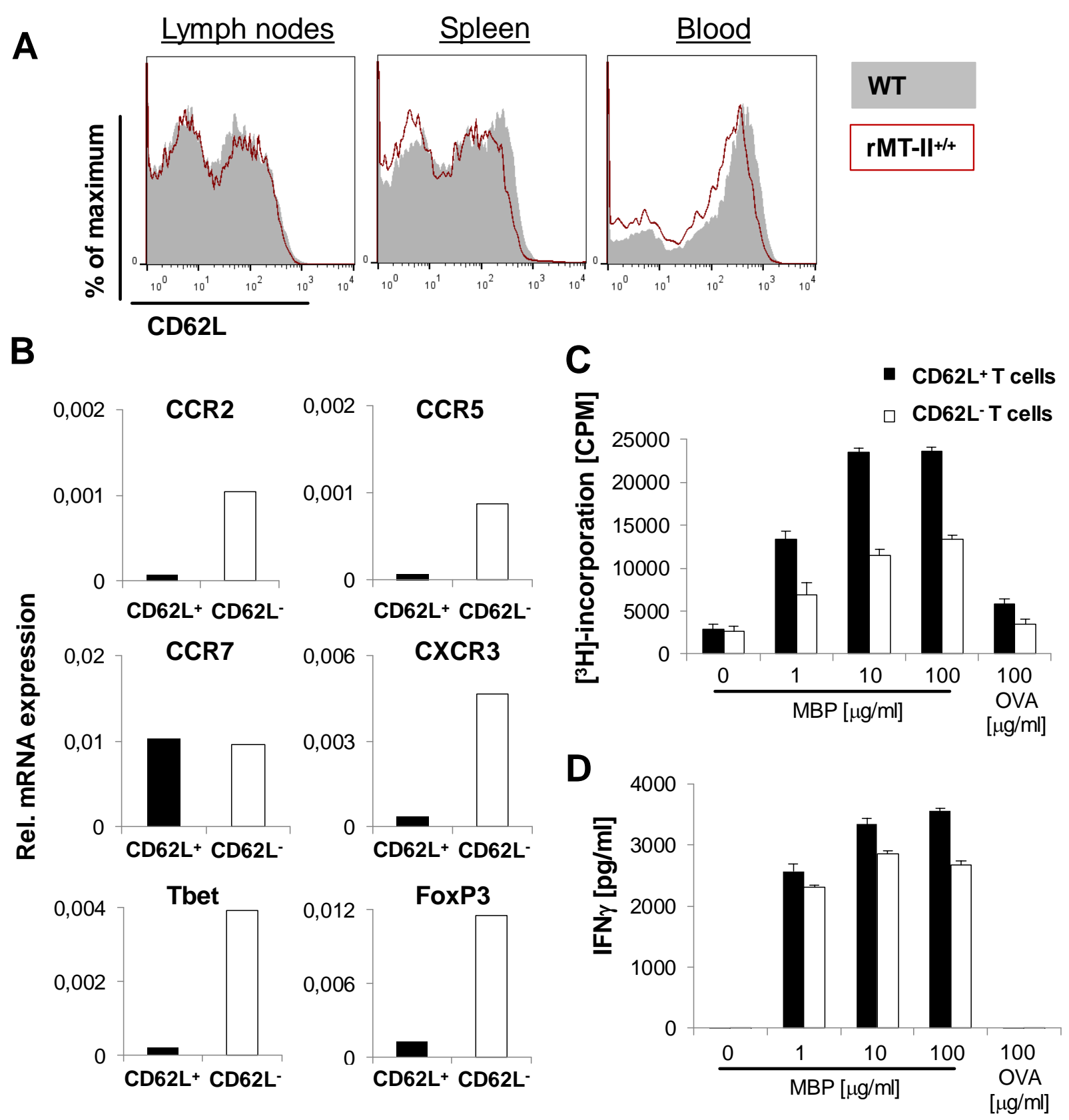

Figure 3.7: Analysis of naïve and memory $T$ cell composition based on CD62L expression. (A) CD62L surface expression in $\mathrm{CD4}^{+} \mathrm{GFP}^{+} \mathrm{T}$ cells isolated from lymph nodes and blood of $\mathrm{rMT}-\mathrm{II}^{+/+}$rats (red line) and wild type littermates (grey area). (B) Representative bar charts of CCR2, CCR5, CCR7 and CXCR3 mRNA expression normalized to $\beta$-actin mRNA expression of

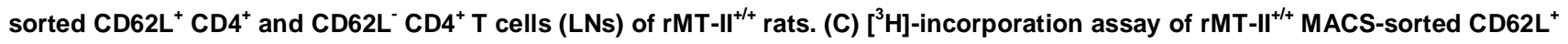
or CD62L- T cells stimulated with antigen for $48 \mathrm{~h}$. (D) Rat IFN $\gamma$ ELISA of supernatant assayed from rMT-II ${ }^{+/+}$MACS-sorted CD62L $^{+}$ or CD62L' T cells stimulated with antigen for $48 \mathrm{~h}$. 


\subsubsection{7 $\mathrm{rMT}^{-} \mathrm{II}^{+/+} \mathrm{T}$ CELLS RESPOND TO THE SPECIFIC ANTIGEN IN VIVO}

Naïve recipients were injected into the hind limbs with splenocytes of $\mathrm{rMT}^{-\mathrm{II}^{+/+}}$rats and locally immunized to confirm the antigen responsiveness in vivo.

To this extent, $5 \times 10^{6}$ lymphocytes were injected into the right hind limb of naïve recipient rats. After $16 \mathrm{~h}$, the recipients were immunized with $10 \mu \mathrm{g}$ MBP or $10 \mu \mathrm{g}$ OVA in CFA at the same location. T cell numbers were analyzed by cell count of $\mathrm{GFP}^{+}$cells within the draining popliteal lymph nodes three days after immunization.

As shown in Figure 3.8, in vivo $\mathrm{T}$ cell expansion after immunization was stronger upon antigen challenge with MBP compared to OVA with a 5-fold increase of cell numbers.

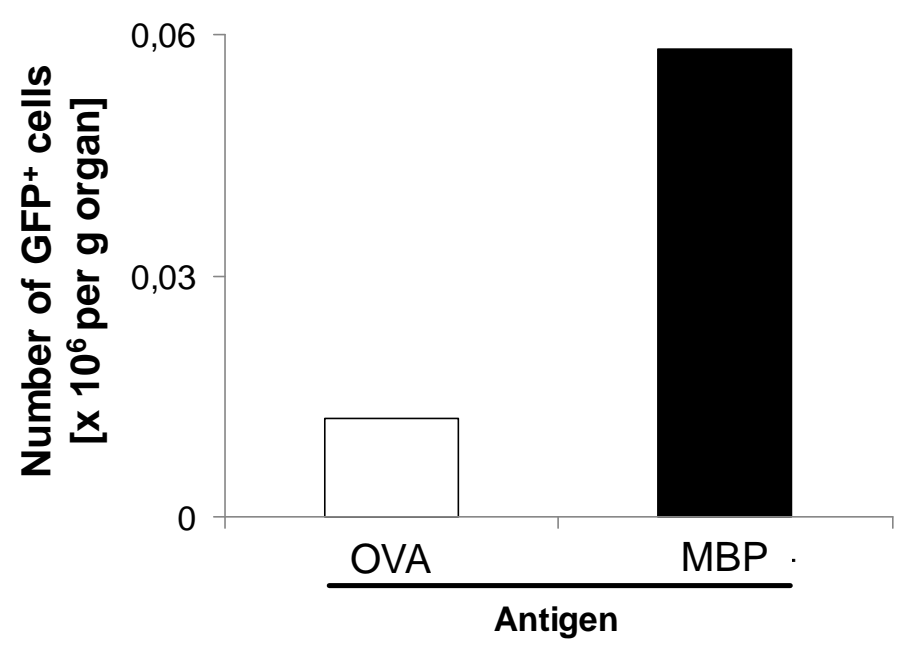

Figure 3.8: In vivo antigen response of ${\mathrm{rMT}-\mathrm{I}^{+/+}}^{++}$ splenocytes. Splenocytes were injected subcutaneously and afterwards animals were immunized. Three days after immunization with either OVA or MBP in CFA, GFP ${ }^{+}$cells per gram of draining popliteal lymph node were counted via FACS analysis. 


\subsubsection{OVALBUMIN-SPECIFIC TCR TRANSGENIC RATS}

\subsubsection{CLONING OF AN OVALBUMIN-SPECIFIC TCR}

To clone a Lewis rat TCR recognizing chicken egg ovalbumin protein (OVA), we first established an effector $T$ cell line from lymph nodes of a rat immunized with OVA in CFA. After one week of primary culture, $T$ cells were restimulated with antigen and 2 days later magnetically enriched for cells expressing the TCR-VB16 chain (Fig 3.9 A). Activated blast T cells were then diluted to a clonal density ( 1 cell per well of a 96 -well plate, later called clonoids) and cultured in the presence of growth factors. After several rounds of in vitro restimulation with ovalbumin, 24 clonoid $T$ cell lines were individually stained for V $\beta 16$ expression and used for CDNA isolation. Figure 3.9 B shows an exemplary result of FACS analysis of three clonoid lines with \#15 and \#18 positive for V $\beta 16$. Clonoid\#15 and \#18 were chosen for detailed sequence analysis. A PCR was performed for the $V \beta$ chain with primers annealing in the leader region of the rat V $\beta 16$ gene (Gold et al., 1992) and in the constant region of the $V \beta$ chains (Smith et al., 1991). The amplified PCR product was sequenced and the following VJ-combinations were deduced: V $\beta 16-J \beta 1.4-C \beta 1$ for clonoid $\# 15$ and $\mathrm{V} \beta 16$-J $\beta 1.3-\mathrm{C} \beta 1$ for clonoid \#18 (Fig. 3.9 C). For identification of the $\alpha$-chain, a PCR was performed using a set of primers recognizing families of $V_{\alpha}$ genes (Buenafe et al., 1997) and a reverse primer binding within the constant region of the TCR $\alpha$-chain (Fig. 3.9 D). The resulting PCR products were sequenced and only the V $\alpha 13-P C R$ fragment, which showed the highest homology to the mouse $V_{\alpha} 15$ segment, sequence (V $\alpha 13-\mathrm{J} \alpha \mathrm{N}$ $\mathrm{C} \alpha$ ) was in frame for clonoid \#15 (Fig. 3.9 E and F) as was $V_{\alpha} 3$ for clonoid \#18 (V $\alpha 3-J \alpha N N-$ $\mathrm{C} \alpha$ ). After this we could design primers to amplify the full-length TCR $\alpha$ chains. TCR $\alpha$ and TCRB coding sequences were then combined with EGFP in a tricistronic cassette and inserted into a lentivirus as described earlier for the MBP-specific TCR (Fig. 3.1 C).

As for the MBP-specific receptor we tested the antigenic response in a TCR-negative hybridoma cell line (derived from mouse a BW 58C thymoma line) infected with concentrated lentiviral preparation. Analysis of GFP and surface TCR-V $\beta 16$ expression showed that about $20 \%$ of the hybridoma cells expressed both proteins (Fig. 3.9 G). Coculture of infected hybridomas with thymic Lewis rat APCs in the presence of antigens revealed a dose-dependent induction of mouse IL-2 in response to the specific antigen OVA but not to MBP (Fig. 3.9 H). Although both constructs appeared to confer the correct specificity, the TCR variant of clonoid \#15 might possess a higher affinity as the response 
was evident at a lower concentration of OVA than for the TCR construct derived from clonoid \#18. Thus, the TCR construct of clonoid \#15 was used for the generation of OVAspecific TCR transgenic rats.

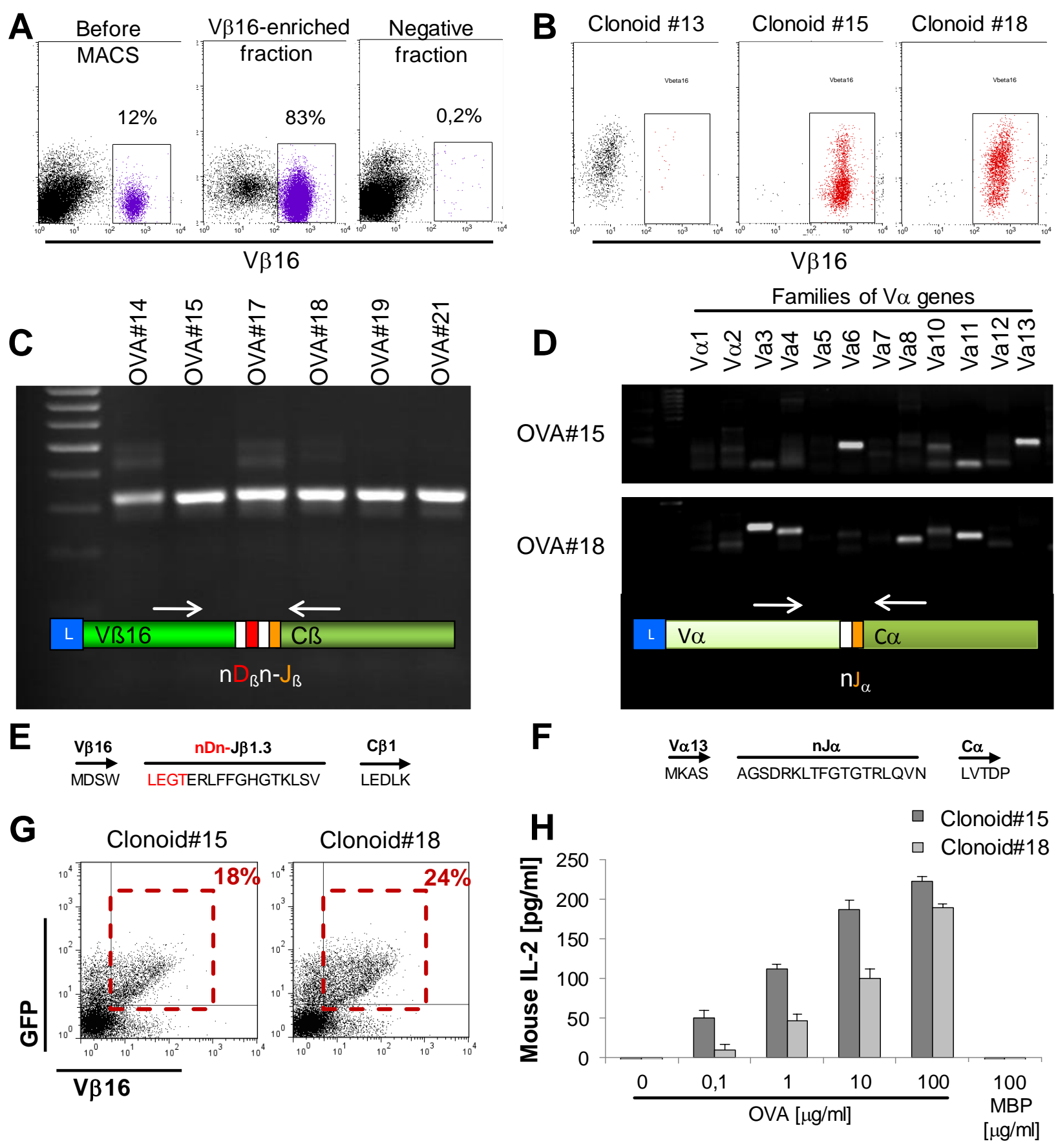

Figure 3.9: Generation and sequencing of OVA-specific T cell clonoids. (A) FACS analysis of polyclonal OVA-specific T cells before and after MACS enrichment for V $\beta 16$ (B) FACS analysis of OVA-specific $T$ cell clonoids after expansion from single-cell cultures for V $\beta$ 16. (C) PCR results for V $\beta 16$ gene expression in different OVA-specific $T$ cell clonoids with the indicated primers. (D) PCR results for $V \alpha$-chain gene expression in OVA-specific $T$ cell clonoids \#15 and \#18 with the indicated primer sets. $(E+F)$ Amino acid sequence for $V \alpha 13$ and $V \beta 16$ of clonoid \#15. (G) FACS analysis for GFP and V $\beta 16$ surface expression of lentivirally transduced TCR-negative BW 58C hybridoma. (H) Results of mouse IL-2 ELISA assay performed on supernatants from hybridoma transduced with TCR\#15 and TCR\#18 constructs and stimulated with different concentrations of ovalbumin or with MBP as a negative control. Graphs depicted as Mean \pm SEM. 
Generation of TCR transgenic Lewis rats was achieved by injecting lentiviral concentrate into fertilized Lewis rat oocytes. Embryos which developed into a two-cell stage were transferred into pseudopregnant Wistar rat recipients. Rat pups were genotyped and phenotyped three weeks after birth. For genotyping, genomic DNA was used as a PCR template with primers binding within the P2A sequence and the variable segment of the V $\beta 16$ chain (Fig. 3.10 A). FACS analysis of blood cells showed that GFP and the V $\beta 16$ chain were expressed in peripheral T cells of some founder animals (Fig. 3.10 B).

Founder animals PCR-positive for integration of the provirus were mated among each other and the $\mathrm{F} 1$ generation was again phenotyped by analyzing blood lymphocytes three weeks after birth. In the F1 generation, all $\mathrm{CD} 4^{+} \mathrm{T}$ cells expressed GFP and showed an increased proportion of $\mathrm{V} \beta 16^{+}$(50-60\% of $\mathrm{T}$ cells, data not shown). The new Lewis strain was

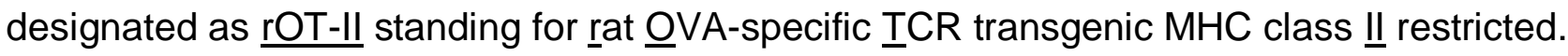
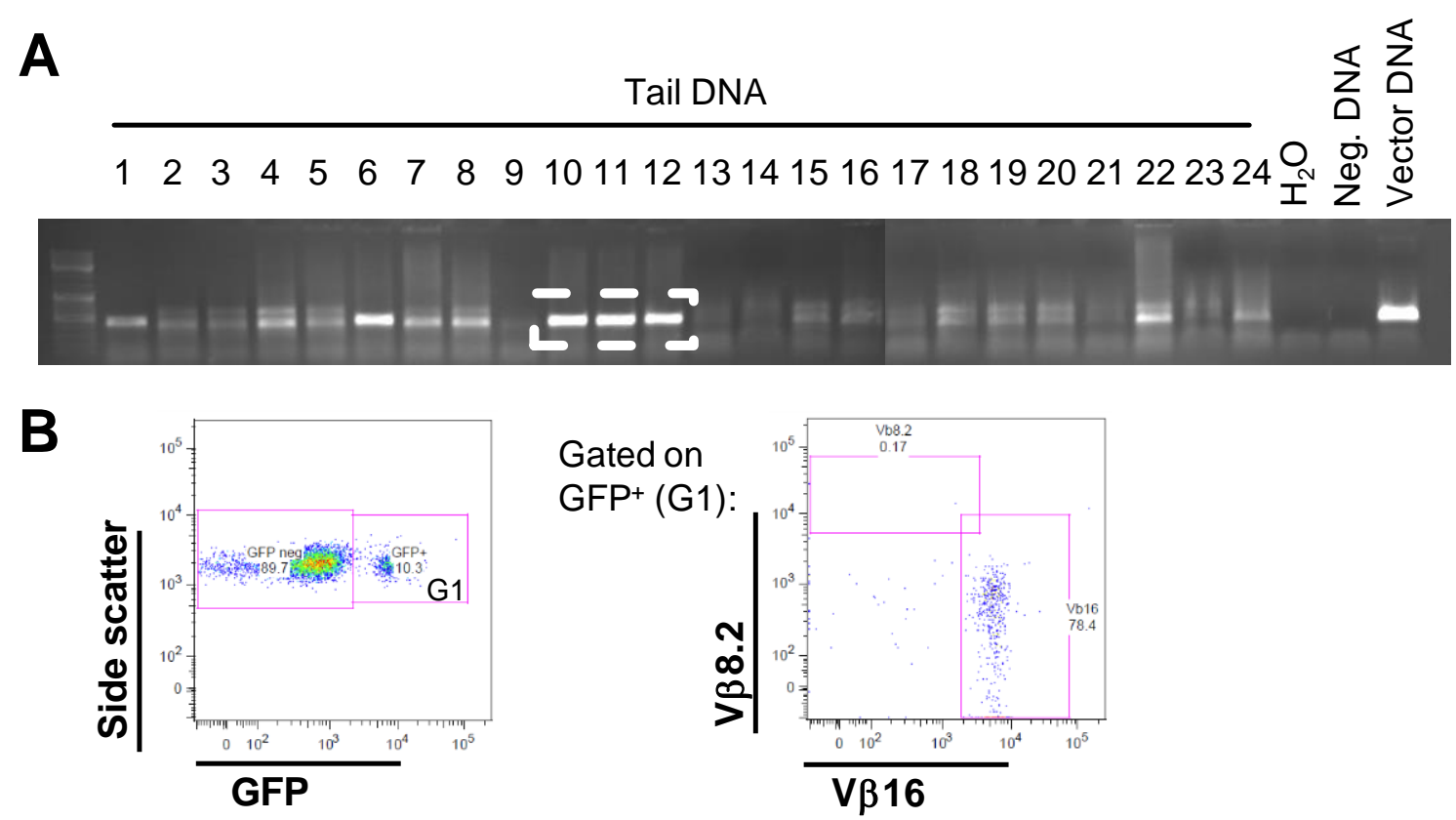

Figure 3.10: Founder analysis of OVA-specific TCRtg rats. (A) PCR analysis of genomic tail DNA of founder animals. (B) FACS analysis of blood cells from founder animal no. 12 (A), stained with mAb specific for TCR-VB8.2 and TCR-VB16 (transgenic chain). Data shown in (B) were generated by Dr. Henrike Fischer, Department of Immunology, laboratory of Prof. Holger Reichardt. 
Similar to the rMT-II strain, the levels of GFP- and TCR-V $\beta 16$-expression in the peripheral blood $T$ cells and the manner of their inheritance were indicative of wild type (WT), heterozygous $\left(\right.$ rOT- $\mathrm{II}^{+/}$) and homozygous $\left(\right.$rOT- $\mathrm{II}^{+/+}$) genotypes. In contrast to the $\mathrm{rMT}-\mathrm{II}$ strain, we were not able to obtain progenies from pairs of homozygous breeders. Whereas rOT- $\mathrm{II}^{+/+}$males were fertile when crossed to a WT Lewis partner, the fertility of $\mathrm{rOT}-\mathrm{II}^{+/+}$ females appeared to be compromised, possibly due to a genomic effect of viral integration.

\subsubsection{EXPRESSION OF GFP AND THE TRANSGENIC TCR IN ROT-II RATS}

Blood, spleens and lymph nodes of WT, rOT- $\mathrm{II}^{+/-}$and $\mathrm{rOT}-\mathrm{II}^{+/+}$rats were analyzed for GFP expression. As previously described for rMT-II rats, the GFP expression was higher in homozygous rOT- $-\mathrm{II}^{+/+}$rats compared to heterozygous rOT- $-\mathrm{II}^{+/}$rats. Myeloid cells and T cells from rOT- $\mathrm{II}^{+/+}$rats express a higher level of GFP than B cells (Fig. 3.11 A).

In both $\mathrm{rOT}-\mathrm{II}^{+/-}$and $\mathrm{rOT}-\mathrm{II}^{+/+}$animals the percentages of TCR-V $\beta 16$-positive cells were significantly increased (Fig. 3.11 B and C). In blood, about $10 \%$ of WT T cells expressed the $\mathrm{V} \beta 16$-chain. The proportion of TCR-V $\beta 16^{+}$lymphocytes reached $72 \%$ and $90 \%$ in rOT$\mathrm{II}^{+/-}$and rOT- $\mathrm{II}^{+/+}$rats, respectively (Fig. 3.11 B and C). In lymph nodes, these values were $12 \%$ for WT, $62 \%$ for rOT- $\mathrm{II}^{+/-}$and $95 \%$ for $\mathrm{rOT}^{-\mathrm{II}^{+/+}}$rats. V $\beta 16$-positive T cells could be further divided into a TCR ${ }^{\text {medium }}-\mathrm{V} \beta 16^{\text {high }}$ and a $\mathrm{TCR}^{\text {high }}-\mathrm{V} \beta 16^{\text {medium }}$ fraction (indicated in red and purple gates in Fig. $3.11 \mathrm{~B}$ ). $\mathrm{rOT}_{-1 \mathrm{II}^{+/+}}$rats showed a strong preponderance of the $\mathrm{TCR}^{\text {medium }}-\mathrm{V} \beta 16^{\text {high }}$ population. Whereas $\mathrm{rOT}-\mathrm{II}^{+/-}$rats still expressed a "endogenous" $\mathrm{V} \beta 16^{\text {high }}$ population analogous to the one in WT littermates, $\mathrm{rOT}-\mathrm{II}^{+/+}$rats did not possess

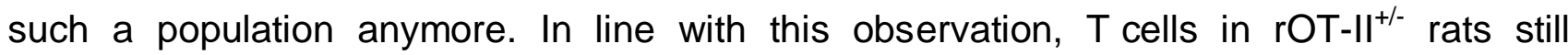
expressed other endogenous $\mathrm{V} \beta$ chains $(\mathrm{V} \beta 8.5$ and $\mathrm{V} \beta 8.2)$ which were strongly diminished in $\mathrm{rOT}-\mathrm{II}^{+/+}$rats (Fig $3.11 \mathrm{~B}$ and $\mathrm{C}$ ). 

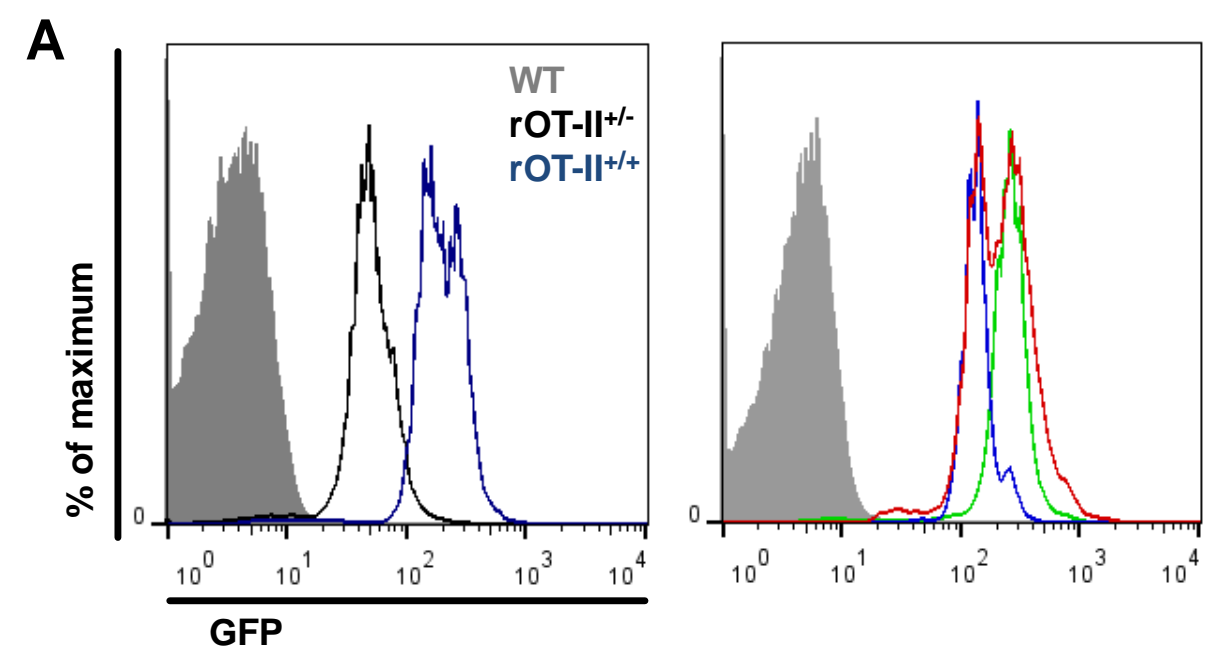

WT Lymphocytes

$B$ cells $\left(O X-33^{+}\right)$

T cells $\left(\mathrm{abTCR}^{+}\right)$

Myeloid cells (OX-42+)

B

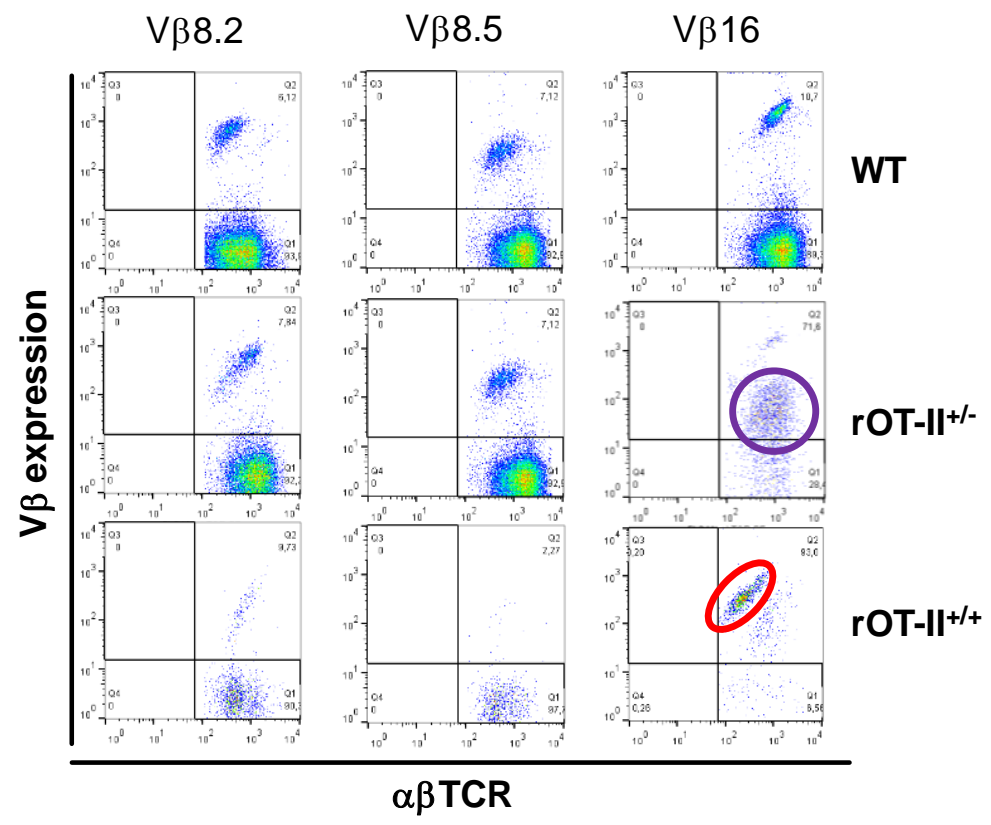

C

Blood

Lymph nodes

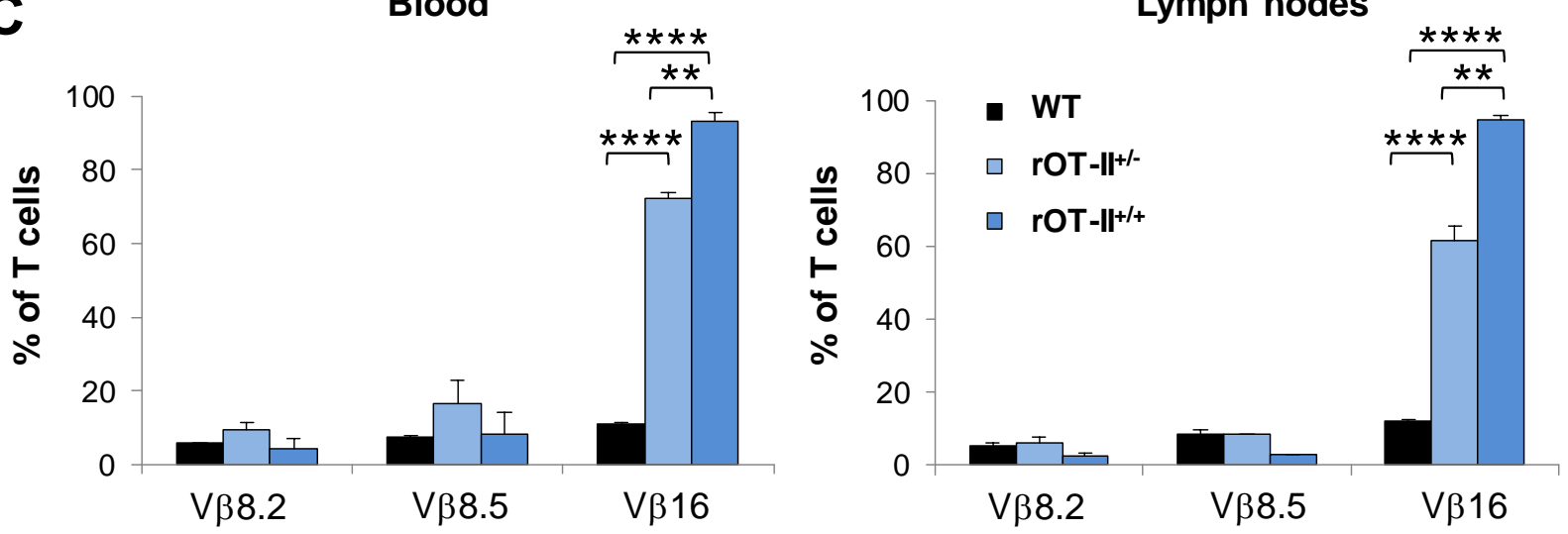

Figure 3.11: Analysis of GFP and V $\beta$ 16-expression in rOT-II rats. (A) GFP-expression niveau in lymphocytes of wild type, rOT-II $^{+/-}$ and $\mathrm{rOT}^{-\mathrm{II}^{+/+}}$Lewis rats. (B) GFP-expression niveau in lymphocyte subsets of rOT- $\mathrm{II}^{+/+}$Lewis rats. (C) FACS plots depicting expression of $\mathrm{V} \beta$-chains in blood of $\mathrm{WT}$, rOT- $-\mathrm{I}^{+/-}$and rOT-II ${ }^{+/+}$rats. In rOT-II rats, two populations of TCR transgenic $\mathrm{T}$ cells could be identified: $T C R^{\text {medium }}-\mathrm{V} \beta 16^{\text {high }}$ (red circle) and a $T_{C R} R^{\text {high }}-V_{\beta} 16^{\text {medium }}$ (purple circle). (D) Quantification of $V_{\beta} 16^{+} T$ cells in blood and lymph nodes of WT, $\mathrm{rOT}^{-\mathrm{II}^{+/}}$and $\mathrm{rOT}-\mathrm{II}^{+/+}$rats. (C) and (D) gated on $\mathrm{GFP}^{+}$lymphocytes. $\mathrm{n}=3$ per genotype. Graphs depicted as Mean \pm SEM. 
Analysis of total cell numbers in the thymus and peripheral lymphoid organs showed that rOT-II animals were lymphopenic. In the lymph nodes of rOT- $\mathrm{I}^{+-}\left(216 \times 10^{6} / \mathrm{g}\right.$ organ) and rOT- $^{+/++}\left(234 \times 10^{6} / \mathrm{g}\right.$ organ $)$ rats cellularity was reduced compared to WT rats (586 $\times 10^{6} / \mathrm{g}$ organ). The same trend could also be observed in thymus and spleen but not in blood of rOT-Il rats (Fig. 3.12 A).

FACS analysis of the lymphocyte composition showed a reduced number of $\mathrm{T}$ cells in lymph nodes (WT $75 \%$, rOT- $-\mathrm{II}^{+/-} 46 \%$, rOT- $\mathrm{II}^{+/+} 53 \%$ ) and a significant reduction in the

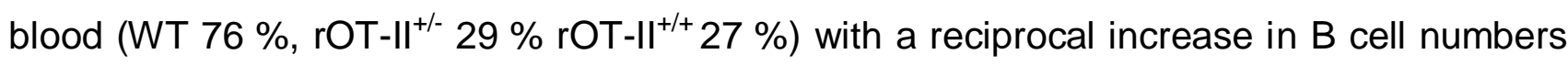
to around $40 \%$ in lymph nodes and $50 \%$ in blood of both $\mathrm{rOT}-\mathrm{II}^{+/-}$and $\mathrm{rOT}^{-\mathrm{II}^{++}}$rats. This manifested itself as a reduction of the T/B cell ratio in both $\mathrm{rOT}-\mathrm{II}^{+/-}$and $\mathrm{rOT}_{-} \mathrm{II}^{+/+}$rats (Fig. 3.12 B and C).

To address whether the development of T cells was altered in rOT-II rats, we analyzed thymi for the expression of CD4 and CD8 surface markers. A pronounced reduction of $\mathrm{CD}^{+} \mathrm{SP}$ thymocytes was found in $\mathrm{rOT}^{-\mathrm{II}^{+-}}$thymus resembling thymic CD4/CD8 pattern of $\mathrm{rMT}^{-\mathrm{II}^{+/}}$animals (Fig. 3.12 D and Fig. 3.3 D). This however again did not result in a peripheral CD4/CD8 imbalance as $75 \%$ of rOT- $\mathrm{II}^{+-}$LN T cells were CD4 ${ }^{+}$(Fig. $3.12 \mathrm{E}$ ).

Thymic development was severely disturbed in $\mathrm{rOT}-\mathrm{II}^{+/+}$rats. This was presented as a depletion of $\mathrm{CD}^{+} \mathrm{SP}$ and DP populations with prominent accumulation of thymocytes at the DN (up to $50 \%$ ) and $\mathrm{CD}^{+} \mathrm{SP}$ stages (25-30\%, Fig. $3.12 \mathrm{D}$ ). Unexpectedly, the peripheral T cell repertoire in $\mathrm{VOT}_{-} \mathrm{II}^{+/+}$animals was dominated by CD8 ${ }^{+}$SP cells $(70-80 \%$, Fig. $3.12 \mathrm{E})$. 


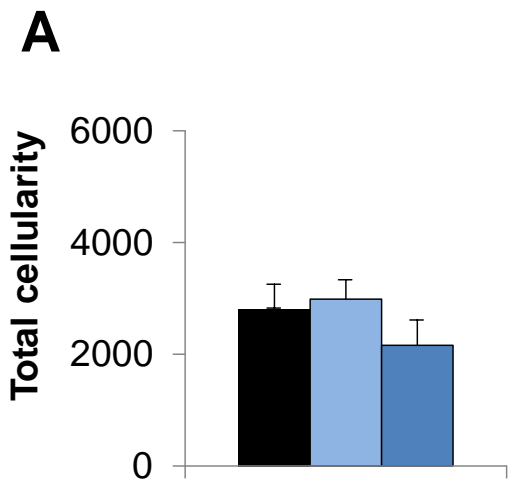

Thymus

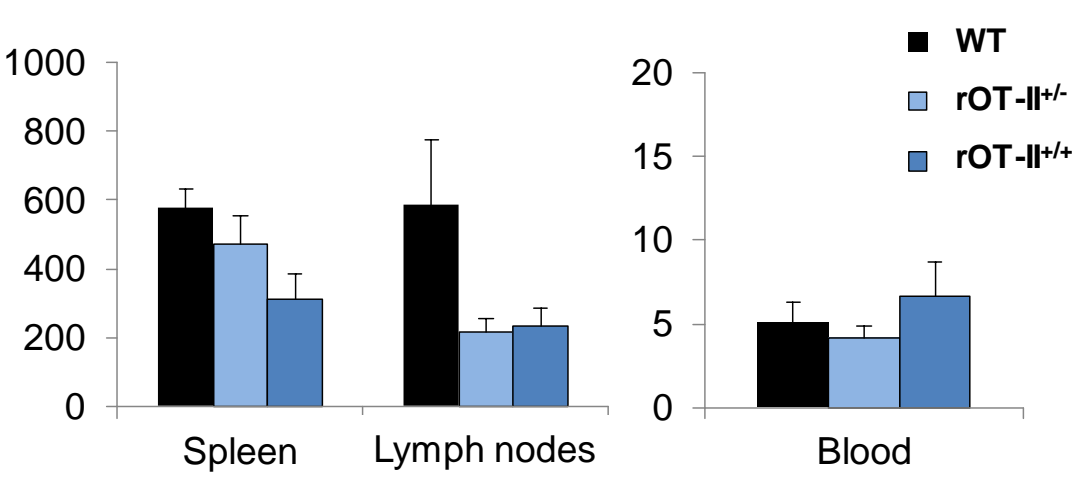

B
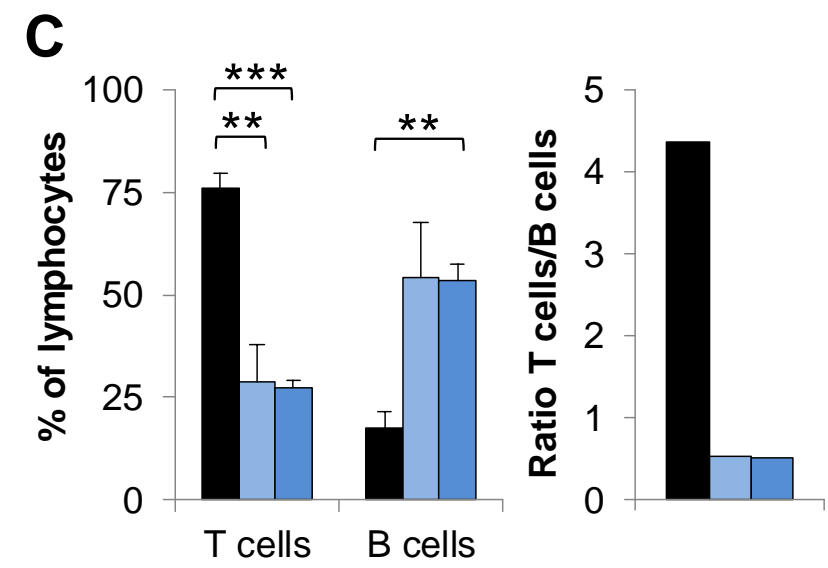

D
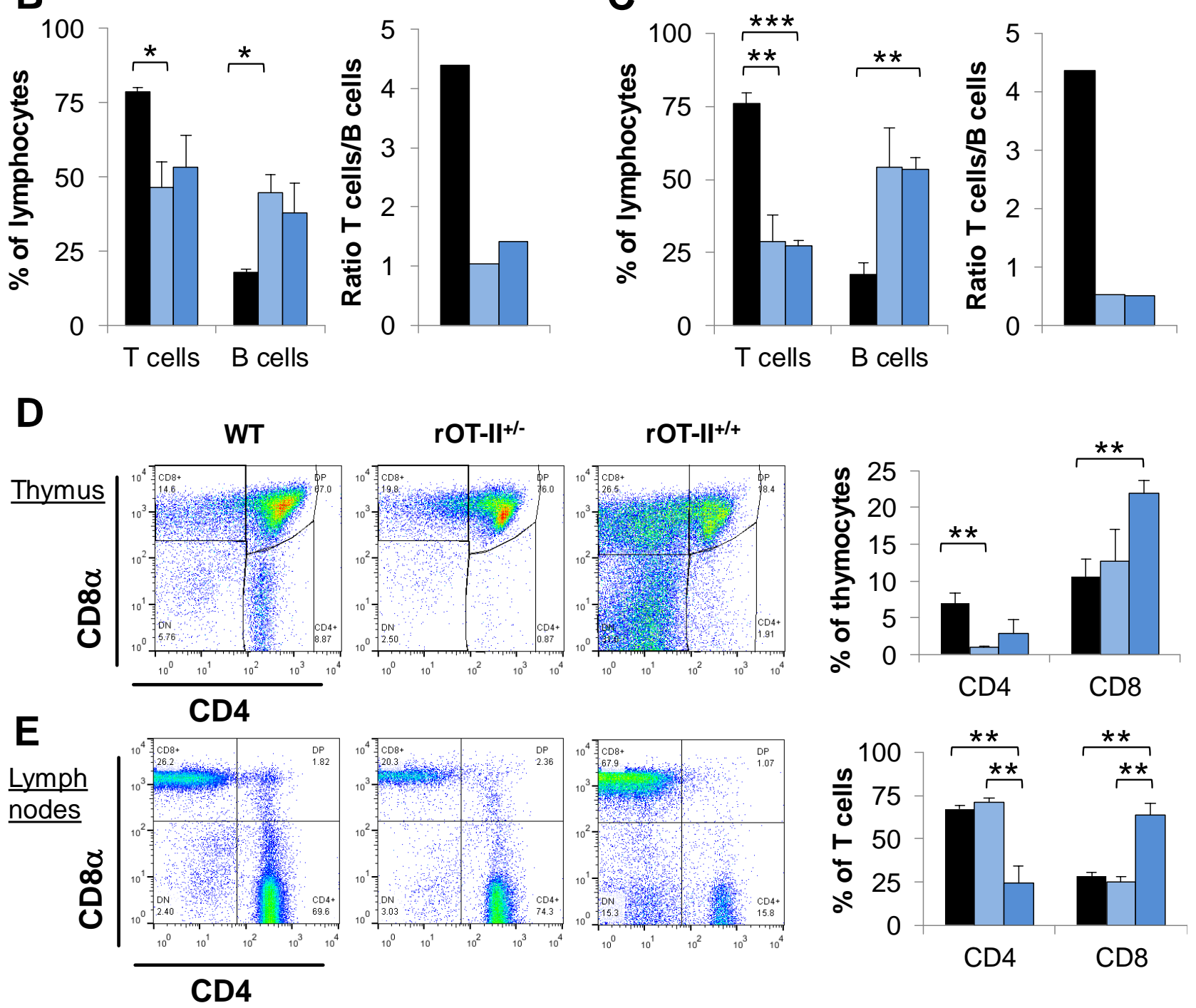

Figure 3.12: (A) Total cellularity of different lymphoid organs was determined by cell counting. Shown are numbers per g of organ or $\mathrm{ml}$ of blood in millions of cells. Percentages of GFP ${ }^{+} \mathrm{T}$ cells and B cells in lymph nodes (B) and blood (C) determined by flow cytometry. (D,E) Representative FACS plots of CD4/CD8 stained cells isolated from the thymus (D) and lymph nodes (E). Quantification of CD4/CD8 expressing GFP ${ }^{+}$lymphocytes depicted on the right. $\mathrm{n}=3$ per genotype. Graphs depicted as Mean \pm SEM. Color code for genotypes (A) applies also to (B-E). 
Analysis of the CD4 ${ }^{-C D} 8^{-}$DN population of thymocytes revealed that a developmental block in $\mathrm{rOT} \mathrm{II}^{+/+}$thymus is likely to occur at the DN2 stage (CD25+ CD44 ${ }^{+}$, Fig. $\left.3.13 \mathrm{~A}\right)$. Notably, a clear expression of the $\alpha \beta T C R$ by the majority of DN cells was evident in both rOT-II and rMT-II strains (Fig. 3.13 B-C). This however did not result in an obvious DN block in developing rMT-II thymocytes (Fig. 3.13 A, see also Fig. 3.3 D).

Closer analysis of CD8 T cells from lymph nodes of $\mathrm{rOT}-\mathrm{Il}^{+/+}$rats indicated that those were not a developmentally subverted CD8 $\alpha \alpha$ population but expressed also a CD8 $\beta$ chain as the majority of $\mathrm{CD}^{+} \mathrm{T}$ cells did in WT animals (Fig. $3.13 \mathrm{D}$ ).
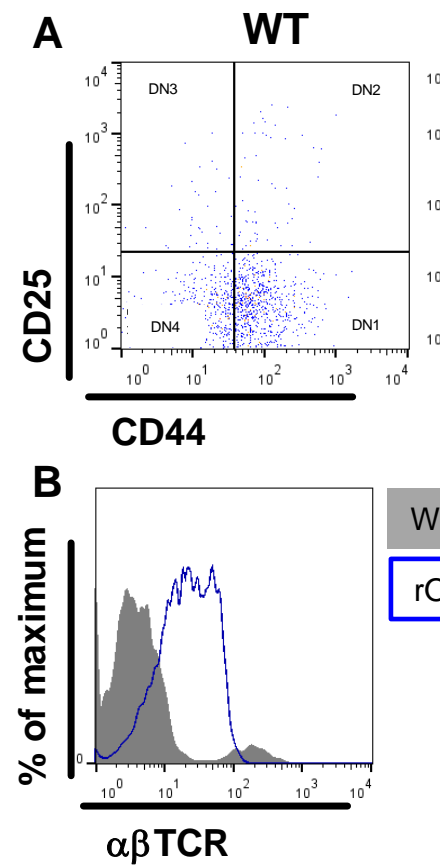
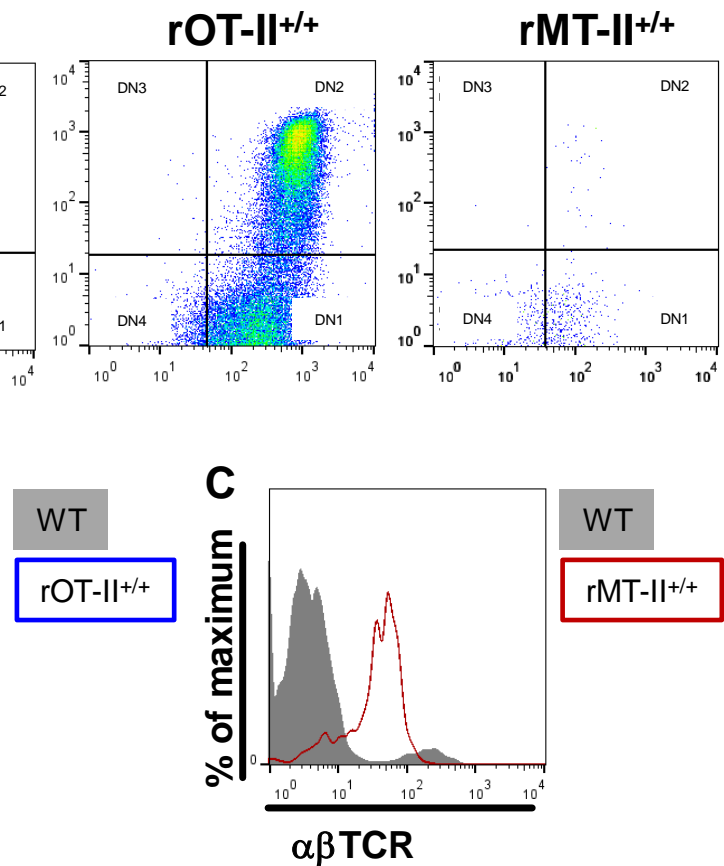
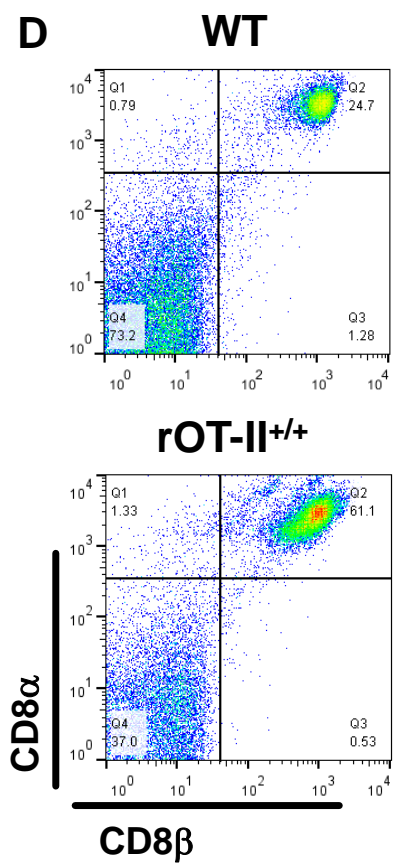

Figure 3.13: FACS analysis of aberrant T cell populations in rOT- $\mathrm{II}^{+/+}$host. The CD25/CD44 (A) and $\alpha \beta T C R(B, C)$ expression in DN thymocytes of TCRtg and WT rats. (D) Coexpression of CD8 $\alpha$ and CD8 $\beta$ chains in T cells isolated from lymph nodes of WT and rOT-II+/+ rats.

\subsubsection{REDUCED PROPORTION OF NAÏVE T CELLS IN rOT-II RATS}

To characterize the distribution of naïve and memory rOT-II T cells, lymph node and blood cells were stained for the expression of $L$-selectin (CD62L).

In $\mathrm{CD}^{+}$and in $\mathrm{CD}^{+} \mathrm{T}$ cells of WT rats, the distribution of naïve versus memory $\mathrm{T}$ cells was similar. In $\mathrm{CD}^{+} \mathrm{T}$ cells of $\mathrm{rOT}_{-1 I^{+-}}$and $\mathrm{rOT}-\mathrm{II}^{+/+}$rats this distribution was clearly shifted towards CD62L-negative population. More CD62L' T cells were detected among CD8 ${ }^{+}$rOT$\mathrm{II}^{+/-} \mathrm{T}$ cells as well. More naïve $\mathrm{T}$ cells were present in lymph nodes in relation to memory $\mathrm{CD}^{+} \mathrm{T}$ cells of $\mathrm{rOT}-\mathrm{II}^{+/+}$rats. Altogether a strong reduction of naïve $\mathrm{CD}^{2} 2 \mathrm{~L}^{+} \mathrm{T}$ cell numbers was observed in rOT-II ${ }^{+/+}$rats (Fig. 3.14). 


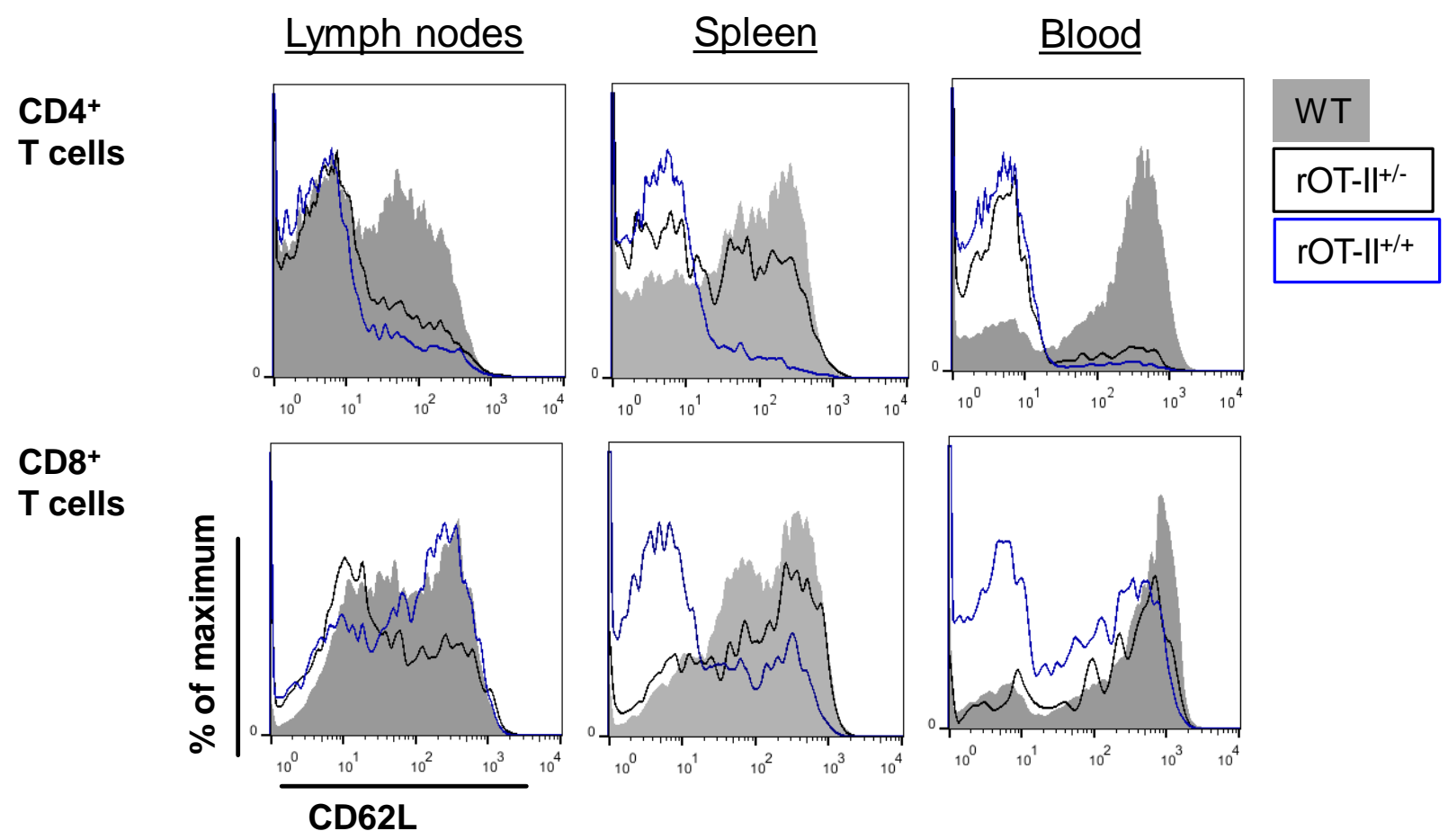

Figure 3.14: Analysis of numbers of naïve T cells in rOT-Il strain. Histograms of CD62L surface expression on CD4 and CD8 $\mathrm{T}$ cells in lymph nodes, spleen and blood of $\mathrm{rOT}-\mathrm{II}^{+/-}$and $\mathrm{rOT}-\mathrm{II}^{+/+}$rats compared to WT littermates are shown.

\subsubsection{NK CELLS AND $\gamma \delta$ T CELLS IN rOT-II ANIMALS}

In line with our observations made in rMT-II rats, expression of the rOT-II transgene had an effect on relative numbers of NK and $\gamma \delta T$ cells. Both heterozygous and homozygous rOT-II rats possessed increased numbers of NK cells in lymph nodes (Fig. 3.15 A) and in the blood whereas the number of NK T cells is similar to WT. For rMT-II transgenic rats it was shown in Figure $3.4 \mathrm{~B}$ that the number of $\gamma \delta \mathrm{T}$ cells war reduced in both blood and lymph nodes. In rOT-II animals, the reduction of $\gamma \delta$ T cells in lymph nodes ranges from $1.5 \%$ in WT rats to $0.3 \%$ in rOT- $-\mathrm{Il}^{+/-}$rats and further to $0.1 \%$ in rOT- $\mathrm{II}^{+/+}$rats (Fig. $3.15 \mathrm{~B}$ ).

A

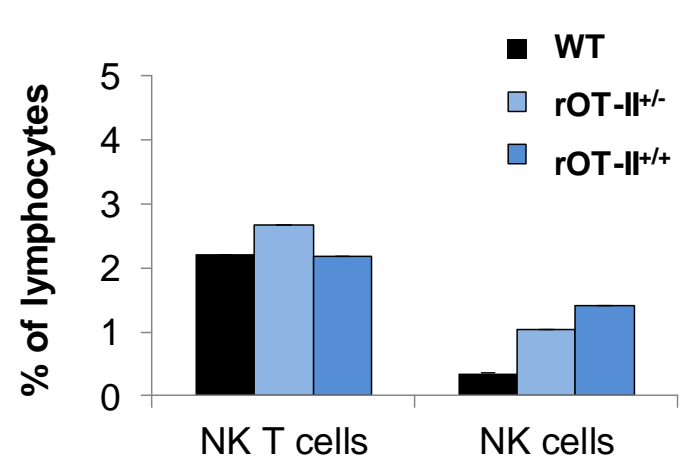

B

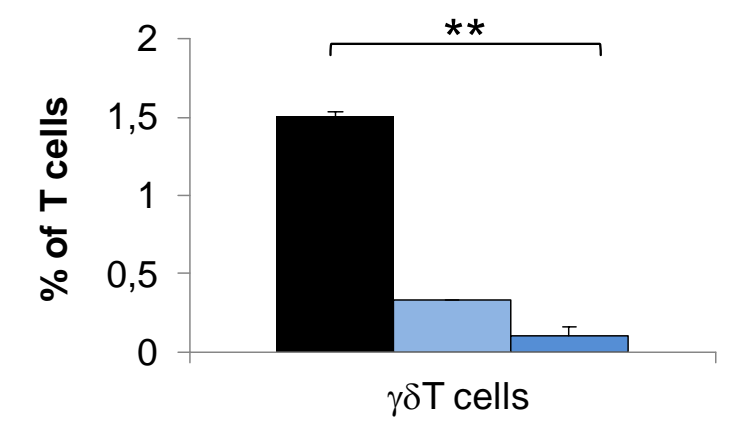

Figure 3.15: Quantification of FACS analysis for NK cell and $\gamma \delta$ T cell markers. (A) Percentage of NK and NK T cells in lymph nodes. (B) Percentage of $\gamma \delta \mathrm{T}$ cells in the lymph nodes gated on $\mathrm{CD}^{+} \mathrm{GFP}^{+}$cells. $\mathrm{n}=3$ per genotype. Data are Mean $\pm \mathrm{SEM}$ 


\subsubsection{7 $\mathrm{rOT}^{-\mathrm{II}^{+/+}}$T CELLS RESPOND TO OVALBUMIN EX VIVO}

Lymph node cells of $\mathrm{rOT}-\mathrm{II}^{+/-}$rats and $\mathrm{rOT}-\mathrm{II}^{+/+}$rats were stimulated with different concentrations of OVA protein. We also tested the response to the $\mathrm{OVA}_{323-339}$ peptide, which is the immunodominant ovalbumin antigen in Lewis rats. As shown in Figure 3.17 A, lymphocytes derived from $\mathrm{rOT}_{-1 \mathrm{II}^{++}}$rats readily proliferated upon OVA protein and $\mathrm{OVA}_{323-339}$ challenge in a dose-dependent manner. Proliferation was completely blocked by treatment with OX-6 mAb specific for the rat RT1.B complex (MHCII). Additionally, the IFN level in the supernatant of stimulated lymphocytes was measured by ELISA and revealed a dose-dependent production of IFN $\gamma$ in response to OVA (Fig. 3.17 B). Intracellular staining

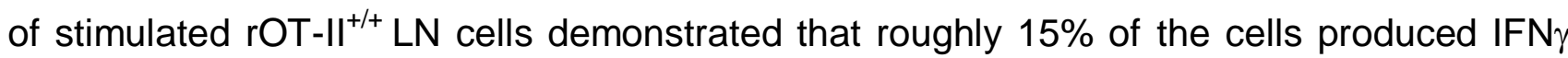
and other $5 \%$ produced IL-17 when stimulated with a high amount of antigen (Fig. 3.17 C and D). Production of IFN $\gamma$ could be abrogated by OX-6 treatment.

rOT- $\mathrm{II}^{+/+}$lymphocytes were challenged with $10 \mu \mathrm{g} / \mathrm{ml}$ of OVA and the RNA was isolated at different time points to determine the kinetic of the transcriptional response induced by antigenic stimulation. This analysis showed a high induction of IFN $\gamma$ mRNA that peaked at $18 \mathrm{~h}$ after stimulation. At this time point, maximal level were detected also for TNF $\alpha$ and IL2 mRNA (Fig. 3.16). In vitro stimulation of lymphocytes resulted in a fast upregulation of CXCR3 and CCR7 mRNA - two molecules important for T cell migration - within 6 hours after stimulation.

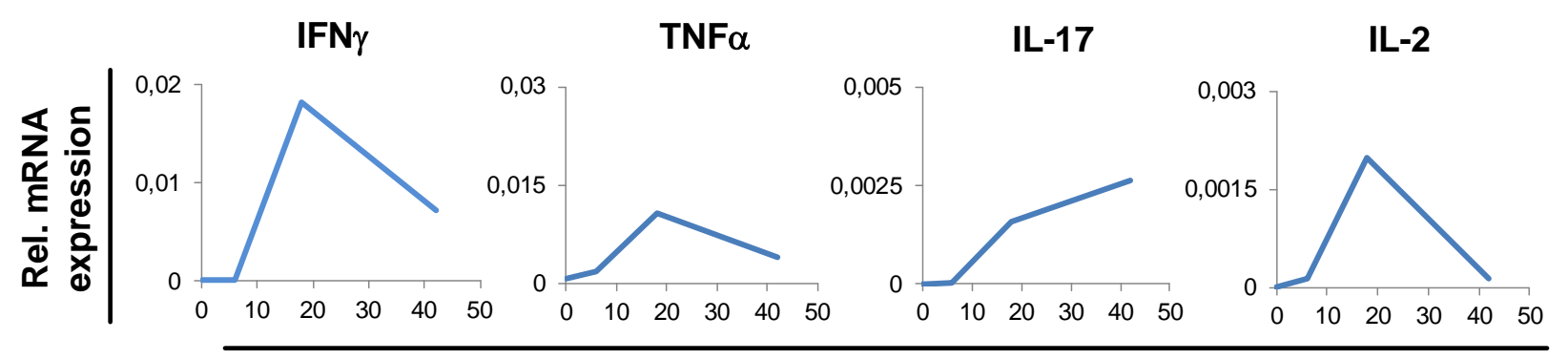

Time after stimulation [h]

CXCR3

CCR7

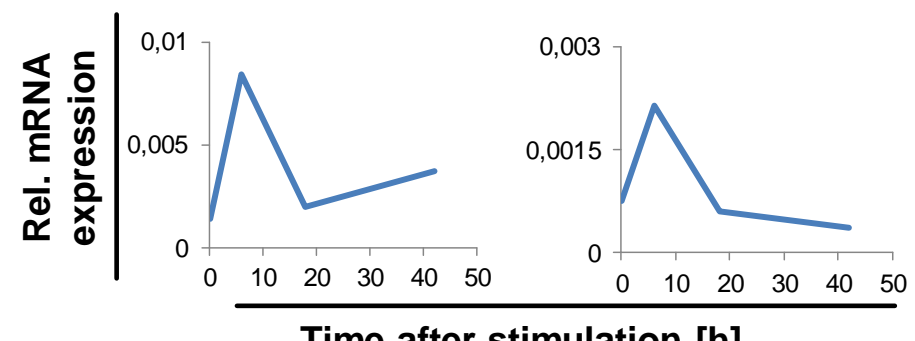

Time after stimulation [h]

Figure 3.16: Kinetic of transcriptional activation in rOT-II ${ }^{+/+}$LN T cells. mRNA expression level of proinflammatory cytokines IFN $\gamma$, IL-17, IL-2 and TNF $\alpha$ and chemokine receptors CXCR3 and CCR7 were determined after stimulation with $10 \mu \mathrm{g} / \mathrm{ml}$ OVA protein. Relative mRNA expression normalized to $\beta$-actin expression level is shown. 

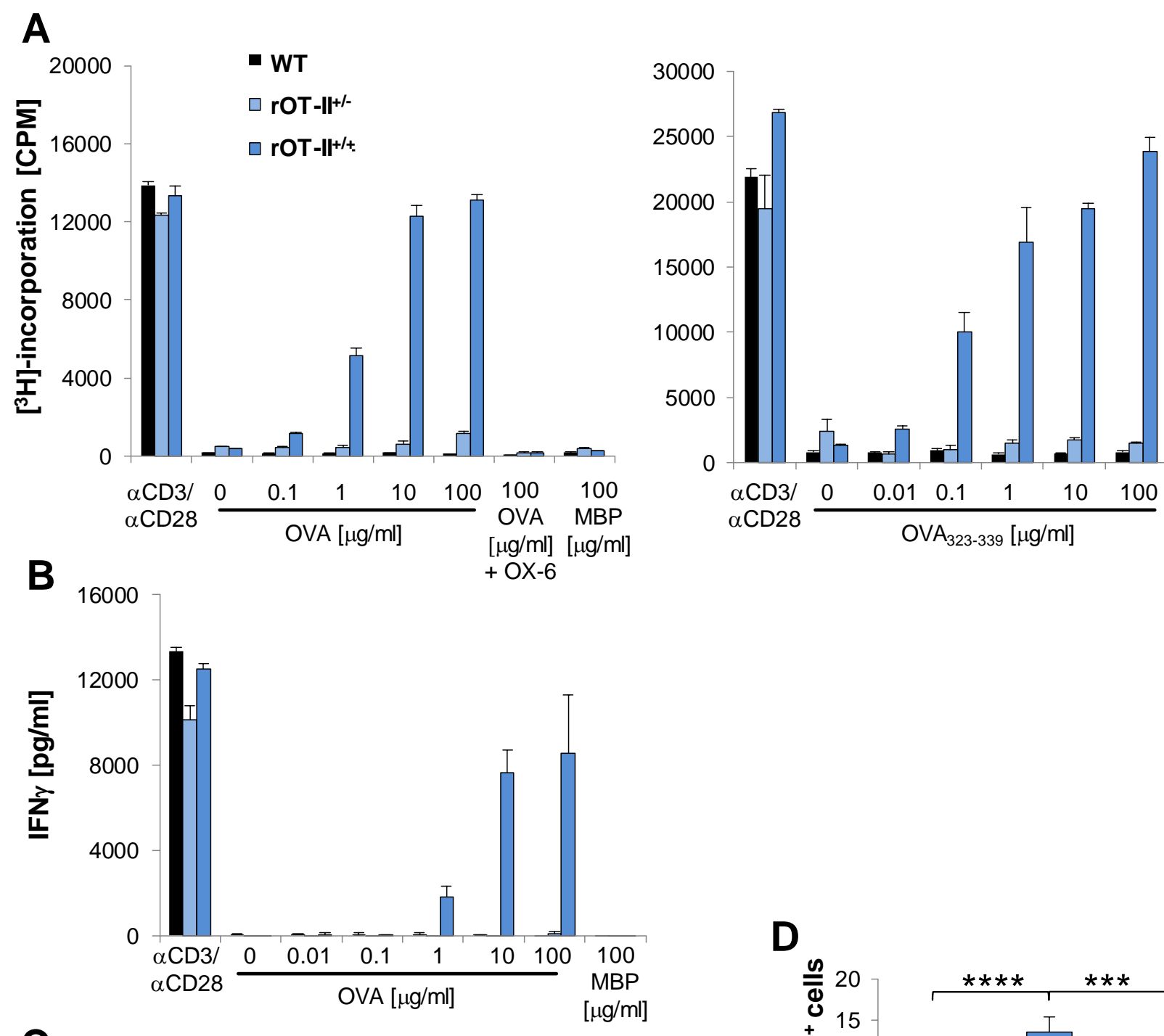

C
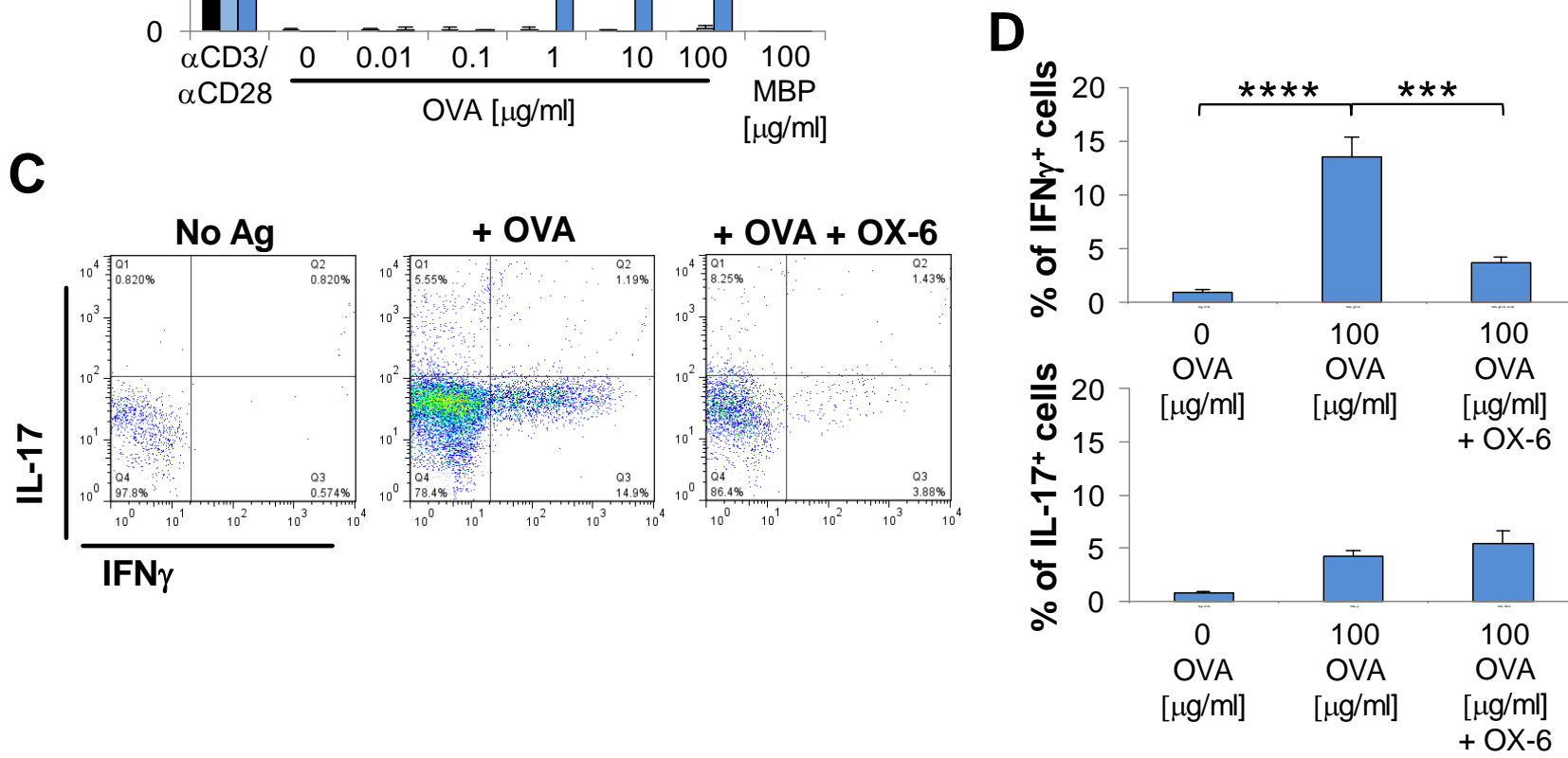

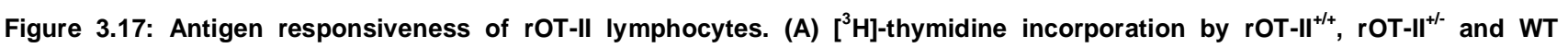
lymphocytes stimulated with OVA protein and $\mathrm{OVA}_{323-339}$ peptide measured $48 \mathrm{~h}$ after stimulation. (B) IFN $\gamma$ production determined by ELISA of supernatants form lymphocytes stimulated with OVA for $48 \mathrm{~h}$. (C) Production of IFN $\gamma$ and IL-17 by stimulated lymphocytes assessed by intracellular staining and flow cytometry. (D) Quantification of cytokine positive cells. Graphs depicted as Mean \pm SEM. 
The majority of $\mathrm{T}$ cells in $\mathrm{LNs}$ of $\mathrm{rOT}^{-\mathrm{II}^{+/+}}$rats are $\mathrm{CD}^{+} \mathrm{T}$ cells (Fig. 3.12 E). However, the proliferation and induction of IFN $\gamma$ was abolished by blocking the MHC class II molecules. Thus, the detected antigen response could be mediated solely by a minority of CD4 ${ }^{+}$rOT$\mathrm{II}^{+/+} \mathrm{LN}$ cells. To address the reactivity of $\mathrm{CD}^{+}$and $\mathrm{CD}^{+}$subsets, we depleted mixed a population of $\mathrm{LN}$ cells of either $\mathrm{CD}^{+}$or $\mathrm{CD}^{+} \mathrm{T}$ lymphocytes by magnetic separation and restimulated them with OVA protein. Interestingly, both CD4- and CD8-depleted lymphocytes proliferated and produced IFN $\gamma$ upon antigen challenge in a dose-dependent manner (Fig. 3.18 A and B). CD8-depleted lymphocytes (= CD4 ${ }^{+} \mathrm{T}$ cells) reacted to the antigen at a lower concentration than CD4-depleted lymphocytes (= CD8 ${ }^{+} \mathrm{T}$ cells).

CD4- or CD8-depleted lymphocytes were subcutaneously injected into the hind limb of naïve recipients. $16 \mathrm{~h}$ post transfer the recipients were immunzied with either OVA or MBP at the same location and 3 days later the in vivo expansion (cell number) of the transferred T cells was determined in the draining LNs by flow cytometry. Both CD4- and CD8-depleted lymphocytes proliferated upon immunization with OVA in the draining LN (Fig. $3.18 \mathrm{C}$ ).
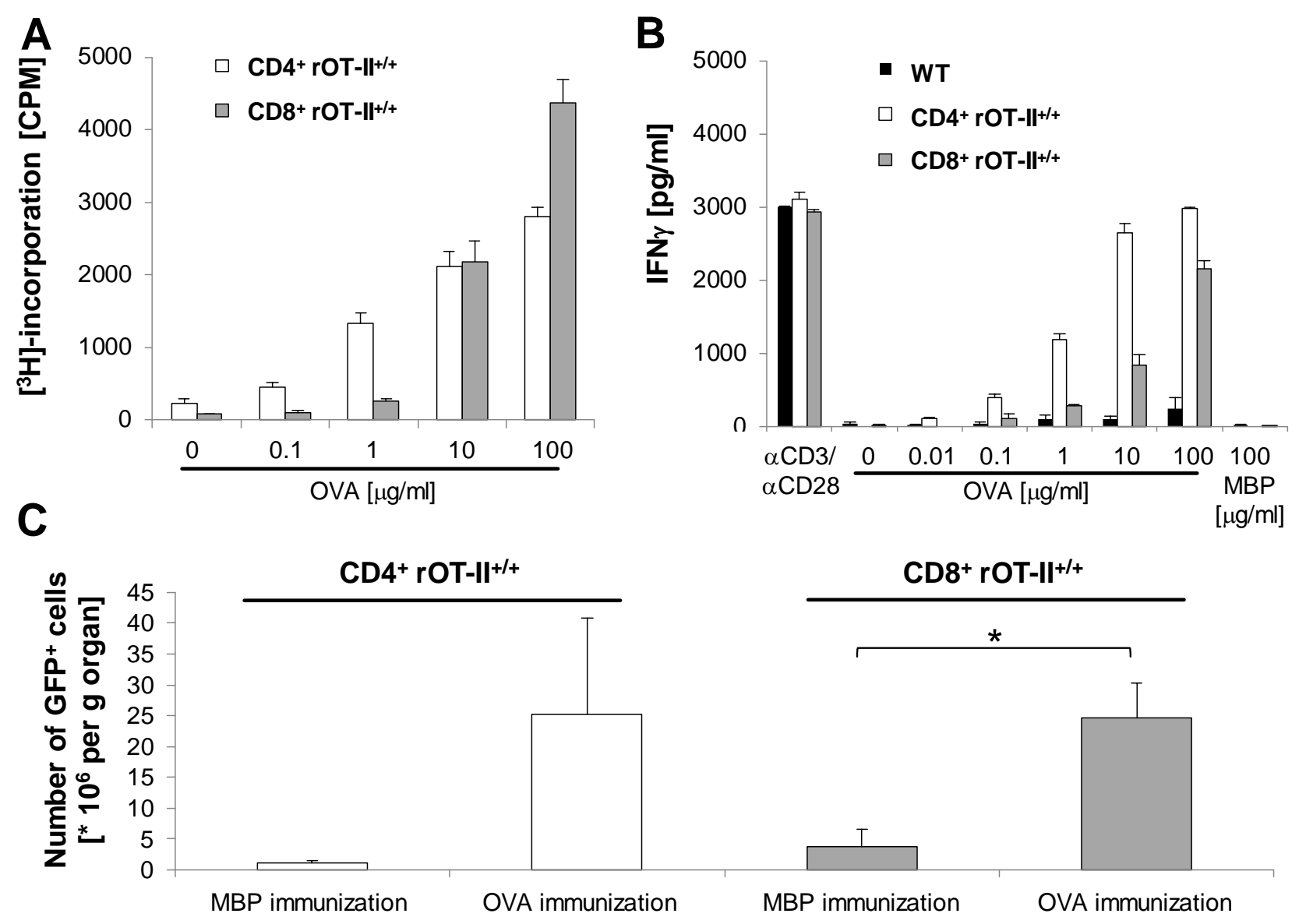

Figure 3.18: Antigen responses of $\mathrm{CD}^{+}$and $\mathrm{CD} 8^{+}$rOT- $\mathrm{II}^{+++} \mathrm{T}$ cells after MACS separation. (A) $\left.{ }^{3} \mathrm{H}\right]$-incorporation of $\mathrm{CD}^{+}$and $\mathrm{CD}^{+}$rOT-II $^{+/+} \mathrm{T}$ cells stimulated with OVA in vitro for $48 \mathrm{~h}$. (B) Concentration of IFN $\gamma$ determined by ELISA in supernatants of

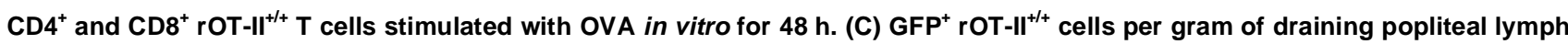
node after separated $\mathrm{CD}^{+}$or $\mathrm{CD}^{+}{ }^{+} \mathrm{rOT}_{-} \mathrm{II}^{+/+} \mathrm{T}$ cell transfer 3 days after immunization in vivo. Graphs depicted as Mean $\pm \mathrm{SEM}$. 


\subsection{1 rMT-II RATS DEVELOPED ACTIVE EAE WITH AN ACCELERATED DISEASE} ONSET

rMT- $^{+I^{++}}$rats were observed for a time period longer than one year. The rats did not develop EAE spontaneously. Furthermore, we have not found any subclinical T cell or other immune cell infiltration into the CNS of transgenic animals by FACS analysis (not shown).

EAE induction could readily be achieved by immunizing $\mathrm{rMT}-\mathrm{Il}$ rats with $75 \mu \mathrm{g} \mathrm{MBP}$ in CFA $(300 \mu \mathrm{g})$. All immunized $\mathrm{rMT}^{-\mathrm{II}^{+/}}$and $\mathrm{rMT}^{-\mathrm{II}^{+/+}}$developed EAE with a significantly accelerated disease onset (day $6 \mathrm{pi}$ for $\mathrm{MT}-\mathrm{II}^{+/+}$and day $8 \mathrm{pi}$ for $\mathrm{rMT}-\mathrm{II}^{+/-}$rats) compared to WT littermates (onset at day $10 \mathrm{pi}$ ). The disease progression and severity were slightly increased compared to WT EAE (Fig. 3.19 A - C). Interestingly, although the majority of $T$ cells in rOT-Il rats expressed the OVA-specific $T$ cell receptor, the residual nontransgenic repertoire of rOT-II rats still maintained the capacity to mediate MBP-induced EAE. Only $50 \%$ of the $\mathrm{rOT}-\mathrm{II}^{+/-}$and $15 \%$ of the rOT- $\mathrm{I}^{+/+}$rats developed EAE after immunization with MBP in CFA however with delayed disease onset (12-13 dpi) comparing to WT controls. Nevertheless, the rOT-II rats which did develop the disease presented EAE with the same progression and severity as WT controls (Fig. 3.19 D).

Immunization with OVA in CFA failed to evoke EAE development in any of rMT-II or rOT-II rats (data not shown). 

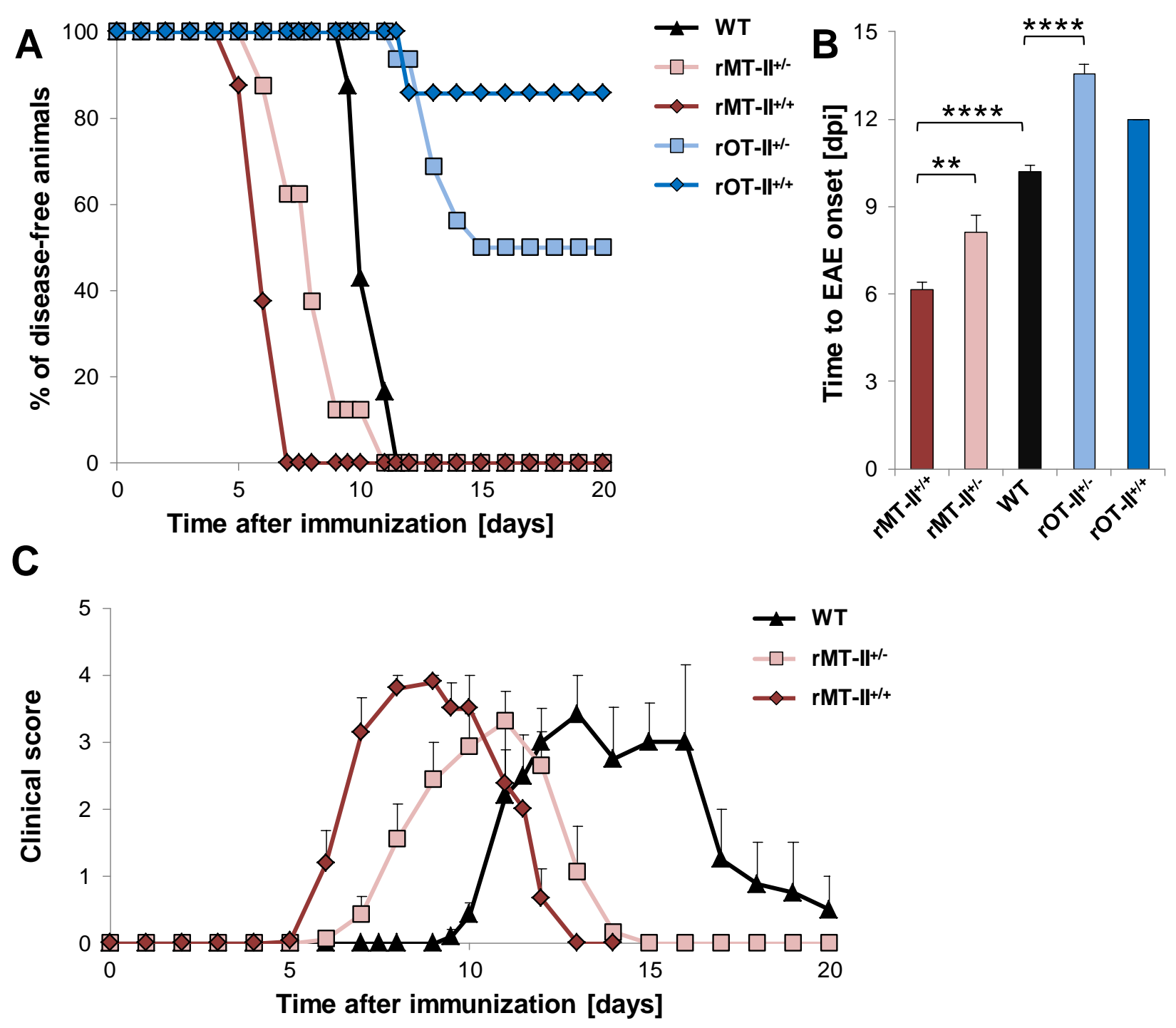

D

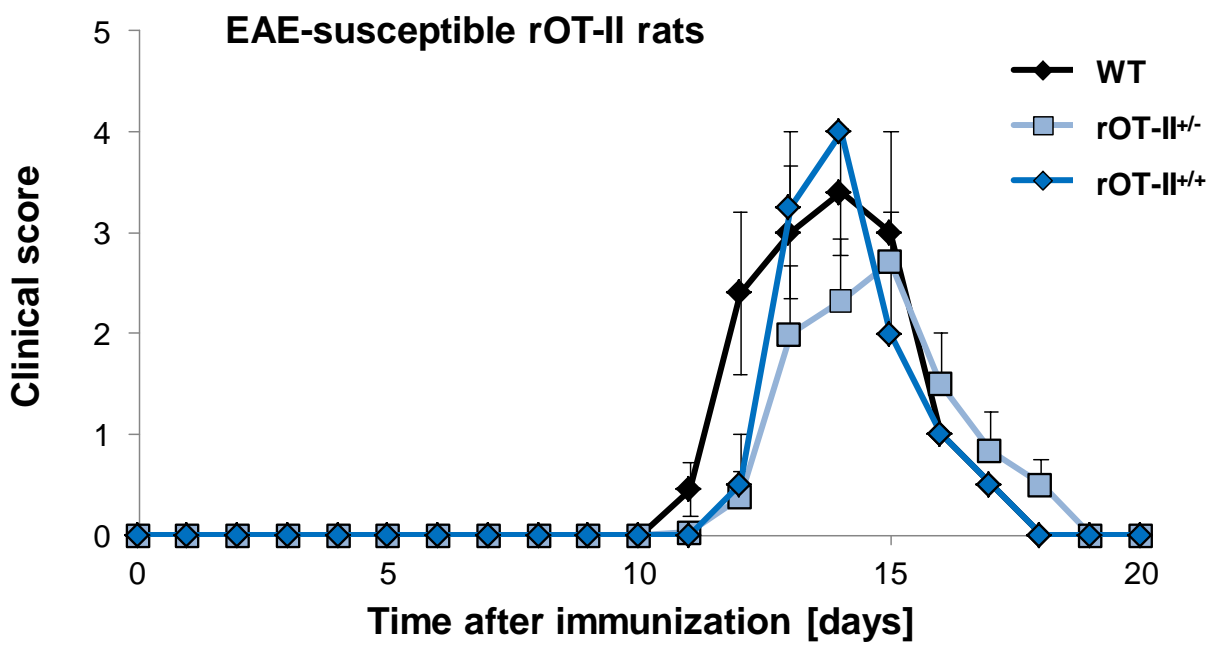

Figure 3.19: Active EAE in TCR transgenic Lewis rats. (A) Percentages of disease-free animals per genotype after active immunization with MBP. (B) Average time before onset of clinical EAE for different genotypes. Data are Mean \pm SEM. (C) The course of active EAE in the rMT strain. (D) EAE disease course in susceptible rOT Lewis rats. $n \geq 7$ per genotype. Graphs show Mean \pm SEM. 


\subsection{2 rMT-II RATS DEVELOPED EAE UPON SUBOPTIMAL IMMUNIZATION}

In order to determine the minimal immune challenge sufficient to induce EAE development, we decreased the amount of CFA and immunized $\mathrm{rMT}-\mathrm{II}^{++}$rats with MBP (Fig. $3.20 \mathrm{~A}$ and B). CFA contains heat-inactivating Mycobacterium tuberculosis thus predominantly activating the $\mathrm{CD}^{+} \mathrm{T}$ cells with a bias toward a Th1/Th17 response type.

In $\mathrm{rMT}^{-\mathrm{II}^{+/+}}$rats, $1 / 5$ of the usually used amount of CFA still induced full EAE development. Titrating down the CFA concentration showed that 1/20 (15 $\mu \mathrm{g} \mathrm{CFA)} \mathrm{was} \mathrm{enough} \mathrm{to} \mathrm{evoke}$ $\mathrm{EAE}$ in $75 \%$ of the $\mathrm{rMT}-\mathrm{II}^{+/+}$rats with later disease onset and reduced disease severity but no CFA amount lower than $300 \mu \mathrm{g}$ was able to induce EAE in WT rats (WT plots not shown). Notably, in this experiment the usual immunization protocol $(75 \mu \mathrm{g} \mathrm{MBP}+300 \mu \mathrm{g}$ CFA) caused the death of all $\mathrm{rMT}-\mathrm{II}^{+/+}$rats in this group.

As a next step, we analyzed the minimal amount of antigen sufficient to induce EAE. To this end, $\mathrm{rMT}^{-\mathrm{II}^{+/+}}$rats were immunized with $75 \mu \mathrm{g}, 15 \mu \mathrm{g}, 7.5 \mu \mathrm{g}$ or $0.75 \mu \mathrm{g}$ MBP in CFA $(300 \mu \mathrm{g})$. In this experiment (Fig. $3.20 \mathrm{C}$ ), $\mathrm{rMT}^{-\mathrm{II}^{+/+}}$rats immunized with $75 \mu \mathrm{g}, 15 \mu \mathrm{g}$ and $7.5 \mu \mathrm{g}$ developed severe EAE with a disease onset 5-6 dpi and necessary termination of the experiment due to a high clinical score in nearly all immunized rats. However, $\mathrm{rMT}-\mathrm{II}^{+/+}$ rats immunized with $0.75 \mu \mathrm{g}$ MBP in CFA developed EAE with a slightly delayed disease onset ( $9 \mathrm{dpi}$ ) and reduced severity.

Taken together, the EAE induction results confirm a high responsiveness of the transgenic T cells in vivo when challenged with $1 \%$ of the usual amount of cognate but not irrelevant antigen in Th1/Th17-favouring adjuvant. However, neither adjuvant in combination with irrelevant antigen nor global stimulation of the immune system with LPS could evoke active EAE in the rMT-II strain. 
rMT-II+/+
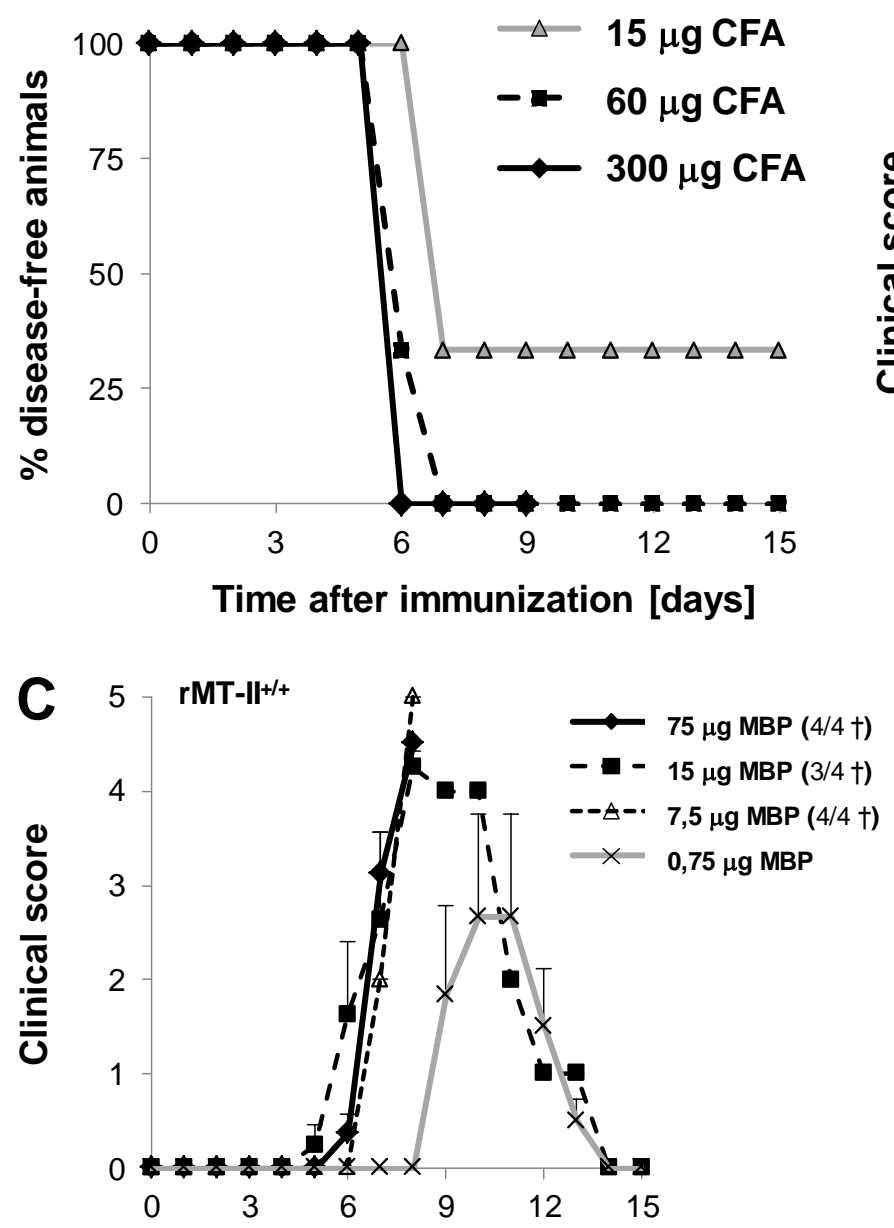

Time after immunization [days]
B $\quad$ rMT-II+++
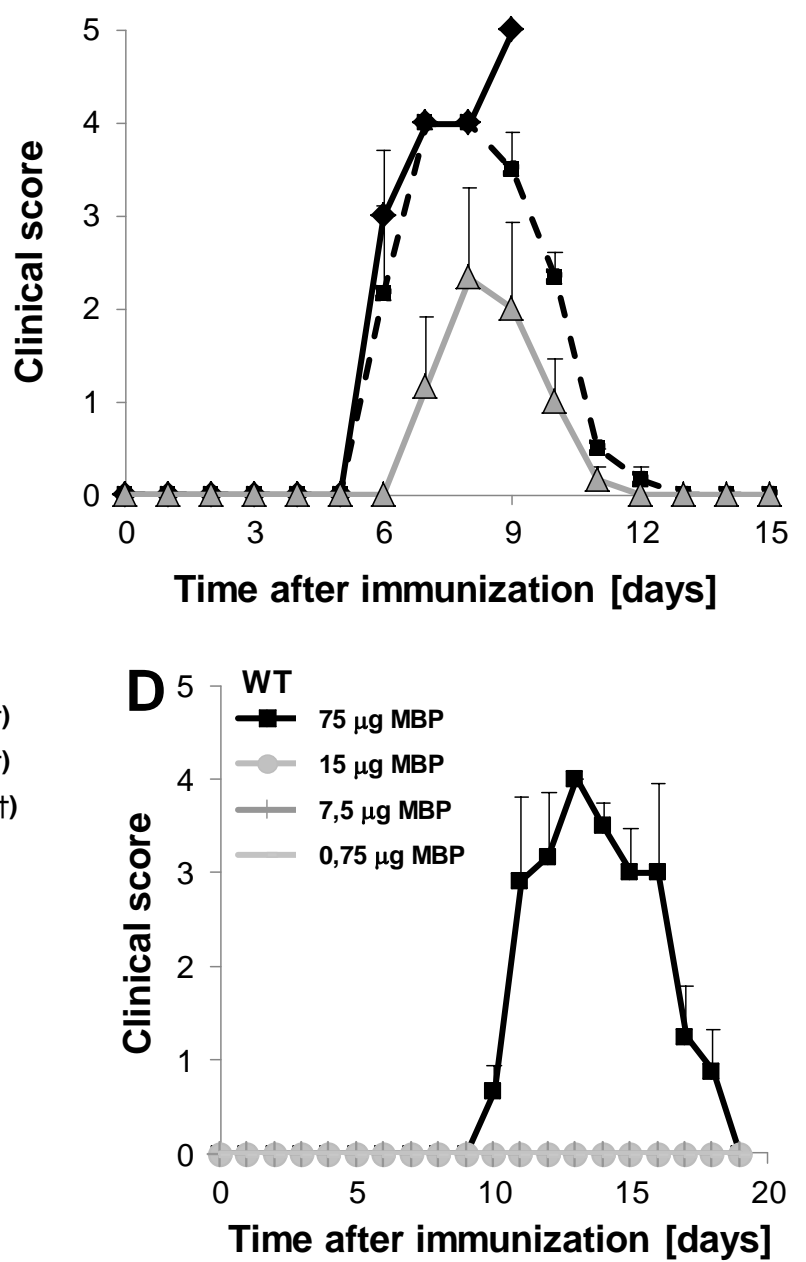

Figure 3.20: EAE induction in $\mathrm{rMT}-\mathrm{II}^{+/+}$Lewis rats with decreased CFA or antigen concentrations. (A) Percentage of disease-free animals after immunization with $75 \mu \mathrm{g}$ MBP in combination with $300 \mu \mathrm{g}, 60 \mu \mathrm{g}$ or $15 \mu \mathrm{g}$ CFA. $\mathrm{n}=3$ per group. (B) Clinical course of EAE induced with reduced amounts of CFA. $n=3$ per group. Same legend as shown in (A). (C) Clinical course of immunization with $300 \mu \mathrm{g}$ CFA and reduced amounts of MBP. In this experiment immunization with 7,5 - $75 \mu \mathrm{g}$ MBP resulted in strong disease manifestation with death of the indicated number of animals per group in $\mathrm{rMT}-\mathrm{II}^{+/+}$rats but not in (D) WT control animals. $\mathrm{n}=4$ per group. Graphs depicted as Mean \pm SEM.

\subsubsection{SUSCEPTIBILITY OF rMT-II RATS TO A REPEATED IMMUNIZATION AND FK506 TREATMENT}

Lewis rats were reported to be resistant to a second immunization with MBP (Sun et al., 1999). Efficient induction of regulatory $T$ cells upon immunization may be responsible for this phenomenon. To test whether rMT-II rats are also resistant to a second disease

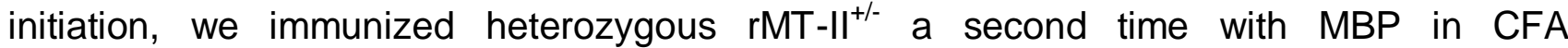
(Fig. 3.21 A) 10 days after recovery from the first disease bout. 
In contrast to WT rats, which turned out to be completely resistant to a second immunization (red line), the $\mathrm{rMT}^{-\mathrm{II}^{+-}}$cohort developed a mild clinical episode (pink line) 5 days after the second immunization. This EAE reached a maximum clinical score of 1.5 - 2 . Naïve WT controls (black line) immunized in parallel using the same preparation of Ag/CFA emulsion, developed EAE with classical clinical manifestation starting 10 days after immunization. This secondary disease bout could not be explained by a simple lack of regulatory $\mathrm{T}$ cells (Treg) in the $\mathrm{rMT}$-II pre-immune repertoire, known to occur in some TCRtg mice, as the numbers of $\mathrm{CD} 4^{+} \mathrm{CD} 25^{+} \mathrm{T}$ cells were only marginally reduced in rMT$\mathrm{II}^{+/+}$rats relative to WT levels (Fig. $3.21 \mathrm{~B}$ ).

A
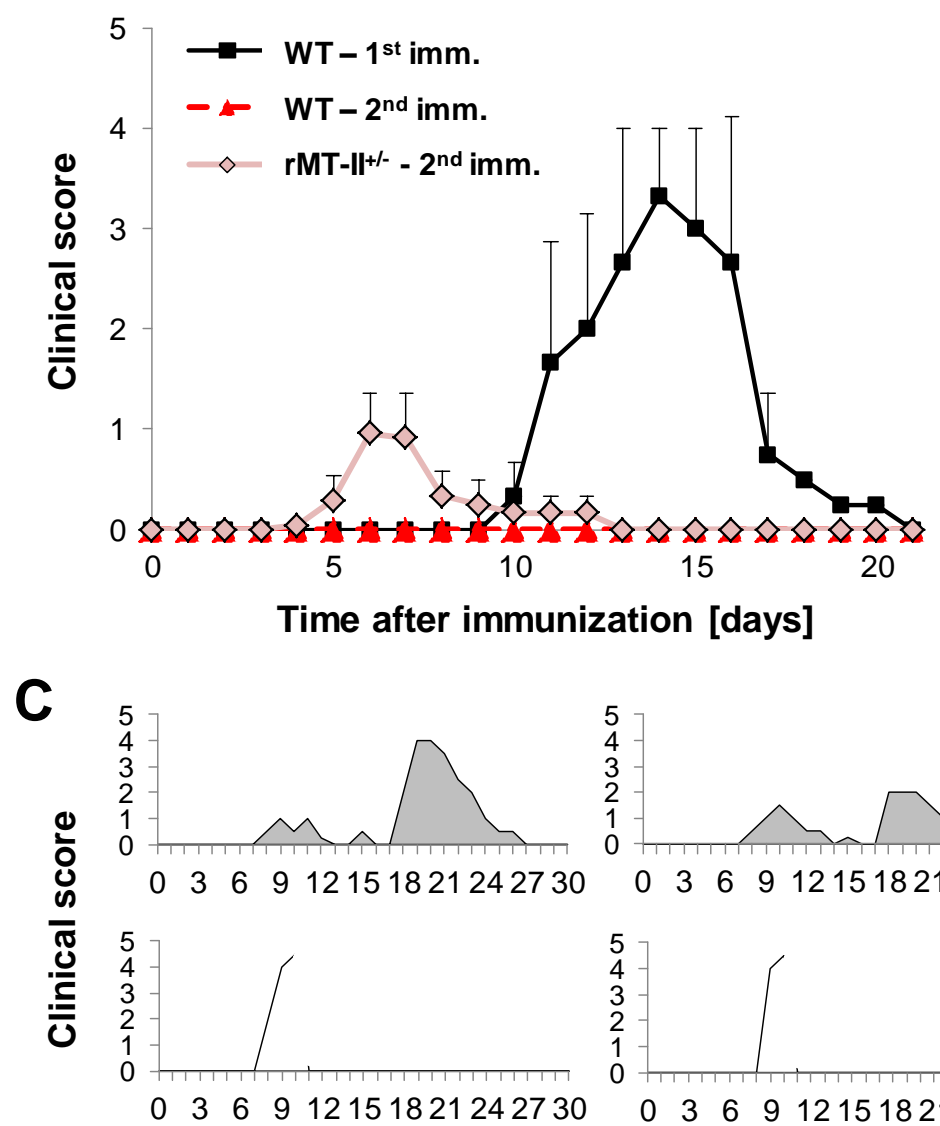
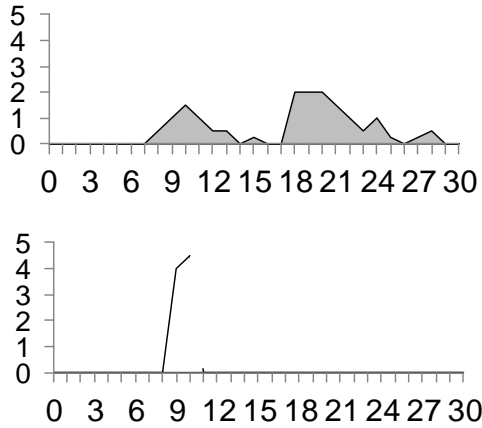
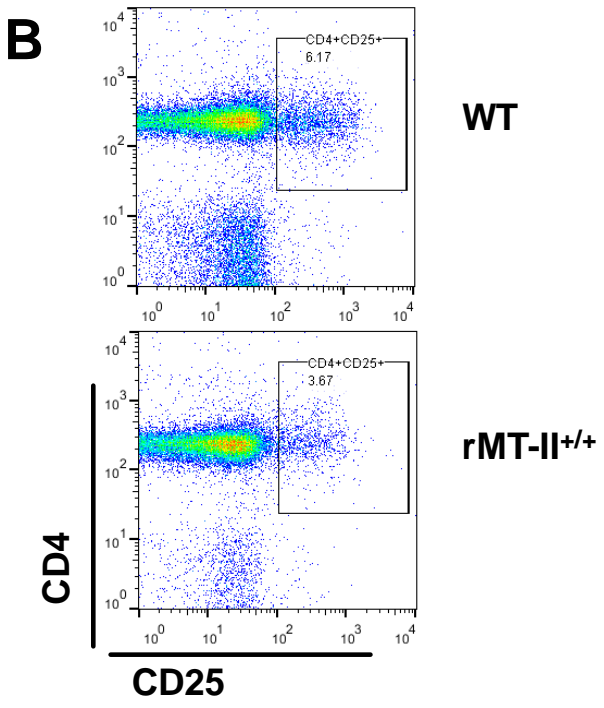

FK506
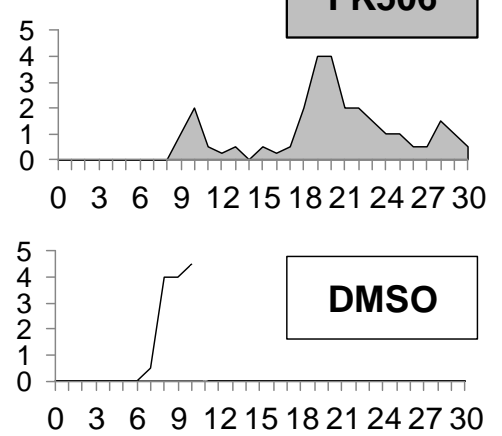

Time after immunization [days]

Figure 3.21: Differential EAE progression in $\mathrm{rMT}^{-\mathrm{II}^{+/+}}$Lewis rats. (A) Disease course of $\mathrm{rMT}^{-\mathrm{II}^{+/-}}$rats immunized with MBP for a second time 10 days after recovery from the first acute disease bout. $n=3$ per group. Graphs depicted as Mean \pm SEM. (B) FACS analysis of LN cells stained for CD4 and CD25 in naïve WT and $\mathrm{rMT}-\mathrm{II}^{+/+}$rats. (C) Representative clinical courses of individuals with active EAE in $\mathrm{rMT}_{-1 \mathrm{II}^{+/+}}$rats treated with low dose of FK506 or DMSO on every other day.

Treatment with low doses of calcineurin inhibitors cyclosporin $A$ (CsA) or FK506 was reported to modify the monophasic course of active Lewis rat EAE to a relapsing or chronic progression (Polman et al., 1988; Chelmicka-Schorr et al., 1998). A possible reason of such 
a conversion could be a selective impact of the treatment on Treg cells, which are extremely dependent on IL-2 signaling regulated by calcineurin activity. To test whether this also applies to the EAE on the rMT-II background, we immunized $\mathrm{rMT}^{-\mathrm{II}^{+/+}}$animals with a low antigen amount $(0.75 \mu \mathrm{g}$ MBP) and treated them every other day with $800 \mu \mathrm{g}$ of FK506 per $\mathrm{kg}$ of body weight from the day of immunization until the onset of clinical symptoms. Remarkably, low-dose FK506 treatment induced a relapsing-remitting disease course in $\mathrm{rMT} \mathrm{II}^{+/+}$rats whereas control transgenic rats treated with DMSO developed a single severe disease bout (Fig. 3.21 C).

\subsubsection{CLASSICAL IMMUNIZATION IS REQUIRED FOR INDUCTION OF EAE IN rMT-II RATS}

To address the question whether the generation of a proinflammatory milieu within CNS and a compromising integrity of the blood-brain barrier would suffice to trigger EAE in MBPTCRtg hosts, naïve $\mathrm{rMT}^{-\mathrm{II}^{++}}$animals were intrathecally injected with LPS combined with cognate (MBP) or irrelevant (OVA) antigen. None of experimental conditions resulted in a paralytic disease within an observation period of 20 days (Tab. 3.1). Moreover, intrathecal transfer of ex vivo pre-activated $\mathrm{rMT}^{-\mathrm{II}^{+/+}}$lymphocytes (exposed to MBP two days before injection) did not evoke EAE development (data not shown). We also tried to induce EAE by immunizing rMT-II rats with MBP in incomplete Freund's adjuvant (IFA). This challenge also failed to induce clinical EAE development within 20 days of observation (Tab. 3.1).

Table 3.1: The incidence of EAE upon alternative immunization protocols

\begin{tabular}{|c|c|c|}
\hline Genotype & Treatment & Incidence \\
\hline WT & $\begin{array}{l}\text { LPS + MBP i.t. } \\
\text { LPS + OVA i.t. }\end{array}$ & $\begin{array}{l}0 / 2 \\
0 / 2\end{array}$ \\
\hline rMT-II'-- & $\begin{array}{l}\text { LPS + MBP i.t. } \\
\text { LPS + OVA i.t. }\end{array}$ & $\begin{array}{l}0 / 2 \\
0 / 2\end{array}$ \\
\hline rMT-II ${ }^{+/+}$ & $\begin{array}{l}\text { LPS + MBP i.t. } \\
\text { LPS + OVA i.t. }\end{array}$ & $\begin{array}{l}0 / 5 \\
0 / 4\end{array}$ \\
\hline WT & MPB + IFA s.c. & $0 / 3$ \\
\hline rMT-II ${ }^{+/-}$ & MPB + IFA s.c. & $0 / 3$ \\
\hline rMT-II ${ }^{+/+}$ & MPB + IFA s.c. & $0 / 3$ \\
\hline
\end{tabular}


Expression of GFP in TCRtg rats is driven by the promoter of the human ubiquitin $\mathrm{C}$ gene, which is active in a broad range of cell types and tissues. We analyzed the expression pattern of GFP within the in the spinal cord of homozygous TCRtg rats by histology. High signals of green fluorescence were detected in both meningeal and parenchymal blood vessels labelled by intravenously injected red fluorescent dextran (Fig. 3.22).

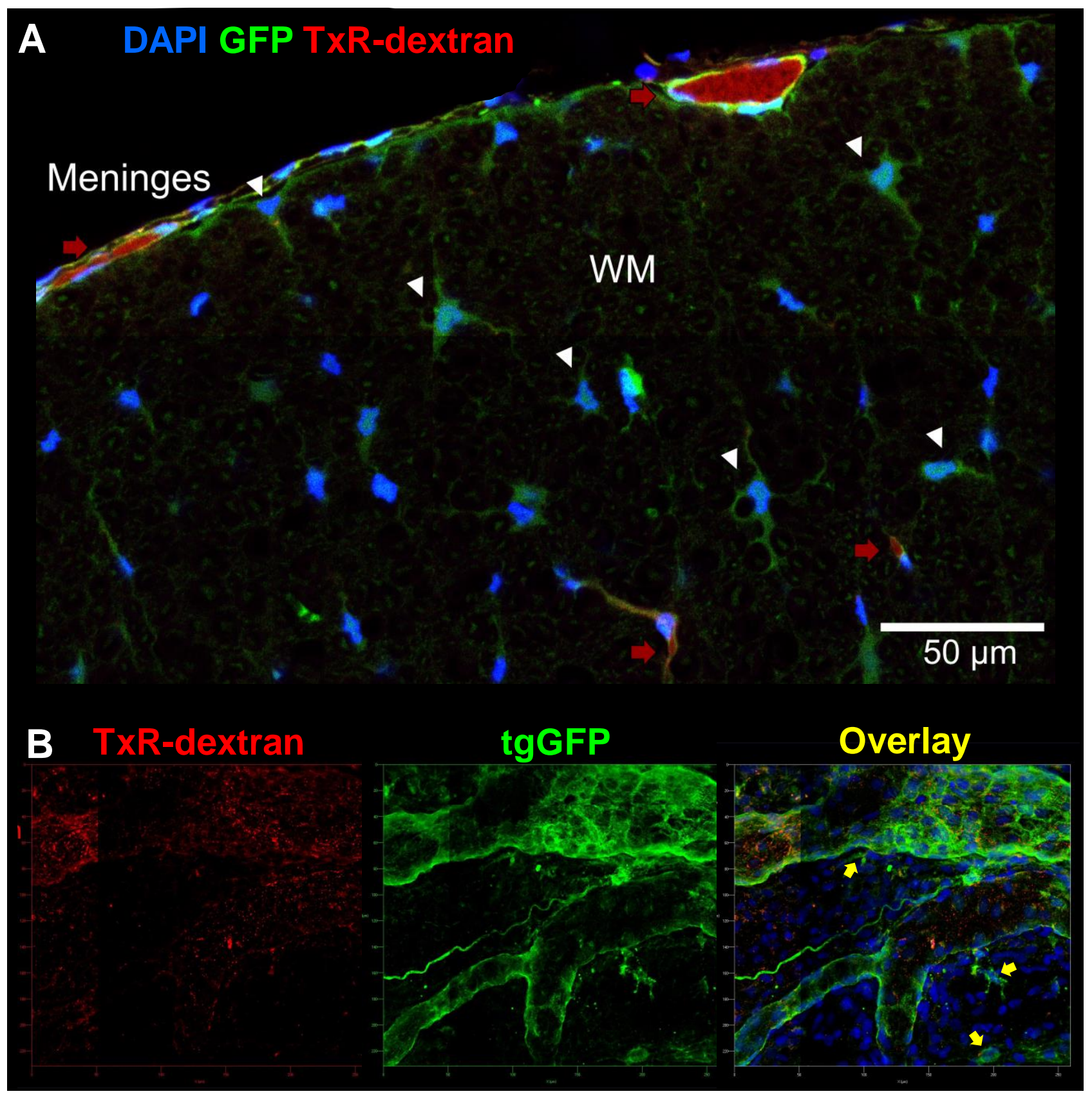

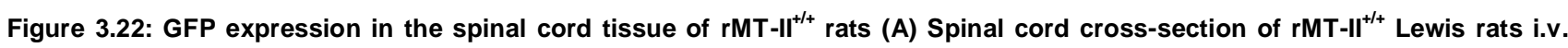
injected with TexasRed-conjugated $3 \mathrm{kDa}$ dextran $24 \mathrm{~h}$ before perfusion analyzed by confocal microscopy. Vascular structures (red arrows) and GFP $^{+}$white matter cells (white arrows) are indicated. (B) 3D-rendered tile scan image of whole-mount meningeal surface of lumbal spinal cord of a rMT-II ${ }^{++}$animal stained with DAPI. TxR-dextran is taken up by endothelial cells of pial vessels. Cells around the blood vessels with strong GFP signal are indicated by yellow arrows. 

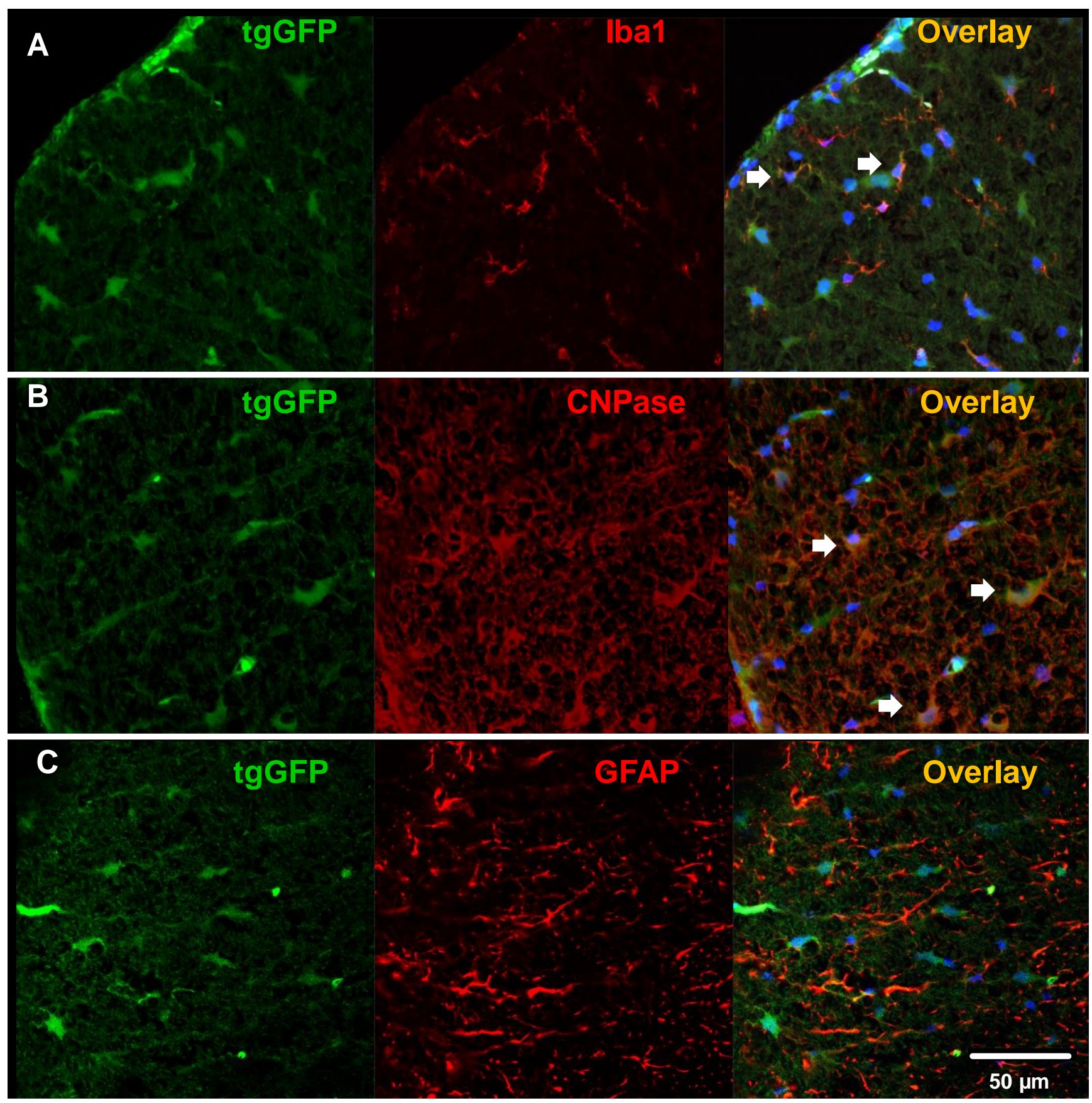

Figure 3.23: Expression of GFP in glial cells of the spinal cord WM in rMT- $-\mathrm{II}^{+/+}$rats. Frozen sections of spinal cord were stained with antibodies to lba1 (A), CNPase (B) and GFAP (C) proteins and analyzed by confocal microscopy. White arrows indicate double-positive microglia (A) and oligodendroglia (B) cells. Nuclei were stained by DAPI (shown in blue for overlay images).

In the white matter some resident polymorphic cells resembling oligodendroglia (ODC) were also GFP high (Fig. 3.22). We stained the tissue for different glial markers (Fig. 3.23) and found that Iba1-positive microglia and CNPase-positive ODC express higher level of GFP than GFAP-positive astrocytes. 
In the leptomeninges some perivascular cells also were highly positive for the expression of transgenic GFP (Fig. 3.22). To test whether the differential expression of GFP marker in the CNS can be used to visualize meningeal structures in intravital imaging settings, spinal cords of homozygous rMT-II and rOT-II animals were subjected to TPM analysis (Fig. 3.24). In these experiments, the GFP signal clearly delineated endothelial cells of leptomeningeal vessels. Moreover, a network of stationary $\mathrm{GFP}^{+}$cells scanning the microenvironment by extension and retraction of cellular processes was present within perivascular and intervascular spaces. This behaviour is characteristic for perivascular/meningeal macrophages, which are known to originate from bone marrow and possess phagocytotic activity. When RFP-tagged bone marrow was transferred into irradiated rOT-II host, RFP ${ }^{+}$ cells were found to populate the meninges of $\mathrm{GFP}^{+}$host and form a similar pattern as putative $\mathrm{GFP}^{+}$meningeal macrophages do (Fig. 3.24 A).

In turn, the $\mathrm{rOT}_{-\mathrm{II}^{+/+}}$bone marrow transferred to irradiated WT recipients also gave rise to a $\mathrm{GFP}^{+}$meningeal population with characteristic morphology and distribution (Fig. 3.24 B), which could be labelled by intrathecal injection of fluorescent TexasRed-dextran (Fig. 3.24 C). This data indicate that GFP expressing cells visualized by TPM in the meninges of TCRtg animals are meningeal phagocytes of myeloid origin that are known to be proficient in antigen presentation to CD4 T cells (Hickey and Kimura, 1988). 


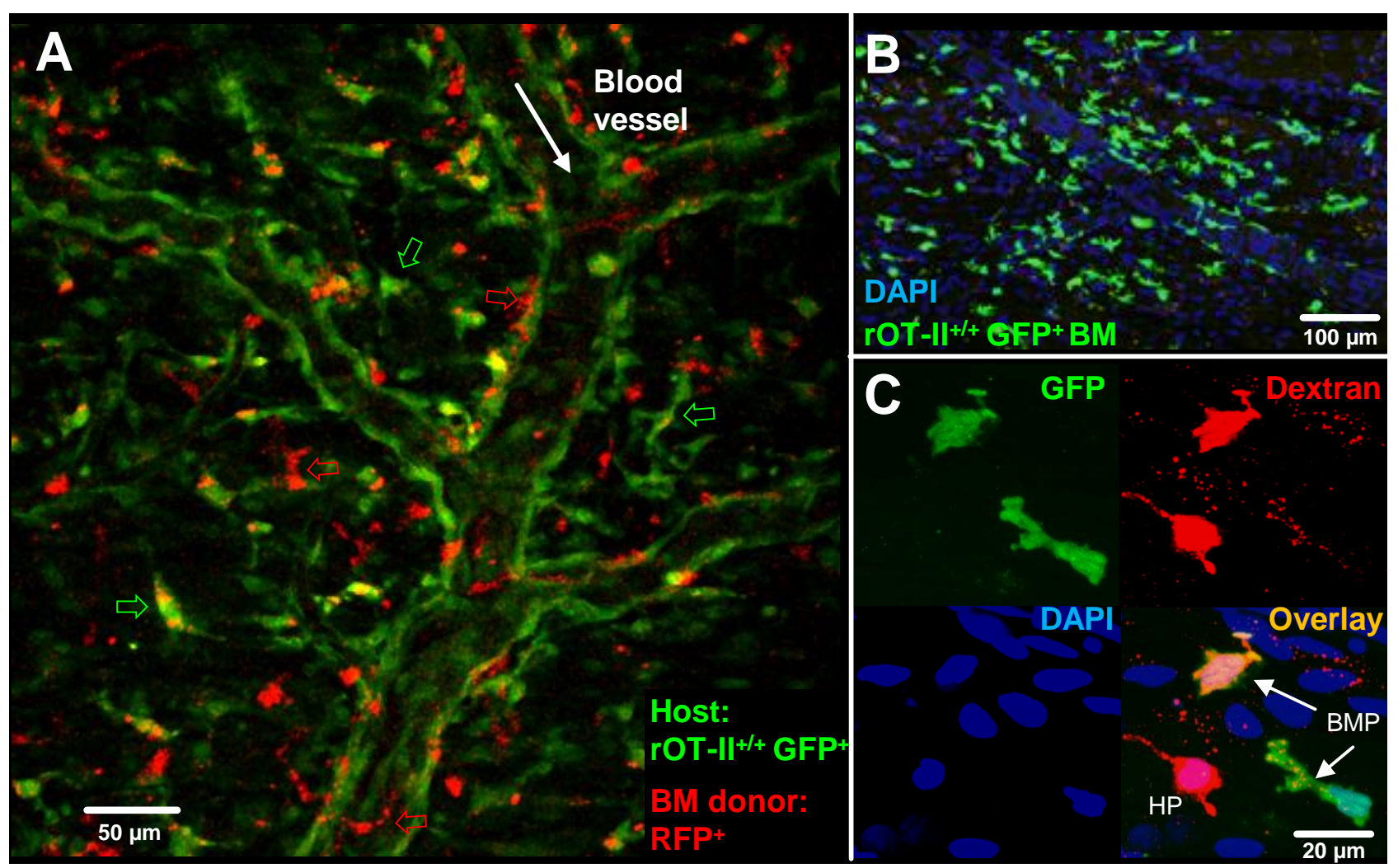

Figure 3.24: Transgenic GFP expression highlights meningeal endothelial cells and perivascular macrophages. (A) Selected frame of two-photon recording of the spinal cord meninges in a bone marrow chimera rat generated by the transfer of RFP $^{+}$ bone marrow into irradiated $\mathrm{rOT}-\mathrm{II}^{+/+}$host. Host meningeal phagocytes indicated by green arrows, donor bone marrow originating cells indicated by red arrows. (B) Confocal tile scan image of spinal cord meningeal preparation from rOT-II-BM / WT host chimera stained with DAPI. (C) Meninges of BM chimera (B) $24 \mathrm{~h}$ after intrathecal injection of TexasRed-dextran stained with DAPI and analyzed by confocal microscopy. HP, host meningeal phagocyte; BMP, rOT-II BM-derived meningeal phagocytes. 


\subsubsection{EFFECTOR T CELL LINES ESTABLISHED FROM rMT- $\mathrm{II}^{+/+}$AND $\mathrm{rOT}-\mathrm{II}^{+/+} \mathrm{RATS}$}

Effector $\mathrm{T}$ cell lines were established from transgenic $\mathrm{rMT}_{-} \mathrm{II}^{+/+}$or $\mathrm{rOT}-\mathrm{Il}^{+/+}$hosts. Resting $\mathrm{rMT} \mathrm{II}^{+/+}$and $\mathrm{rOT}-\mathrm{II}^{+/+}$effector T cells were analyzed for GFP, $\alpha \beta \mathrm{TCR}, \mathrm{CD} 4$ and CD62L expression and compared to retrovirally engineered WT effector $\mathrm{T}_{\mathrm{MBP}}$-GFP or $\mathrm{T}_{\mathrm{OVA}}$-GFP lines (Flügel et al., 1999). As shown in Figure 3.25 A, rMT-II ${ }^{+/+}$effector T cells expressed lower levels of GFP and $\alpha \beta$ TCR but matched $\mathrm{T}_{\mathrm{MBP}}$-GFP effector $\mathrm{T}$ cells in the expression level of CD4 and the absence of CD62L on the cell surface. Additionally, the transcriptional response to antigen challenge in vitro was tested revealing similar expression kinetics of proinflammatory cytokine mRNA in $\mathrm{rMT}^{-\mathrm{II}^{+/+}}$effector $\mathrm{T}$ cells and $\mathrm{T}_{\mathrm{MBP}}$-GFP effector $\mathrm{T}$ cells (Fig. 3.24 B), although $\mathrm{rMT}^{-\mathrm{II}^{+/+}}$effector T cells produced higher amounts of IFN $\gamma$ and lower amounts of IL-17 and IL-2 mRNA. CXCR3 and CCR7, chemokine receptors important for the entry of T cells into the CNS (Alt et al., 2002; Noor and Wilson, 2012; Schläger, 2013), were regulated following a similar kinetic in $\mathrm{MMT}^{-\mathrm{II}^{+/+}}$effector and $\mathrm{T}_{\mathrm{MBP}}$-GFP effector $\mathrm{T}$ cells. In effector $\mathrm{rOT}-\mathrm{II}^{+/+} \mathrm{T}$ cells, the GFP and $\alpha \beta$ TCR levels were lower compared to TovA-GFP $\mathrm{T}$ cells and showed the same amount of CD62L (Fig. 3.25 C). However, $\mathrm{rOT}-\mathrm{II}^{+/+} \mathrm{T}$ cells also exhibited a slightly lower expression level of the CD4 coreceptor. Given that donor rOT- $\mathrm{Il}^{+/+}$rats possessed a higher number of $\mathrm{CD}^{+} \mathrm{T}$ cells before immunization, these data suggest that the immunization protocol and ex vivo culturing favour the propagation of CD4 ${ }^{+} \mathrm{T}$ cells.

The kinetic of antigen-induced mRNA expression of proinflammatory cytokines IFN $\gamma$, IL-17, IL-2 and TNF $\alpha$ as well as the expression levels of CXCR3 and CCR7 in rOT- $\mathrm{II}^{+/+}$effector T cells followed the same kinetic as in WT TovA-GFP cells (Fig. 3.25 D). 

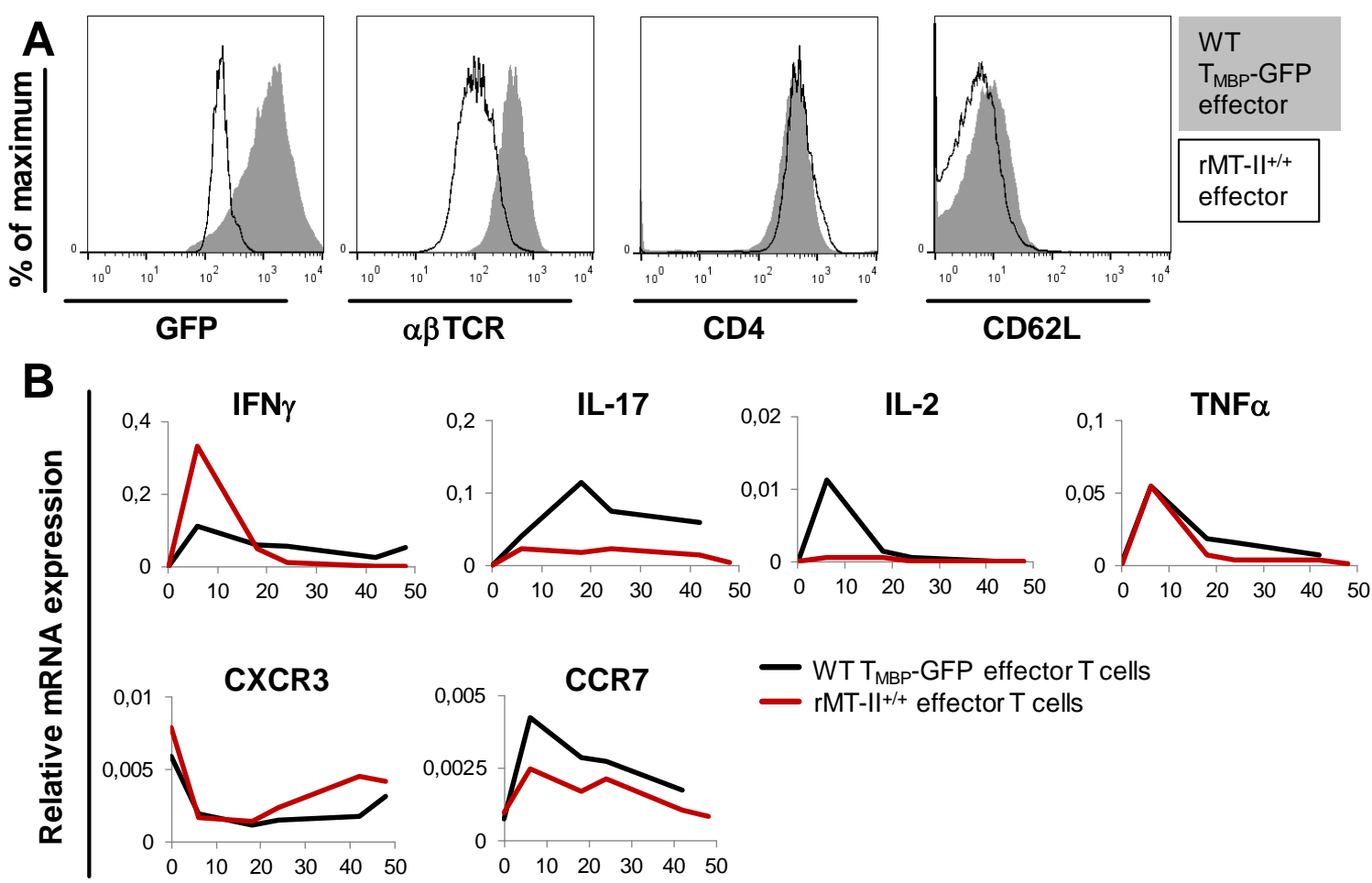

- WT T $T_{M B P}-$ GFP effector T cells

- rMT-II+/+ effector T cells

Time after stimulation [h]
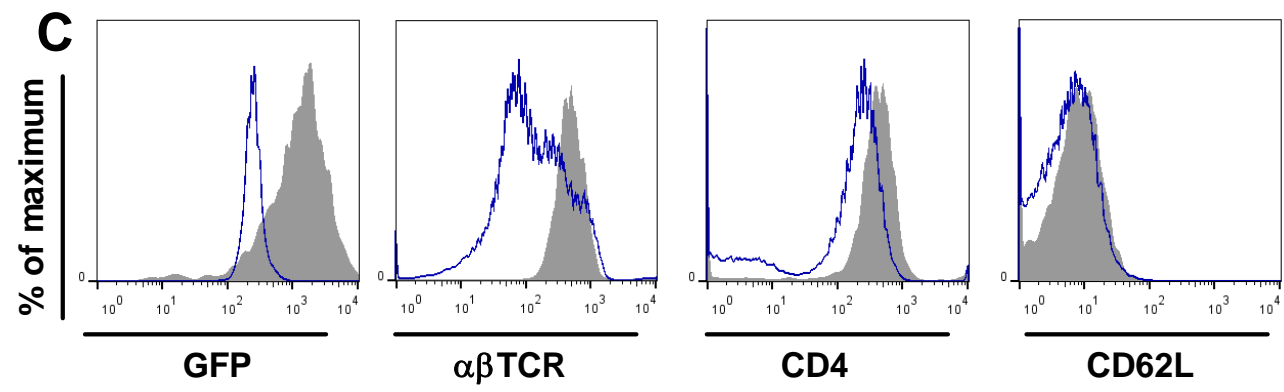

WT

TOVA-GFP

effector

rOT-II+/+

effector

D
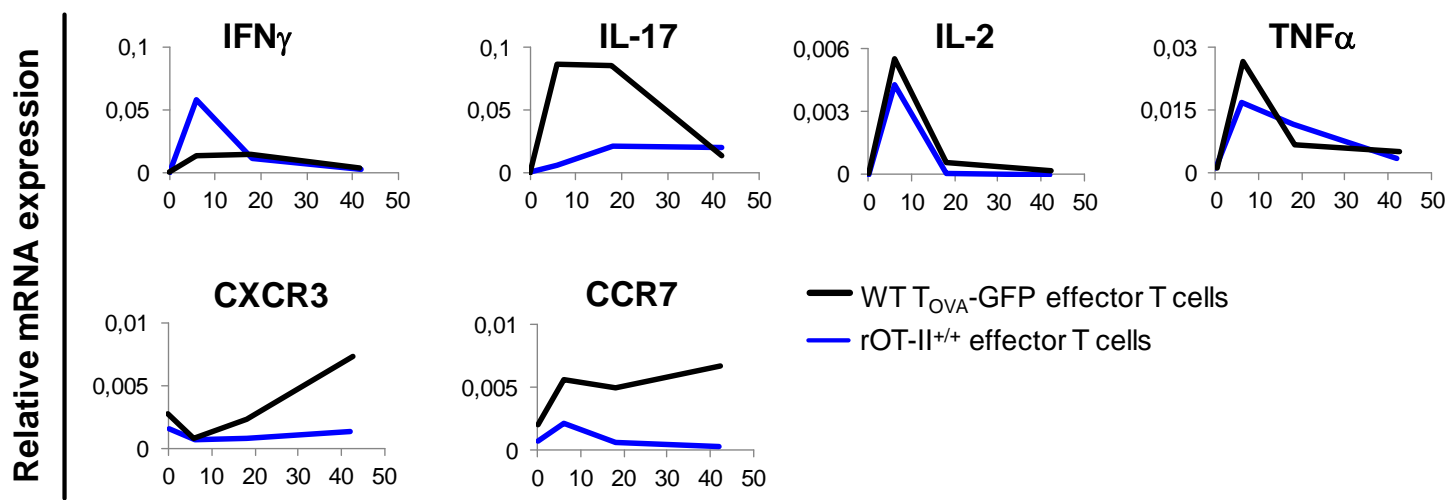

- WT T OVA $_{\text {-GFP effector T cells }}$

— rOT-II+/+ effector T cells

Time after stimulation [h]

Figure 3.25: In vitro characterization of effector T cell lines. (A) Surface expression of GFP, $\alpha \beta T C R, C D 4$ and CD62L in a conventional $\mathrm{T}_{\mathrm{MBP}}$-GFP (grey/black) and a rMT- $\mathrm{II}^{+/+}$effector $\mathrm{T}$ cell line (red) assessed by flow cytometry. (B) Comparison of changes in mRNA expression of proinflammatory cytokines and chemokine receptors in response to in vitro stimulation with $10 \mu \mathrm{g} / \mathrm{ml}$ MBP. (C) Surface expression of GFP, $\alpha \beta T C R$, CD4 and CD62L in a conventional TovA-GFP (grey) and a rOT-II ${ }^{+/+}$effector $T$ cell line (blue) assessed by flow cytometry. (D) mRNA expression kinetics of proinflammatory cytokines and chemokine

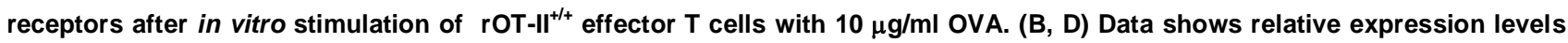
normalized to $B$-actin message. 


\subsubsection{ENCEPHALITOGENIC POTENTIAL OF rMT- $-I^{+/+}$EFFECTOR T CELLS}
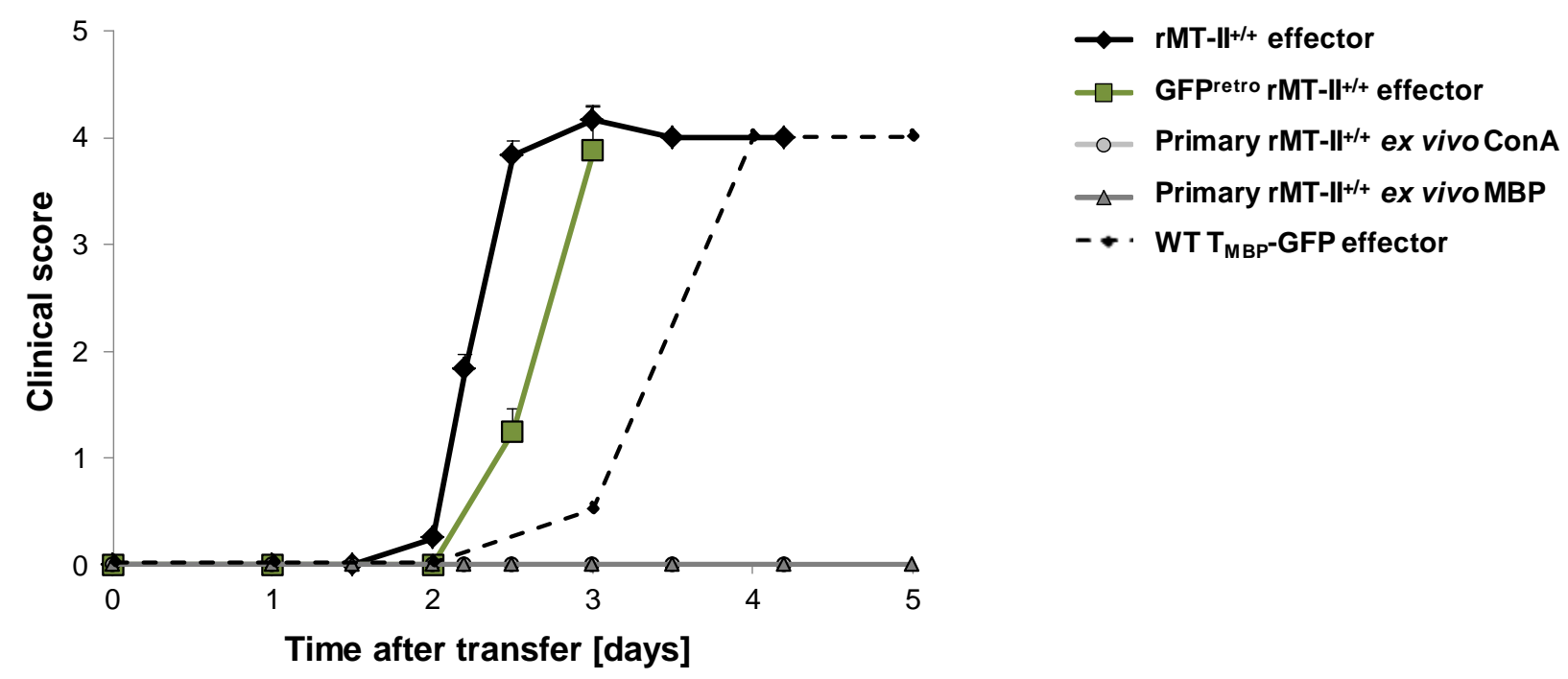

Figure 3.26: The course of EAE induced by adoptive transfer of $r M T-{ }_{-1 I^{++}}$effector $\mathrm{T}$ cell lines, WT $\mathrm{T}_{\mathrm{MBP}}$-GFP $\mathrm{T}$ cells or isolated naïve lymphocytes activated in vitro for two days with concanavalin A (ConA) or MBP. GFP ${ }^{\text {retro }}$, effector $\mathrm{T}$ cell line transduced with GFP-retrovirus. $n=3$ per group. Graphs depicted as Mean \pm SEM.

Two effector $\mathrm{T}$ cell lines derived from $\mathrm{rMT}^{-\mathrm{II}^{+/+}}$rats with or without additional retroviral transduction of GFP were intravenously transferred into naïve recipients $\left(5{ }^{*} 10^{6} \mathrm{~T}\right.$ cells/recipient, Fig. 3.26).

Both the $\mathrm{rMT}^{-\mathrm{II}^{+/+}}$effector $\mathrm{T}$ cell line and the GFP-transduced $\mathrm{rMT}-\mathrm{II}^{+/+}$effector $\mathrm{T}$ cells (GFP retro) induced fulminant EAE development with a disease onset 2 - 2.5 days after transfer. Animals did not only develop conventional EAE symptoms but also atypical neurological symptoms like hyperesthesia, tremor and partial tetraparesis. Pronounced front limb weakness developed before the onset of a complete hind limb paralysis. Due to the strong disease manifestation, most of the experiments had to be terminated at the peak of the disease. In comparison, WT TMBP-GFP cells induced typical adoptive transfer EAE reported earlier (Flügel et al., 1999).

To assess whether also naïve $\mathrm{IMT}^{-\mathrm{II}^{+/+}}$lymph node cells briefly primed in vitro inherit the capability to induce EAE, lymph node cells were taken into culture (without prior immunization) and either unspecifically stimulated with concanavalin $A(1 \mu \mathrm{g} / \mathrm{ml})$ or specifically with MBP $(10 \mu \mathrm{g} / \mathrm{ml})$. On day 2 after stimulation, T cells were transferred intravenously into naïve recipients but did not evoke clinical EAE.

The atypical neurological symptoms observed after transfer of $\mathrm{rMT}^{-\mathrm{Il}^{+/+}}$effector $\mathrm{T}$ cells hinted not only of a T cell infiltration into the spinal cord but also regions of the brain. 
$\mathrm{GFP}^{+} \mathrm{T}$ cell numbers in spinal cord and brain regions were assessed via FACS analysis as before. Numbers of $T$ cells infiltrating the lumbal and cervical spinal cord at the peak of the disease were comparable in recipients of $\mathrm{rMT}^{-\mathrm{II}^{+/}}$and $\mathrm{WT} \mathrm{T}_{\mathrm{MBP}}$-GFP effector cell lines. However, more $\mathrm{GFP}^{+} \mathrm{T}$ cells infiltrating cerebrum and cerebellum were found in recipients of $\mathrm{rMT}-\mathrm{II}^{+/+}$effector T cellss (Fig. $3.27 \mathrm{~A}$ ).

Immunohistochemical analysis for activation of microglia/macrophage infiltration by immunostaining for Iba-1 and CD68 (ED1) showed stronger signals for lba-1 and ED1 expression in cerebellum and cerebrum in brain sections from $\mathrm{rMT}^{-\mathrm{I}^{+/+}}$effector $\mathrm{T}$ cell induced EAE at the peak of disease compared to TMBP-GFP EAE (Fig. 3.27 B and C). 
A

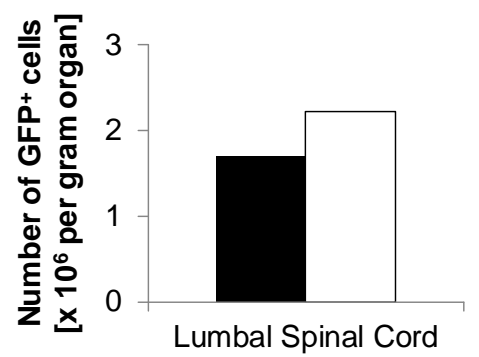

B

rMT-II $^{+/+}$effector $\mathrm{T}$ cells

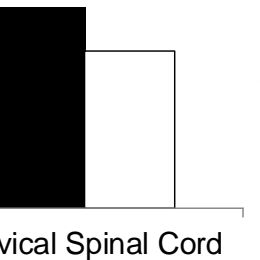

WT $T_{M B P}$-GFP effector $T$ cells

rMT-Il+/+ effector T cells

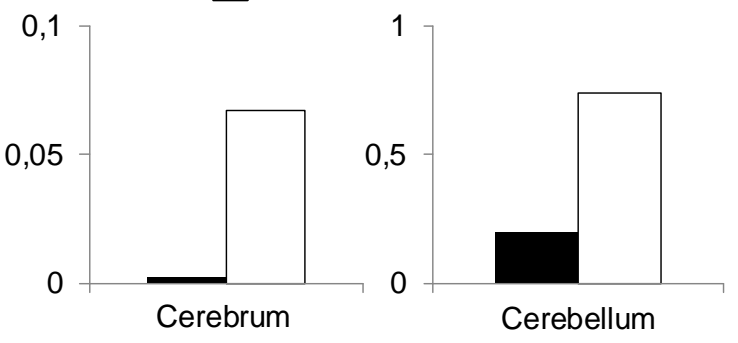

\section{8}

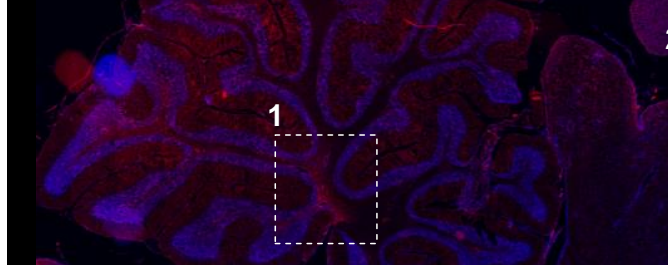

2

WT $T_{\text {MBP-GFP effector } T \text { cells }}$

ED1 DAPI
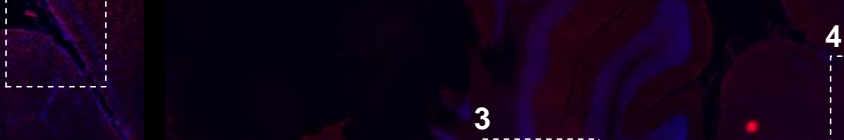

3
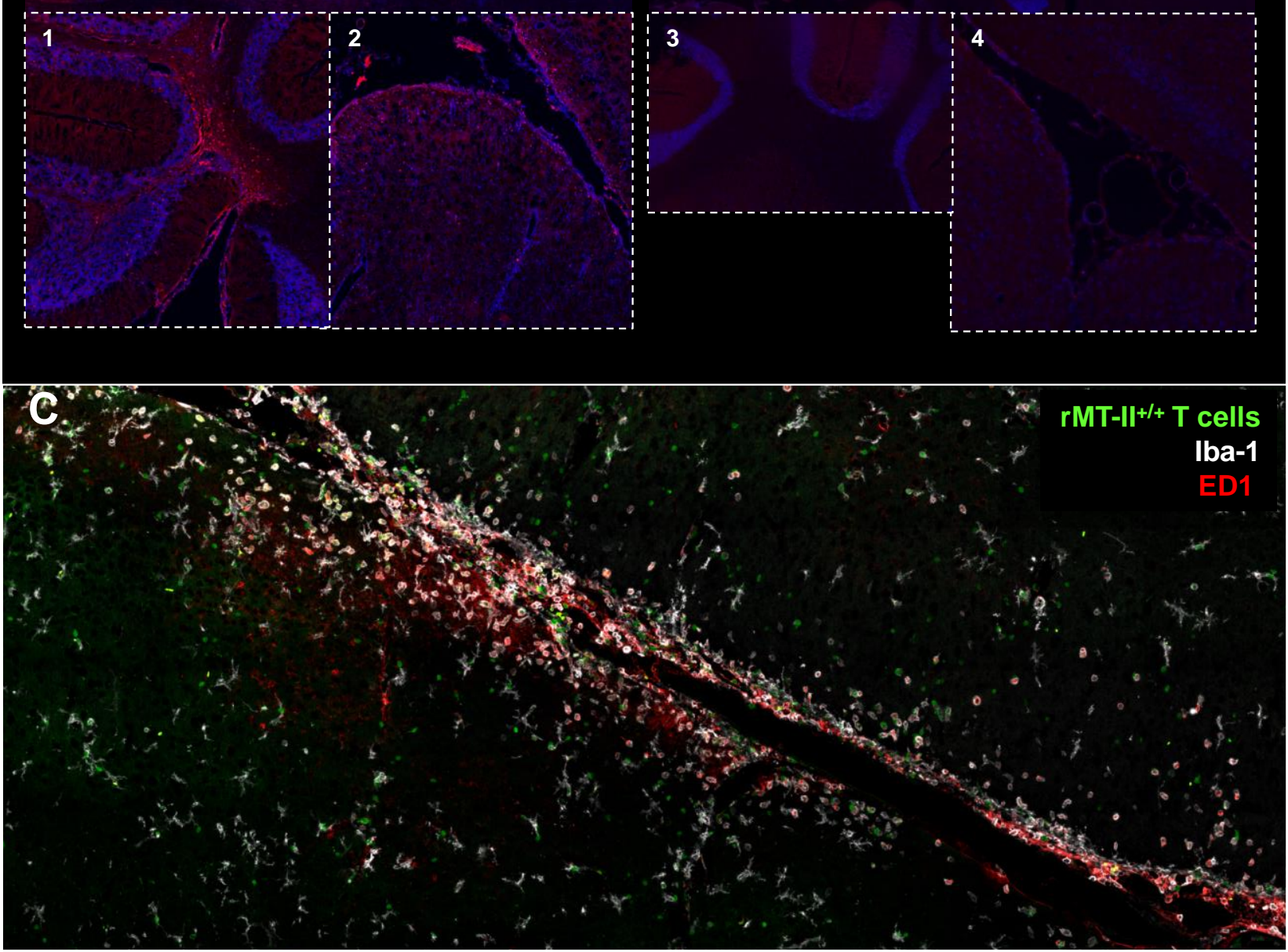

Figure 3.27: Analysis of brain regions in adoptive transfer EAE of $\mathrm{rMT}-\mathrm{II}^{+/+}$effector $\mathrm{T}$ cell lines at the peak of the disease. (A) GFP $^{+}$cells per gram organ in different CNS compartments after adoptive rMT-II+/ effector and $T_{M B P}$-GFP T cell transfer. $n=1$ per group. (B) CD68 (ED1) expression in cerebellum and cerebrum at the peak of disease. (C) CD68 and lba-1 expression in cerebrum. 


\subsubsection{TRANSFER OF SPLENIC rMT-II $^{+/+}$CELLS BEFORE IMMUNIZATION ACCELERATES THE ONSET OF ACTIVE EAE}

As GFP is expressed under control of the ubiquitin promoter, not only $T$ cells but also many other cell types in TCRtg rats express this fluorescent marker (e.g. Fig. 3.22). To circumvent this inconvenience, splenocytes of untreated $\mathrm{rOT}-\mathrm{II}^{+/+}$or $\mathrm{rMT}-\mathrm{II}^{+/+}$rats were s.c. transferred into the hind limbs of naïve WT recipients. Many of these T cells seem to migrate to the draining $\mathrm{LN}$ and accumulate there. 16 hours post transfer recipients were s.c. immunized with MBP antigen in CFA at the same location where T cells were injected. This enables analysis of early activation events of T cells in the draining popliteal LNs and their migratory routes.

In this setup, rats receiving $\mathrm{rMT}-\mathrm{II}^{+/+}$splenocytes developed EAE 6 days post immunization whereas recipients receiving $\mathrm{rOT}_{-1 \mathrm{II}^{+/+}}$splenocytes developed EAE $11 \mathrm{dpi}$ as did WT rats not receiving any cell supplementation (Fig. 3.28 B, WT EAE plot is not shown). Disease

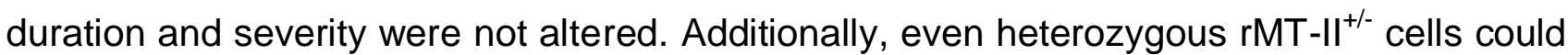
evoke an earlier disease onset (day 8 post immunization) albeit with a slightly reduced disease severity.
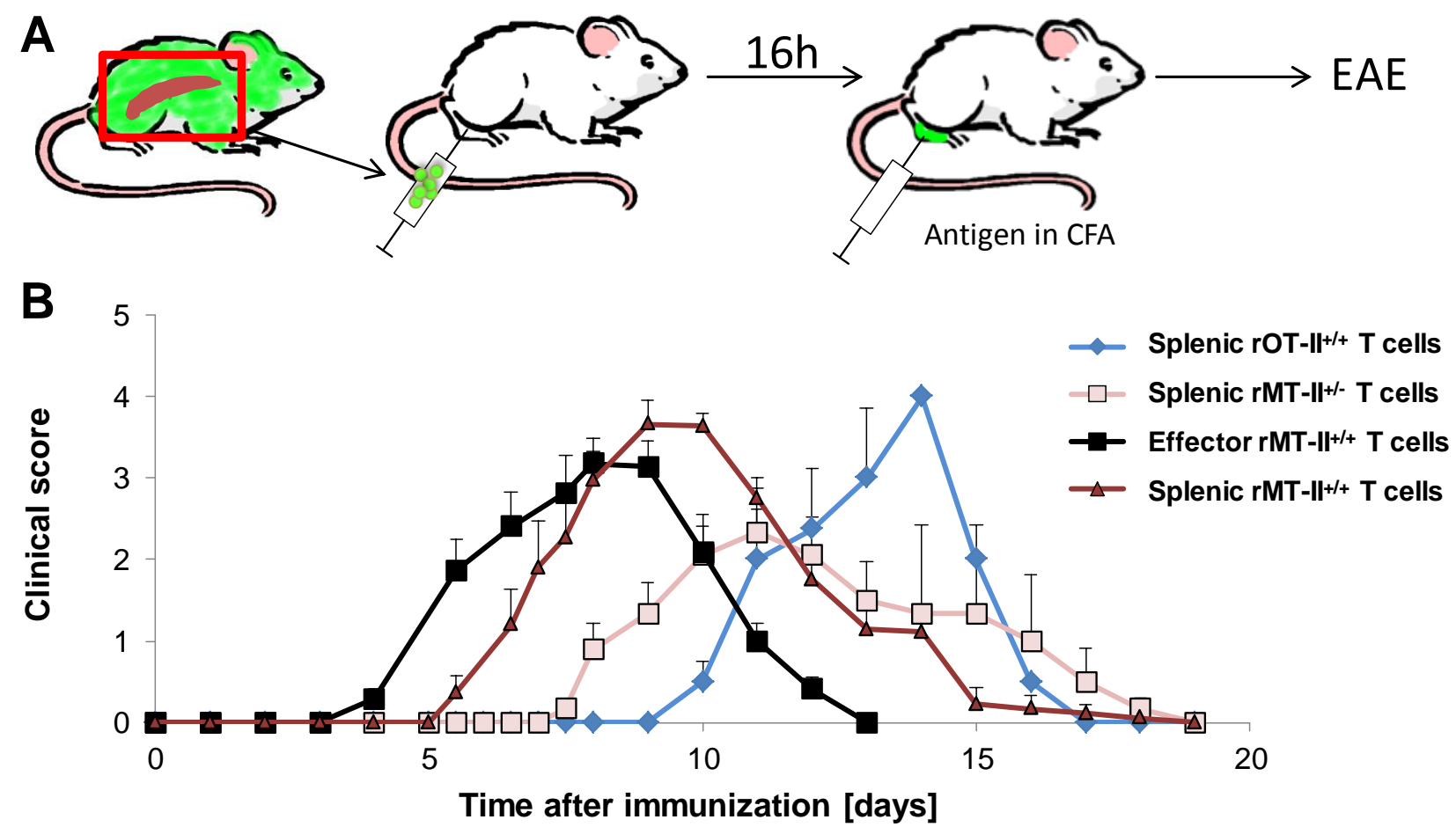

Figure 3.28: Clinical disease courses after local activation of $T$ cells. (A) EAE curve after local transfer of splenic cells derived

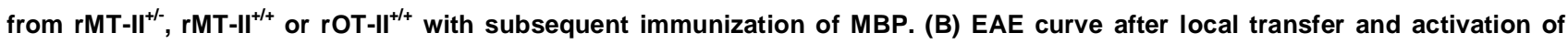
effector $T$ cells derived from $r M T-I^{+/+}$rats. $n \geq 3$. Graphs depicted as Mean \pm SEM. 
Interestingly, subcutaneous transfer of an effector $\mathrm{T}$ cell line derived from $\mathrm{rMT}-\mathrm{II}^{+/+}$rats with subsequent immunization could further accelerated the disease onset (4 days post immunization) but neither alter the disease duration nor the severity (Fig. 3.27 B).

\subsubsection{MIGRATORY PATTERN OF SPLENIC $\mathrm{rMT}-\mathrm{II}^{+/+}$CELLS AND EFFECTOR $\mathrm{rMT}-\mathrm{II}^{+/+}$ T CELLS AFTER LOCAL ACTIVATION IN LYMPH NODES}

To follow the migratory route of $\mathrm{rMT}-\mathrm{II}^{+/+}$splenocytes or effector $\mathrm{T}$ cells derived from rMT$\mathrm{II}^{+/+}$animals, either cell type was injected into the right hind limb of naïve recipients. Animals were immunized at the same location and expansion and the migratory route of $\mathrm{T}$ cells were monitored by assessing the $\mathrm{GFP}^{+}$cell number in distinct organs.

Splenic $T$ cells first expanded in the draining popliteal lymph node with a peak 4 days after immunization (Fig. 3.30 A). The expanded $\mathrm{GFP}^{+}$cells were further characterized by FACS analysis showing that all $\mathrm{GFP}^{+}$cells expressed CD4 and additionally $\mathrm{CD} 8 \alpha$, which can here be used as a marker for T cell activation (Fig. 3.29 A, Kenny et al., 2004). The transferred splenocytes also contained B cells and macrophages. However, FACS analysis could show that only $T$ cells entered the draining lymph nodes and expanded (Fig. 3.29 A) after transfer and during the whole kinetic $\mathrm{GFP}^{+}$cells were always $\alpha \beta \mathrm{TCR}^{+}$.

Three days after immunization, T cells appeared in blood, spleen (Fig. 3.30 A) and other lymph nodes (data not shown) before entering the meninges and the CNS parenchyma 5-6 dpi. The cells were also detectable in both meninges and CNS parenchyma 7 days after immunization when animals reached the peak of the disease and some cells still circulated in the blood. 
A Splenic $\mathrm{rMT}^{+/+} \mathrm{T}$ cells
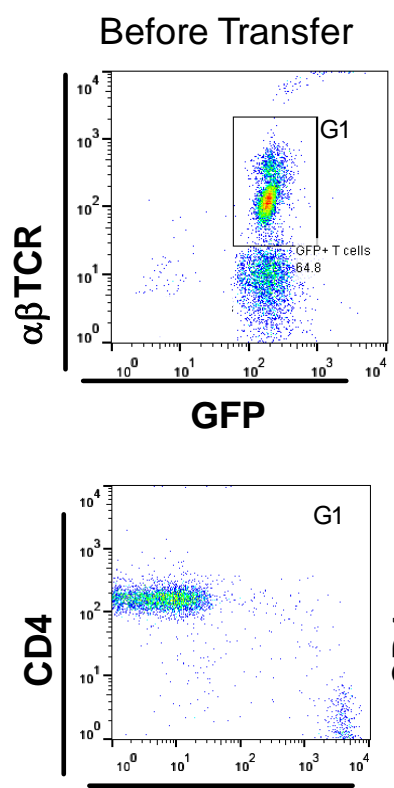

CD8 $\alpha$

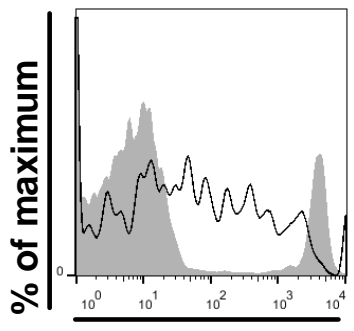

CD8 $\alpha$
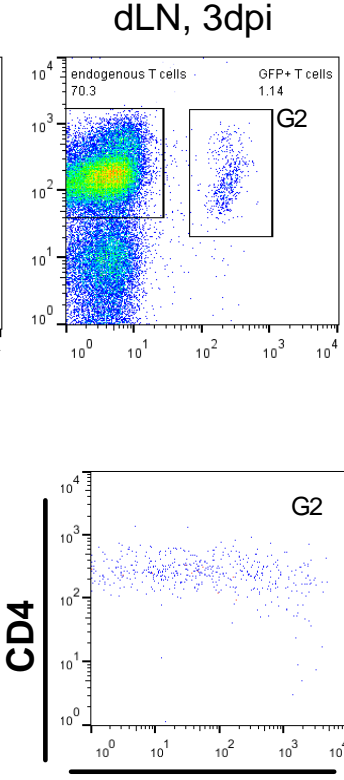

CD8 $\alpha$

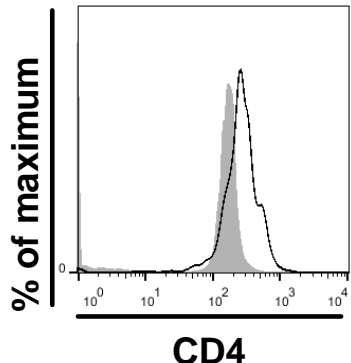

B

Effector $\mathrm{rMT}^{+/+} \mathrm{T}$ cells
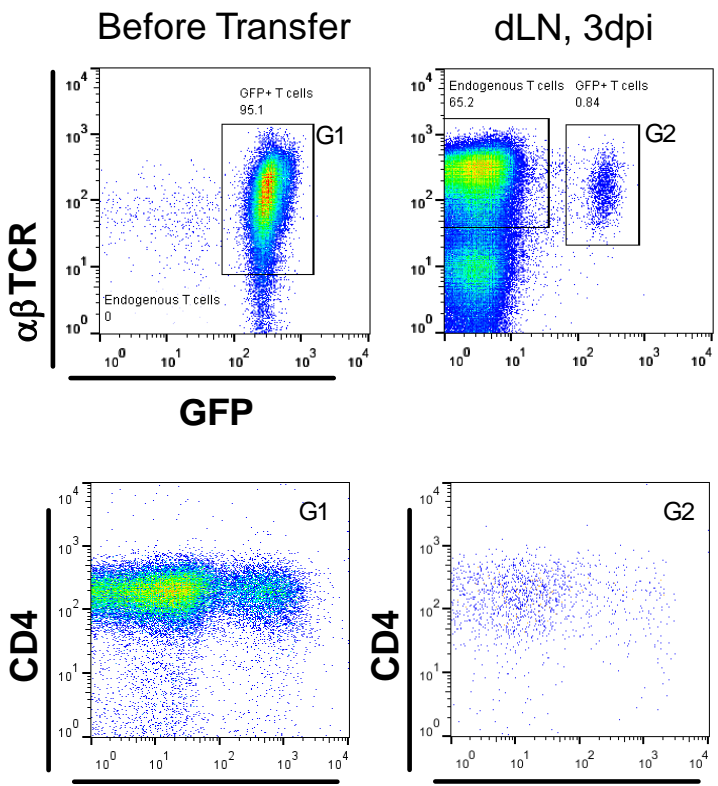

CD8 $\alpha$

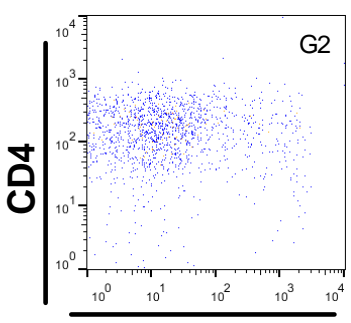

CD8 $\alpha$

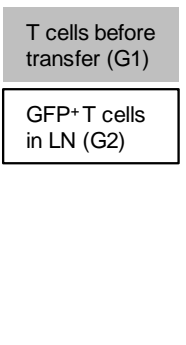

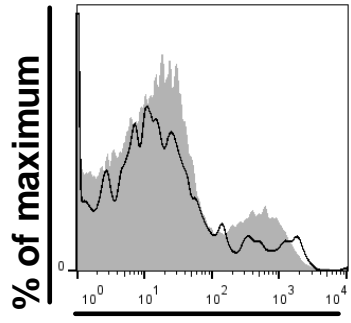

$\operatorname{CD} 8 \alpha$

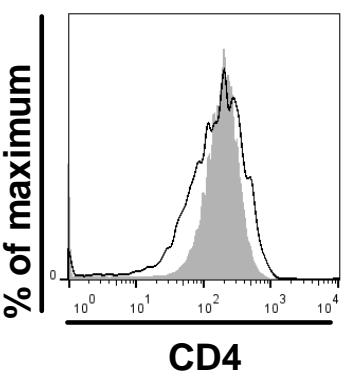

Figure 3.29: FACS analysis of $\alpha \beta T C R$, CD4 and CD8 $\alpha$ expression on transferred splenic (A) and effector (B) rMT-II ${ }^{++} \mathrm{T}_{\text {cells }}$ before and after activation in draining lymph nodes (dLN).

Effector $\mathrm{rMT}-\mathrm{II}^{+/+} \mathrm{T}$ cells followed a similar migratory route to the CNS with a rapid expansion in the draining lymph node peaking already two days after immunization. All GFP $^{+}$cells were $T$ cells and expressed CD4 in draining lymph nodes 3 days post immunization (Fig. 3.29 B).

On day 3 the T cells appeared in blood (Fig. 3.30 B) and 1 day later, during the onset of disease, were detectable in spleen, meninges and CNS parenchyma. However, at the peak of the disease nearly no $\mathrm{GFP}^{+} \mathrm{T}$ cells were detectable in blood, meninges and CNS parenchyma.

All in all, the maximum total cell number of $\mathrm{GFP}^{+}$cells in all organs except CNS parenchyma of rats transferred with splenic $T$ cells was reduced 10 -fold for peripheral organs and meninges and 200 -fold for blood compared to the transfer of effector $\mathrm{T}$ cells. 
A Splenic $\mathrm{rMT}^{+/+} \mathrm{T}$ cells

Popliteal LN

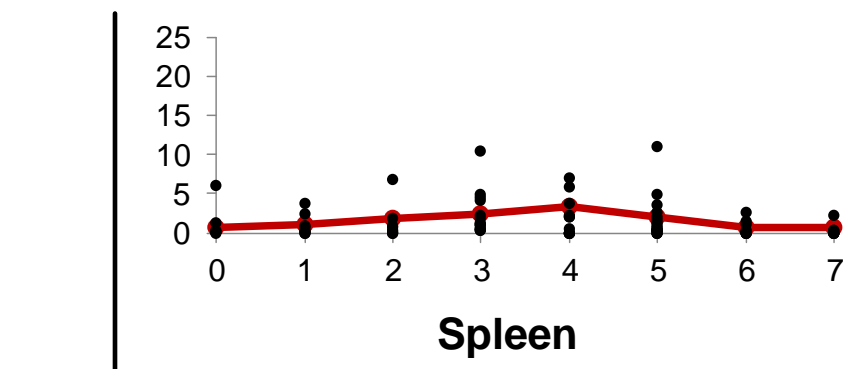

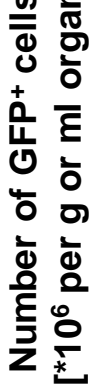

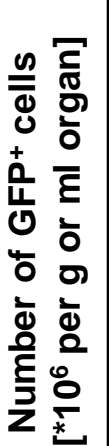

B Effector $\mathrm{rMT}^{+/+} \mathrm{T}$ cells

\section{Popliteal LN}
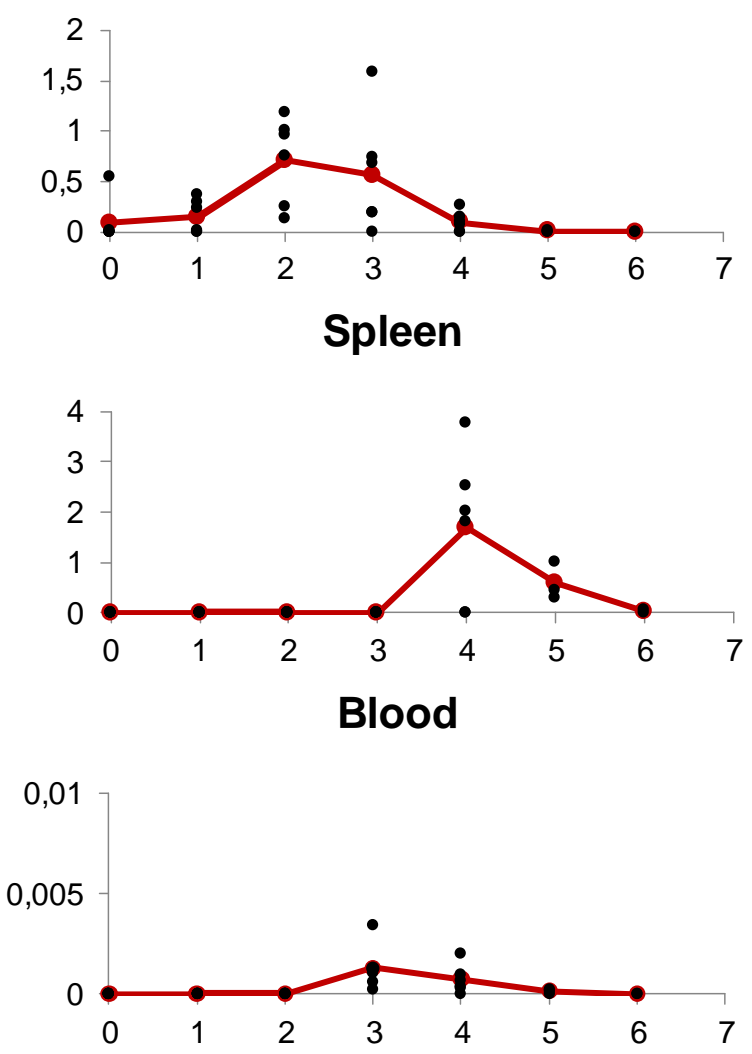

Men

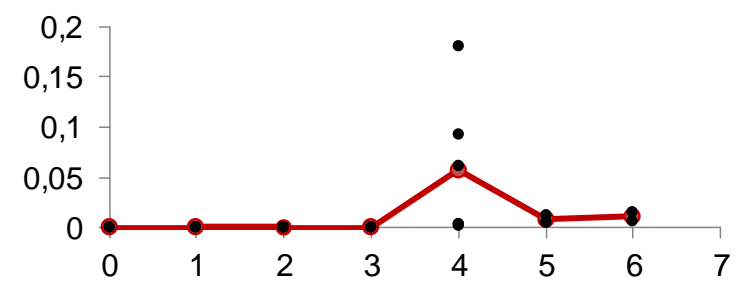

\section{CNS}

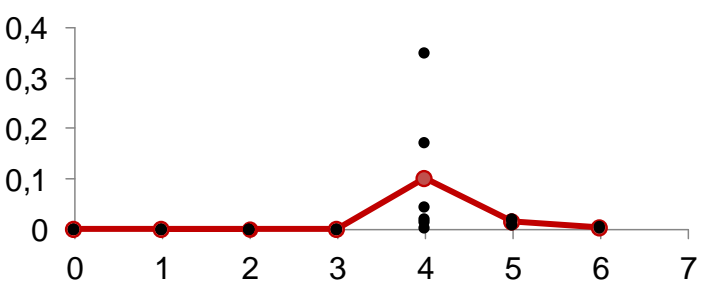

Time after immunization [days]

Figure 3.30: $\mathrm{GFP}^{+}$cells per gram or $\mathrm{ml}$ organ in million cells counted by FACS analysis after transfer of splenic rMT-II+/ $(A)$ and effector (B) $r M T-I^{+/+}$cells at the indicated days after immunization. $n \geq 3$ per day. Graphs depicted as single values (black dots) and mean (red line). 


\subsection{5 $\mathrm{rMT}-\mathrm{II}^{+++} \mathrm{T}$ CELLS BECOME REACTIVATED IN THE CNS AND PRODUCE PROINFLAMMATORY CYTOKINES}

To analyse the activation status of transferred $T$ cells along their migratory route, cell suspensions of different organs at different time points were stained for FACS analysis with an anti-CD25 antibody. CD25, the $\alpha$-chain of the IL-2 receptor, could be used as a marker for activation as it is upregulated on the $T$ cell surface after antigen recognition.

As shown in Fig. 3.31 A, both splenic GFP ${ }^{+} \mathrm{T}$ cells as well as effector $\mathrm{T}$ cells expressed basal levels of CD25 on the cell surface before subcutaneous transfer and before immunization with MBP. Effector T cells already showed an enhanced basal expression of CD25. However, analysis of the CNS at the EAE onset revealed an accelerated CD25 surface expression of splenic and effector $T$ cells in meninges and CNS parenchyma confirming a reactivation of both $T$ cell populations within the target tissue.

This observation could be confirmed by dissecting the gene expression of proinflammatory cytokines of the transferred T cells. To this extent, $\mathrm{GFP}^{+}$cells were sorted from various organs at different timepoints and mRNA expression levels were analyzed via qPCR (Fig. $3.31 \mathrm{~B}$ ).

Splenic T cells upregulated IFN $\gamma$ mRNA one day after immunization. Circulating $T$ cells in the blood during the onset of the disease did not express IFN $\gamma$ mRNA but the number of transcripts increased drastically within $T$ cells isolated from CNS meninges and parenchyma at the disease onset. $T$ cells recovered from the CNS compartments at the disease onset also expressed IL-17 and TNF $\alpha$ mRNA. While TNF $\alpha$ mRNA was still expressed at high levels during the peak of the disease in the CNS compartments, expression levels of IFN $\gamma$ and IL-17 mRNA dropped drastically. Interestingly, we observed upregulated IFN $\gamma$ expression in T cells recovered from the blood during the peak of the disease indicating that there might by a subpopulation of T cells leaving the CNS meninges or parenchyma after local reactivation.

In comparison to splenic $T$ cells, effector $T$ cells sorted from the different compartments expressed 4-10-fold higher levels of proinflammatory cytokine mRNA (Fig. 3.31 C). In detail, we observed an upregulation not only of IFN $\gamma$ but also of IL-17 and TNF $\alpha$ within the popliteal lymph node one and three days post immunization. At the disease onset, IFN $\gamma$ and TNF $\alpha$ mRNA was detectable in the blood and - in addition to IL-17 mRNA - in CNS meninges and parenchyma. At the peak of the disease, IFN $\gamma$ and IL-17 as well as TNF $\alpha$ 
mRNA levels dropped drastically. There was no proinflammatory cytokine mRNA production observed in the cells recovered from the blood during the peak of the disease.

A Splenic $\mathrm{rMT}^{+/+} \mathrm{T}$ cells Effector $\mathrm{rMT}^{+/+} \mathrm{T}$ cells

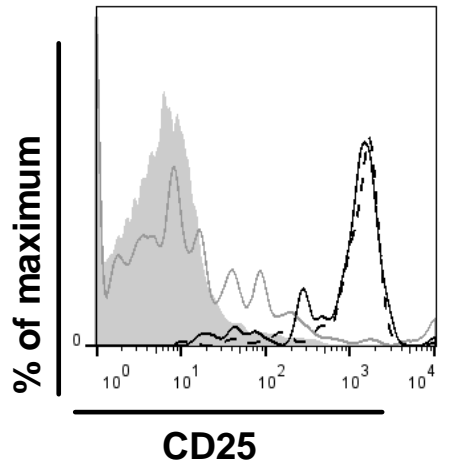

B

Splenic rMT+/+ T cells

$\mathrm{IFN \gamma}$

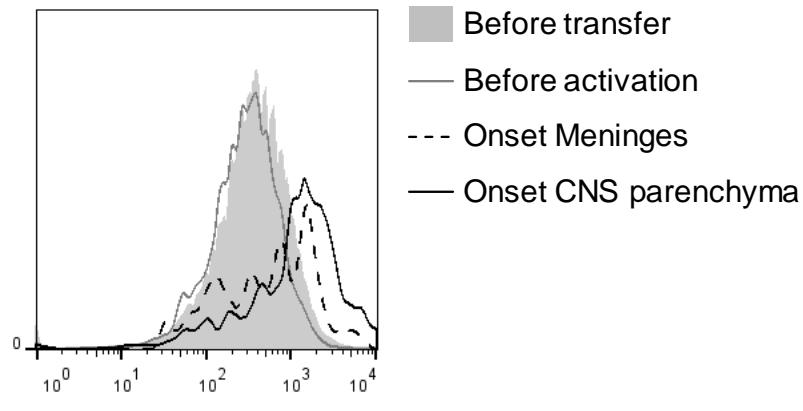

C

\section{Effector $\mathrm{rMT}^{+/+} \mathrm{T}$ cells}

IFN $\gamma$

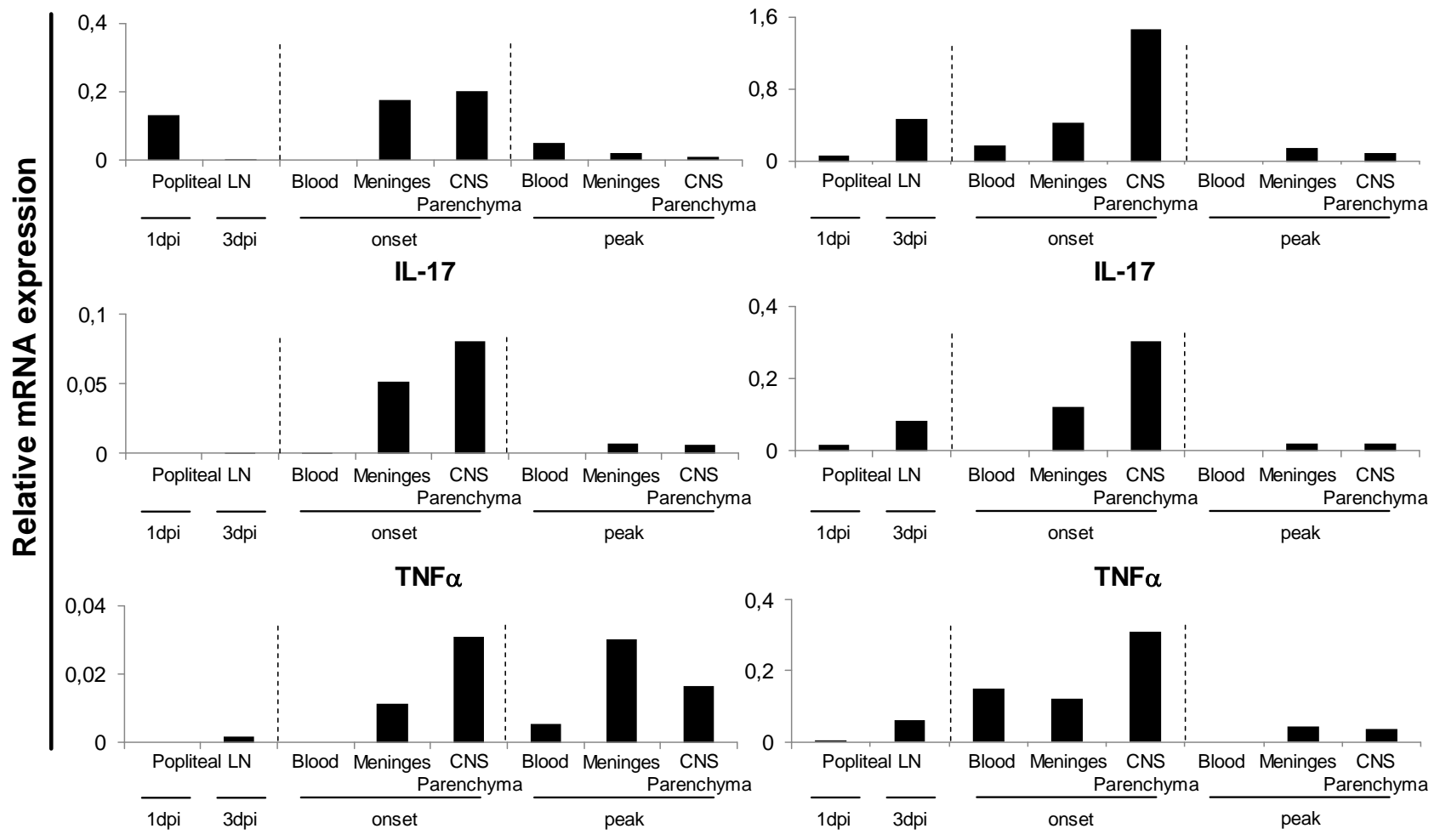

Figure 3.31: Analysis of splenic rMT- $\mathrm{I}^{+/+}$and effector $\mathrm{rMT}-\mathrm{II}^{+/+} \mathrm{T}$ cells during EAE. (A) Representative FACS histogram of CD25 surface expression of $\mathrm{GFP}^{+} \mathrm{T}$ cells at different time points during EAE development. Representative plots of mRNA expression level normalized to $\beta$-actin of proinflammatory cytokines during EAE development from sorted $\mathrm{GFP}^{+}$cells after splenic rMT-II $^{+/+}$ (B) and effector $\mathrm{rMT}-\mathrm{II}^{+/+} \mathrm{T}$ cell transfer (C). 
Conventional $T_{M B P}-G F P$ effector $T$ cells are known to crawl along the endothelium of leptomeningel blood vessels before transmigrating into the CNS parenchyma (Bartholomaus et al., 2009).

When analyzing the migratory behaviour of $\mathrm{rMT}^{-\mathrm{II}^{+/+}}$derived effector $\mathrm{T}$ cells $48 \mathrm{~h}$ (before disease onset) after intravenous transfer via two-photon live microscopy we could observe a certain fraction of cells crawling intraluminally along the vessel endothelium (Fig 3.32 B). However, splenic $\mathrm{rMT}-\mathrm{II}^{+/+} \mathrm{T}$ cells transferred subcutaneously and activated locally did not show this intraluminal crawling phenotype before disease onset (Fig. 3.32 A).

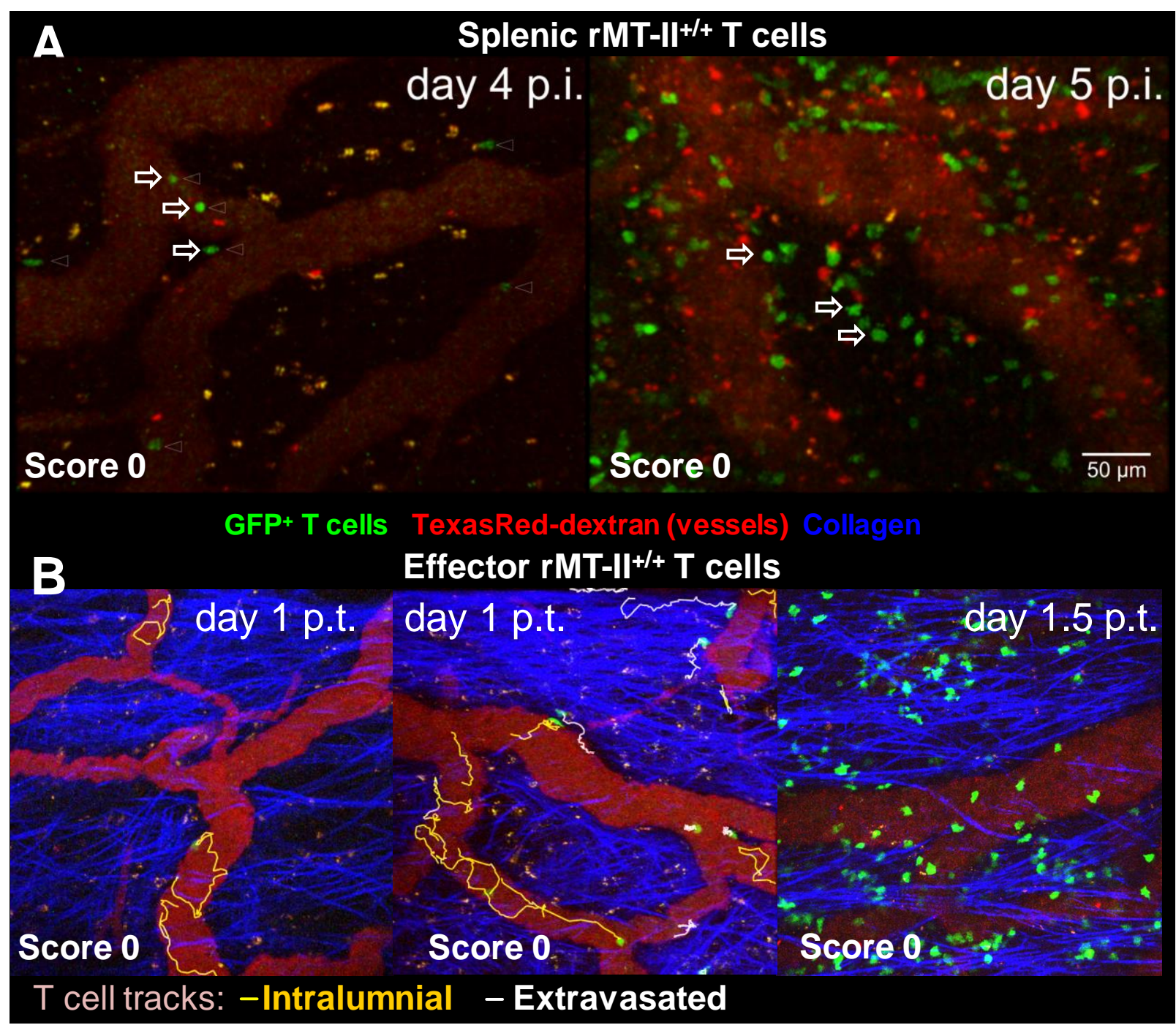

Figure 3.32: Two-photon live microscopy analysis of T cells invading leptomeninges of the spinal cord during atEAE. (A) First $\mathrm{rMT}_{-1 \mathrm{II}^{+/+}} \mathrm{T}$ cells after priming in the popliteal lymph node appeared in the CNS meninges 4 days after immunization (arrows). Massive $T$ cell infiltration before clinical manifestation could be observed 5 days after immunization. T cells do not crawl within the blood vessels but nevertheless can efficiently transmigrate the BBB (arrows). (B) Adoptive transfer of activated GFPretro $\mathrm{rMT}_{-1 \mathrm{II}^{+/+}}$effector T cells. Already $24 \mathrm{~h}$ after transfer first T cells with intraluminally crawling (yellow tracks) and few extravasated ones (white tracks) can be seen. 
As chemokine receptors such as CXCR3 and CCR5 are thought to be key mediatiors in the crawling and transmigration process of $\mathrm{T}$ cells through the blood-brain barrier (Schläger, 2013) we sorted $\mathrm{GFP}^{+}$T cells from different organs and analyzed their chemokine receptor expression pattern.

In both splenic and effector T cells an upregulation of CXCR3 mRNA was observed in blood, CNS meninges and CNS parenchyma during EAE onset although with a higher expression level in effector T cells (Fig. 3.33 A and B). Effector T cells further expressed CXCR3 mRNA during the peak of disease. CCR5 was only detectable in effector T cells sorted from blood, CNS meninges and parenchyma during the disease onset. Effector $\mathrm{T}$ cells expressed CCR2 mRNA, a molecule involved in the recruitment of $\mathrm{T}$ cells to inflammatory sites, at higher levels than splenic $T$ cells.

Splenic T cells expressed CCR7, a chemokine receptor either expressed on naïve or effector-memory $\mathrm{T}$ cells, during the disease onset in blood and in blood and meninges at the peak of the disease. Interestingly, the splenic $\mathrm{T}$ cell population which could be recovered from blood during the peak of disease expressed CCR2, CCR7 and CXCR3 mRNA.

Taken together, these results showed a differential chemokine receptor expression pattern in splenic $\mathrm{T}$ cells and effector $\mathrm{T}$ cells entering the CNS compartment during the onset of EAE. As especially CXCR3 and CCR5 are associated with a crawling phenotype of T cells along the endothelium of blood vessels, the lower expression level or absence of expression could explain the lack of crawling observed in splenic T cells with two-photon microscopy.

Additionally, the expression of CCR2, CCR7 and CXCR3 recovered from blood as well as the expression of CCR7 within CNS tissues during the peak of the disease hint at a heterogeneity of $\mathrm{T}$ cell subpopulations present in splenic $\mathrm{T}$ cells but not in effector $\mathrm{T}$ cells. 


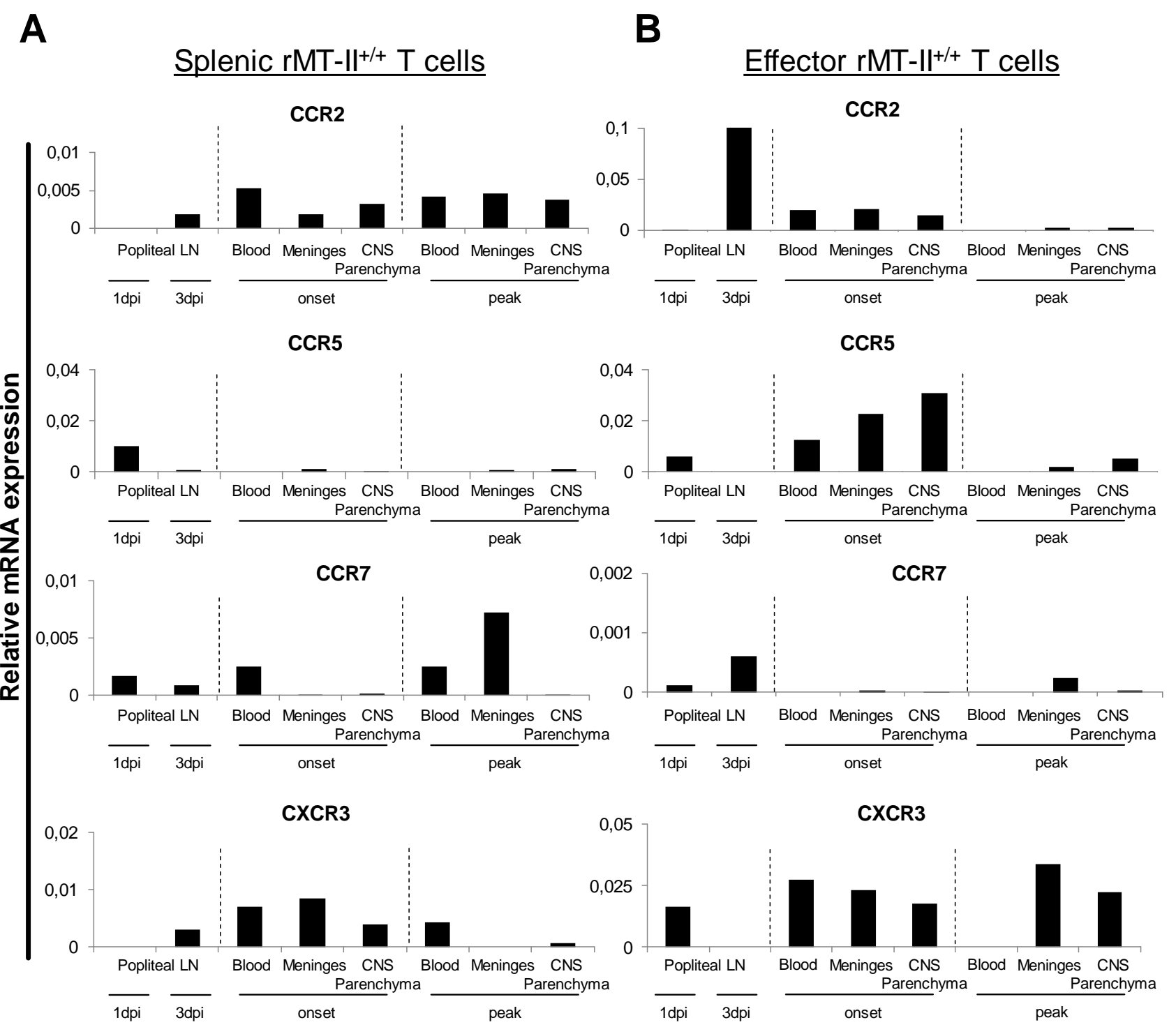

Figure 3.33: Analysis of splenic $\mathrm{rMT}-\mathrm{II}^{+/+}$and effector $\mathrm{rMT}-\mathrm{II}^{+/+} \mathrm{T}$ cells during EAE. Representative plots of mRNA expression level of chemokine receptors during EAE development from sorted $\mathrm{GFP}^{+}$cells after splenic $\mathrm{rMT}^{-\mathrm{II}^{+/+}}(\mathrm{A})$ and effector $\mathrm{rMT}^{-\mathrm{II}^{+/+}}$ $T$ cell transfer (B). 
As an additional read-out for $\mathrm{T}$ cell activation, cell suspensions were stained for CD62L surface expression which is expressed on naïve $T$ cells and central-memory $T$ cells $\left(T_{C M}\right)$ and down-regulated after activation and completely absent on effector $\mathrm{T}$ cells.

Before transfer, around $40 \%$ of the transferred splenic $\mathrm{rMT}^{-\mathrm{II}^{+/+}} \mathrm{T}$ cells expressed CD62L. In the $\mathrm{GFP}^{+} \mathrm{T}$ cells, CD62L expression was downregulated on day 3 after immunization suggesting that splenic $\mathrm{rMT}^{-\mathrm{II}^{+/+}} \mathrm{T}$ cells were completely activated by the immunization

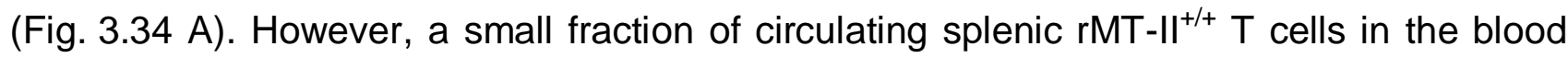
one day before the disease onset expressed CD62L but none of the splenic rMT- $\mathrm{II}^{+/+} \mathrm{T}$ cells observed in CNS parenchyma at the disease onset. Additionally, circulating effector

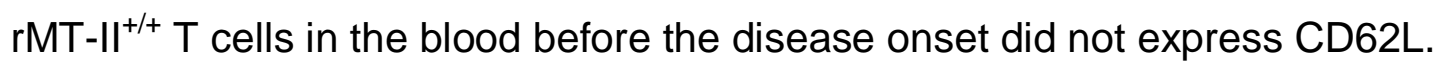

As both naïve and $T_{C M} T$ cells express $C D 62 L$, we were interested in determining the phenotype of this cell population in more detail. $\mathrm{GFP}^{+} \mathrm{CD} 2 \mathrm{~L}^{+}$or $\mathrm{CD}^{2} 2 \mathrm{~L}^{-} \mathrm{T}$ cells as well as endogenous $\mathrm{CD} 2 \mathrm{~L}^{+}$or $\mathrm{CD} 2 \mathrm{~L}^{-} \mathrm{T}$ cells were sorted from the blood before the disease onset and analyzed for the gene expression of proinflammatory cytokines IFN $\gamma$ and TNF $\alpha$, chemokine receptors CCR2, CCR5 and CCR7.

$\mathrm{GFP}^{+} \mathrm{CD} 2 \mathrm{~L}^{+} \mathrm{T}$ cells expressed higher levels of IFN $\gamma$ and TNF $\alpha$ mRNA compared to endogenous $\mathrm{CD} 2 \mathrm{~L}^{+} \mathrm{T}$ cells. Furthermore, $\mathrm{GFP}^{+} \mathrm{T}$ cells and endogenous $\mathrm{T}$ cells featured the same expression pattern of chemokine receptors with $\mathrm{CD}^{2} 2 \mathrm{~L}^{-} \mathrm{T}$ cells expressing higher levels of CCR2 and CCR5 compared to $\mathrm{CD}^{2} 2 \mathrm{~L}^{+} \mathrm{T}$ cells. However, both $\mathrm{GFP}^{+}$and endogenous $\mathrm{CD} 2 \mathrm{~L}^{+} \mathrm{T}$ cells expressed more CCR7 mRNA than CD62L $\mathrm{T}$ cells (Fig. 3.34 B). 
A Splenic rMT- $\|^{+++} \mathrm{T}$ cells Effector $\mathrm{rMT}-\|^{+++} \mathrm{T}$ cells
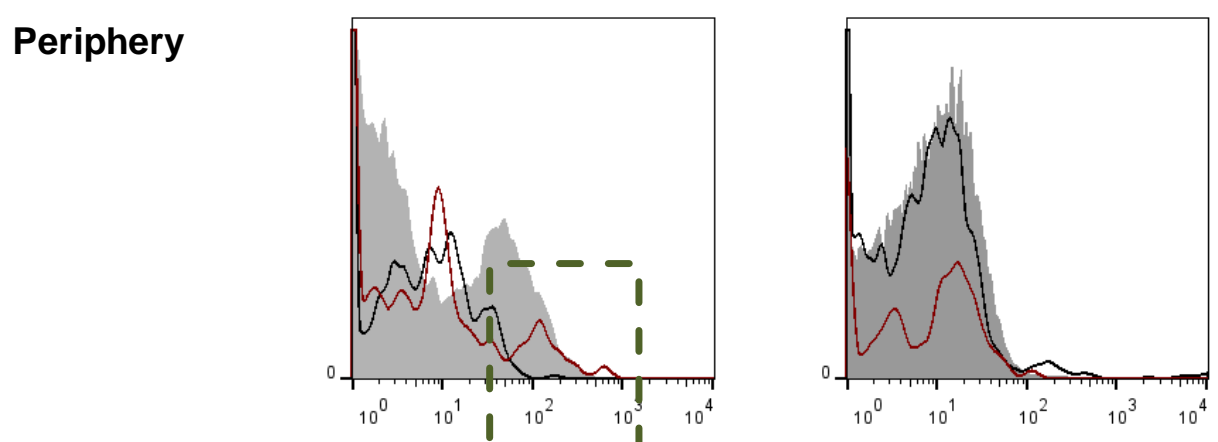

Before transfer

— 3dpi Draining LN

— Onset Blood

CNS
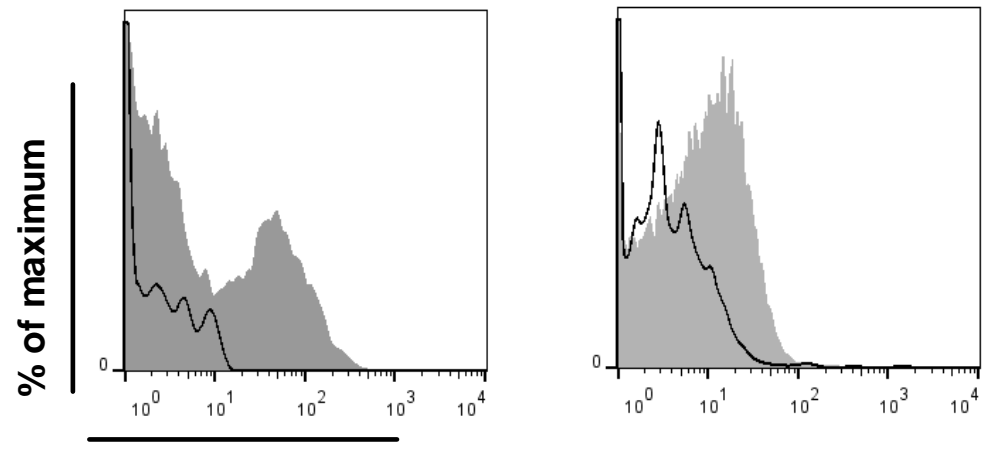

Before transfer

- Onset CNS

CD62L

B

IFN $\gamma$

TNF $\alpha$
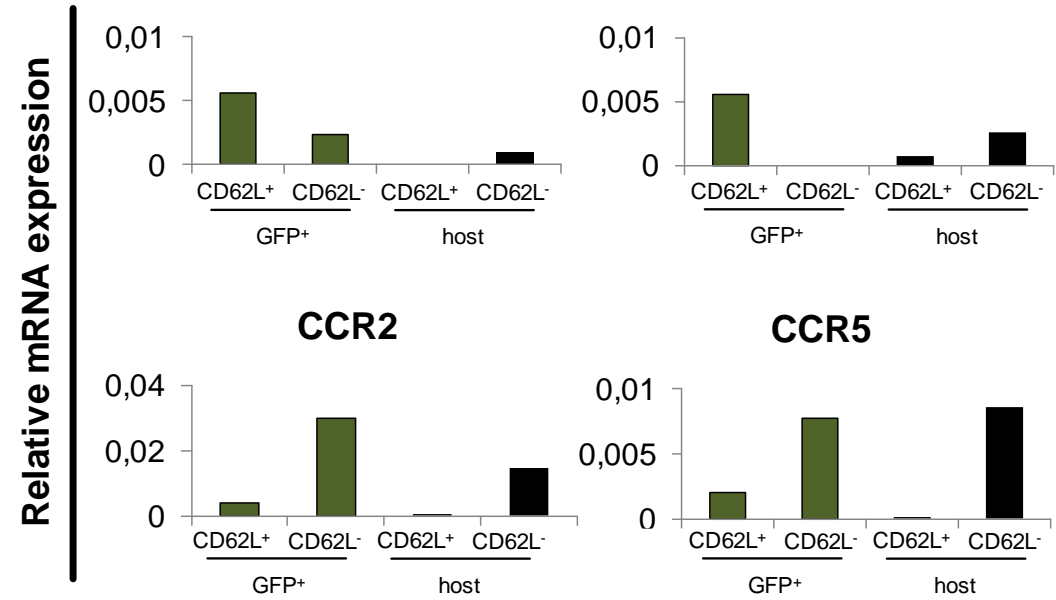

CCR5

CCR7
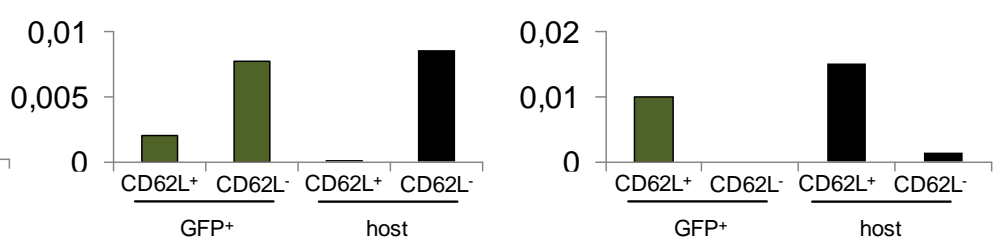

Figure 3.34: Analysis of a $\mathrm{CD}_{2} \mathrm{~L}^{+} \mathrm{T}$ cell population circulating in the blood. (A) Histogram overlays of CD62L surface expression in the periphery and CNS at different time points during EAE development. (B) Representative mRNA expression plots of sorted adoptively transferred $\mathrm{GFP}^{+}$or host-derived $\mathrm{CD} 6 \mathrm{~L}^{+}$and $\mathrm{CD} 6 \mathrm{~L}^{-} \mathrm{T}$ cell populations from the blood. 


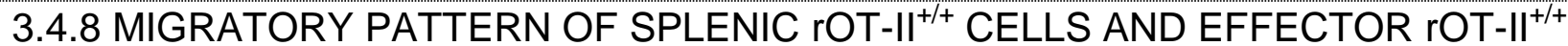 T CELLS AFTER LOCAL ACTIVATION}

As the migratory route we observed for $\mathrm{rMT}-\mathrm{II}^{+/+}$after subcutaneous transfer and activation might be a $T$ cell intrinsic migratory program not restricted to autoimmune $T$ cells, we transferred $\mathrm{rOT}-\mathrm{II}^{+/+}$splenocytes or effector $\mathrm{T}$ cells derived from $\mathrm{rOT}-\mathrm{II}^{+/+}$animals and immunized recipients locally with OVA in CFA. The migratory route was monitored by assessing the $\mathrm{GFP}^{+}$cell number in distinct organs.

Splenic T cells first expanded in the draining popliteal lymph node with a peak 3-4 days after immunization (Fig. 3.35 A). Three - four days after immunization, $T$ cells appeared in blood, spleen (Fig. $3.35 \mathrm{~A}$ ) and other lymph nodes (plots not shown). As there was no target antigen present for these T cells in the CNS, there was no inflammation and the cells could not be detected in the CNS or meninges (plots not shown).

Effector $\mathrm{rOT}-\mathrm{II}^{+++} \mathrm{T}$ cells followed a similar migratory route with a rapid expansion in the draining lymph node peaking 3-4 days after immunization. On day 3 the T cells appeared in blood (Fig. 3.35 B) and spleen but again did not enter meninges and CNS parenchyma.

All in all, the maximum total cell number of $\mathrm{GFP}^{+}$cells in all organs was reduced 10 -fold for peripheral organs and blood compared to splenic rOT- $\mathrm{II}^{+/+} \mathrm{T}$ cells.

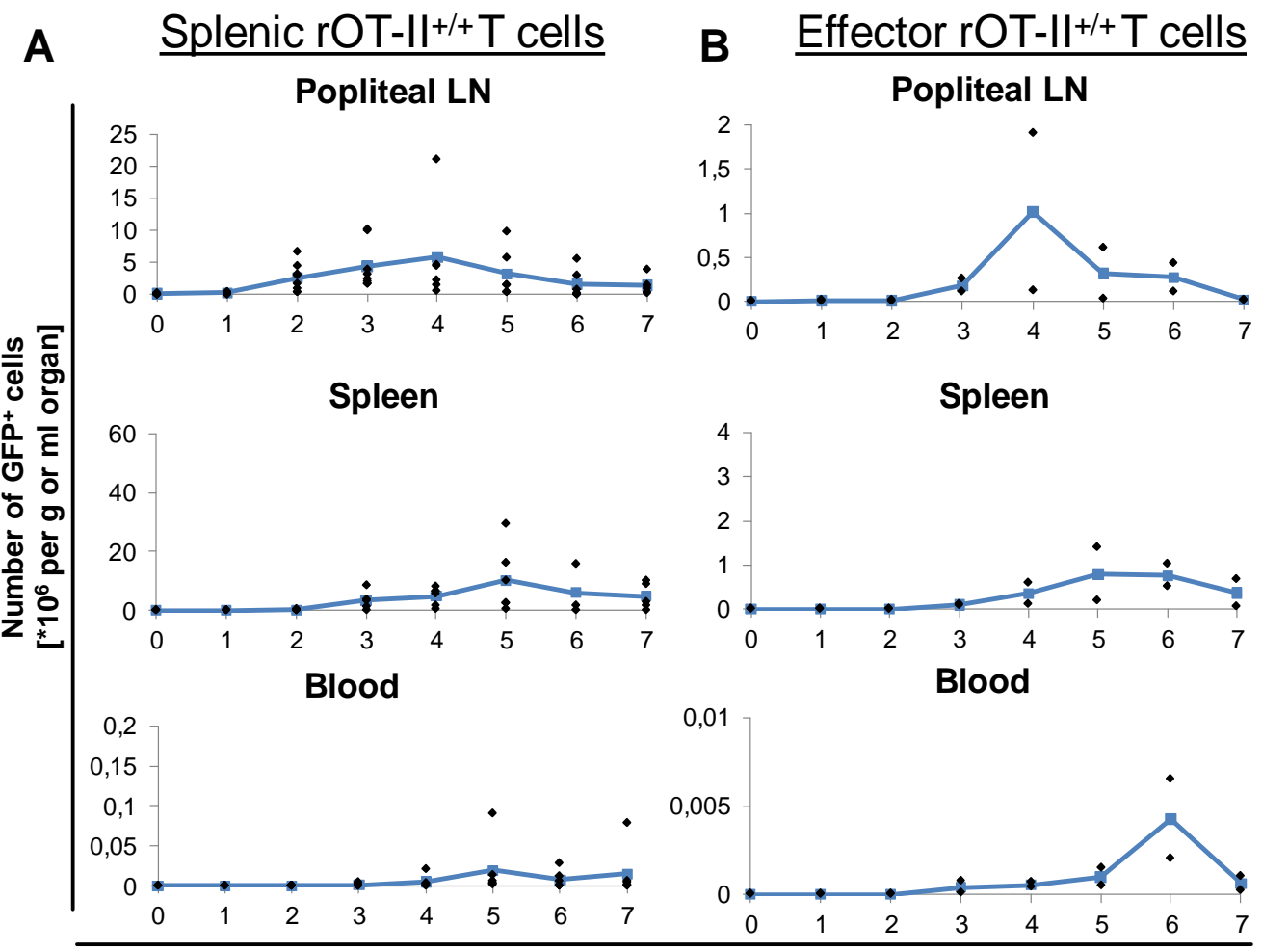

Time after immunization [days]

Figure 3.35: $\mathrm{GFP}^{+}$cells per gram organ after transfer of splenic rOT- $-\mathrm{II}^{+/+}\left(\mathrm{A}, \mathrm{n} \geq 3\right.$ per day) and effector $\left(\mathrm{B}, \mathrm{n}=2\right.$ per day) rOT- $-\mathrm{I}^{+/+} \mathrm{T}$ cells at the indicated days after immunization. Graphs depicted as single values (black dots) and mean (blue line). 


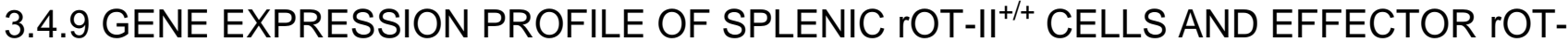

$\mathrm{II}^{+/+} \mathrm{T}$ CELLS AFTER LOCAL ACTIVATION

Elucidating the chemokine receptor mRNA expression levels, both splenic and effector T cells upregulated CCR2 and CXCR3 mRNA in T cells sorted from blood circulation 5-7 days after immunization with an approximately 10-fold higher expression level in effector T cells (Fig. 3.36). CCR5 was only detectable in splenic T cells sorted from blood and effector $\mathrm{T}$ cells obtained from the draining popliteal lymph node at indicated time points. Splenic T cells expressed CCR7 during their expansion in the draining lymph node as well as during blood circulation 5 and 7 days after immunization. At day 7 after immunization, effector $\mathrm{T}$ cells recovered from the blood did also express CCR7.

Taken together, these results showed a differential chemokine receptor expression pattern in splenic $T$ cells and effector $T$ cells circulating in the blood at time points when encephalitogenic $T$ cells would potentially cause EAE. At this point of observation, the mRNA expression pattern again hints at a heterogeneity of $T$ cell subpopulations which need to be clarified further.

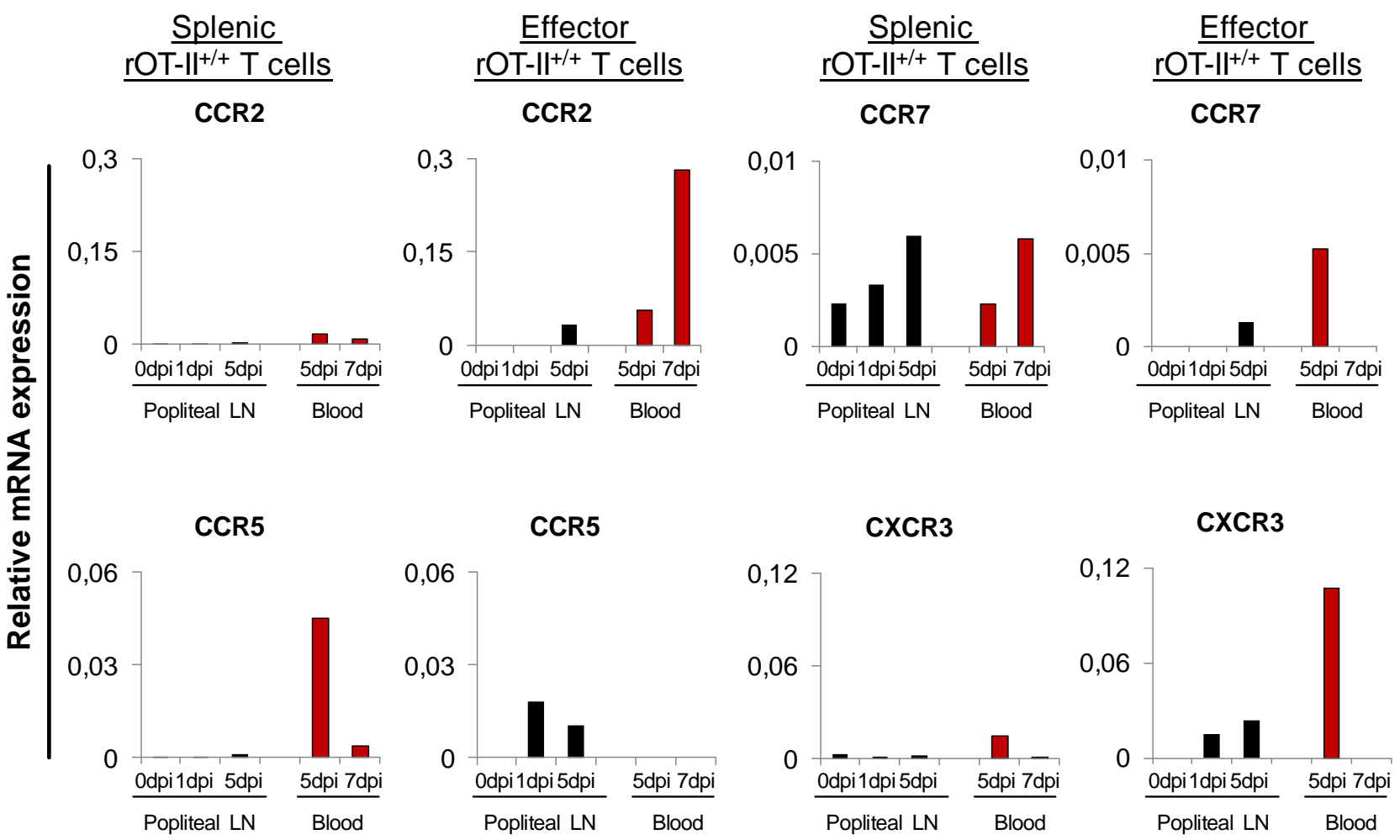

Figure 3.36: Analysis of splenic rOT- $\mathrm{II}^{+/}$and effector rOT- $\mathrm{II}^{+/+} \mathrm{T}$ cells after local activation. Representative plots of mRNA expression level of chemokine receptors CCR2, CCR5, CCR7 and CXCR3 during EAE development from sorted GFP ${ }^{+}$cells after splenic rOT- $\mathrm{II}^{+/+}$and effector $\mathrm{rOT}-\mathrm{II}^{+/+} \mathrm{T}$ cell transfer. 


\section{DISCUSSION}

Lewis rat $E A E$ is a classical model for studying acute inflammatory pathomechanisms in the CNS. The adoptive transfer of MBP-specific $\mathrm{CD} 4^{+}$effector $\mathrm{T}$ cells cultured ex vivo induces a monophasic paralytic disease. Because effector $T$ cells can be genetically manipulated ex vivo to express fluorescent markers, adoptive transfer EAE is a well suited method for intravital imaging of autoreactive and non-pathogenic T cells in CNS tissue. Such an analysis however is limited to an effector $\mathrm{Th} 1 \mathrm{CD} 4^{+} \mathrm{T}$ cell population; its behavior may also be biased by prolonged ex vivo culturing with multiple restimulation cycles. We aimed to provide the Lewis rat EAE model with new experimental modalities, for example an access to naïve T cells of defined specificity. This can be achieved by generating TCR transgenic animals which have proven to be a powerful approach for providing useful tools for immunological and CNS autoimmunity research (Goverman et al., 1993; Lafaille et al., 1994; Bettelli et al., 2003). The first aim of this study was therefore the generation and characterization of TCR transgenic Lewis rats. Secondly, we wanted to investigate the migratory behaviour of naïve antigen-specific T cells upon in vivo priming and in the course of EAE.

\subsection{GENERATION AND INITIAL ANALYSIS OF TCR TRANSGENIC RATS}

\subsubsection{MBP-SPECIFIC TCR TRANSGENIC RATS}

We used the previously established effector T cell line Z85 (Chluba et al., 1989) with characterized composition of the TCRß chain - utilizing the VB8.2 segment detectable by mAb R73 (Torres-Nagel et al., 1993) - to reconstruct a MBP-specific TCR. This receptor was reported to recognize myelin self-antigen presented by Lewis rat MHC class II molecules. As the Z85 line was established from a normal T cell repertoire of a Lewis rat, the thymocytes harbouring this TCR would presumably be able to escape negative selection against self-reactive clones during development and be eventually present in the peripheral immune system of transgenic animals. We were able to identify a TCR $\alpha$ chain that, upon combination with the Z85 TCRß chain and subsequent viral transfer into receptor-negative hybridoma, confers surface expression of a functional $\alpha ß T C R$. This receptor mediated a response to MBP presented by Lewis rat APCs (Fig. 3.1 D-E). 
High-titer lentiviruses carrying genes for one fluorescent marker and two TCR chains were prepared and used for transduction of early Lewis rat embryos. Although several founders with genomic integration of the provirus were identified, only few of them exhibited GFP expression in blood cells. Further breeding resulted in animals which expressed GFP marker, albeit at different levels, in all peripheral blood leukocytes and displayed a high proportion of mature $T$ cells expressing the TCR-V $\beta 8.2$ chain. This phenotype seems to be stably inherited through several generations in a new Lewis strain which has been designated rMT-II. The levels of GFP expression and their inheritance suggest that a single chromosomal integration site (one allele) is present in rMT-II rats. Importantly, $\mathrm{rMT}^{-\mathrm{II}^{+/+}}$and $\mathrm{rMT}^{-\mathrm{II}^{+/}}$genotypes which can be deduced from GFP expression associate with quite distinct properties of the mature T cell repertoire (Fig 3.3). In mice, a monoallelic expression of the transgenic TCR is usually enough to cause allelic exclusion of $\beta$ chain expression and minimize the number of $T$ cells expressing endogenously rearranged TCR genes distinct from the transgenic TCR. In $\mathrm{rMT}^{-\mathrm{II}^{+/}}$rats, allelic exclusion is not very efficient. It is tempting to speculate that the TCR ${ }^{\text {high }}-\mathrm{V} \beta 8.2^{\text {medium }}$ population of $\mathrm{T}$ cells (Fig. 3.2 C, similar also in Fig. 3.11 $\mathrm{B}$ for $\mathrm{rOT}-\mathrm{II}^{+/-} \mathrm{TCR}^{\text {high }}-\mathrm{V} \beta 16^{\text {medium }}$ ) may express two different TCRs - one transgenic and another endogenous, e.g. $V \beta 8.5$ or $V \beta 16$. This possibility has to be addressed by further analysis.

The reason for inefficient allelic exclusion could be a suboptimal transcription rate driven by the ubiquitin promoter in rat T cells. Two observations argue in favour of this explanation. First, in rOT-II heterozygotes (discussed below) where TCR transcription is driven by the same promoter, allelic exclusion is also inefficient. Second, mean levels of $\alpha \beta T C R$ (and CD3) expression in homozygous rMT-II and rOT-II T cells is lower than in WT T cells. Hence, it is rather the nature of the lentiviral promoter than an effect of the integration site that mediates the lack of allelic exclusion. Furthermore, even in $\mathrm{rMT}^{-\mathrm{II}^{++}} \mathrm{T}$ cells the expression of GFP is only of a moderate level, i.e. several fold lower than the expression achieved by retroviral transduction of T cells (Flügel et al., 1999). This level is fully sufficient for FACS analyses and confocal microscopy, but for intravital imaging the introduction of additional bright fluorescent markers would be an advantage. It should be noted, that the rMT-II strain can be maintained on a homozygous background, which is not the case for several other transgenic rat strains, e.g. rOT-II or AsRed (RFPtg).

$\mathrm{rMT} \mathrm{II}^{+/+} \mathrm{T}$ cells challenged with antigen in vitro responded by proliferation and production of proinflammatory cytokines in a dose-dependent manner, thus confirming both the 
functionality and the specificity of the receptor (Fig. 3.6). The blocking of TCR interaction with MHC class II complex by the monoclonal OX-6 antibody completely prevented proliferation and cytokine production and confirmed the MHC class II restriction of the TCR (Fig. 3.6).

Collectively, initial phenotyping of rMT-II animals indicated that lentiviral transgenesis is a suitable approach for the generation of TCRtg rats with pre-determined antigenic specificity including self-antigens.

\subsubsection{CHARACTERISATION OF THE T CELL COMPARTMENT IN IMT-II RATS}

As expected, the proportion of $\mathrm{CD}^{+} \mathrm{T}$ cells in the periphery of $\mathrm{rMT}-\mathrm{II}^{+/+}$animals is reduced due to an expanded $\mathrm{CD} 4^{+}$population, which is in line with MHC class II restriction of the transgenic TCR. This also suggests that our transgenic self-reactive TCR is spared by negative selection in the thymus. The preferential commitment to $\alpha \beta$ T cell lineage due to early expression of the transgenic TCR is a likely reason for reduced number of $\gamma \delta \mathrm{T}$ cells (also in the rOT-II strain). In the $\mathrm{LN}$ and spleen of $\mathrm{rMT}-\mathrm{II}^{+/+}$rats roughly half of the $\mathrm{T}$ cells expressed L-selectin (CD62L), a marker of naïve lymphocytes. The abundance of $\mathrm{CD}^{2} \mathrm{~L}^{+}$ T cells was similar between WT and MBP-TCRtg animals. Furthermore, CD45RC, another marker for naïve rat $T$ cells, was present in a similar proportion of $T$ cells as CD62L (data not shown). Sorting out $\mathrm{CD} 2 \mathrm{~L}^{+}$and $\mathrm{CD} 2 \mathrm{~L}^{-} \mathrm{T}$ cells by flow cytometry and analyzing their gene expression revealed higher levels of CCR2, CCR5 and CXCR3 mRNA in CD62L' T cells (Fig. 3.7 A, B). Expression of these chemokine receptors which are important for infiltration of inflamed tissues would be more appropriate in the memory subset, as memory $\mathrm{T}$ cells are considered to be equipped with a molecular repertoire that rapidly hoists an immune response upon antigen challenge. Interestingly, CCR7, a chemokine receptor usually used as a marker for naïve T cells, was expressed on the mRNA level to the same degree in $\mathrm{CD} 2 \mathrm{~L}^{+}$and $\mathrm{CD} 2 \mathrm{~L}^{-} \mathrm{T}$ cells sorted from rMT- $\mathrm{II}^{+/+}$rats. In 2005, Unsoeld and Pircher reported a similar observation as they described three distinct memory $T$ cell subtypes (Unsoeld and Pircher, 2005): $\mathrm{CD} 6 \mathrm{~L}^{+} \mathrm{CCR}^{+}, \mathrm{CD} \mathrm{CL}^{-} \mathrm{CCR} 77^{-}$and $\mathrm{CD}^{-} \mathrm{L}^{-}$ $\mathrm{CCR}^{+}$. $\mathrm{CD} 2 \mathrm{~L}^{+} \mathrm{CCR} 7^{+}$memory $\mathrm{T}$ cells were classified as central-memory $\mathrm{T}$ cells $\left(\mathrm{T}_{\mathrm{CM}}\right)$ and CD62L ${ }^{-}$CCR7 $7^{-}$as effector-memory $T$ cells $\left(T_{E M}\right)$. CD62 $L^{-} C C R 7^{+}$memory $T$ cells were subsequently described as intermediate memory $T$ cells $\left(T_{\text {IM }}\right)$. Furthermore in $\mathrm{rMT}^{-\mathrm{II}^{+/+}}$ animals, not stimulated $\mathrm{CD}_{2} \mathrm{~L}^{-} \mathrm{T}$ cells expressed higher mRNA levels of Tbet and FoxP3 
transcription factors, characteristic for antigen-experienced cells. Thus, CD62 $\mathrm{L}^{+} \mathrm{T}$ cells found in LNs and spleen of rMT-II rats are likely to be naïve MBP-specific T lymphocytes. Surprisingly, when stimulated with MBP (Fig. 3.7 C, D), CD62L ${ }^{+} \mathrm{T}$ cells proliferated even stronger than $\mathrm{CD}^{2} \mathrm{~L}^{-} \mathrm{T}$ cells (Fig $3.7 \mathrm{C}$ ). This observation was quite unexpected as $\mathrm{CD}^{-} \mathrm{L}^{-}$ memory $\mathrm{T}$ cells are reported to be more rapidly responsive upon antigen challenge. Increased responsiveness of the "naïve" $\mathrm{CD}_{2} \mathrm{~L}^{+} \mathrm{T}$ cell pool might indicate a presence of $\mathrm{CD} 2 \mathrm{~L}^{+}$memory $\mathrm{T}$ cells $\left(\mathrm{T}_{\mathrm{CM}}\right)$. Nevertheless, the kinetic of activation of splenic $\mathrm{rMT}^{-\mathrm{II}^{+/+}}$ cells (where $\sim 50 \%$ are $\mathrm{CD} 2 \mathrm{~L}^{+}$) in vitro shows that maximal expression of IFN $\gamma$ occurs relatively late - at $42 \mathrm{~h}$ after stimulation (Fig 3.5 A). Activation of $\mathrm{rOT}-\mathrm{II}^{+/+}$cells (discussed later; $\sim 5 \%$ are $\mathrm{CD}_{2} 2 \mathrm{~L}^{+}$) appears to proceed faster with a maximum of IFN $\gamma$ detected at $18 \mathrm{~h}$ post stimulation (Fig. 3.16). Effector $\mathrm{rMT}^{-\mathrm{II}^{++}}$cells which are uniformly CD62L show maximal mRNA level of IFN $\gamma$ already at $8 \mathrm{~h}$ post stimulation (Fig. 3.25 B). These data indicate that the proportion of $\mathrm{CD} 2 \mathrm{~L}^{+} \mathrm{T}$ lymphocytes in a given population reflects the number of true naïve cells and determines the kinetic (rapidity) of $T$ cell response to the antigen.

In the future, it will be important to assess the utility of the CD45RC, CD27 and CD28 markers to discriminate naïve and memory $T$ cell subsets in TCRtg rats (Okada et al., 2008; Bunce and Bell, 1997) and to determine the distribution of naïve versus memory phenotypes in younger rMT-II animals.

\subsubsection{OVA-SPECIFIC TCR TRANSGENIC RATS}

Our experience with $\mathrm{rMT}-\mathrm{II}$ rats indicated that the availability of the mAb for detecting a TCRB chain of the transgenic receptor is of significant advantage for later analyses. Therefore, we used the HIS-42 mAb to enrich a polyclonal OVA-specific Lewis T cell line for TCR-VB16-positive cells. Further, we used limiting dilution and sequential restimulation in culture to obtain clonal T cell lines (called clonoids; Fig. 3.9 A, B). In this way, we were able to clone a handful of $\alpha \beta T C R$ candidates without performing the procedure of cell fusion and screening of hybridomas. After testing expression and antigenic specificity, we selected one $\alpha \beta T C R$ (V $\alpha 13-J \alpha-C \alpha$ and $V \beta 16-J \beta 1.3-C \beta 1$ ) for the generation of transgenic rats. Lentiviral transduction of embryos yielded a number of founder rats in which the integration of the provirus was identified by PCR analysis. In few of those animals only a small fraction of blood leukocytes exhibited expression of GFP. Breeding of $\mathrm{GFP}^{+}$founders resulted in 
animals which expressed either high, moderate or no GFP levels. As in case of the rMT-II strain, the rOT-II allele was inherited according to Mendelian rule and the GFP expression level correlated with abundance of peripheral T cells expressing the TCR-VB16 chain. Homozygous $\mathrm{rOT}^{-\mathrm{II}^{+/+}}$rats had $\sim 90 \%$ of $\mathrm{V} \beta 16^{+} \mathrm{T}$ cells in the blood and secondary lymphoid organs (Fig. $3.11 \mathrm{~B}$ ). Accordingly, strong proliferation and induction of IFN $\gamma$ in response to ovalbumin protein and $\mathrm{OVA}_{323-339}$ peptide substantiate the engineered antigen-specificity of rOT-II animals (Fig. 3.17).

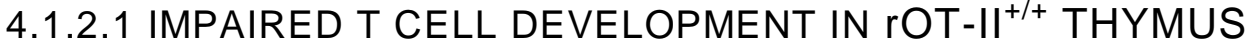

In contrast to rMT-II rats, rOT-II animals presented themselves as moderately lymphopenic. Further analysis of the immune system uncovered a severe disturbance of $T$ cell development (Fig. 3.12). In the rOT- $\mathrm{II}^{+/+}$thymus, an abnormal increase in CD8 SP and DN and a reduction of DP and CD4 SP populations were found.

T cell progenitors enter the thymus in a state when CD4 and CD8 molecules are not yet expressed. These cells are then regarded as DN thymocytes. According to the surface expression of CD44 and CD25 molecules, DN thymocytes can be further divided into DN1-DN4 subpopulations. During the transition throughout DN stages, $\mathrm{T}$ cells undergo $\beta$-selection. In this process, the TCR $\beta$-chain pairs with an invariant pre-T $\alpha$ chain. If the $\beta$-checkpoint generates positive signal(s), thymocytes proliferate and transit to the DP stage.

Defects in $T$ cell development were already reported for some TCRtg mice (Kisielow et al., 1988; Barnden et al., 1998; Lacorazza et al., 2001). The early co-overexpression of the transgenic $\alpha$-chain and $\beta$-chain in TCRtg mice impairs $\beta$-selection as the affinity for $\beta$-chain- $\alpha$-chain pairing is higher than $\beta$-chain-preT $\alpha$ chain pairing (Trop et al., 2000). This drastically reduces the ability of TCR transgenic thymocytes to undergo $\beta$-selection (Borowski et al., 2004). Baldwin et al. could show that the timing of $\alpha$-chain expression is indeed critical for thymocyte development and $\mathrm{T}$ cell selection processes (Baldwin et al., 2005).

Analysis of the DN population in $\mathrm{rOT}-\mathrm{II}^{+/+}$rats revealed a prominent accumulation of cells at the DN2 stage (Fig. 3.13 A). The expression of the $\alpha \beta T C R$ was indeed high in DN thymocytes of $\mathrm{rOT}^{-\mathrm{II}^{++}}$rats (Fig. $3.13 \mathrm{~B}$ ). This fact of premature expression of the $\alpha$-chain is unlikely to be solely responsible for the DN2 block, as a similar expression was also 


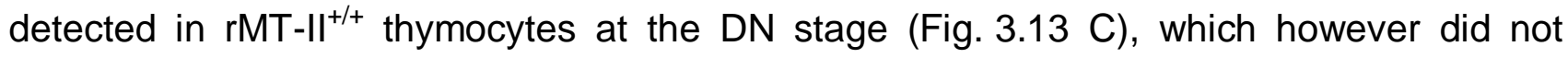
manifest in disturbed DN to DP transition.

Additionally, $\mathrm{rOT}^{-\mathrm{II}^{+/+}}$thymocytes accumulated in the CD8 SP stage. This might also be caused by a lack of signalling as DN thymocytes first upregulate CD8 and then CD4 for transition to the DP stage. Signals necessary to upregulate CD4 might also be hampered as upregulation of coreceptors is linked to the $\alpha$-chain locus rearrangement (Starr et al., 2003; Hernandez-Munain et al., 1999). Another possible explanation might be the high affinity of the cloned OVA-specific $T$ cell receptor. Due to this high affinity, CD4 ${ }^{+}$ T cells strongly interacting with $\mathrm{MHC}$ class II molecules might be deleted from the repertoire enabling predominantly $\mathrm{CD}^{+} \mathrm{T}$ cells (expressing a "wrong" coreceptor) to interact with a lower affinity with MHC class II (Tyznik et al., 2004), continue maturation and eventually leave the thymus. Finally, the effect of the transgenic integration site cannot be excluded to contribute to thymic abnormalities in the rOT- $\mathrm{II}^{+/+}$strain.

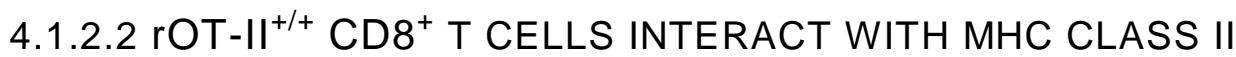

T cells isolated from $\mathrm{rOT}_{-\mathrm{II}^{+/+}}$lymph nodes reacted to the antigen ovalbumin in a MHC class II restricted manner, demonstrated by that fact that a blocking of MHC II by OX-6 antibody fully abolished $\mathrm{T}$ cell proliferation and cytokine production (Fig. 3.17). However, not only $\mathrm{CD}^{+}$but also $\mathrm{CD}^{+}$separated $\mathrm{T}$ cells reacted to ovalbumin in a dose-dependent manner (Fig. 3.18). Moreover, isolated $\mathrm{CD}^{+}$cells also were responsive to the $\mathrm{OVA}_{323-339}$ peptide which is selectively presented by MHCII complex (data not shown).

Speculatively, $\mathrm{rOT}^{-\mathrm{II}^{+/+}} \mathrm{CD}^{+} \mathrm{T}$ cells could be either true cytotoxic CD8 T cells which have undergone homeostatic proliferation in the periphery or misguided pseudo-CD8 T cells that failed to upregulate CD4 but nevertheless can exercise helper functions. The latter were previously reported in CD4 ${ }^{-/-}$mice: In this setting, MHC class II restricted T cells develop into CD8 ${ }^{+}$T cells (Matechak et al., 1996). CD8 T cells were reported to be able to interact with MHC class II (Tyznik et al., 2004). In mice it was recently shown that a CD8-MHC II interaction is possible and important for shaping the proliferation and differentiation of CD8 ${ }^{+}$ T cells (Do et al., 2012).

Details of $\mathrm{OT}-\mathrm{II}^{+/+} \mathrm{CD}^{+} \mathrm{T}$ cell function should be clarified by further analyses. 
TCR transgenic mice models with receptors specific for MBP, PLP or MOG did develop spontaneous EAE - depending on the mouse strain, housing conditions and antigen (Goverman et al., 1993; Lafaille et al., 1994; Bettelli et al., 2003; Pollinger et al., 2009). We observed rMT-II rats for more than one year and found neither signs of clinical symptoms nor any subclinical infiltrations of immune cells into the CNS of rMT-II rats.

In MBP-TCRtg transgenic mouse strains it is also possible to induce EAE development by activating the innate immune system through injection of LPS (Goverman et al., 1993). To test whether our TCR transgenic rats might be susceptible to EAE induction by stimulation of Toll-like receptors, we injected LPS intrathecally with or without additional antigen directly targeting the integrity of the BBB and activating innate immune cells of the CNS. This treatment failed to induce clinical EAE. This indicates that the mere opening of the BBB and generation of a local proinflammatory environment are insufficient to trigger quiescent peripheral myelin-specific $T$ cells to attack the CNS. Moreover, i.t. transfer of recently activated $\mathrm{rMT}_{-1 \mathrm{I}^{+++}} \mathrm{T}$ cells also failed to induce disease, showing that not only the access to CNS tissue but also some intrinsic properties of $T$ cells presumably acquired during post-activatory maturation are critical for initiation of $\mathrm{T}$ cell mediated CNS inflammation.

\subsubsection{ACTIVE EAE INDUCTION IN TCR TRANSGENIC ANIMALS}

To analyse the impact of the MBP-specific and OVA-specific transgenic $T$ cells on EAE development, we immunized heterozygous and homozygous rMT-II and rOT-II as well as wild type littermates with MBP in CFA. We observed a remarkably accelerated disease onset in $\mathrm{rMT}-\mathrm{II}$ rats and a delayed onset and a reduced incidence of EAE in rOT-II rats. However, susceptible rOT-II rats developed EAE with a similar severity and progression as WT littermates (Fig. 3.19).

As the majority of $T$ cells in $r M T-I I$ rats expressed the transgenic V $\beta 8.2$ chain, the accelerated disease onset could be explained by a higher number of MBP-specific $T$ cells in their immune repertoire. Upon immunization, $T$ cells proliferate and migrate in higher numbers into the CNS where these cells become reactivated and cause severe inflammation. In contrast, WT rats host a smaller population of autoreactive T cells, which need longer to reach numbers after amplification, able to start a similar immune response 
within the CNS. Concerning disease duration and severity, EAE in rMT-II rats resembled the disease course of WT littermates. This indicates a role for the TCR transgenic T cells only in disease initiation but not in maintenance and resolution of the inflammatory response in the target tissue.

On the contrary, rOT-II rats possessed predominantly OVA-specific T cells which left only a minority of $T$ cells with autoaggressive specificity. Therefore, we already observed a reduced incidence of EAE development in heterozygous $\mathrm{COT}$-II rats which was even more pronounced in homozygous rOT-II rats. However, in rOT-II rats which did develop EAE, the disease manifested itself with the same clinical course and disease severity as observed in WT littermates, also supporting the observation that the mere number of autoaggressive $T$ cells is important for disease initiation.

We additionally aimed to induce EAE with differential disease progressions. To this extent,

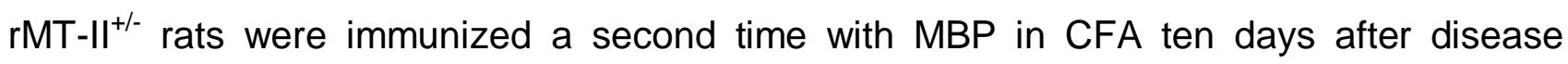
resolution. Here we could induce a second disease bout whereas WT littermates remained resistant as was previously reported (Sun et al., 1999). Interestingly, the treatment of immunized $\mathrm{rMT}-\mathrm{II}^{+/+}$rats with the calcineurin inhibitor FK506 during the prodromal phase resulted in a mild first clinical episode synchronized to EAE onset in the control group followed by short remission and a second, severe bout of paralysis which however eventually also resolved (Fig. 3.21). Taken together these results suggest that the absolute number of autoreactive $T$ cells and induction of Treg response determine the initiation of EAE and acquired resistance to it. However, other factors, e.g. those preventing chronic neuroinflammation, play a role in the Lewis rat model of EAE. 


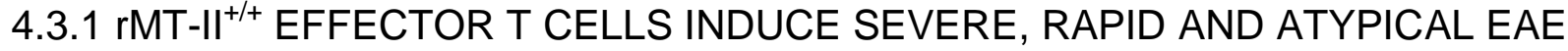

For comparison of splenic antigen inexperienced $T$ cells and effector $T$ cells, we generated effector $\mathrm{T}$ cell lines derived from $\mathrm{rMT}^{-\mathrm{II}^{+/+}}$and $\mathrm{rOT}-\mathrm{II}^{+/+}$hosts. In vitro analysis of surface markers and kinetics of mRNA expression showed similarities in transgenic effector $T$ cells compared to conventional (polyclonal) effector $T$ cell lines generated from WT animals (Fig. 3.25). Our conventional $T$ cell lines are retrovirally engineered to express GFP (Flügel et al., 1999). Endogenous GFP expression in homozygous transgenic rats did not reach equal expression levels. Thus, we additionally transduced $\mathrm{rMT}-\mathrm{II}^{+++}$effector $\mathrm{T}$ cells with our GFP retrovirus (termed GFP retro) to boost GFP expression levels (data not shown) and guarantee a better visualisation by the means of epifluorescence microscopy or twophoton microscopy.

When applied for adoptive transfer EAE, both $\mathrm{rMT}^{-\mathrm{II}^{+/+}}$and GFP ${ }^{\text {retro }} \mathrm{rMT}^{-\mathrm{II}^{+/+}}$effector $\mathrm{T}$ cells induced strong EAE with an onset already two days after transfer with not only typical ascending paralysis but also atypical neurological symptoms like partial tetraparesis, hyperaesthesia and tremor (Fig. 3.26). This prompted us to analyse the distribution of inflammatory infiltrates throughout the CNS. The number of infiltrating $T$ cells into lumbal and cervical spinal cord did not differ significantly at the peak of the disease between $\mathrm{rMT}_{-\mathrm{II}^{+/+}}$effector $\mathrm{T}$ cell-induced EAE and conventional $\mathrm{T}_{\mathrm{MBP}}$-GFP-induced EAE. However, rMT- $\mathrm{II}^{++}$effector $\mathrm{T}$ cells did infiltrate brain regions including the cerebellum, medulla and cerebrum as well. Additionally, we observed a stronger activation of microglia and recruitment of macrophages in regions where T cells infiltrated (Fig. 3.27).

Taken together, $\mathrm{rMT}-\mathrm{II}^{+++}$effector T cells induced fulminant EAE affecting both spinal cord and brain. Whether this infiltration pattern is an intrinsic feature of these $T$ cell lines caused by their homogenous specificity for MBP or a higher basal activity enabling these cells to enter the CNS more rapidly remains to be investigated. Odoardi et al. recently reported that conventional $\mathrm{T}_{\mathrm{MBP}}$-GFP effector T cells could not enter the CNS directly but have to migrate through the periphery to acquire a migratory phenotype (Odoardi et al., 2012). As the first

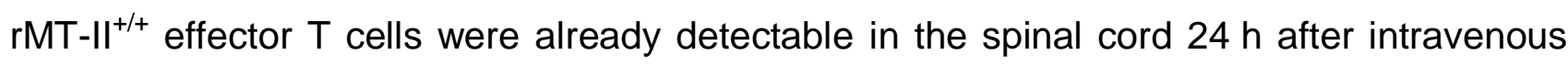
transfer and the disease onset was accelerated compared to conventional $\mathrm{T}_{\text {MBP-GFP }}$ adoptive transfer EAE, it will be interesting to analyse the gene expression pattern and its kinetic in $\mathrm{rMT}-\mathrm{II}^{+/+}$effector $\mathrm{T}$ cells during the prodromal phase of EAE in more detail. 


\subsubsection{SPLENIC AND EFFECTOR rMT-II ${ }^{+/+}$CELLS ACCELERATE EAE ONSET AFTER LOCAL ACTIVATION}

In rOT-II and rMT-II rats, GFP and TCR expression are under the control of the introduced ubiquitin $\mathrm{C}$ promoter leading to the expression of GFP in almost all cell types. Specifically for histology and two-photon live imaging, the GFP expression in all cell types is a limitation as endogenous $\mathrm{GFP}^{+} \mathrm{T}$ cells cannot be easily distinguished from the GFP background signal. To circumvent this inconvenience, we established a transfer system with local activation of transferred $T$ cells in the popliteal lymph node. In this system, transferred spleen-derived $T$ cells or effector $T$ cell lines migrate to the popliteal lymph node where

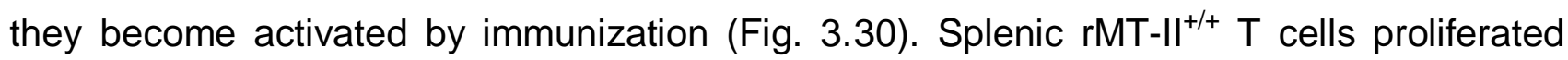
locally and entered the blood circulation approximately 3-4 days post immunization before infiltrating CNS meninges and parenchyma 5-6 days post immunization causing an accelerated EAE onset (Fig. 3.28 and 3.30 A). Transfer of splenic $\mathrm{rOT}^{-\mathrm{II}^{+/+}} \mathrm{T}$ cells in a control experiment resulted in a disease onset around day 10 after MBP-immunization. Interestingly, heterozygous $\mathrm{rMT}^{-\mathrm{II}^{+-}}$transferred splenic $\mathrm{T}$ cells also caused an accelerated disease onset 8 days post immunization. Subcutaneous transfer of resting $\mathrm{rMT}^{-\mathrm{II}^{+/+}}$effector $\mathrm{T}$ cells and subsequent immunization even further accelerated the disease onset $(4 \mathrm{dpi}$, Fig. 3.28) and was accompanied by a rapid proliferation of $T$ cells in the popliteal lymph nodes and infiltration into CNS meninges and parenchyma 4 dpi (Fig. 3.30 B). Notably, the absolute numbers of $\mathrm{GFP}^{+} \mathrm{T}$ cells in the different organs for $\mathrm{rMT}^{-\mathrm{II}^{+/+}}$effectors were 10 to 200 -fold lower than numbers of splenic $\mathrm{rMT}^{-\mathrm{II}^{+/+}} \mathrm{T}$ cells. Presumably, differentiation into effector subset already allows a small number of $T$ cells to enter the target organ and mount the immune response whereas splenic antigen inexperienced $T$ cells need a longer period to expand to sufficient numbers and reach a sufficient activation/maturation state.

We analyzed splenic and effector T cells in the CNS meninges and parenchyma for CD25 surface expression, a marker for activation. Similar levels of CD25 were expressed on both types of $T$ cells upon re-activation in the target tissue. However, the effector $T$ cells showed a much higher basal expression of CD25 before transfer and during peripheral migration. This indicates that the effector phenotype predisposes $T$ cells to a stronger activation by repeated antigen encounter than the splenic naïve/memory population. The higher responsiveness was also reflected at the mRNA level, as $\mathrm{rMT}^{-\mathrm{II}^{+/+}}$effector $\mathrm{T}$ cells produced a 4-10-fold higher amount of the proinflammatory cytokines IFN $\gamma$, IL-17 and TNF $\alpha$ in the CNS meninges and parenchyma during the disease onset (Fig. 3.31). 
Collectively these data could show a capability of rMT-II-derived cells to accelerate the EAE onset. Effector T cells appeared in lower numbers in the periphery and the target tissue but inherited a stronger activation status manifested by increased production of proinflammatory cytokine mRNA. On the other hand, splenic antigen inexperienced T cells appeared in higher numbers. This might be due to the execution of a different migratory program, which could compensate a lower production of proinflammatory cytokines and result in a similar clinical disease.

Additionally, the migratory route of $T$ cells after local activation might follow a $T$ cell intrinsic programme. Splenic $\mathrm{rOT}-\mathrm{II}^{+/+}$and $\mathrm{rOT}-\mathrm{II}^{+/+}$effector T cells expanded first within the popliteal lymph nodes and traffic via the blood circulation to other peripheral organs following a similar time schedule as $\mathrm{rMT}_{-1 \mathrm{II}^{+/+}}$derived T cells, again with lower total numbers of effector $\mathrm{T}$ cells (Fig. 3.34). To confirm this observation, rOT- $-\mathrm{II}^{+/+} \mathrm{T}$ cells have to be characterized in detail in this experimental setup for surface molecule expression and gene regulation.

\subsubsection{SPLENIC AND EFFECTOR $r M T-I^{+/+}$T CELLS INFILTRATE THE CNS UTILIZING} DIFFERENT SETS OF CHEMOKINE RECEPTORS

We then aimed to compare the migratory behaviour of splenic $\mathrm{rMT}^{\mathrm{II}}{ }^{+++} \mathrm{T}$ cells and effector

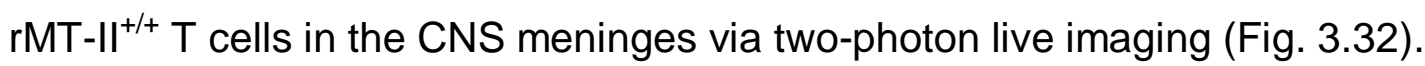

In both settings we could observe a massive infiltration of $\mathrm{GFP}^{+} \mathrm{T}$ cells in the CNS meninges before the onset of clinical symptoms. Notably, when analyzing the migratory phenotype of splenic rMT-II+/+ $\mathrm{T}$ cells, we could not observe any $\mathrm{T}$ cells crawling along the blood vessel endothelium before transmigrating into the CNS tissue.

Transmigration of $T$ cells across the blood-brain barrier is described as a four-step process. First, $T$ cells roll along the blood vessel endothelium in the direction of the blood flow and adhere to the vessel endothelium via interaction with integrins (e.g. ICAM-1 and VCAM-1). This enables $T$ cells to change their migratory phenotype and crawl along the blood vessel endothelium against the direction of the blood flow resulting in subsequent diapedesis. The crawling process can be mediated by chemokine receptor signalling as the chemokines CCL19 and CCL21 are upregulated in endothelial cells of the mouse CNS during EAE and CXCR3, a receptor capable of interacting with CCL21 (Alt et al., 2002), is expressed on effector T cells.

A member of our group, Dr. C. Schläger, showed in his $\mathrm{PhD}$ thesis study that in Lewis rat EAE the crawling process is indeed dependent on CXCR3-mediated interactions with the 
endothelium as intravenous injection of a monoclonal blocking CXCR3 abrogates crawling behaviour of T cells (Schläger, 2013). Although we observed crawling behaviour of effector

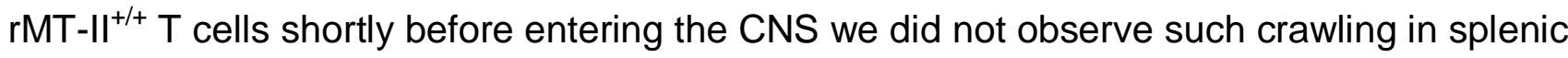

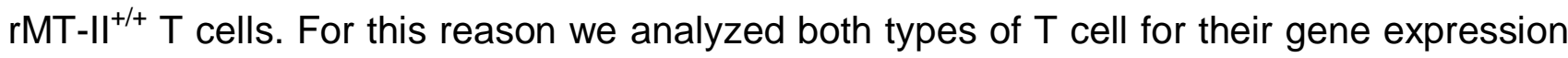
level of CXCR3, CCR2 and CCR5 and could show that effector T cells expressed higher levels of these chemokine receptors in cells sorted from blood before the disease onset (Fig. 3.33). Lower expression levels of CXCR3 and CCR5 might account for the absence of crawling behaviour in splenic rMT- $\mathrm{II}^{+/+} \mathrm{T}$ cells. Nevertheless, splenic $\mathrm{T}$ cells were also able to cross the blood barrier and induce disease implying that other mechanism for transmigration must be involved for these T cells. Another chemokine receptor interacting with CCL19 and CCL21 is CCR7. mRNA levels of CCR7 were upregulated in splenic

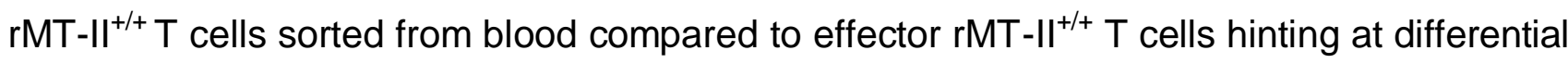
roles in chemokine receptor - endothelium interaction for splenic and effector $\mathrm{T}$ cells.

An analysis will be performed of chemokine receptor expression but also expression of integrins using molecular methods in combination with intravital imaging to further dissect the factors and mechanisms utilized by recently primed and by fully differentiated effector $T$ cells to cross the blood-brain barrier.

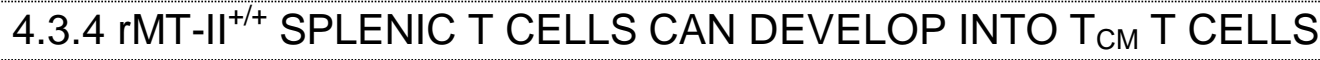

As we observed heterogenous $T$ cell subpopulations in untreated rats concerning the CD62L-CCR7 coexpression, we followed the regulation of CD62L surface expression during the course of EAE after local activation.

Interestingly, we could obtain a CD62 $\mathrm{L}^{+} \mathrm{T}$ cell subpopulation from blood during the disease onset in splenic $\mathrm{rMT}^{-\mathrm{II}^{+/+}}$induced EAE but not in effector $\mathrm{rMT}-\mathrm{II}^{+/+} \mathrm{T}$ cell induced EAE Fig. 3.34). Gene expression analysis of $\mathrm{GFP}^{+} \mathrm{CD} 2 \mathrm{~L}^{+}$and $\mathrm{GFP}^{+} \mathrm{CD}^{-} 2 \mathrm{~L}^{-}$splenic $\mathrm{rMT}^{-\mathrm{II}^{+/+}}$ T cells sorted from blood in comparison to endogenous $\mathrm{CD}^{2} \mathrm{~L}^{+}$or $\mathrm{CD}^{-} \mathrm{L}^{-} \mathrm{T}$ cells showed an upregulation of IFN $\gamma$ and TNF $\alpha$ mRNA as well as the expression of CCR7 but the lack of CCR2 or CCR5 mRNA expression identifying these cells as central-memory $T$ cells (Sallusto et al., 1999; Zhang et al., 2010). As this T cell population was not present during effector $\mathrm{rMT}-\mathrm{II}^{+/+} \mathrm{T}$ cell induced EAE, we can conclude that some splenic $\mathrm{rMT}^{-\mathrm{II}^{+/+}}$possess the capability to develop into central-memory $T$ cells while this aptitude seems to be absent in effector T cells. 


\subsubsection{MIGRATORY PATTERN IS A T CELL INTRINSIC FEATURE}

As the migratory routes we observed for $\mathrm{rMT}^{-\mathrm{II}^{+/+}} \mathrm{T}$ cells after subcutaneous transfer and activation might be a part of $\mathrm{T}$ cell intrinsic migratory programme common for $\mathrm{T}$ cells of any specificity, we also analyzed rOT- $\mathrm{II}^{+/+}$splenocytes and effector $\mathrm{rOT}^{-\mathrm{II}^{+/+}} \mathrm{T}$ cells in the same experimental settings (Fig. 3.35).

Interestingly, OVA-specific splenic and effector $\mathrm{T}$ cells followed a similar migratory route with first a massive expansion in the draining popliteal lymph node, migration into the blood and subsequent homing to other lymph nodes, spleen and lung. Moreover, splenic rOT- $\mathrm{I}^{1 /+}$ T cells expressed lower mRNA levels of chemokine receptors necessary to home into inflamed tissues similar to autoreactive $\mathrm{rMT}^{-\mathrm{II}^{+/+}} \mathrm{T}$ cells (Fig. 3.36). 
Autoreactive T cells directed against CNS antigens seem to play an essential role at least in the initiation of multiple sclerosis. To improve our understanding about the function of pathogenic $T$ cells in CNS autoimmunity we aimed to endow the classical neuroimmunlogical Lewis rat EAE model with new analytic power. To do this, we generated two TCR transgenic Lewis strains: the rMT-II strain carrying $T$ cells specific for the selfantigen myelin basic protein and the rOT-II strain in which the transgenic TCR is specific for chicken ovalbumin. To our knowledge, these are first available TCRtg models created in R. norvegicus.

The immune system of the $\mathrm{rMT}^{-\mathrm{II}^{+/+}}$strain is characterised by a high proportion of $\mathrm{CD} 4^{+}$ MHC class II restricted T cells readily responding to MBP challenge by proliferating and producing proinflammatory cytokines. Although no spontaneous EAE was observed in rMT-II rats, this strain is highly susceptible to an early-onset severe monophasic EAE induced by active immunization even with reduced amounts of adjuvant or antigen. Repeated immunization induced relapse EAE in rMT-II, but not in WT Lewis rats. Peripheral T cells isolated from $r M T-I I$ donors were able to mediate an accelerated onset of active $E A E$ upon transfer into WT recipients. Remarkably, the effector $\mathrm{T}$ cell lines established from rMT-II rats were highly encephalitogenic and caused severe EAE including atypical symptoms with increased propensity to infiltrate not only the spinal cord but also brain tissue.

In the $\mathrm{rOT}-\mathrm{II}^{+/+}$strain the majority of peripheral T cells express a transgenic TCR specific for ovalbumin. In this strain, however, thymic development is disturbed leading to moderate lymphopenia, aberrant expression of the CD8 coreceptor in mature OVA-reactive T cells and reduction of the $\mathrm{CD}_{2} \mathrm{~L}^{+}$population. Still, this line can be used to track priming and migration of non-pathogenic OVA-specific T cells upon adoptive transfer.

A green fluorescent marker which is co-expressed with each transgenic TCR greatly facilitates phenotyping and analysis of $T$ cell migration. Further, its high expression by endothelial and myeloid cells can be exploited to visualize interaction of meningeal BBB structures with invading immune cells by TPM using rOT-II animals as a host for transfer experiments.

Using an experimental setup comprising adoptive transfer and local activation in the draining LN, we performed analysis of migration and gene expression of cytokines and 
chemokine receptors in naïve and effector populations of MBP- and OVA-specific $T$ cells in vivo. Furthermore, TPM analysis of $\mathrm{rMT}^{-\mathrm{II}^{+/+}}$cells invading the spinal cord during EAE induced by peripheral $T$ cell activation revealed differences in behaviour of primary versus effector $\mathrm{T}$ cell subtypes. 
't Hart,B.A., Gran,B., and Weissert,R. (2011). EAE: imperfect but useful models of multiple sclerosis. Trends Mol. Med. 17, 119-125.

Ahmed,R. and Gray,D. (1996). Immunological memory and protective immunity: understanding their relation. Science 272, 54-60.

Alt,C., Laschinger,M., and Engelhardt,B. (2002). Functional expression of the lymphoid chemokines CCL19 (ELC) and CCL 21 (SLC) at the blood-brain barrier suggests their involvement in Gprotein-dependent lymphocyte recruitment into the central nervous system during experimental autoimmune encephalomyelitis. Eur. J. Immunol. 32, 2133-2144.

Anderson,A.C., Chandwaskar,R., Lee,D.H., Sullivan,J.M., Solomon,A., Rodriguez-Manzanet,R., Greve,B., Sobel,R.A., and Kuchroo,V.K. (2012). A transgenic model of central nervous system autoimmunity mediated by CD4+ and CD8+ T and B cells. J. Immunol. 188, 2084-2092.

Arden,B., Clark,S.P., Kabelitz,D., and Mak,T.W. (1995). Mouse T-cell receptor variable gene segment families. Immunogenetics 42, 501-530.

Arstila,T.P., Casrouge,A., Baron,V., Even,J., Kanellopoulos,J., and Kourilsky,P. (1999). A direct estimate of the human alphabeta $T$ cell receptor diversity. Science 286, 958-961.

Ascherio,A. and Munger,K.L. (2007). Environmental risk factors for multiple sclerosis. Part I: the role of infection. Ann. Neurol. 61, 288-299.

Babbe,H., Roers,A., Waisman,A., Lassmann,H., Goebels,N., Hohlfeld,R., Friese,M., Schroder,R., Deckert,M., Schmidt,S., Ravid,R., and Rajewsky,K. (2000). Clonal expansions of CD8(+) T cells dominate the $\mathrm{T}$ cell infiltrate in active multiple sclerosis lesions as shown by micromanipulation and single cell polymerase chain reaction. J. Exp. Med. 192, 393-404.

Baldwin,T.A., Sandau,M.M., Jameson,S.C., and Hogquist,K.A. (2005). The timing of TCR alpha expression critically influences T cell development and selection. J. Exp. Med. 202, 111-121.

Barker,C.F. and Billingham,R.E. (1977). Immunologically privileged sites. Adv. Immunol. 25, 1-54.

Barnden,M.J., Allison,J., Heath,W.R., and Carbone,F.R. (1998). Defective TCR expression in transgenic mice constructed using cDNA-based alpha- and beta-chain genes under the control of heterologous regulatory elements. Immunol. Cell Biol. 76, 34-40.

Bartholomäus,I., Kawakami,N., Odoardi,F., Schläger,C., Miljkovic,D., Ellwart,J.W., Klinkert,W.E., Flügel-Koch,C., Issekutz,T.B., Wekerle,H., and Flügel,A. (2009). Effector T cell interactions with meningeal vascular structures in nascent autoimmune CNS lesions. Nature 462, 94-98.

Bartholomaus,I., Kawakami,N., Odoardi,F., Schlager,C., Miljkovic,D., Ellwart,J.W., Klinkert,W.E., Flugel-Koch,C., Issekutz,T.B., Wekerle,H., and Flugel,A. (2009). Effector T cell interactions with meningeal vascular structures in nascent autoimmune CNS lesions. Nature 462, 94-98.

BELL,J. and PATERSON,P.Y. (1960). Rapid induction of allergic encephalomyelitis in rats without the use of mycobacteria. Science $131,1448$. 
Ben-Nun,A., Wekerle,H., and Cohen,I.R. (1981). The rapid isolation of clonable antigen-specific T lymphocyte lines capable of mediating autoimmune encephalomyelitis. Eur. J. Immunol. 11, 195199.

Bettelli,E., Baeten,D., Jager,A., Sobel,R.A., and Kuchroo,V.K. (2006). Myelin oligodendrocyte glycoprotein-specific $T$ and $B$ cells cooperate to induce a Devic-like disease in mice. J. Clin. Invest 116, 2393-2402.

Bettelli,E., Pagany,M., Weiner,H.L., Linington,C., Sobel,R.A., and Kuchroo,V.K. (2003). Myelin oligodendrocyte glycoprotein-specific $\mathrm{T}$ cell receptor transgenic mice develop spontaneous autoimmune optic neuritis. J. Exp. Med. 197, 1073-1081.

Blair,K., Leitch,H.G., Mansfield,W., Dumeau,C.E., Humphreys,P., and Smith,A.G. (2012). Culture parameters for stable expansion, genetic modification and germline transmission of rat pluripotent stem cells. Biol. Open. 1, 58-65.

Blakemore,W.F. (1973). Demyelination of the superior cerebellar peduncle in the mouse induced by cuprizone. J. Neurol. Sci. 20, 63-72.

Borowski,C., Li,X., Aifantis,I., Gounari,F., and von,B.H. (2004). Pre-TCRalpha and TCRalpha are not interchangeable partners of TCRbeta during T lymphocyte development. J. Exp. Med. 199, 607-615.

Brownlie,R.J. and Zamoyska,R. (2013). T cell receptor signalling networks: branched, diversified and bounded. Nat. Rev. Immunol. 13, 257-269.

Brück,W., Popescu,B., Lucchinetti,C.F., Markovic-Plese,S., Gold,R., Thal,D.R., and Metz,I. (2012). Neuromyelitis optica lesions may inform multiple sclerosis heterogeneity debate. Ann. Neurol. 72, 385-394.

Buenafe,A.C., Tsu,R.C., Bebo,B., Jr., Bakke,A.C., Vandenbark,A.A., and Offner,H. (1997). A TCR V alpha CDR3-specific motif associated with Lewis rat autoimmune encephalomyelitis and basic protein-specific T cell clones. J. Immunol. 158, 5472-5483.

Bunce,C. and Bell,E.B. (1997). CD45RC isoforms define two types of CD4 memory T cells, one of which depends on persisting antigen. J. Exp. Med. 185, 767-776.

BURNET,M. (1959). Auto-immune disease. II. Pathology of the immune response. Br. Med. J. 2, 720-725.

Cao,Y., Toben,C., Na,S.Y., Stark,K., Nitschke,L., Peterson,A., Gold,R., Schimpl,A., and Hunig,T. (2006). Induction of experimental autoimmune encephalomyelitis in transgenic mice expressing ovalbumin in oligodendrocytes. Eur. J. Immunol. 36, 207-215.

Carroll,D. (2011). Genome engineering with zinc-finger nucleases. Genetics 188, 773-782.

Chelmicka-Schorr,E., Wiegmann,K., Wollmann,R., Arnason,B.G., and Kim,D.H. (1998). Immunoaugmenting effect of FK 506 on experimental allergic encephalomyelitis in Lewis rats. J. Autoimmun. 11, 329-334. 
Chluba,J., Steeg,C., Becker,A., Wekerle,H., and Epplen,J.T. (1989). T cell receptor beta chain usage in myelin basic protein-specific rat T lymphocytes. Eur. J. Immunol. 19, 279-284.

Compston,A. and Coles,A. (2002). Multiple sclerosis. Lancet 359, 1221-1231.

Davis,M.M. and Bjorkman,P.J. (1988). T-cell antigen receptor genes and T-cell recognition. Nature 334, 395-402.

Deli,M.A., Abraham,C.S., Kataoka,Y., and Niwa,M. (2005). Permeability studies on in vitro bloodbrain barrier models: physiology, pathology, and pharmacology. Cell Mol. Neurobiol. 25, 59-127.

Do,J.S., Valujskikh,A., Vignali,D.A., Fairchild,R.L., and Min,B. (2012). Unexpected role for MHC IIpeptide complexes in shaping CD8 T-cell expansion and differentiation in vivo. Proc. Natl. Acad. Sci. U. S. A 109, 12698-12703.

Dull,T., Zufferey,R., Kelly,M., Mandel,R.J., Nguyen,M., Trono,D., and Naldini,L. (1998). A thirdgeneration lentivirus vector with a conditional packaging system. J. Virol. 72, 8463-8471.

Engelhardt,B. and Ransohoff,R.M. (2005). The ins and outs of T-lymphocyte trafficking to the CNS: anatomical sites and molecular mechanisms. Trends Immunol. 26, 485-495.

Engelhardt,B. and Sorokin,L. (2009). The blood-brain and the blood-cerebrospinal fluid barriers: function and dysfunction. Semin. Immunopathol. 31, 497-511.

Eylar,E.H. (1978). Peptides and autoimmune disease. Adv. Exp. Med. Biol. 98, 259-281.

Flügel,A., Willem,M., Berkowicz,T., and Wekerle,H. (1999). Gene transfer into CD4+ T lymphocytes: green fluorescent protein-engineered, encephalitogenic $T$ cells illuminate brain autoimmune responses. Nat. Med. 5, 843-847.

Fujino,M., Funeshima,N., Kitazawa,Y., Kimura,H., Amemiya,H., Suzuki,S., and Li,X.K. (2003). Amelioration of experimental autoimmune encephalomyelitis in Lewis rats by FTY720 treatment. J. Pharmacol. Exp. Ther. 305, 70-77.

Geurts,A.M., Cost,G.J., Freyvert,Y., Zeitler,B., Miller,J.C., Choi,V.M., Jenkins,S.S., Wood,A., Cui,X., Meng,X., Vincent,A., Lam,S., Michalkiewicz,M., Schilling,R., Foeckler,J., Kalloway,S., Weiler,H., Menoret,S., Anegon,I., Davis,G.D., Zhang,L., Rebar,E.J., Gregory,P.D., Urnov,F.D., Jacob,H.J., and Buelow,R. (2009). Knockout rats via embryo microinjection of zinc-finger nucleases. Science $325,433$.

Gold,D.P., Vainiene,M., Celnik,B., Wiley,S., Gibbs,C., Hashim,G.A., Vandenbark,A.A., and Offner,H. (1992). Characterization of the immune response to a secondary encephalitogenic epitope of basic protein in Lewis rats. II. Biased T cell receptor $\mathrm{V}$ beta expression predominates in spinal cord infiltrating T cells. J. Immunol. 148, 1712-1717.

Gourraud,P.A., Harbo,H.F., Hauser,S.L., and Baranzini,S.E. (2012). The genetics of multiple sclerosis: an up-to-date review. Immunol. Rev. 248, 87-103. 
Goverman,J., Woods,A., Larson,L., Weiner,L.P., Hood,L., and Zaller,D.M. (1993). Transgenic mice that express a myelin basic protein-specific $T$ cell receptor develop spontaneous autoimmunity. Cell 72, 551-560.

Greter,M., Heppner,F.L., Lemos,M.P., Odermatt,B.M., Goebels,N., Laufer,T., Noelle,R.J., and Becher,B. (2005). Dendritic cells permit immune invasion of the CNS in an animal model of multiple sclerosis. Nat. Med. 11, 328-334.

Hernandez-Munain,C., Sleckman,B.P., and Krangel,M.S. (1999). A developmental switch from TCR delta enhancer to TCR alpha enhancer function during thymocyte maturation. Immunity. 10, 723733.

Herold,M.J., van den Brandt,J., Seibler,J., and Reichardt,H.M. (2008). Inducible and reversible gene silencing by stable integration of an shRNA-encoding lentivirus in transgenic rats. Proc. Natl. Acad. Sci. U. S. A 105, 18507-18512.

Hickey,W.F. and Kimura,H. (1988). Perivascular microglial cells of the CNS are bone marrowderived and present antigen in vivo. Science 239, 290-292.

Hogquist,K.A., Jameson,S.C., Heath,W.R., Howard,J.L., Bevan,M.J., and Carbone,F.R. (1994). T cell receptor antagonist peptides induce positive selection. Cell 76, 17-27.

Holst,J., Vignali,K.M., Burton,A.R., and Vignali,D.A. (2006). Rapid analysis of T-cell selection in vivo using T cell-receptor retrogenic mice. Nat. Methods 3, 191-197.

Huitinga,I., Ruuls,S.R., Jung,S., Van,R.N., Hartung,H.P., and Dijkstra,C.D. (1995). Macrophages in $\mathrm{T}$ cell line-mediated, demyelinating, and chronic relapsing experimental autoimmune encephalomyelitis in Lewis rats. Clin. Exp. Immunol. 100, 344-351.

Huseby,E.S., Liggitt,D., Brabb,T., Schnabel,B., Ohlen,C., and Goverman,J. (2001a). A pathogenic role for myelin-specific CD8(+) T cells in a model for multiple sclerosis. J. Exp. Med. 194, 669676.

Huseby,E.S., Sather,B., Huseby,P.G., and Goverman,J. (2001b). Age-dependent T cell tolerance and autoimmunity to myelin basic protein. Immunity. 14, 471-481.

Jagessar,S.A., Kap,Y.S., Heijmans,N., van,D.N., van,S.L., Bajramovic,J.J., Brok,H.P., Blezer,E.L., Bauer,J., Laman,J.D., and 't Hart,B.A. (2010). Induction of progressive demyelinating autoimmune encephalomyelitis in common marmoset monkeys using MOG34-56 peptide in incomplete freund adjuvant. J. Neuropathol. Exp. Neurol. 69, 372-385.

Kap,Y.S., Smith,P., Jagessar,S.A., Remarque,E., Blezer,E., Strijkers,G.J., Laman,J.D., Hintzen,R.Q., Bauer,J., Brok,H.P., and 't Hart,B.A. (2008). Fast progression of recombinant human myelin/oligodendrocyte glycoprotein (MOG)-induced experimental autoimmune encephalomyelitis in marmosets is associated with the activation of MOG34-56-specific cytotoxic T cells. J. Immunol. 180, 1326-1337.

Kappler,J.W., Roehm,N., and Marrack,P. (1987). T cell tolerance by clonal elimination in the thymus. Cell 49, 273-280. 
Kenny,E., Mason,D., Saoudi,A., Pombo,A., and Ramirez,F. (2004). CD8 alpha is an activation marker for a subset of peripheral CD4 T cells. Eur. J. Immunol. 34, 1262-1271.

Kisielow,P., Teh,H.S., Bluthmann,H., and von,B.H. (1988). Positive selection of antigen-specific T cells in thymus by restricting MHC molecules. Nature $335,730-733$.

Kobayashi,T., Kato-Itoh,M., Yamaguchi,T., Tamura,C., Sanbo,M., Hirabayashi,M., and Nakauchi,H. (2012). Identification of rat Rosa26 locus enables generation of knock-in rat lines ubiquitously expressing tdTomato. Stem Cells Dev. 21, 2981-2986.

Kouskoff,V., Signorelli,K., Benoist,C., and Mathis,D. (1995). Cassette vectors directing expression of $T$ cell receptor genes in transgenic mice. J. Immunol. Methods 180, 273-280.

Krangel,M.S. (2009). Mechanics of T cell receptor gene rearrangement. Curr. Opin. Immunol. 21, 133-139.

Krishnamoorthy,G., Lassmann,H., Wekerle,H., and Holz,A. (2006). Spontaneous opticospinal encephalomyelitis in a double-transgenic mouse model of autoimmune T cell/B cell cooperation. J. Clin. Invest 116, 2385-2392.

Lacorazza,H.D., Tucek-Szabo,C., Vasovic,L.V., Remus,K., and Nikolich-Zugich,J. (2001). Premature TCR alpha beta expression and signaling in early thymocytes impair thymocyte expansion and partially block their development. J. Immunol. 166, 3184-3193.

Lafaille,J.J., Nagashima,K., Katsuki,M., and Tonegawa,S. (1994). High incidence of spontaneous autoimmune encephalomyelitis in immunodeficient anti-myelin basic protein $\mathrm{T}$ cell receptor transgenic mice. Cell 78, 399-408.

Lassmann,H., Brück,W., and Lucchinetti,C. (2001). Heterogeneity of multiple sclerosis pathogenesis: implications for diagnosis and therapy. Trends Mol. Med. 7, 115-121.

Li,P., Tong,C., Mehrian-Shai,R., Jia,L., Wu,N., Yan,Y., Maxson,R.E., Schulze,E.N., Song,H., Hsieh,C.L., Pera,M.F., and Ying,Q.L. (2008). Germline competent embryonic stem cells derived from rat blastocysts. Cell 135, 1299-1310.

LIPTON,M.M. and FREUND,J. (1952). Encephalomyelitis in the rat following intracutaneous injection of central nervous system tissue with adjuvant. Proc. Soc. Exp. Biol. Med. 81, 260-261.

LIPTON,M.M. and FREUND,J. (1953). Allergic encephalomyelitis in the rat induced by the intracutaneous injection of central nervous system tissue and adjuvants. J. Immunol. 71, 98-109.

Litzenburger,T., Fassler,R., Bauer,J., Lassmann,H., Linington,C., Wekerle,H., and Iglesias,A. (1998). B lymphocytes producing demyelinating autoantibodies: development and function in gene-targeted transgenic mice. J. Exp. Med. 188, 169-180.

Lodygin,D., Odoardi,F., Schlager,C., Korner,H., Kitz,A., Nosov,M., van den Brandt,J., Reichardt,H.M., Haberl,M., and Flugel,A. (2013). A combination of fluorescent NFAT and H2B sensors uncovers dynamics of $\mathrm{T}$ cell activation in real time during CNS autoimmunity. Nat. Med. 19, 784-790. 
Lois,C., Hong,E.J., Pease,S., Brown,E.J., and Baltimore,D. (2002). Germline transmission and tissue-specific expression of transgenes delivered by lentiviral vectors. Science 295, 868-872.

Lublin,F.D. and Reingold,S.C. (1996). Defining the clinical course of multiple sclerosis: results of an international survey. National Multiple Sclerosis Society (USA) Advisory Committee on Clinical Trials of New Agents in Multiple Sclerosis. Neurology 46, 907-911.

Lucchinetti,C., Brück,W., Parisi,J., Scheithauer,B., Rodriguez,M., and Lassmann,H. (2000). Heterogeneity of multiple sclerosis lesions: implications for the pathogenesis of demyelination. Ann. Neurol. 47, 707-717.

Madsen,L.S., Andersson,E.C., Jansson,L., krogsgaard,M., Andersen,C.B., Engberg,J., Strominger,J.L., Svejgaard,A., Hjorth,J.P., Holmdahl,R., Wucherpfennig,K.W., and Fugger,L. (1999). A humanized model for multiple sclerosis using HLA-DR2 and a human T-cell receptor. Nat. Genet. 23, 343-347.

Markowitz,D., Goff,S., and Bank,A. (1988). A safe packaging line for gene transfer: separating viral genes on two different plasmids. J. Virol. 62, 1120-1124.

Matechak,E.O., Killeen,N., Hedrick,S.M., and Fowlkes,B.J. (1996). MHC class II-specific T cells can develop in the CD8 lineage when CD4 is absent. Immunity. 4, 337-347.

MEDAWAR,P.B. (1948). Immunity to homologous grafted skin; the fate of skin homografts transplanted to the brain, to subcutaneous tissue, and to the anterior chamber of the eye. Br. J. Exp. Pathol. 29, 58-69.

Mendel,I., Kerlero de,R.N., and Ben-Nun,A. (1995). A myelin oligodendrocyte glycoprotein peptide induces typical chronic experimental autoimmune encephalomyelitis in $\mathrm{H}-2 \mathrm{~b}$ mice: fine specificity and $T$ cell receptor $V$ beta expression of encephalitogenic $T$ cells. Eur. J. Immunol. 25, 19511959.

Miller,S.D., Vanderlugt,C.L., Begolka,W.S., Pao,W., Yauch,R.L., Neville,K.L., Katz-Levy,Y., Carrizosa,A., and Kim,B.S. (1997). Persistent infection with Theiler's virus leads to CNS autoimmunity via epitope spreading. Nat. Med. 3, 1133-1136.

Milo,R. and Kahana,E. (2010). Multiple sclerosis: geoepidemiology, genetics and the environment. Autoimmun. Rev. 9, A387-A394.

Mitchell,J. and Caren,C.A. (1982). Degeneration of non-myelinated axons in the rat sciatic nerve following lysolecithin injection. Acta Neuropathol. 56, 187-193.

Momcilovic,M., Miljkovic,Z., Popadic,D., Miljkovic,D., and Mostarica-Stojkovic,M. (2008). Kinetics of IFN-gamma and IL-17 expression and production in active experimental autoimmune encephalomyelitis in Dark Agouti rats. Neurosci. Lett. 447, 148-152.

Mullins,L.J. and Mullins,J.J. (1996). Transgenesis in the rat and larger mammals. J. Clin. Invest 97, 1557-1560. 
Na,S.Y., Cao,Y., Toben,C., Nitschke,L., Stadelmann,C., Gold,R., Schimpl,A., and Hunig,T. (2008). Naïve CD8 T-cells initiate spontaneous autoimmunity to a sequestered model antigen of the central nervous system. Brain 131, 2353-2365.

Na,S.Y., Hermann,A., Sanchez-Ruiz,M., Storch,A., Deckert,M., and Hunig,T. (2012). Oligodendrocytes enforce immune tolerance of the uninfected brain by purging the peripheral repertoire of autoreactive CD8+ T cells. Immunity. 37, 134-146.

Noor,S. and Wilson,E.H. (2012). Role of C-C chemokine receptor type 7 and its ligands during neuroinflammation. J. Neuroinflammation. 9, 77.

Noseworthy,J.H., Wolinsky,J.S., Lublin,F.D., Whitaker,J.N., Linde,A., Gjorstrup,P., and Sullivan,H.C. (2000). Linomide in relapsing and secondary progressive MS: part I: trial design and clinical results. North American Linomide Investigators. Neurology 54, 1726-1733.

Nylander,A. and Hafler,D.A. (2012). Multiple sclerosis. J. Clin. Invest 122, 1180-1188.

Odoardi,F., Kawakami,N., Li,Z., Cordiglieri,C., Streyl,K., Nosov,M., Klinkert,W.E., Ellwart,J.W., Bauer,J., Lassmann,H., Wekerle,H., and Flügel,A. (2007). Instant effect of soluble antigen on effector $T$ cells in peripheral immune organs during immunotherapy of autoimmune encephalomyelitis. Proc. Natl. Acad. Sci. U. S. A 104, 920-925.

Odoardi,F., Sie,C., Streyl,K., Ulaganathan,V.K., Schläger,C., Lodygin,D., Heckelsmiller,K., Nietfeld,W., Ellwart,J., Klinkert,W.E., Lottaz,C., Nosov,M., Brinkmann,V., Spang,R., Lehrach,H., Vingron,M., Wekerle,H., Flügel-Koch,C., and Flügel,A. (2012). T cells become licensed in the lung to enter the central nervous system. Nature 488, 675-679.

Okada,R., Kondo,T., Matsuki,F., Takata,H., and Takiguchi,M. (2008). Phenotypic classification of human CD4+ T cell subsets and their differentiation. Int. Immunol. 20, 1189-1199.

OLITSKY,P.K. and YAGER,R.H. (1949). Experimental disseminated encephalomyelitis in white mice. J. Exp. Med. 90, 213-224.

Pollinger,B., Krishnamoorthy,G., Berer,K., Lassmann,H., Bosl,M.R., Dunn,R., Domingues,H.S., Holz,A., Kurschus,F.C., and Wekerle,H. (2009). Spontaneous relapsing-remitting EAE in the SJL/J mouse: MOG-reactive transgenic T cells recruit endogenous MOG-specific B cells. J. Exp. Med. 206, 1303-1316.

Polman,C.H., Matthaei,I., de Groot,C.J., Koetsier,J.C., Sminia,T., and Dijkstra,C.D. (1988). Lowdose cyclosporin $A$ induces relapsing remitting experimental allergic encephalomyelitis in the Lewis rat. J. Neuroimmunol. 17, 209-216.

Rivers,T.M., Sprunt,D.H., and Berry,G.P. (1933). OBSERVATIONS ON ATTEMPTS TO PRODUCE ACUTE DISSEMINATED ENCEPHALOMYELITIS IN MONKEYS. J. Exp. Med. 58, 39-53.

Rosenberg,S.A., Spiess,P.J., and Schwarz,S. (1978). In vitro growth of murine T cells. I. Production of factors necessary for T cell growth. J. Immunol. 121, 1946-1950.

Sallusto,F., Lenig,D., Forster,R., Lipp,M., and Lanzavecchia,A. (1999). Two subsets of memory T lymphocytes with distinct homing potentials and effector functions. Nature 401, 708-712. 
Schatz,D.G. and Swanson,P.C. (2011). V(D)J recombination: mechanisms of initiation. Annu. Rev. Genet. 45, 167-202.

Schläger, C. Live tracking of chemokine effects on effector T cell invasion into the central nervous tissue. 2013. unpusblished.

Schmidt,S. (1999). Candidate autoantigens in multiple sclerosis. Mult. Scler. 5, 147-160.

Shen,B., Zhang,J., Wu,H., Wang,J., Ma,K., Li,Z., Zhang,X., Zhang,P., and Huang,X. (2013). Generation of gene-modified mice via Cas9/RNA-mediated gene targeting. Cell Res. 23, 720723.

Shirwan,H., Ohanjanian,M., Burcham,G., Makowka,L., and Cramer,D.V. (1993). Structure and diversity of rat $\mathrm{T}$ cell receptor alpha-chain genes. J. Immunol. 150, 2295-2304.

Smith,L.R., Kono,D.H., and Theofilopoulos,A.N. (1991). Complexity and sequence identification of 24 rat $\mathrm{V}$ beta genes. J. Immunol. 147, 375-379.

Sobottka,B., Harrer,M.D., Ziegler,U., Fischer,K., Wiendl,H., Hunig,T., Becher,B., and Goebels,N. (2009). Collateral bystander damage by myelin-directed CD8+ T cells causes axonal loss. Am. J. Pathol. 175, 1160-1166.

Srivastava,R., Aslam,M., Kalluri,S.R., Schirmer,L., Buck,D., Tackenberg,B., Rothhammer,V., Chan,A., Gold,R., Berthele,A., Bennett,J.L., Korn,T., and Hemmer,B. (2012). Potassium channel KIR4.1 as an immune target in multiple sclerosis. N. Engl. J. Med. 367, 115-123.

Starr,T.K., Jameson,S.C., and Hogquist,K.A. (2003). Positive and negative selection of T cells. Annu. Rev. Immunol. 21, 139-176.

Stosic-Grujicic,S., Ramic,Z., Bumbasirevic,V., Harhaji,L., and Mostarica-Stojkovic,M. (2004). Induction of experimental autoimmune encephalomyelitis in Dark Agouti rats without adjuvant. Clin. Exp. Immunol. 136, 49-55.

Stromnes,I.M., Cerretti,L.M., Liggitt,D., Harris,R.A., and Goverman,J.M. (2008). Differential regulation of central nervous system autoimmunity by $\mathrm{T}(\mathrm{H}) 1$ and $\mathrm{T}(\mathrm{H}) 17$ cells. Nat. Med. 14, 337342.

Sun,D., Whitaker,J.N., and Wilson,D.B. (1999). Regulatory T cells in experimental allergic encephalomyelitis. I. Frequency and specificity analysis in normal and immune rats of a $\mathrm{T}$ cell subset that inhibits disease. Int. Immunol. 11, 307-315.

Szymczak,A.L. and Vignali,D.A. (2005). Development of 2A peptide-based strategies in the design of multicistronic vectors. Expert. Opin. Biol. Ther. 5, 627-638.

Teh,H.S., Kisielow,P., Scott,B., Kishi,H., Uematsu,Y., Bluthmann,H., and von,B.H. (1988). Thymic major histocompatibility complex antigens and the alpha beta T-cell receptor determine the CD4/CD8 phenotype of T cells. Nature 335, 229-233. 
THOMAS,L., PATERSON,P.Y., and SMITHWICK,B. (1950). Acute disseminated encephalomyelitis following immunization with homologous brain extracts; studies on the role of a circulating antibody in the production of the condition in dogs. J. Exp. Med. 92, 133-152.

Tonegawa,S. (1983). Somatic generation of antibody diversity. Nature 302, 575-581.

Tong,C., Huang,G., Ashton,C., Li,P., and Ying,Q.L. (2011). Generating gene knockout rats by homologous recombination in embryonic stem cells. Nat. Protoc. 6, 827-844.

Torres-Nagel,N.E., Gold,D.P., and Hunig,T. (1993). Identification of rat Tcrb-V8.2, 8.5, and 10 gene products by monoclonal antibodies. Immunogenetics 37, 305-308.

Trop,S., Rhodes,M., Wiest,D.L., Hugo,P., and Zuniga-Pflucker,J.C. (2000). Competitive displacement of $\mathrm{pT}$ alpha by TCR-alpha during TCR assembly prevents surface coexpression of pre-TCR and alpha beta TCR. J. Immunol. 165, 5566-5572.

Tuohy,V.K., Sobel,R.A., and Lees,M.B. (1988). Myelin proteolipid protein-induced experimental allergic encephalomyelitis. Variations of disease expression in different strains of mice. J. Immunol. 140, 1868-1873.

Tyznik,A.J., Sun,J.C., and Bevan,M.J. (2004). The CD8 population in CD4-deficient mice is heavily contaminated with MHC class II-restricted T cells. J. Exp. Med. 199, 559-565.

Unsoeld,H. and Pircher,H. (2005). Complex memory T-cell phenotypes revealed by coexpression of CD62L and CCR7. J. Virol. 79, 4510-4513.

van den Brandt,J., Wang,D., Kwon,S.H., Heinkelein,M., and Reichardt,H.M. (2004). Lentivirally generated eGFP-transgenic rats allow efficient cell tracking in vivo. Genesis. 39, 94-99.

van den Brandt,J., Kwon,S.H., Hunig,T., McPherson,K.G., and Reichardt,H.M. (2005). Sustained pre-TCR expression in Notch1IC-transgenic rats impairs $\mathrm{T}$ cell maturation and selection. J. Immunol. 174, 7845-7852.

Waldner,H., Whitters,M.J., Sobel,R.A., Collins,M., and Kuchroo,V.K. (2000). Fulminant spontaneous autoimmunity of the central nervous system in mice transgenic for the myelin proteolipid proteinspecific T cell receptor. Proc. Natl. Acad. Sci. U. S. A 97, 3412-3417.

Weissert,R., Wallstrom,E., Storch,M.K., Stefferl,A., Lorentzen,J., Lassmann,H., Linington,C., and Olsson,T. (1998). MHC haplotype-dependent regulation of MOG-induced EAE in rats. J. Clin. Invest 102, 1265-1273.

Wekerle,H., Kojima,K., Lannes-Vieira,J., Lassmann,H., and Linington,C. (1994). Animal models. Ann. Neurol. 36 Suppl, S47-S53.

Wekerle,H., Linington,C., Lassmann,H., and Meyermann,R. (1986). Cellular immune reactivity within the CNS. Trends Neurosci. 9, 271-277.

Wekerle,H. and Sun,D.M. (2010). Fragile privileges: autoimmunity in brain and eye. Acta Pharmacol. Sin. 31, 1141-1148. 
Wucherpfennig,K.W., Gagnon,E., Call,M.J., Huseby,E.S., and Call,M.E. (2010). Structural biology of the T-cell receptor: insights into receptor assembly, ligand recognition, and initiation of signaling. Cold Spring Harb. Perspect. Biol. 2, a005140.

Yang,J.S., Xu,L.Y., Xiao,B.G., Hedlund,G., and Link,H. (2004). Laquinimod (ABR-215062) suppresses the development of experimental autoimmune encephalomyelitis, modulates the Th1/Th2 balance and induces the Th3 cytokine TGF-beta in Lewis rats. J. Neuroimmunol. 156, 39.

Yednock,T.A., Cannon,C., Fritz,L.C., Sanchez-Madrid,F., Steinman,L., and Karin,N. (1992). Prevention of experimental autoimmune encephalomyelitis by antibodies against alpha 4 beta 1 integrin. Nature 356, 63-66.

Zhang,H.H., Song,K., Rabin,R.L., Hill,B.J., Perfetto,S.P., Roederer,M., Douek,D.C., Siegel,R.M., and Farber,J.M. (2010). CCR2 identifies a stable population of human effector memory CD4+ T cells equipped for rapid recall response. J. Immunol. 185, 6646-6663.

Zhang,F., Cong,L., Lodato,S., Kosuri,S., Church,G.M., and Arlotta,P. (2011). Efficient construction of sequence-specific TAL effectors for modulating mammalian transcription. Nat. Biotechnol. 29, 149-153.

Zinkernagel,R.M., Bachmann,M.F., Kundig,T.M., Oehen,S., Pirchet,H., and Hengartner,H. (1996). On immunological memory. Annu. Rev. Immunol. 14, 333-367.

Zschemisch,N.H., Glage,S., Wedekind,D., Weinstein,E.J., Cui,X., Dorsch,M., and Hedrich,H.J. (2012). Zinc-finger nuclease mediated disruption of Rag1 in the LEW/Ztm rat. BMC. Immunol. 13, 60. 
7 ABBREVIATIONS

\begin{tabular}{|c|c|c|c|}
\hline 2-PM & 2-photon microscopy & IL-10 & Interleukin 10 \\
\hline ACK & Ammonium Chloride Potassium erythrocyte lysis buffer & IL-17 & Interleukin 17 \\
\hline APC & Antigen presenting cells & $\mathrm{IL}-2 \mathrm{R}$ & Interleukin 2 receptor \\
\hline atEAE & Adoptive transfer experimental auotimmune encephalomyelitis & LN & Lymph node \\
\hline $\mathrm{BBB}$ & Blood-brain barrier & LPS & lipoloysaccharide \\
\hline bp & base pairs & $\mathrm{mAb}$ & Monoclonal antibody \\
\hline BSA & Bovine serum albumin & MAG & Myelin-associated glycoprotein \\
\hline CCR2 & CC-chemokine receptor 2 & MBP & Myelin basic protein \\
\hline CCR5 & CC-chemokine receptor 5 & MOG & Myelin oligodendrocyte glycoprotein \\
\hline CCR7 & CC-chemokine receptor 7 & $\mathrm{MHC}$ & Major histocompatibility complex \\
\hline CD & Cluster of differentiation & mRNA & messenger RNA \\
\hline CD3 & CD3 antigen & MS & Multiple sclerosis \\
\hline CD4 & CD4 antigen & NK & Natural killer ((T) cells) \\
\hline CD8 & CD8 antigen & ODC & Oligodendrocyte \\
\hline CD25 & CD25 antigen, Interleukin 2 receptor $\alpha$ chain & OVA & Ovalbumin \\
\hline CD44 & CD44 antigen & OX-6 & anti rat $\mathrm{MHC}$ class II blocking antobody \\
\hline CD62L & CD62L antigen (L-selectin) & p.i. & post immunization \\
\hline CFA & Complete Freund's adjuvant & p.t. & post transfer \\
\hline CNS & Central nervous system & PBS & Phosphate buffered saline \\
\hline CPM & Counts per minute & PCR & Polymerase chain reaction \\
\hline CsA & Cyclosporine A & PFA & Paraformaldehyde \\
\hline CXCR3 & CXC-chemokine receptor 3 & PLP & Proteolipid protein \\
\hline CXCR4 & CXC-chemokine receptor 4 & PP-MS & Primary progressive multiple sclerosis \\
\hline DNA & Desoxy Ribonucleic Acid & PR-MS & Progressive relapsing multiple sclerosis \\
\hline DMEM & Dulbecco's Modified Eagle's Medium & qPCR & Quantitative polymerase chain reaction \\
\hline DN & Double-negative (CD4 CD8') & rMT-II & rat MBP-specific TCR, MHC class II \\
\hline $\mathrm{DP}$ & Double-positive $\left(\mathrm{CD} 4^{+} \mathrm{CD} 8^{+}\right)$ & restricted & \\
\hline dpi & days post immunization & rOT-II & rat OVA-specific TCR, MHC class II \\
\hline $\mathrm{EAE}$ & Experimental autoimmune encephalomyelitis & restricted & \\
\hline $\mathrm{EH}$ & Eagle's HEPES medium & $\mathrm{RM}$ & Restimulation medium \\
\hline ELISA & Enzyme linked immunosorbent assay & RR-MS & Remitting relapsing multiple sclerosis \\
\hline FACS & Fluorescent activated cell scanning & S1P1 & Sphingosine-1-phosphate receptor 1 \\
\hline FM & Freezing Medium & s.c. & subcutaneous \\
\hline GFP & Green fluorescent protein & SP-MS & Secondary progressive multiple sclerosis \\
\hline Gy & Gray & SP & Single-positive \\
\hline HBS & HEPES-buffered saline & TBE & Tris borat EDTA buffer \\
\hline $\mathrm{HCl}$ & Hydrochloric acid & TCGF & T cell growth factor \\
\hline $\lg G$ & Immunoglobulin G & TCM & $\mathrm{T}$ cell medium \\
\hline IFA & Incomplete Freund's Adjuvant & TCR & T cell receptor \\
\hline i.e. & that is & TCRtg & T cell receptor transgenic \\
\hline i.p. & intraperitoneal & $\mathrm{T}_{\mathrm{MBP}}-\mathrm{GFP}$ & GFP expressing effector $T$ cell line \\
\hline i.t. & intrathecal & TNFa & Tumour necrosis factor $\alpha$ \\
\hline i.v. & intravenous & TPM & Two-photon microscopy \\
\hline $\mathrm{IFN} \gamma$ & Interferon $-\gamma$ & TPLSM & Two-photon laser scanning microscopy \\
\hline $\mathrm{IHC}$ & Immunohistochemistry & WM & White matter \\
\hline $\mathrm{IL}-2$ & Interleukin 2 & WT & Wild type (non transgenic) \\
\hline IL-4 & Interleukin 4 & & \\
\hline IL-7R & IL-7 receptor & & \\
\hline
\end{tabular}


First of all I express my gratitude to Prof. Alexander Flügel for the opportunity to perform this PhD project in his department on such an inspiring research topic and for his support and advice throughout this thesis.

Moreover, I would like to thank Dr. Dmitri Lodygin for his excellent supervision, guidance and encouragement.

In sincerely thank Prof. Holger Reichardt, Dr. Jens van den Brandt and Dr. Henrike Fischer for our collaboration on the generation of the TCR transgenic rat strains.

I would also like to extend my thanks to the additional members of my thesis committee and examination board Prof. Wolfgang Brück, Prof. Detlev Schild, Prof. Hannelore Ehrenreich and Prof. Jürgen Wienands.

I'm grateful to Dr. Francesca Odoardi, Dr. Christian Schläger and Michael Haberl for performing the two-photon live imaging experiments and for the productive scientific discussions I had with them. I also appreciated Fred Lühder's input during the discussion of our results.

As I'm not known for extensive speeches, l'd like to keep it short and thank all the technicians of our department for their excellent technical assistance (especially Adriane, Simon, Nancy and Simone), Cathy Ludwig for help with any topics of bureaucracy and proof reading, my fellow PhDs and anyone else involved (present or former) for the gorgeous working environment within and outside of the lab (in alphabetical order): Anne, Birgit, Brigitte, Christopher, Corinna, Fatma, Fred, Giuseppe, Henrike (Thank you for proofreading!), Jasi, Maike, Martina, Michael B., Regine, Tanja.

Special thanks to Manuel von Osten - not only for being an important member of the AG Lodygin - but also for being a friend.

Finally, I would like to thank my family and friends for their patience and constant support during all of my academic education. 


\section{Personal Information}

$\begin{array}{ll}\text { Name } & \text { Alexandra Kitz } \\ \text { Data of Birth } & 18^{\text {th }} \text { October } 1985 \\ \text { Place of Birth } & \text { Witten, NRW } \\ \text { Nationality } & \text { German } \\ \text { Contact } & \text { Institute for Multiple Sclerosis Research } \\ & \text { Department of Neuroimmunology } \\ & \text { Room 2.118 } \\ & \text { Waldweg 33 } \\ & 37073 \text { Göttingen } \\ & \text { Phone: +49-(0)551-39-13344 } \\ & \text { Email: alexandra.kitz@med.uni-goettingen.de }\end{array}$

\section{Education}

$\begin{array}{ll}\text { 04/2010 - present } & \begin{array}{l}\text { Institute for Multiple Sclerosis Research, Department of } \\ \text { Neuroimmunology } \\ \text { Program of the DFG Research Center Molecular Physiology of the } \\ \text { Brain (CMPB), Göttingen Graduate School for Neurosciences and } \\ \text { Molecular Biosciences (GGNB) }\end{array} \\ 01 / 2009-12 / 2009 & \begin{array}{l}\text { SG Experimental Surgery } \\ \text { Department of General Surgery and Transplantation Surgery } \\ \text { University Hospital Essen, Germany } \\ \text { Diploma thesis: „Modulation of the LPS/LBP-balance in vivo using a } \\ \text { rat model” }\end{array} \\ 10 / 2005-03 / 2010 & \begin{array}{l}\text { Ruhr-University of Bochum, Germany } \\ \text { Diploma in biology (grade 1,6) }\end{array} \\ 1996-2005 & \text { Bert-Brecht-Gymnasium, North Rhine Westfalia, Dortmund } \\ \text { Abitur }\end{array}$




$\begin{array}{ll}07.2008-09.2008 & \begin{array}{c}\text { Chemosensory principles of pheromone perception } \\ \text { Advanced course } \\ \text { Molecular, cell and developmental biology of plants } \\ \text { Advanced course }\end{array} \\ 06.2008 & \begin{array}{c}\text { Functional neuroanatomy, neurochemistry and brain development } \\ \text { Basic course } \\ 05.2008\end{array} \\ 03.2008-04.2008 \text { Physiological chemistry } \\ \text { Advanced course - non-biological minor subject } \\ 01.2008-03.2008 & \begin{array}{l}\text { Developmental Neurobiology } \\ \text { Advanced course }\end{array} \\ 11.2007-12.2007 & \begin{array}{l}\text { Plant Physiology } \\ \text { Basic course }\end{array} \\ 10.2007-11.2007 & \begin{array}{l}\text { Central nervous information processing } \\ \text { Basic course } \\ \text { Developmental Neurobiology, Ruhr-University of Bochum } \\ \text { Student research assistant }\end{array} \\ 04.2006-06.2008 & \begin{array}{l}\text { Main task: Reconstruction of neurons in organotypic cultures of the } \\ \text { visual cortex using the Neurolucida system }\end{array}\end{array}$

\section{Publications}

Lodygin,D., Odoardi,F., Schlager,C., Korner,H., Kitz,A., Nosov,M., van den Brandt,J., Reichardt,H.M., Haberl,M., and Flugel,A. (2013). A combination of fluorescent NFAT and $\mathrm{H} 2 \mathrm{~B}$ sensors uncovers dynamics of $\mathrm{T}$ cell activation in real time during CNS autoimmunity. Nat. Med. 19, 784-790.

\section{Talks and Poster presentations}

2011 Talk $-3^{\text {rd }}$ DGfl Autumn School Current Concepts in Immunology, Bad Schandau, Germany

2011 Poster $-2^{\text {nd }}$ GGNB Science Day, Göttingen

2011 Poster $-1^{\text {st }}$ PhD CMPB Symposium Bridging Microscopy and Neurosciences, Göttingen 